\title{
“Great Blue Hole” (Lighthouse Reef, Belize, Central America): a late Holocene high-resolution storm and climate archive
}

(174 Seiten, 25 Abbildungen, 5 Tabellen, digitales Zusatzmaterial)

\author{
Dissertation \\ zur Erlangung des Doktorgrades \\ der Naturwissenschaften
}

vorgelegt beim Fachbereich Geowissenschaften

der Johann Wolfgang Goethe-Universität

in Frankfurt am Main

von

Dominik Schmitt

aus Lohr am Main

Frankfurt am Main, 2020

(D30) 
vom Fachbereich 11 der

Johann Wolfgang Goethe-Universität als Dissertation angenommen.

Dekan: Prof. Dr. Georg Rümpker

Gutachter: (1) Prof. Dr. Eberhard Gischler; (2) Prof. Dr. Flavio Anselmetti

Datum der Disputation: 15.04.2021 


\section{TABLE OF CONTENTS}

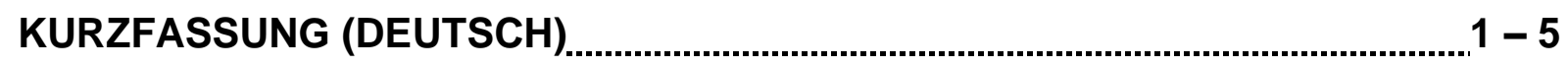

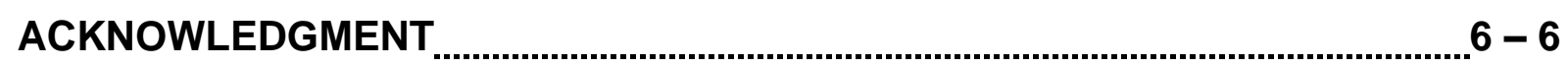

LIST OF TABLES

LIST OF FIGURES

LIST OF SUPPLEMENTARY MATERIAL (DIGITAL) ........................................11-12

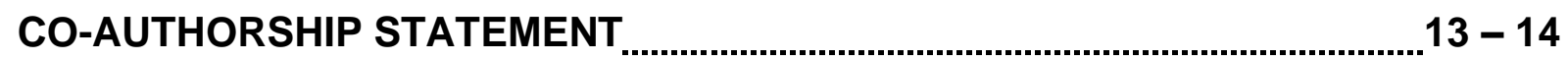

\section{CHAPTER 1: INTRODUCTION AND THESIS OVERVIEW}

1. Introduction $15-16$

2. Instrumental record limitation $16-17$

3. Paleoclimate research in the Caribbean: state-of-the-art. $17-20$

4. Paleoclimate reconstruction: application in sinkhole settings $20-22$

5. Ph.D. thesis: hypotheses and objectives $22-23$

6. Ph.D. thesis: structure and outlines $24-24$

\section{CHAPTER 2: SCIENTIFIC REPORTS MANUSCRIPT}

"Caribbean cyclone activity: an annually-resolved Common Era record"

1. Abstract $25-26$

2. Introduction $.26-33$

3. Results $33-42$

3.1. TC record: quality check $33-34$

3.2. Proxy results: quantification of TC-frequency. $34-37$

3.3. Correlation between event bed texture and historical TC record ......37 - 39

3.4. Qualitative long-term patterns of textural characteristics $39-39$

3.5. Climatological control of Maya civilisation decline $39-40$

3.6. TC-frequency modulation by SST- and AMO variability. $40-41$

3.7. Statistical wavelet analysis: AMO control of SST variability. $41-42$

4. Discussion 43-50 
4.1. Comparison with other TC records. $43-45$

4.2. Common Era TC activity: a conceptual and comparative view ......... $45-50$

5. Conclusions $50-50$

6. Methods $50-54$

6.1. Fieldwork in Lighthouse Reef $50-50$

6.2. Core description: photo documentation and stratigraphy. $50-51$

6.3. Systematic sampling $51-51$

6.4. Age dating: varve counting and radiocarbon calibration $51-52$

6.5. Quantitative textural analysis and sediment characterization. $52-53$

6.6. X-Ray fluorescence analysis: a new cyclone indicator. $53-54$

6.7. Tropical cyclone identification $54-54$

6.8. Statistical wavelet analysis $54-54$

\section{CHAPTER 3: QUATERNARY SCIENCE REVIEW MANUSCRIPT}

"Great Blue Hole" (Lighthouse Reef, Belize): a continuous, annually resolved record of Common Era sea surface temperature, Atlantic Multidecadal Oscillation and cyclone-controlled run-off"

1. Abstract $55-56$

2. Introduction $56-59$

3. Setting $59-63$

3.1. Geography and geomorphology $59-62$

3.2. Mainland geology and reef development. $62-62$

3.3. Climate and oceanography. $63-63$

4. Material and methods $64-68$

5. Results $69-78$

5.1. Sedimentology $69-70$

5.2. Inorganic geochemistry $70-72$

5.3. Organic geochemistry $72-74$

5.4. Time series analysis $74-75$

5.5. XRF data $76-78$

6. Discussion $78-94$

6.1. Quality check: $\delta^{18} \mathrm{O}$ and TEX $\mathrm{X}_{86}$ applications as SST proxies $78-80$ 
6.2. Comparison: SST records and Common Era climate variability.......80 - 84

6.3. Quality check: $\delta^{13} \mathrm{C}$ application as climate proxy..............................84-84

6.4. $\delta^{13} \mathrm{C}$ signals: proxy for TC modulation of soil-erosion/run-off...........84-87

6.5. Cyclicity in time series and AMO control on SW-Caribbean SST .....87- 88

6.6. Conceptual Common Era climate model: a comparative view..........88- 84

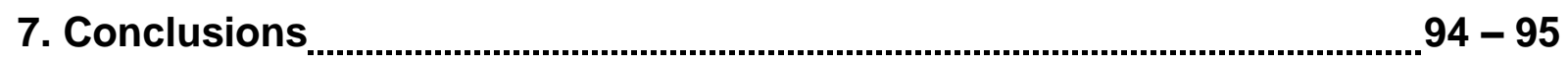

\section{CHAPTER 4: FACIES MANUSCRIPT}

"Holocene sediments of an inundated sinkhole - facies analysis of the Great Blue Hole, Lighthouse Reef, Belize"

1. Abstract $96-97$

2. Introduction $97-100$

3. Setting $100-102$

3.1. Geography and geomorphology $100-101$

3.2. Quaternary reef formation $101-101$

3.3. Climate and oceanography. $101-102$

4. Methods $102-104$

5. Results $105-116$

5.1. Average sediment composition of the "Great Blue Hole". $105-106$

5.2. Average background and event bed composition $107-107$

5.3. Textural facies classification. $107-108$

5.4. Combined textural and compositional facies classification $108-110$

5.5. Statistical analysis - facies verification $110-112$

5.6. Key characteristics for facies identification and classification .....113-113 5.7. Temporal changes of sediment composition $113-114$

6. Discussion $116-125$

6.1. Major sediment constituents: surface-sinkhole feedback $116-117$

6.2. Reefal depositional environments and sedimentation dynamics.117-118

6.3. "Great Blue Hole", a lagoon-like deposition environment $118-119$

6.4. Background and event sedimentation - cyclone modulation. $120-121$

6.5. Texture and composition - a combined TC identification tool......121-124 6.6. Temporal composition changes $124-125$ 


\section{CHAPTER 5: CONCLUSIONS AND FORECAST}

1. Ph.D. thesis: key objectives-summary $127-129$

1.1. Summary (English) $127-128$

1.2. Zusammenfassung (Deutsch). $128-129$

2. Ph.D. thesis: conclusive results $129-141$

2.1. Conclusions (English) $129-134$

2.2. Schlussfolgerungen (Deutsch) $134-141$

3. Follow-up project: outline $141-145$

3.1. Motivation $141-142$

3.2. Objectives $142-142$

3.3. Key questions and hypotheses $143-145$

REFERENCES $146-165$ 


\section{KURZFASSUNG (DEUTSCH)}

Paläoklimarekonstruktionen, die es sich zum Ziel gesetzt haben, Klima-Mensch Interaktionen auf lange Zeitreihen betrachtet zu erforschen, nehmen begünstigt durch die aktuell intensiv geführte Klimadebatte, einen immer größer werdenden Stellenwert in der öffentlichen und wissenschaftlichen Wahrnehmung ein. Denn trotz aller wissenschaftlicher Fortschritte, die in den vergangenen Jahrzehnten im Bereich der modernen Klimaforschung gemacht wurden, bleibt die zuverlässige Vorhersage und Modellierung von zukünftigen Klimaveränderungen noch immer eine der größten Herausforderungen unser heutigen Zeit. Betrachtet man die Karibik exemplarisch in diesem Rahmen, dann prognostizieren viele Modellrechnungen, infolge steigender Ozeantemperaturen, ein deutlich häufigeres Auftreten von tropischen Stürmen und Hurrikanen sowie eine Verschiebung hin zu höheren Sturmstärken. Dieser Trend stellt für die Karibik und viele daran angrenzende Staaten eine der größten Gefahren des modernen Klimawandels dar, den es wissenschaftlich über einen langen Zeitrahmen zu erforschen gilt.

Klimaprognosen stützen sich meist vollständig auf hoch-aufgelöste instrumentelle Datensätze. Diese sind aber alle durch einen wesentlichen Aspekt limitiert. Aufgrund ihrer eingeschränkten Verfügbarkeit ( 150 Jahre) fehlt ihnen die erforderliche Tiefe, um die auf langen Zeitskalen operierenden Prozesse der globalen Klimadynamik adäquat abbilden zu können. Betrachtet man das Holozän in seiner Gesamtheit, so wurde die globale Klimadynamik über die vergangenen 11,700 Jahre von periodisch auftretenden Prozessen und Abläufen gesteuert. Diese wirken grundsätzlich über Zeiträume von mehreren Jahrzehnten, teilweise Jahrhunderten und in einigen Fällen sogar Jahrtausenden. Viele dieser natürlichen Prozesse, können in der kurzen Instrumentellen Ära nicht gänzlich identifiziert und angemessen in Klimamodellen berücksichtig werden. Die alleinige Berücksichtigung der Instrumentellen Ära bietet daher nur eine eingeschränkte Perspektive, um die Ursachen und Abläufe von vergangenen sowie mögliche Folgen von zukünftigen Klimaveränderungen zu verstehen. Um diese Einschränkung zu überwinden, ist es somit erforderlich, dass die geowissenschaftliche Forschung mit Proxymethoden ein zusammenfassendes und mechanistisches Verständnis über alle Holozänen Klimaveränderungen erlangt. 
Wenn man sich diese Limitierung, die ansteigenden Ozeantemperaturen und das in der Karibik in den vergangen 20 Jahren vermehrte Auftreten von starken tropischen Zyklonen ins Gedächtnis ruft, ist es nachvollziehbar, dass im Rahmen dieser Doktorarbeit ein zwei Jahrtausende langer und jährlich aufgelöster Klimadatensatz erarbeitet werden soll, der spät Holozäne Variationen von Ozeanoberflächenwassertemperaturen (SST) und daraus resultierende lang-zeitliche Veränderungen in der Häufigkeit tropischer Zyklone widerspiegelt. In Zentralamerika wird das Ende der Maya Hochkultur (900-1100 n.Chr.) mit drastischen Umweltveränderungen (z.B. Dürren) assoziiert, die während der Mittelalterlichen Warmzeit (MWP; 900-1400 n.Chr.) durch eine globale Klimaveränderung hervorgerufen wurde. Die aus einem "Blue Hole" abgeleiteten Informationen über Klimavariationen der Vergangenheit können als Referenz für die gegenwärtige Klimakriese verwendet werden.

Als „Blue Hole“ wird eine Karsthöhle bezeichnet, die sich subaerisch während vergangener Meeresspiegeltiefstände im karbonatischen Gerüst eines Riffsystems gebildet hat und in Folge eines Meeresspiegelanstiegs vollständig überflutet wurde. In einigen wenigen marinen "Blue Holes" treten anoxische Bodenwasserbedingungen auf. Die in diesen anoxischen Karsthöhlen abgelagerten Abfolgen mariner Sedimente können als einzigartiges Klimaarchiv verwendet werden, da sie aufgrund des Fehlens von Bioturbation eine jährliche Schichtung (Warvierung) aufweisen.

In dieser kumulativen Dissertation über das "Great Blue Hole" werden die Ergebnisse eines 3-jährigen Forschungsprojekts vorgestellt, dass das Ziel verfolgte einen wissenschaftlich herausragenden spät Holozänen Klimadatensatz für die südwestliche Karibik zu erzeugen. Beim "Great Blue Hole" handelt es sich um ein weltweit einzigartiges marines Sedimentarchiv für diverse spät Holozäne Klimaveränderungen, das im Zuge dieser Dissertation sowohl nach paläoklimatischen als auch nach sedimentologischen Fragestellungen untersucht wurde. Die vorliegende Doktorarbeit befasst sich im Einzelnen mit (1) der Ausarbeitung eines jährlich aufgelösten Archives für tropische Zyklone, (2) der Entwicklung eines jährlich aufgelösten SST Datensatzes und (3) einer kompositionellen Quantifizierung der sedimentären Abfolgen sowie einer faziell-stratigraphischen Charakterisierung von Schönwetter-Sedimenten und Sturmlagen. $\mathrm{Zu}$ jedem dieser drei Aspekte, wurde jeweils ein Fachartikel bei einer anerkannten wissenschaftlichen Fachzeitschrift mit „peer-review“ Verfahren veröffentlicht. 
Der insgesamt 8.55 m lange Sedimentbohrkern („BH6“), der für diese Dissertation untersucht wurde, stammt vom Boden des $125 \mathrm{~m}$ tiefen und $320 \mathrm{~m}$ breiten „Great Blue Holes", das sich in der flachen östlichen Lagune des $80 \mathrm{~km}$ vor der Küste von Belize (Zentralamerika) gelegenen "Lighthouse Reef" Atolls befindet. Durch seine besondere Geomorphologie wirkt das, innerhalb des atlantischen „Hurrikan Gürtels“ positionierte, "Great Blue Hole" wie eine gigantische Sedimentfalle. Die unter Schönwetter-Bedingungen kontinuierlich abgelagerten Abfolgen feinkörniger karbonatischer Sedimente, werden von groben Sturmlagen unterbrochen, die auf „over-wash“ Prozesse von tropischen Zyklonen zurückzuführen sind.

In Kapitel 1 dieser Arbeit wird eine kurze Einleitung in das Thema, die Forschungsmotivation, der gegenwärtige Forschungsstand, der Rahmen des Projekts und der strukturelle Aufbau dieser Dissertation präsentiert. Die folgenden drei Kapitel, die im Stil von wissenschaftlichen Fachartikeln angefertigt wurden, stellen den eigentlichen Hauptteil dieser Doktorarbeit dar. In Kapitel 2 wird ein wissenschaftlicher Fachartikel präsentiert, der eine 1,885 Jahre lange Rekonstruktion von Sturmhäufigkeiten in der süd-westlichen Karibik aufzeigt. Die Verwendung eines innovativen multi-proxy Ansatzes (Textur, Komposition und Geochemie) stellt, verglichen mit allen bisher in dieser Richtung durchgeführten Forschungsprojekten, einen entscheidenden Fortschritt dar, der eine zuverlässigere Identifikation von Sturmlagen gewährleistet. Die Forschungsergebnisse, die mit dieser Rekonstruktion einhergingen, lassen sich auf vier wesentliche Punkte zusammenfassen: (1) Veränderungen in der Sonneneinstrahlung und/oder Phasen hoher Vulkantätigkeit haben über die letzten $\sim 2,000$ Jahre fünf unterschiedliche Klimaveränderungen hervorgerufen. Diese hatten wiederum Reaktionen von Klimaphänomenen, wie etwa der El-Niño-Südlichen-Oszillation (ENSO), der Nord Atlantischen Oszillation (NAO) und der Atlantischen Multidekadischen Oszillation (AMO) zur Folge. Im tropischen Atlantik üben diese Klimaphänomene einen starken Einfluss auf die Häufigkeit von tropischen Zyklonen aus, indem sie in großem Maßstab betrachtet thermo-dynamische Voraussetzungen schaffen, die die Bildung von tropischen Zyklonen sowohl fördern als auch hemmen. (2) Vor allem auf lange Zeitskalen ( $\geq$ multi-dekadisch) betrachtet, nehmen diese Klimaphänomene eine sehr viel größere und gewichtigere Rolle für die Häufigkeit von tropischen Zyklonen ein als regionale SST Variationen in deren Hauptbildungsregionen, die die Sturmaktivität 
eher auf kurzen Zeitskalen (inter-annuell) steuern. (3) Über einen Zeitraum von 1,700 Jahren konnte nachgewiesen werden, dass die AMO die Häufigkeit von Sturmereignissen auf multi-dekadischen Zeitskalen steuert. (4) Die Sturmhäufigkeit hat sich in der süd-westlichen Karibik von einem stabilen und inaktiven Niveau ( 100-900 n.Chr.) hin zu einem deutlich aktiveren und variableren Regime (>1100 n.Chr.) verschoben. Für die Yucatán Halbinsel wurde für die MWP eine sehr hohe und mit der heutigen Situation vergleichbare Sturmaktivität rekonstruiert. Dieser signifikante Anstieg der Sturmhäufigkeit hat vermutlich zusätzlich zu mehreren wiederkehrenden Dürrephasen dazu beigetragen, dass die klassische Maja Hochkultur im Verlauf der MWP allmählich ihrem Niedergang entgegensteuerte.

In Kapitel 3 dieser Arbeit wird auf einen jährlich aufgelösten SST Datensatz eingegangen, der auf der Grundlage von stabilen Isotopen $\left(\delta^{18} \mathrm{O}\right)$ und molekularen und von der Salinität unabhängigen Proxyanwendungen (TEX ${ }_{86}$ ) gewonnen wurde. Die hier gezeigte SST Rekonstruktion $\left(\delta^{18} \mathrm{O}=\right.$ relativ; TEX ${ }_{86}=$ absolut $)$ übertrifft alle für den Atlantik verfügbaren SST Rekonstruktionen um mehr als 700 Jahre. Für die süd-westliche Karibik konnte ein Temperaturanstieg von $0.5^{\circ} \mathrm{C}$ bis $1.3^{\circ} \mathrm{C}$ rekonstruiert werden, der etwa ab dem Einsetzen der MWP begonnen hat. Die Regulierung von SSTs lief über die letzten $~ 2,000$ Jahre betrachtet auf zwei unterschiedlichen Zeitniveaus ab: (1) Starke Sonnenaktivität und/oder Phasen erhöhter Vulkantätigkeit verursachten spät Holozänen Klimaschwankungen, welche wiederum zu einer Reaktion bestimmter Klimaphänomene führte (z.B. ENSO, NAO und $A M O)$. Deren sich verändernde Wirkungsmechanismen zueinander konnten als mögliche Ursachen für primäre und über mehrere Jahrhunderte ablaufende Schwankungen von SST identifiziert werden. (2) Unter Berücksichtigung des $\delta^{18} \mathrm{O}$ Datensatzes war weiterhin eine sekundäre Regulierung von SST zu erkennen, die auf multi-dekadischen Zeitskalen mit einer Periodizität von 32-64 Jahren operiert. Diese SST Schwankungen konnten erfolgreich mit zyklischen AMO Phasenwechseln (50-70 Jahre) korreliert werden. Der Einfluss der AMO auf die SST Variabilität reicht damit mindestens 1,885 Jahre in die Vergangenheit zurück. Kohlenstoffisotope, die an den Warven gemessen wurden, reflektieren einen Zusammenhang zwischen hoher Sturmaktivität, stärkerem fluviatilem Abfluss und höheren Raten von Bodenerosion, der durch ${ }^{13} \mathrm{C}$-abgereicherte Signaturen angezeigt wird. Der $\delta^{13} \mathrm{C}$ Datensatz weist insgesamt nur zwei signifikante negative Anomalien auf. Die erste 
dieser beiden Anomalien (1000-1400 n.Chr.) tritt, während der MWP auf, also genau dem Klimaintervall, dass durch eine ausgesprochen hohe Sturmtätigkeit gekennzeichnet war. Tropische Zyklone, die das Land erreichen, haben deutlich erhöhten Niederschlag, gleichzeitig höhere Raten von Bodenerosion und damit einen überschüssigen Transport von ${ }^{12} \mathrm{C}$ in den Ozean zur Folge. Die zweite Anomalie (>1900 n.Chr.) tritt während einer weiteren Phase hoher Sturmaktivität auf, ist aber höchstwahrscheinlich das Ergebnis des "Suess Effekts", also der Auswirkung der Industriellen Revolution auf die Zusammensetzung von Kohlenstoffisotopen.

In Kapitel 4 dieser Doktorarbeit wird ein wissenschaftlicher Fachartikel präsentiert, der sich allgemein mit sedimentologischen Aspekten des "Great Blue Holes" und im speziellen mit einer Klassifikation von sedimentären Fazies anhand von Dünnschliffen und Texturdaten befasst. Sedimente, die unter SchönwetterBedingungen abgelagert wurden, sind durch eine Korngröße $<20 \mu \mathrm{m}$ charakterisiert. Sie bestehen im Durchschnitt aus 81\% aragonitischem Feinmaterial, 12\% Halimeda Plättchen, 3\% Korallenfragmenten, 2\% organischem Material, 1\% Mollusken Schalen, 1\% Foraminiferen Gehäusen und wenigen Fragmenten koralliner Rotalgen und Echinodermen $(<1 \%)$. Die zwischengeschalteten Sturmlagen sind deutlich gröber (20-300 $\mu \mathrm{m})$ und unterscheiden sich durch niedrigere Anteile aragonitischen Feinmaterials (50\%) und einer erhöhten Häufigkeit von aus dem Randriff eingeschwemmten Halimeda Plättchen (28\%) und Bruchstücken von Korallen (6\%). In der Sedimentabfolge des "Great Blue Holes" konnten vier primäre sedimentäre Fazies nachgewiesen werden, die eindeutig zur Schönwetter- (mudstone) oder Sturmsedimentation (Halimeda wackestone, algae-rich packstone, coralgal rudstone) zugeordnet werden konnten. Die texturelle und kompositionelle Identifikation der drei Sturmfazies konnte als weiteres wichtiges Hilfsmittel etabliert werden, um Sturmlagen von tropischen Zyklonen in „Blue Hole“ Abfolgen zu identifizieren.

In Kapitel 5 wird eine Zusammenfassung der Hauptergebnisse dargeboten. Das Kapitel enthält weiterhin einen Ausblick auf ein künftiges Projekt, das im „Great Blue Hole" realisiert werden könnte. Diese Dissertation zeigt damit eindrucksvoll, dass die Sedimente des "Great Blue Holes“ die späte Holozäne Klimavariabilität während fünf unterschiedlicher Klimaintervalle zuverlässig widerspiegeln. Unsers Wissen über hoch-aufgelöste Manifestationen der Klimasteuerung, konnte mit dieser Doktorarbeit bis zu einer fast zwei Jahrtausende umfassenden Perspektive erweitert werden. 


\section{ACKNOWLEDGMENT}

First of all, I would like to thank my supervisor, Dr. Eberhard Gischler (Frankfurt), for his support and guidance throughout three valuable years of cooperation. In consequence of his outstanding knowledge in the field of carbonate systems as paleoclimate archives, many fruitful discussions and an overall excellent supervision during all project phases, I was able to undertake this Ph.D. thesis. I would like to thank Eberhard straight away for fascinating me for bio-sedimentology and giving me the unique opportunity to travel to and work in one of the most exotic and beautiful locations of the world. I am very grateful to Dr. Hendrik Vogel (Bern), Dr. Daniel Birgel (Hamburg), Dr. Jörn Peckmann (Hamburg) and Dr. Flavio Anselmetti (Bern) for their assistance and resources on this project and especially to Flavio for serving on my supervisory committee.

I would like to thank captain Norlan Lamb (Belize City) and the entire crew of his vessel "Miss Phillippa" for their invaluable fieldwork assistance and tireless efforts to realise this project despite hurricane warning and logistical problems. I feel much obliged for my German colleagues Gabriela Mayer (Frankfurt) and Stefan Haber (Bad Karlshafen), who assisted me in many technical and operative ways during the fieldwork. I also would like to thank the Belize Audubon Society and the Belize Fisheries Department for site access to the "Great Blue Hole", work permission and sample export permission. I also owe a great debt of gratitude to Nils Prawitz (Frankfurt) for thin-section preparation, Doris Bergman-Dörr (Frankfurt), Sven Hofmann (Frankfurt) and Dr. Jens Fiebig (Frankfurt) for access to lab facilities and assistance in textural and geochemical measurements. The assistance of both student helpers Jacques-Maurice Osthoff (Frankfurt) and Daniel Parwareschnia (Frankfurt) during long hours of sample preparation, sampling and measuring is gratefully acknowledged.

I would like to emphasize that this project could never have been realised without financial support (Gl 222/31-1) from the Deutsche Forschungsgemeinschaft (DFG).

Finally, I would like to thank both my friends and my family for their continual support and financial contributions, but especially my parents Klaus und Petra and my great love Lena without whom I could never have finished this Ph.D. thesis. 


\section{LIST OF TABLES ${ }^{\star}$}

\section{CHAPTER 3}

Table 1 $66-66$

${ }^{14} \mathrm{C}$ AMS geochronology: comparison with varve counting approach.

\section{CHAPTER 4}

Table 2 $103-103$

Sample list: thin-section numbers and depth intervals $(\mathrm{cm})$.

Table 3 $106-106$

Correlation matrix: textural and compositional sediment characteristics.

Table 4 $110-110$

Summary of sedimentary facies: textural and compositional sediment characteristics.

Table 5 $113-113$

(a) Multi-proxy-TC-identification approach: criteria to distinguish between event bed and background sedimentation; (b) summary of sedimentary facies: key characteristics.

* All tables are only presented electronically on the attached CD due to their large size and the impossibility to incorporate them into the main text. The page numbers refer to the position in the main text, in which the tables are first mentioned. 


\section{LIST OF FIGURES}

\section{CHAPTER 2}

Figure 1 $29-30$

Multi-panel figure: (a) geographical overview; (b) satellite image of Lighthouse Reef Atoll; (c) aerial view of the "Great Blue Hole" with coring sites; (d) cyclone track map; (e) core photograph and (a) schematic cross section.

Figure 2 $32-32$

Age model: combined plot of sediment age (years CE) against core depth $(\mathrm{cm})$ as determined by ${ }^{14} \mathrm{C}$ AMS radiocarbon geochronology and by varve counting off buffgreen/organic-rich background sediment couplets.

Figure 3 $35-36$

Multi-panel figure: (a) global SST reconstruction; (b) cyclone frequency reconstruction; (c) event layer thickness- and (d) event bed grain size measurements.

\section{Figure 4}

Multi-panel figure: (a) instrumental record AMO anomaly; (b) calibration of cyclone activity with AMO phases and calibration of AMO phases with (c) event layer thickness and (d) mean grain size.

\section{Figure 5} $42-42$

Wavelet power spectra: (a) cyclone counts power spectrum; (b) event layer thickness power spectrum and (c) event layer grain size power spectrum.

\section{Figure 6} $46-46$

Multi-panel figure: (a) comparison of site-specific cyclone activity reconstructions with (b) solar irradiance; (c) AMO; (d) NAO; (e) SST and (f) ENSO/NINO3 reconstructions.

\section{CHAPTER 3}

\section{Figure 7} $60-61$

Multi-panel figure: (a) geographical overview; (b) geological and tectonic map; (c) satellite image of Lighthouse Reef Atoll; (d) core photograph and sampling methodology and (e) aerial view of the "Great Blue Hole" with coring sites. 
Proxy record for SST: 2000-year $\delta^{18} \mathrm{O}$ time series.

Figure 9 $71-71$

Proxy record for cyclone-controlled run-off/soil erosion: 2000-year $\delta^{13} \mathrm{C}$ time series.

Figure 10 $72-73$

Multi-panel figure: (a) 2000-year TEX ${ }_{86}$ time series for SST reconstruction and (b) statistical correlation between $\delta^{18} \mathrm{O}$ and TEX $\mathrm{X}_{86}$ proxy data.

Figure 11 $73-73$

Multi-panel figure: (a) records of $\sim 2000$-years $\delta^{18} O$ and TEX ${ }_{86}$ SST reconstructions; (b) comparison to coral-based relative SST records; (c) to coral-based absolute SST records; (d) to foraminifer- and sclerosponge-based absolute SST records and (e) to broader Northern Hemisphere and global SST curves.

Figure 12 $75-75$

Wavelet power spectra: (a) $\delta^{18} \mathrm{O}$ power spectrum and (b) $\delta^{13} \mathrm{C}$ power spectrum.

Figure 13 $77-78$

Multi-panel figure: XRF-based proxy approaches for (a) carbonate availability and salinity/water content; (b) cyclone activity and primary production and (c) terrestrial run-off and soil erosion.

Figure 14 $90-90$

Multi-panel figure: (a) 2000-years $\delta^{18} \mathrm{O}$ and TEX ${ }_{86}$ SST reconstructions; reconstructions of (b) solar irradiance; (c) AMO; (d) NAO and (e) ENSO/NINO3.

\section{CHAPTER 4}

Figure 15 $98-98$

Multi-panel figure: (a) geographical overview; (b) geological and tectonic map; (c) satellite image of Lighthouse Reef; (d) aerial view of the "Great Blue Hole" with coring sites; (e) core photograph and (f) schematic cross section.

Figure 16 $106-106$

Multi-panel figure: bar charts of (a) average sediment composition; (b) average composition of background sedimentation under fair-weather conditions and (c) average composition of event sedimentation under storm conditions. 
Multi-panel figure: bar charts of average facies composition including (a) background sedimentation related mudstone facies: (b) background and event sedimentation related wackestone facies; (c) event sedimentation related algae-rich packstone facies; (d) event sedimentation related coralgal rudstone facies and (e) separation of wackestone facies with regard to background and event sedimentation affiliation.

Figure 18 $111-111$

Dendrogram of cluster analysis: classification of sedimentary facies.

Figure 19 $112-113$

Plot of principal component analysis (PCA): classification of sedimentary facies.

Figure 20 $115-116$

Multi-panel figure: temporal trends in sediment composition; (a, b) combined consideration of background and event sedimentation samples; (c-g) consideration of event sedimentation sections only and $(\mathbf{h}-\mathbf{j})$ consideration of background sedimentation sections only.

Figure 21 $117-117$

Schematic cross section through the eastern marginal reef and lagoon of Lighthouse reef: major sedimentation environments and sedimentation dynamics under fair-weather conditions.

Figure 22 $120-120$

Conceptual model of event bed formation under tropical cyclone influence: cyclonecontrolled sedimentation and depositional dynamics in the "Great Blue Hole" sediment trap.

Figure 23 $122-123$

Multi-panel figure: (a) core photos including one section from core $\mathrm{BH} 7$ and six sections from core $\mathrm{BH6}$; (b) magnified core images of mudstone (background), wackestone (overprinted-background), Halimeda wackestone (event bed), algae rich packstone (event bed) and coralgal-rudstone (event bed) facies.

\section{CHAPTER 5}

Figure 24 $142-142$

Multi-panel figure: (a) Overview of Holocene climate variability-globally stacked SST anomaly. (b) Maya culture population influence on soil erosion rates and pollen disturbance. 
Comparison of cyclone records from Belize, the Gulf Coast, and the Antilles archipelago.

\section{LIST OF SUPPLEMENTARY MATERIAL*}

\section{CHAPTER 2}

Supplementary material 1 $32-32$

Multi-panel figure of core log files: visualisation of raw data for the multi-proxy-TCidentification approach.

\section{Supplementary material 2} $33-33$

Correlation of historical cyclone record and proxy-based event layer detection on core BH6.

\section{Supplementary material 3} $44-44$

Multi-panel figure: (a) conceptual figure of the genesis regions of the four main Caribbean cyclone clusters; (b, c, d, e) major landfall sites of the four cyclone clusters.

\section{Supplementary material 4}

Multi-panel figure: core loge files with detailed lithological and stratigraphic description.

\section{Supplementary material 5}

Raw data of textural analysis (sieving results $<2 \mathrm{~mm}-63 \mu \mathrm{m}$ ).

\section{Supplementary material 6}

Raw data for age (year CE) to core depth $(\mathrm{mm})$ calibration.

Supplementary material 7

${ }^{14} \mathrm{C}$ AMS radiocarbon geochronology and comparison with varve counting results.

\section{Supplementary material 8}

Raw data of grain size and sorting calculations including grain sizes $<63 \mu \mathrm{m}$.

\section{Supplementary material 9}

Raw data of XRF measurements (element content in raw counts). 
Raw data of cyclone counts, event layer thickness and grain size.

\section{CHAPTER 3}

Supplementary material 11

$65-65$

Raw data of the age model: core depth $(\mathrm{cm})$ against varve counting years and ${ }^{14} \mathrm{C}$ ages.

Supplementary material 12 $70-70$

Raw data: $\delta^{18} \mathrm{O}, \delta^{13} \mathrm{C}$ and TEX ${ }_{86}$ against core depth $(\mathrm{cm})$, and correlation of $\delta^{18} \mathrm{O}$ and TEX

\section{CHAPTER 4}

Supplementary material 13 $104-104$

Textural analysis of thin-section samples: mean grain size and sorting.

\section{Supplementary material 14} $123-123$

Multi-panel figure: (a-g) core log files including sedimentary facies extrapolation. Combined view with other datasets derived from the multi-proxy-TC-identification approach.

\footnotetext{
* all supplementary files are only presented electronically on the attached CD due to their large size and the impossibility to incorporate them into the main text. The page numbers refer to the position in the main text, in which the supplementary materials are first mentioned.
} 


\section{CO-AUTHORSHIP STATEMENT}

The following Ph.D. thesis is the result of a cumulative dissertation and inspired by three research articles, which have been published/accepted in peer-reviewed scientific journals under my banner. It is the intention of the author to present the Ph.D. thesis in five different chapters. The first chapter (Chapter 1) provides a general introduction into the field of climatology and paleo-climate reconstruction, an overview about research motivation, the general scope of the Ph.D. project, research objectives and a structural thesis outline. The following three chapters represent the main text body of this thesis, which is completely presented in manuscript format.

All chapters presented in manuscript format have been collaborative efforts between me and different project team members. For this reason, I would like to outline the work personally done and the contributions made by the co-authors of the different manuscripts. As the corresponding author of this Ph.D. thesis, the work is predominantly my own, with major guidance from my supervisor Dr. Eberhard Gischler and minor contributions of all the manuscript co-authors. Dr. Eberhard Gischler was responsible for the project conceptualization and the chosen methodology. In order to collect sediment cores for my analyses, fieldwork was undertaken by myself and my supervisor Dr. Eberhard Gischler.

Chapter 2 includes my first written Ph.D. paper, published by Scientific Reports journal, that presents an annually-resolved Common Era record of Caribbean cyclone activity. I personally performed the required laboratory work comprising all sampling processes, core descriptions and textural analyses. Photo documentation and XRF-measurements of trace elements have been done in cooperation with Dr. Flavio Anselmetti (Bern) and Dr. Hendrik Vogel (Bern). I personally carried out all data analyses and elaborated the corresponding data interpretation. As the corresponding author, I wrote the original draft of the manuscript with Dr. Eberhard Gischler, Dr. Flavio Anselmetti and Dr. Hendrik Vogel giving guidance and editorial comments.

Chapter 3 is my second written Ph.D. paper, published by Quaternary Science Review journal. The related manuscript presents a continuous, annually-resolved 
record of Common Era sea-surface-temperature (SST), Atlantic Multidecadal Oscillation (AMO) and cyclone-controlled run-off/soil-erosion. I personally performed the sampling processes and made the sample preparation for geochemical $\left(\delta^{18} \mathrm{O} / \delta^{13} \mathrm{C}\right)$ and molecular proxy (TEX) measurements. These measurements have been done, both by my co-authors (Dr. Jörn Peckmann and Dr. Daniel Birgel) and inhouse specialists of the stable isotopes lab (Sven Hofmann and Dr. Jens Fiebig). I personally made all formal data analyses and wrote the original draft of the manuscript including all data visualisations. All project team members together, discussed the results and provided equally input to the manuscript by reviewing and editing the original draft.

Chapter $\mathbf{4}$ is a project related paper, written by me, which have been developed in the wake of Daniel Walkenfort's B.Sc. thesis. This manuscript was currently accepted by the Facies journal and focusses on a quantitative facies analysis of the Holocene sediment succession of the "Great Blue Hole" of Lighthouse Reef. My coauthor Daniel Walkenfort (Frankfurt) performed the thin-section point counting analysis, conducted the statistical analyses and prepared data interpretation in cooperation with and guidance by me. Even though, some parts of the paper have been included in a less detailed version of Daniel Walkenfort's B.Sc. thesis, major content related improvements have been incorporated to the final manuscript by me, also including a broader data interpretation, a wider scientific focus and an improved data visualisation. My own supervisor Dr. Eberhard Gischler discussed all results and provided equally input to the final version.

Chapter 5 is a general conclusion of the main results of this Ph.D. thesis and provides furthermore a forecast on a future project concerning the "Great Blue Hole" sediment archive. 


\section{CHAPTER 1: \\ INTRODUCTION AND THESIS OVERVIEW}

\section{Introduction}

Paleoclimate reconstructions, which aim at investigating climate-human interactions, currently achieve an outstanding public and scientific perception due to the omnipresent scientific climate debate and public concerns about global warming long-term effects for modern society. Despite all scientific advances that have been made in the field of climate research over the past decades, a reliable prediction and modelling of future climate scenarios remain one of the greatest challenges of our time.

The Holocene $(<11.7 \mathrm{kyr}$ BP) time frame is characterized by several periods of distinct climate changes (Mayewski et al. 2004), which can be scientifically investigated and considered as natural analogues of the present-day climate crisis. Many of these past climate variations had extensive effects on mankind and coincided with demises of extinct high civilizations during the past two millennia (Common Era; 0 CE - present). The Medieval Warm Period (900-1400 CE) is a very good example for such a past climate variation that affected human history, especially in the wider Caribbean region. The cultural demise of the Classical Maya high civilisation followed extensive hydro-climate changes appearing in tropical regions with the onset of the Medieval Warm Period (Kennett et al. 2012). When applying this pattern to the recent climate situation in the Caribbean, variations of sea-surface temperatures (SST) and changes of tropical cyclone activity regimes need to be systematically studied for the past 2000 years as key objectives in paleoclimate inspired research projects.

Meteorological records, regional case studies (Murnane and Liu 2004) and global warming prediction models (Webster et al. 2005) generally agree that rising global SSTs will likely lead to a significant increase in the occurrence of tropical cyclones and/or initiate a shift towards more frequently occurring very intense cyclones e.g., a doubling of cat. 4/5 hurricanes (Goldenberg et al. 2001; Bender et al. 2010). For the Caribbean countries and nearby states, this forecast represents one of the greatest dangers of modern climate change. The prospective increase of tropical cyclone frequency and magnitudes, expressed in the 15th chapter of the IPCC AR5 report, 
entails a rising probability of ecological and social disaster, which were tragically exemplified by several severe cyclone strikes during the past 20 years. Tropical cyclones are among the most destructive storms of the world and cause due to the combination of strong winds, intense rainfalls and storm waves/surges (Keim and Muller 2007) more losses to life and property than any other natural disasters in the wider Central- and North American realm (Murnane and Liu 2004). The Ph.D. thesis, presented her, reports on the results of a 3-years research project, which has the potential to provide new insights into the positive feedback mechanisms of how climate variations influenced SST variability and tropical cyclone frequency in the south-western Caribbean over the past two millennia of Common Era time series.

\section{Instrumental record limitation}

Reliable climate records are crucial prerequisites for nearly all climate modelling approaches. Future climate predictions are contemporary though based on reliable instrumental data with high resolution, but such data sets are only available for the last 150 years. However, a variety of long-term ongoing processes and climate phenomena continuously modulated the global climate dynamics throughout the entire Holocene. These control factors of the global climate system operated in time intervals covering several decades, sometimes multiple centuries, and in some cases even whole millennials. The brief nature of the instrumental record makes an appropriate consideration of such long-term climate patterns in IPCC-grade climate models difficult to achieve. Considering the Instrumental Era (>1850 CE) alone can consequently only offer a limited perspective for understanding causes of past and present as well as consequences of future climate variations. It is thus necessary to provide a synoptic mechanistic understanding regarding the origin of such long-term climate patterns and late Holocene cyclone activity-SST-feedbacks, in order to provide reliable forecast for highly endangered tropical Atlantic regions under future climate scenarios. Extracting millennial-scale proxy data from paleoclimate archives enables a unique opportunity to gain the required long-term climate data for better statistical constraints in climate models. A few regional climate records have already been obtained from different Caribbean archives (e.g., Haug et al. 2001, 2003; Gischler et al. 2008; Kennett et al. 2012). However, they mostly lack the necessary continuity, resolution and duration, which is required to achieve an improvement of the current situation. These issues scientifically justify the development of a new, 
continuous, sufficiently longer, and at the same time annually-resolved paleoclimate record of the south-western Caribbean. This Ph.D. thesis was created, in order to (1) understand the Common Era climate dynamics in general and (2) to decipher longterm SST modulation of tropical cyclone frequency in particular.

\section{Paleoclimate research in the Caribbean: state-of-the-art}

The south-western Caribbean is overall very climate-sensitive and well suited to study the causes of Common Era climate variations and subsequent changing ocean-atmosphere dynamics maintained by responses of prominent climate phenomena. Three climate phenomena exert strong control on Caribbean climate dynamics. Among these are the Atlantic Multidecadal Oscillation (AMO; Gray et al. 2004), the North Atlantic Oscillation (NAO; Trouet et al. 2009) and the El-NiñoSouthern Oscillation (ENSO; Li et al. 2013). Enfield et al. (2005) described the AMO as a major oceanographic feature of climate variability in the North Atlantic region that simultaneously modulates Atlantic (Knight et al. 2005) and Caribbean (Hetzinger et al. 2008) SST patterns on multi-decadal time scales. The NAO, a general measure for air-pressure gradient fluctuations between the Icelandic Low and the Azores High (Elsner et al. 2006), is supposed to be a key mechanism of North Atlantic atmospheric circulation, which was previously considered to explain long-term patterns in tropical Atlantic cyclone activity due to cyclone track modulation (Denommee et al. 2014). Despite the ENSO, a coupled ocean and atmosphere circulation phenomenon, primarily works in the equatorial Pacific, there are also important tele-connections with the tropical western Atlantic (Burn and Palmer 2015). These include multi-annual to decadal modulations of tropical Atlantic SST patterns, changes in tropospheric wind shear stress dynamics and variations of trade wind strength, all affecting tropical Atlantic cyclone frequency and cyclone pathways.

A large number of paleoclimate archives (Emile-Geay et al. 2017) was investigated all over the world with respect both to understand past climate dynamics and to decipher positive feedback mechanisms between individual climate shaping phenomena. Such records are typically based on ice core, tree, organism (shells, skeletons and tests), speleothem or sediment archives. Caribbean climate records are still scarce in this compiled global database and largely not sufficient to understand the climate dynamics of the Caribbean region in its entirety, particularly when considering the marine realm of the south-western Caribbean and the Common 
Era time series. Nearly all Caribbean records derive from continental Mesoamerican lakes (Metcalfe et al. 2000; Hodell et al. 2008) such as Petén-Itzá (Guatemala), Chichanancanab (Mexico) or Miragoane (Haiti). These records have only decadal resolution, target primary Pleistocene-to-Holocene time scales and focus largely on atmospheric elements of the Caribbean climate system. Some sporadic annuallyresolved Caribbean speleothem records allow high-resolution insights into the Common Era climate history (Kennett et al. 2012), however with the same limitation, in that they mostly reflect equally to the lake sediment archives, changes in precipitation patterns and lack information with respect to ocean dynamics. The sedimentary archive from the anoxic Cariaco Basin (Haug et al. 2001, 2003) is the only available marine sediment record of the western Caribbean, but again with the same focus on precipitation changes only.

Tropical Atlantic SST records have been primarily obtained from sclerosponge (Haase-Schramm et al. 2003), foraminifer (Black et al. 2007) and coral (Kuhnert et al. 2002; DeLong et al. 2014; Tierney et al. 2015) archives. These records encompass only very short time series (max: century) compared with those extractable from marine sediment successions (max: millennia). Larger-scale SST reconstructions, covering the entire Common Era, are exclusively smoothed synthesis approaches, compiling several of the short and regional SST records to a "continuous" Northern Hemisphere (Mann et al. 2008) and global (Rosenthal et al. 2017) SST curve.

All the above-mentioned approaches display a satisfactory representation of Pleistocene up to Holocene precipitation patterns in the Caribbean region, but provide only limited insights on tropical Atlantic SST variability throughout Common Era times. For this reason, there is an urgent need for establishing a new Caribbean climate record derived from a sinkhole sediment succession, which targets in particular oceanic (SST) and atmospheric dynamics (tropical cyclone activity) at the same time. Instrumental measurements display a strong connection of SST variations in the Atlantic cyclone main development region (MDR) and tropical cyclone activity on the order of multi-annual time scales (Goldenberg et al. 2001). The multi-annual modulation of cyclone activity is relatively well understood for the Instrumental Era. Sea level atmospheric pressure, West African monsoon, the quasibiennial oscillation of stratospheric wind (Chu 2004), and other ENSO controlled tropospheric modulations (Murakami et al. 2018) exert a major control on multi- 
annual cyclone frequency within the Instrumental Era. Among these, the ENSO appears to be the most dominant factor by creating steady vertical temperature gradients (McTaggart-Cowan et al. 2015), controlling vertical wind shear stress dynamics and modulating tropical Atlantic and MDR SSTs between $26^{\circ} \mathrm{C}$ and $29^{\circ} \mathrm{C}$ (Gray 1986; DeMaria and Kaplan 1994; Murnane and Liu 2004). The role of the two ENSO phases (El-Niño/La-Niña) for modulating the tropical Atlantic cyclone activity is very well-known considering this multi-annual observational time-series (Gray 1984). During El-Niño years, fewer cyclones develop due to stronger influence of vertical wind shear stress, stronger trade winds and an overall greater atmospheric stability. Weaker vertical wind shear stress, weaker trade winds and a lower atmospheric stability favour in turn a higher cyclone activity within La-Niña years.

Multi-decadal variations in cyclone activity are less well understood than multi-annual variations (Denommee et al. 2014). Some efforts have been made to align multidecadal variation of Atlantic cyclone frequency with major Caribbean climate drivers. In the case of multi-decadal variation, long-term changes in Atlantic Basin SSTs and basin-wide atmospheric pressure anomalies have been suspected to exert a major control on cyclone formation (Elsner et al. 1999; Landsea et al. 1999; Goldenberg et al. 2001). The NAO was previously considered as an important North Atlantic atmospheric phenomenon influencing the spatial distribution of cyclones (Elsner et al. 2006). Air pressure gradient variations between the Icelandic Low and the Azores High have been associated with the creation of a thermodynamic environment for enhanced/suppressed cyclone occurrence as response to higher/lower heat transfer rates and lower/higher tropospheric wind shear stress (Elsner et al. 2000). Denommee et al. (2014) previously used long-term positive and negative NAO modes to explain an increased south-western Caribbean cyclone activity (NAO+) during the Medieval Warm Period (900-1400 CE) and a decreased cyclone frequency (NAO-) during the Little Ice Age (1400-1800 CE). The NAO is, however, primarily active during the boreal winter, a time when Atlantic cyclone formation does not occur. This issue raises questions about the suitability of the NAO mode as a major control factor of multi-decadal cyclone modulation. The NAO may be likely better suited to explain long-term changes in the Atlantic hydro-climate and should be consequently regarded only as one part of the entire system, but not as the primary control factor that shapes the cyclone activity on multi-decadal and longer scales. 
There is a contested theory that the AMO could be an alternative control of multidecadal cyclone modulation (Knight et al. 2005). Dijkstra et al. (2012) correlated AMO phase changes to 40-70 years long periodic cycles originating from velocity fluctuations of the thermohaline circulation (THC). There are some evidence for THC acceleration during positive AMO phases and vice versa. This positive feedback mechanism exerts not only control on ocean heat flux rates between the tropical $\left(0^{\circ}\right)$ and Northern Atlantic $\left(60^{\circ}\right)$, but also induces multi-decadal fluctuating SST anomalies in the Caribbean (Hetzinger et al. 2008). The long-term behaviour of the AMO mode could be considered in the same way as the NAO mode as a potential driver of cyclone activity that operates primary on multi-decadal but also on longer time series (Frajka-Williams et al. 2017).

Instead of focusing on the NAO, it seems to be crucial to understand the long-term influence of the AMO mode on centennial-scale SST variations within a positive feedback system of ENSO control. Both AMO and ENSO are, considering the Instrumental Era knowledge, certainly more appropriate to explain long-term patterns of Common Era cyclone activity than the previously favoured boreal winter NAOENSO connection. On centennial- to millennial-scale time frames, the AMO-ENSO interplay is largely unexplored and predominantly limited to tree ring based (e.g., Gray et al. 2004) and discontinuous AMO reconstructions (Delworth and Mann 2000) as well as to a single spatial grid study in the western Caribbean (Burn and Palmer 2015). Till this day it is not entirely clear how far back in time the AMO phenomenon occurs in the Caribbean region and how precisely this climate driver acts together with the better-known ENSO dynamics for shaping the boundary conditions of tropical Atlantic cyclone activity on multi-decadal and even longer time scales. It is thus essential to produce very sensitive and over millennials continuously retraceable Caribbean cyclone and SST records with annual resolution and reliable AMO signal detection to provide a thorough understanding of all involved climate phenomena and boundary conditions.

\section{Paleoclimate reconstruction: application in sinkhole settings}

Shinn et al. (1996) first highlighted the huge potential and advantages for obtaining millennial-scale cyclone and SST records from flooded cave systems. Small-scale sinkholes (Blue Holes) are very special and in terms of "lake-like" sediment successions concurrently unique marine depositional environments of modern reef 
systems (Yao et al. 2020). Anoxic Blue Holes that include annually-layered bottom sediments ("varves") are well suited for geo-scientific surveys addressing both the above-described paleoclimate scope, but also some additional and supportive sedimentary objectives. Despite anoxic sinkhole settings are ideal sites for combined SST, AMO, and cyclone reconstruction approaches, their previous investigation, however, largely was concentrated on the development of continuous cyclone frequency records.

There are some valuable examples of cyclone records obtained from anoxic sinkhole depositional settings with annual, e.g., the Southern Andros Blue Holes (Bahamas; Wallace et al. 2019), multi-annual e.g., the Florida Mullet Pond (Lane et al. 2011) and multi-decadal resolution, e.g., the Bahamas Blackwood (van Hengstum et al. 2016) and Thatchpoint Blue Holes (van Hengstum et al. 2013). Some former site-specific studies investigated sediment cores covering the past 1,380 years from another unique Blue Hole with stratified water column, situated in Lighthouse Reef Atoll (Belize) with regard to multi-annual climate (Gischler et al. 2008, 2013) and cyclone activity (Denommee et al. 2014) reconstructions.

The $125 \mathrm{~m}$ deep and $320 \mathrm{~m}$ wide "Great Blue Hole" of Lighthouse Reef is located within the tropical cyclone belt and acts as consequence of its unique geomorphology as a giant sediment trap for both varved fair-weather sediments and storm deposits. A constant annual input of fine carbonate material with seasonally varying contents of organic material backfills the accommodation space of the "Great Blue Hole" under fair-weather conditions (Gischler et al. 2008). Tropical cyclones repeatedly passing over Lighthouse Reef are a contrasting and profound disruption of the fair-weather sedimentation dynamics (Brown et al. 2014). Storm surges and storm waves initiate an over-wash deposition of marginal reef debris that results in the formation of intercalated coarse and yellow-brown coloured event beds, which sharply differ from their greenish host background sediments on the basis of lithological and sedimentological evidence. The sedimentary archive of this sinkhole still offers the great potential to be analysed at annual resolution, further back in time, and even more important in terms of combined cyclone, SST and AMO research. For this reason, a review and improvement of the Lighthouse Reef climate archive was performed within this Ph.D. project, especially with respect to understand the longterm influence of major Caribbean climate drivers on Common Era SST patterns and 
long-term cyclone activity modulation. In this context, special emphasis was placed on a reliable AMO signal detection in marine sinkhole succession, which are certainly more meaningful to reflect an oceanographic feature than the terrestrial tree ring archives, which largely reflect multi-decadal precipitation changes (Gray et al. 2004).

Another still disregarded element concerning marine sinkholes, is the lack of quantitative data with regard to sediment column composition, sedimentary facies identification and their long-term variation patterns in the wake of Common Era climate variations. In principal, approaches that investigate sedimentological aspects in sinkhole settings are very rare, in particular concerning the south-western Caribbean. The paleoclimatologically inspired approaches of Gischler et al. (2008), Brown et al. (2014) and Denommee et al. (2014) discussed the sediment successions of the wider Yucatan-area sinkholes only qualitative, in terms of general differences (fair-weather vs. event deposits) and superficially on the basis of quantitative textural data (e.g., grain size and layer thickness). Therefore, a sedimentological approach was also included in this Ph.D. project, which in detail addresses the quantification of skeletal carbonate components, the identification of sedimentary facies and their temporal variations.

\section{Ph.D. thesis: hypotheses and objectives}

As a part of a collaborative 3-years research project, this cumulative dissertation presents two major paleoclimate research applications (Chapter 2/3) and a quantitative sedimentological investigations (Chapter 4) that is closely embedded into the paleoclimate scope. For this purpose, the Ph.D. thesis consequently has three major objectives including (1) the development of an annually-resolved Common Era record for tropical cyclone activity, (2) the elaboration of annuallyresolved SST and AMO datasets that encompass the past two millennia and (3) a sedimentary facies identification, characterisation and compositional quantification of the "Great Blue Hole" sediment succession. In order to achieve these major objectives, some key questions have been answered following the initial research hypotheses. The Ph.D. thesis answers the key question of how tropical cyclone frequency and recurrence rates of cyclone strikes varied in the south-western Caribbean over the Common Era time series. This survey confirms the hypothesis, that Common Era cyclone activity was tied to long-scale SST variability and to climate phenomena responses to late Holocene climate variations. Another key 
question, whether the "Great Blue Hole" sediment archive tracks the Common Era climate variability in general, and SST patterns in particular was confirmed by reflecting five late Holocene climate intervals including the Roman Warm Period (0-500 CE), the Dark Ages Cold (500-900 CE), the Medieval Warm Period (900-1400 CE), the Little Ice Age (1400-1800 CE) and the Modern Global Warming (>1800 CE). Moreover, the varved sinkhole succession provides a valuable archive for the detection of AMO signals and for understanding how AMO exerts control on tropical Atlantic SST variability and multi-decadal cyclone frequency modulation. For all these reasons, this Ph.D. thesis is a crucial advancement to understand how climate variability looked like in the Central American realm during the past 2,000 years. To date, the climatological part of this research project offers the longest continuous and concurrently only available combined annually-resolved tropical Atlantic SST $\left(\delta^{18} \mathrm{O}, \mathrm{TEX}{ }_{86}\right)$, AMO variability and cyclone-controlled run-off $\left(\delta^{13} \mathrm{C}\right)$ reconstruction, which builds on the results of an annually-resolved cyclone frequency study. The sedimentological part of this Ph.D. thesis is not only an important approach to quantify sinkhole sediment components, to decipher temporal composition variations, and to distinguish between sedimentary fair-weather and storm-condition facies, but is also closely connected to the climatological part of the project by providing a new proxy method for tropical cyclone event bed identification. Textural and compositional characteristics of event bed deposits have been tested in this survey to be a (semi-) quantitative proxy for event layer detection. As a general research hypothesis, it was presumed that the average composition of the intercalated event beds likely differs, because of storm wave and storm surgeinduced particle over-wash, from those of the varved background sections. The average composition of cyclone-induced over-wash sediments should reflect more likely the marginal reef composition (increased content of coral and coralline algal fragments and Halimeda chips) than the adjacent lagoon composition (dominated by mollusc, foraminifer and fine-grained aragonitic mud), which is assumed to be more similar to the general fair-weather sedimentation. This Ph.D. thesis presents evidence that compositional and textural characteristics of sedimentary "cyclone facies" (Halimeda wackestone, algae-rich packstone and coralgal rudstone) are another valuable and helpful (semi)-quantitative proxy to distinguish event beds of tropical cyclones from fair-weather sediments (mudstone) in unconsolidated sinkhole sediment successions. 


\section{Ph.D. thesis: structure and outlines}

This thesis is structured as follows: Chapter $\mathbf{1}$, in which the introduction and this brief outline is included, is entitled: Introduction and thesis overview. This introductory chapter presents a general introduction into the field of climatology and paleo-climate reconstruction, an overview about research motivation, the general scope of the Ph.D. project and research objectives. It also briefly discusses the application potential of paleoclimate studies within the scope of modern climatology. The main text body contains the following three chapters, which are presented in manuscript format. Two manuscripts have been published in peer-reviewed journals at the time this Ph.D. thesis was created. The third one was accepted after the transcription process was finalised. The three research articles are the main product of the Ph.D. project. Chapter 2 is the primary paleoclimatological manuscript of this Ph.D. thesis published by Scientific Reports journal entitled: "Caribbean cyclone activity: an annually-resolved Common Era record". This chapter presents an annually-resolved, 1,885-years long reconstruction of tropical cyclone activity in the south-western Caribbean. The chronology of all Common Era cyclone strikes was put in context of other cyclone records from sites throughout the Atlantic Basin and considered within the scope of Common Era climate variability. Chapter $\mathbf{3}$ is a closely to the cyclone topic related paleoclimatological manuscript published by Quaternary Science Review journal entitled: "Great Blue Hole (Lighthouse Reef, Belize): a continuous, annually resolved record of Common Era sea surface temperature, Atlantic Multidecadal Oscillation and cyclone-controlled run-off". This chapter presents a continuous, annually-resolved Common Era record of 1,885-years of SST variability, a reliable AMO signal detection and evidence for a cyclone-controlled run-off/soil erosion rate feedback. All records, presented in the third chapter of this Ph.D. thesis, originate from stable isotope measurements $\left(\delta^{18} \mathrm{O} / \delta^{13} \mathrm{C}\right)$ and an innovative molecular proxy application (TEX ${ }_{86}$ ). Chapter 4 is a sedimentological manuscript accepted by Facies journal entitled: "Holocene sediments of an inundated sinkhole-facies analysis of the Great Blue Hole, Lighthouse Reef, Belize". As a collaboration effort with a B.Sc. thesis, this chapter presents a quantitative composition and sedimentary facies analysis of the "Great Blue Hole" sediment succession by using thin-section pointcounting and textural data. The final chapter, Chapter 5, is entitled: Conclusions and forecast. This chapter synthesis the key findings of the Ph.D. project and presents a brief forecast on a continuative and future research effort in the "Great Blue Hole". 


\section{"Caribbean cyclone activity: an annually-resolved Common Era record"}

\section{Abstract}

Tropical cyclones (TC) represent a substantial threat to life and property for Caribbean and adjacent populations. The prospective increase of TC magnitudes, expressed in the 15th chapter of the IPCC AR5 report, entails a rising probability of ecological and social disasters, which were tragically exemplified by several severe Caribbean TC strikes during the past 20 years. Modern IPCC-grade climate models, however, still lack the required spatial and temporal resolution to accurately consider the underlying boundary conditions that modulate long-time TC patterns beyond the Instrumental Era. It is thus necessary to provide a synoptic mechanistic understanding regarding the origin of such long-time patterns, in order to predict reliable changes of TC magnitude and frequency under future climate scenarios. Caribbean TC records are still rare and often lack the necessary continuity and resolution to overcome these limitations. Here, we report on an annually-resolved sedimentary archive from the bottom of the "Great Blue Hole" (Lighthouse Reef, Belize). The TC record encompasses 1885 years and extends all existing sitespecific TC archives both in terms of resolution and duration. We identified a likely connection between long-term TC patterns and climate phenomena responses to Common Era climate variations and offer a conceptual and comparative view considering several involved tropospheric and oceanographic control mechanisms such as the El-Niño-Southern-Oscillation, the North Atlantic Oscillation and the Atlantic Multidecadal Oscillation. These basin-scaled climate modes exercise internal control on TC activity by modulating the thermodynamic environment (sea-surface temperature and vertical wind shear stress dynamics) for enhanced/suppressed TC formation both on millennial (primary) and multi-decadal (secondary) time scales. We interpret the beginning of the Medieval Warm Period (MWP) as an important time interval of the Common Era record and suspect that the southward migration of the intertropical convergence zone (ITCZ) caused, in combination with extensive hydroclimate changes, a shift in the tropical Atlantic TC regime. The TC activity in the 
south-western Caribbean changed in general from a stable and less active stage (100-900 CE) to a more active and variable state (1100 CE-modern).

\section{Introduction}

Atlantic cyclone main development region (MDR) is characterised by a latitudinal extension from $9^{\circ} \mathrm{N}$ to $20^{\circ} \mathrm{N}$ and runs longitudinally along the northern edge of the intertropical convergence zone (ITCZ; van Hengstum et al. 2016). Sea-surface temperatures (SST) exceeding the threshold of $26.5^{\circ} \mathrm{C}$, the influence of low vertical wind shear stress, and the occurrence of steady vertical (tropospheric) temperature gradients are the major natural boundary conditions for TC formation (McTaggartCowan et al. 2015). These boundary conditions facilitate a deep atmospheric convection within the tropical western Atlantic and exercise thus a thermodynamic control on TC activity. Instrumental data (NOAA HURDAT2), case studies (Murnane and Liu 2005) and global warming prediction models (Webster et al. 2005) generally agree that the magnitude of TCs will increase under future greenhouse-climate conditions, whereas the average frequency of the different TC categories will remain the same or indeed slightly decrease (Sugi et al. 2015). In order to reconcile and specify these trends, other prediction models (Bender et al. 2010; Knutson et al. 2010) demonstrate a shift towards more frequently occurring very intense TCs (doubling of cat. 4/5 hurricanes) and a related decline in the frequency of weaker storms. MDR SST variations and coevally occurring changes of vertical wind shear stress dynamics have been successfully identified as the primary TC activity control factors for the short instrumental record (Goldenberg et al. 2001). In addition to the atmospheric modulation in response to the EI-Niño-Southern-Oscillation (ENSO), SST variations are therefore a further key factor to understand future, present and past patterns of TC activity (Murakami et al. 2018). There is a contested theory that the Atlantic Multidecadal Oscillation (AMO) is a major control factor for the North Atlantic climate variability (Enfield et al. 2001) and multi-decadal variability in Atlantic SST (Knight et al. 2005). The AMO mode is attributable to $40-70$ years long periodic cycles originating from velocity fluctuations of the thermohaline circulation (THC; Dijkstra et al. 2006). The interplay of accelerated/decelerated THC and concurrent positive/negative AMO phases exerts control on ocean heat transfer rates between the tropical $\left(0^{\circ}\right)$ and Northern Atlantic $\left(60^{\circ}\right)$, which in turn induces multi-decadal fluctuating SST anomalies (Dijkstra et al. 2006). This connection of SST variability 
and AMO control could be, however, also a potential long-term driver of TC activity patterns (Frajka-Williams et al. 2017). The North Atlantic Oscillation (NAO) is another climate driver, which was previously considered as an important atmospheric phenomenon influencing the tracking of TCs by North Atlantic atmospheric pressure gradient modulations (Elsner et al. 2006). These air pressure gradient variations between the Icelandic Low and the Azores High are also associated with the creation of a thermodynamic environment for enhanced/suppressed TC formation as response to higher/lower heat transfer rates and lower/higher tropospheric wind shear stress (Elsner et al. 2000). This linkage has been previously used as a major climatic variable (Denommee et al. 2014) to explain on centennial scales a higher south-western Caribbean TC activity during the Medieval Warm Period (NAO+) and a lower TC activity during the Little Ice Age (NAO-). The NAO is, however, primarily active during the boreal winter, a time when Atlantic TC formation does not occur. This issue raises questions about the suitability of the NAO mode as a major TC activity control factor. The NAO may be therefore better suited to explain long-term changes in the Atlantic hydro-climate and should be regarded as one part of the entire system, but not as the primary control factor shaping TC activity on longer time scales as suggested in a former site-specific study (Denommee et al. 2014).

In contrast, it is crucial to understand the long-term role of the AMO mode within this positive feedback system. A long-term consideration of the AMO phenomenon enables a coupled consideration of centennial-scaled SST variations and long-term atmospheric ENSO modulations. Both climate modes are certainly more appropriate to explain long-term patterns of Common Era TC activity than the previously assumed NAO connection. The role of the two ENSO phases (EI-Niño/La-Niña) for modulating the Atlantic TC activity is relatively well understood considering multiannual observational time-series (Gray 1984). During El-Niño years, fewer Atlantic TCs develop due to stronger influence of vertical wind shear stress, stronger trade winds and an overall greater atmospheric stability. Weaker vertical wind shear stress, weaker trade winds and a lower atmospheric stability favour in turn a higher TC activity within La-Niña years. The positive feedback between AMO, ENSO and TC activity modulation, is in particular on longer-time scales not fully understood and as described above mainly limited to the Instrumental Era record, a tree ring based AMO reconstruction (Gray et al. 2004) and a spatial grid study in the western 
Caribbean region that focusses on a coupled ENSO and AMO influence for shaping boundary conditions of TC formation (Burn and Palmer 2015). The AMO related uncertainty in former TC activity reconstructions might partly originate from the fact that it is not entirely clear how far back in time the AMO phenomenon occurs and how precisely this climate driver acts together with the ENSO dynamics to shape TC activity patterns on longer than multi-decadal time scales. It is essential to produce sensitive and temporarily continuous TC activity records with annual resolution and reliable AMO signal detection, to overcome this limitation and to provide a thorough understanding of all involved climate modes.

Continuous TC activity records with annual resolution are still rare, often incomplete (duration and spatial resolution) and indicate, in addition, conflicting results in terms of long-term Caribbean activity patterns. Some discontinuous TC records have been obtained from over-washed sand layers, storm rubble and boulder ridges above highest astronomical tides, or from the onshore occurrence of marine organisms within coastal lagoons of Belize (Adomat and Gischler 2017) and Puerto Rico (Donnelly and Woodruff 2007) as well as in the coastal Belize marshes (McCloskey and Keller 2009; McCloskey and Liu 2012). These studies reach only a decadal resolution and assume constant sedimentation rates which is, however, not representative, because of erosional unconformities in the stratigraphic record. Annual resolution records are in general the exception in coastal environments (e.g., Salt Pond, Massachusetts; Donnelly et al. 2015).

Blue Holes are indeed ideal sites for both annually resolved and continuous longterm TC reconstructions, because they are not affected by erosional unconformities or other geomorphological processes related to changes of accommodation space, sediment supply and subsidence, as it is the case in coastal settings. There are some examples of TC records obtained from Blue Hole depositional settings with multi-annual (e.g. the Florida Mullet Pond record; Lane et al. 2011) and multi-decadal resolution (e.g. the Bahamas Blackwood; van Hengstum et al. 2016 and Thatchpoint sinkhole records; van Hengstum et al. 2013), respectively. The most recent study on Southern Andros Blue Holes (Bahamas; Wallace et al. 2019) actually reaches annual resolution. Our study investigates the "Great Blue Hole" of Lighthouse Reef (Belize), which is an inundated, circular and cylindrical-shaped Pleistocene karst cavity acting as sediment trap in the wake of multiple historical TC tracks (Fig. 1 a, b, d). 

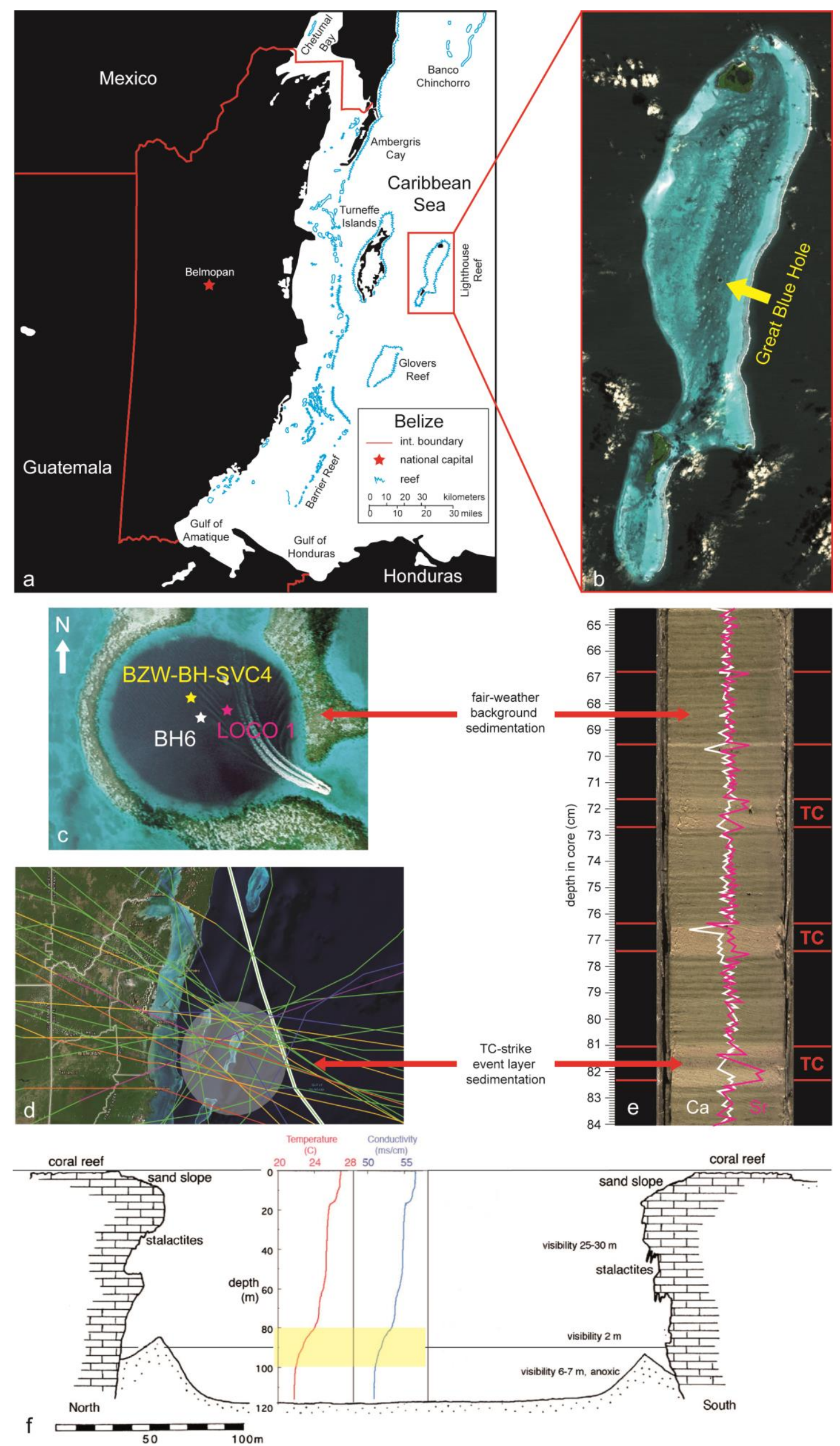
$\leftarrow$ Figure 1. (a) Geographical overview illustrating the position of Belize and offshore atolls in southwestern Caribbean area. The map was produced digitizing open access satellite images using the vector graphic software Adobe Illustrator CS4 V.14.0. We acknowledge the use of imagery from the NASA Worldview application (https://worldview.earthdata.nasa.gov), part of the NASA Earth Observing System Data and Information System (EOSDIS). (b) Open access ASTER satellite image of Lighthouse Reef (https://asterweb.jpl.nasa.gov) supplied by Japan Space Systems, and U.S/Japan ASTER Science TEAM (NASA/METI/AIST/). The "Great Blue Hole" is situated in the eastern lagoon of Lighthouse Reef. (c) Aerial view taken in a previous study (Gischler et al. 2008) indicating the position of the core BH6 $\left(17^{\circ} 18.957^{\prime} \mathrm{N}, 8^{\circ} 32.098^{\prime} \mathrm{W}\right)$ in the "Great Blue Hole" centre as well as cores obtained during previous studies (BZE-BH-SVC4; Denommee et al. 2014 and LOCO1; Gischler et al. 2008). (d) Historical TC record (1850-2017 CE) passing the study area within a hypothetical $100 \mathrm{~km}$ diameter circle (grey shaded). The cyclone track map was downloaded from: https://coast.noaa.gov/hurricanes/ and compared with NOAA HURDAT dataset (Landsea et al. 2019). (e) Core photo (interval BH1: $65.0-84.0 \mathrm{~cm}$ ) of the undisturbed sediment succession at the floor of the "Great Blue Hole" comprising fine-grained, yellow-brown/green laminated couplets and five intercalated coarser sandy event beds (red). Additionally, $\mathrm{Sr}$ (purple) and $\mathrm{Ca}$ (white) overlays of XRFdatasets (elemental intensity: counts per second $=\mathrm{cps}$ ) are included, illustrating the approach of $\mathrm{Sr} / \mathrm{Ca}$ ratios (relative variation to background) for TC detection. (f) The "Great Blue Hole" cross-section with temperature and conductivity profiles (Gischler et al. 2008). Temperature and conductivity decrease significantly between 80 and $100 \mathrm{~m}$ depth; bottom water below ca. $90 \mathrm{~m}$ is anoxic.

The same sinkhole has already been sampled before with cores covering the past ca. 1380 years and 2-4 years resolution (Gischler et al. 2008; Denommee et al. 2014). The sedimentary archive of the "Great Blue Hole" offers, however, the great potential to be analysed further back in time and at annual resolution.

We cored the $8.55 \mathrm{~m}$ long record $(\mathrm{BH} 6)$ at $17^{\circ} 18.957^{\prime} \mathrm{N}, 8^{\circ} 32.098^{\prime} \mathrm{W}$ in the approximate centre of the sinkhole, in August 2017 (Fig. 1 C). The core stratigraphy is bipartite (Fig. $1 \mathrm{e}$ ) and characterized by yellow/brown-greenish, varved fair-weather background sedimentation and yellow/brown storm-induced event layers with varying amounts of skeletal debris (Halimeda, coralline red algae, molluscs, foraminifers, corals, echinoderms) and organic particles (Gischler 1994; Gischler and Zingeler 2002). The annual couplets most likely reflect seasonal changes in primary productivity within the surface waters of the Lighthouse Reef lagoon, resulting in differences in organic matter content between summer (yellow/brown) and winter season (green; Gischler et al. 2008). The varved background sedimentation layers are perfectly preserved in the sedimentary subsurface of the "Great Blue Hole" and totally undisturbed from bioturbation, because of persistent anoxic bottom-water conditions (Fig. 1 f). TCs passing the "Great Blue Hole" sediment trap either cause a sediment slope collapse at the top of the sinkhole, or physically initiate a suspension and settling of coarse-grained carbonate particles $(>63 \mu \mathrm{m})$ from the surrounding lagoon floor and marginal reef through storm wave and surge impact (Brown et al. 
2014). The coarser and sometimes graded event layers reveal both sharp erosive (downslope density flows) and gradual contacts (settling out of suspension) to the varved section (Brown et al. 2014). The gradation trends are generally comparable to the textural behaviour of a classic storm surge deposit. Many storm layers consist of three storm-driven subsections of changing energy levels indicated by mean grain size variation: onset (slightly increased grain size against background deposits), maximum (abrupt increase in grain size) and abatement (decline in grain size) of TC landfall.

Event layers have been generally identified in previous studies on the same sinkhole (Gischler et al. 2008; Denommee et al. 2014) based on colour difference, layer thickness or grain-size estimation. The grain-size estimation, in particular, conveys the impression that all sediment layers in the "Great Blue Hole" exceeding $30 \mu \mathrm{m}$ are generally attributable to event beds. However, there remain in detail some crucial limitations concerning this general grain-size threshold. It is for example particularly important to consider that "lobe-like" event layer geometry causes variations in layer thickness and grain sizes at different coring sites. Core-specific grain-size measurements of the background sedimentation are essential requirements for creating a grain-size related TC identification approach. The background sedimentation in core $\mathrm{BH} 6$ differs from previous thresholds and was determined to have an average grain size of $20 \pm 4 \mu \mathrm{m}$. All measured grain-size values exceeding this threshold have to be compared in the same core to grain-size values of historical record TCs and thus calibrated and verified. This calibration step allows, however, only a limited use of grain-size values in the $\mathrm{BH} 6$ core, because of grain size variations along the core originating from different hydrodynamic characteristics of various reefal carbonate particles. These limitations have large effects on the interpretation of sediment texture and of course hamper a pure TC identification on basis of average core background sedimentation grain-size. The integration of highresolution XRF-scanning datasets ( $>20,000$ samples) is a new valuable TC identification tool usable in sinkholes characterized by calcitic background sedimentation. XRF data are sensitive to record changes in background (containing calcite) versus over-wash (rich in aragonitic reef fragments) sediments. In particular, peaks in the $\mathrm{Sr} / \mathrm{Ca}$-ratio are very suitable to identify event layers in carbonate environments owing to the enrichment of $\mathrm{Sr}$ in aragonite relative to calcite (Fig. $1 \mathrm{e}$ ). 
We applied a multi-proxy-approach to ensure a more reliable TC identification (Suppl. 1) addressing the above-mentioned limitations. Our quantitative approach requires at best match to fulfil five different event layer identification criteria: (1) grainsize $>20-24 \mu \mathrm{m}$; (2) $<85 \%$ of fine material $<63 \mu \mathrm{m}$; (3) layer-thickness $>2.5 \mathrm{~mm}$; (4) yellow/brown colour and (5) Sr/Ca-ratio $>0.025$.

The chronology of individual TC strike event layers in core $\mathrm{BH} 6$ is anchored on two well-established and independent age/depth frameworks (Fig. 2). For this we use a combination of radiocarbon and varve age-models. Both models explicitly show a very strong linear correlation $\left(r^{2}=0.9\right)$ without any significant age offset between the counts of annual green-buff couplets and five ${ }^{14} \mathrm{C}$ ages obtained by AMS dating of entirely marine organic residue $\left(\delta^{13} \mathrm{C}_{\text {org_average }}=-16.0 \%\right.$ ). As such, our age model allows reconstructions of continuous TC activity with annual resolution back to the year $130 \mathrm{CE}$.

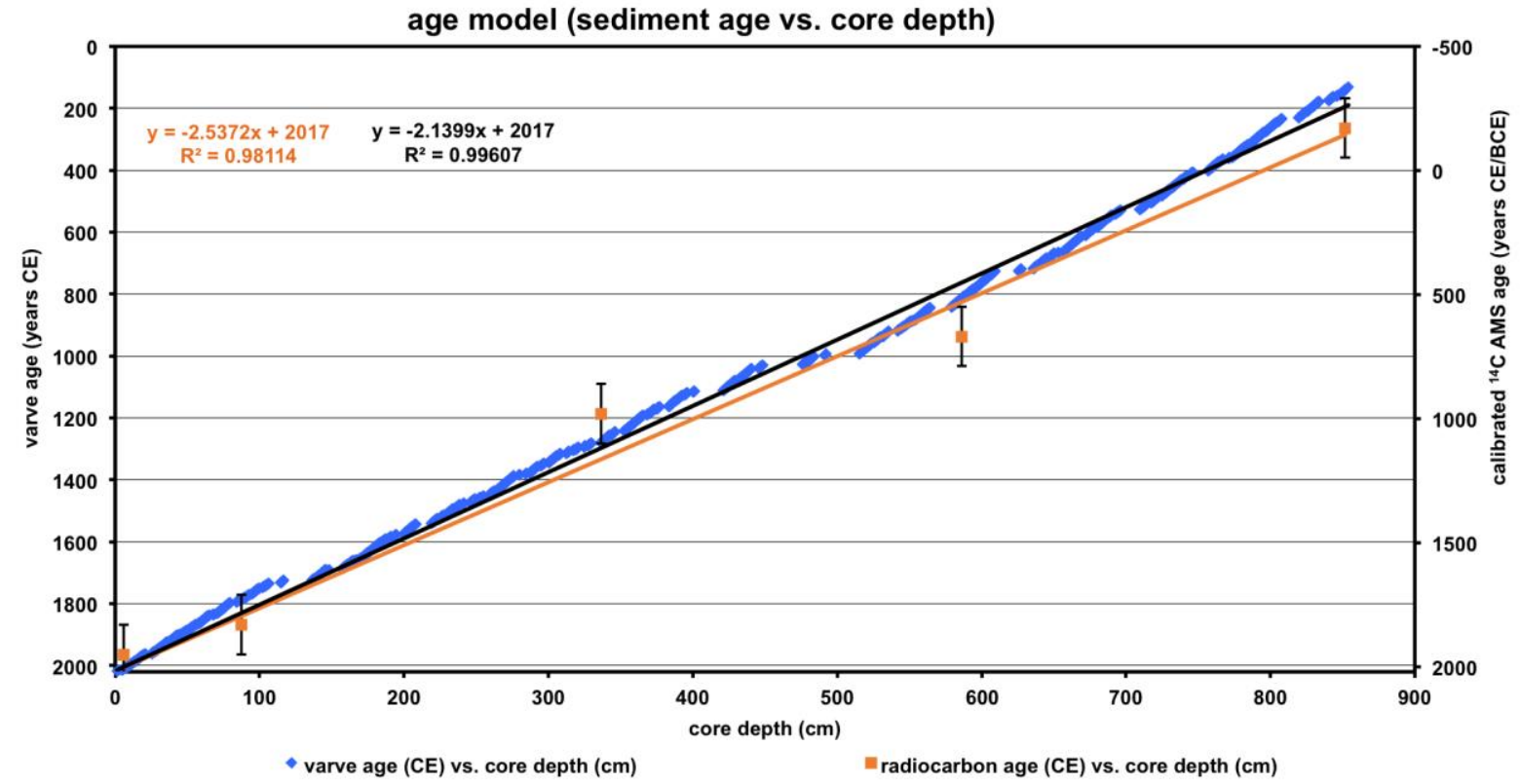

Figure 2. Combined plot of sediment age (years $\mathrm{CE}$ ) against core depth $(\mathrm{cm})$ as determined by both calibrated ${ }^{14} \mathrm{C}$ AMS radiocarbon geochronology of organic matter residue and by varve counting off buff-green background sediment couplets. Event layers have been omitted in our age model (gaps).

The presented multi-proxy-approach combines classical storm-layer detection methods with improved quantitative textural analyses and innovative XRF scanning applications. This proceeding enables, in combination with an annual resolution agemodel (sedimentation rate of $2.5 \mathrm{~mm} /$ year; sampling interval of $2.5 \mathrm{~mm}$ ), a so far unmatched Common Era evaluation of south-western Caribbean TC frequency. TC 
counts and textural parameters have been further investigated using multivariate statistics, in order to decipher possible temporal patterns and statistically significant correlations with climate phenomena such as the AMO and ENSO (Klotzbach 2011; Li et al. 2013).

\section{Results}

\subsection{TC record: quality check}

We compared the occurrence of event layers in the core $\mathrm{BH} 6$ with the historical record of TCs passing Lighthouse Reef within a $100 \mathrm{~km}$ radius to assess the detection sensitivity of the record (Suppl. 2). The TC archive of Lighthouse Reef is generally sensitive to all storm categories. The site has, however, like many other TC archives, a minimum bias of $10 \%$ for undetected storm events. In total, 30 TCs (intensity: tropical depression to major hurricane) passed Lighthouse Reef since 1850 CE. Of these, 21 TCs were matched with detected event layers near the anticipated sediment age of the historical strike year of the storm system, considering age offsets from varve counting of \pm 1 year. Nine storm systems from the historical record could not be observed in the $\mathrm{BH} 6$ core near the expected depth and varve age. Among these are four tropical storms (Kyle 1996 CE, Gert 1992 CE, Laura 1971 CE, Gilda 1954 CE), three hurricanes of category 1-3 (Edith 1972 CE, Abby 1960 CE, Greta 1978 CE) and two major hurricanes of category 4-5 (Keith 2000 CE, Mitch 1998 CE) using the 5-point-Saffir-Simpson scale. Hurricane Mitch (1998 CE) remains probably undetected in the record, because of its untypical southward migration and large catchment area distance (not enough wave energy to produce an event layer). The lack of a storm layer from Hurricane Keith (2000 CE), which directly moved over Lighthouse Reef, remains largely enigmatic. The missing event layer could probably be the result of a spatially limited density-surge deposition. Apparently, event-layer geometry in the "Great Blue Hole" has in many cases the shape of lobes that do not cover the entire bottom of the sinkhole. The remaining four tropical storms and three hurricanes of category 1-3 have been identified in another "Great Blue Hole" core with a detection uncertainty of $20 \%$ (Denommee et al. 2014). This comparison illustrates the challenges in high-resolution paleotempestology and the need of several comparable cores from the same study site. We must admit a $30 \%$ average bias for underrated TC activity in the $\mathrm{BH} 6$ core by missing nine out of 30 historical record storm systems. The general bias of the "Great Blue Hole" for undetected 
storm events decreases down to 7\% combining two site-specific cores $(\mathrm{BH} 6$ and BZWBH-SVC4; Denommee et al. 2014) and their individual historical record calibrations. Eight additional event layers did not match any known historical TCevents since $1850 \mathrm{CE}$. Some of the additional "non-TC layers" of the Instrumental Era may be caused by the fact that the study site is situated next to an active strikeslip zone along the Caribbean and North American plate boundary. Seismic events may also trigger instabilities on the sediment slope located at the top of the "Great Blue Hole" and cause sediment redeposition to the bottom of the sinkhole, thereby leaving a coarser-grained event bed. Two "non-TC layers" (2004 CE and 2017 CE) are probably correlated with strong seismic events adjacent to the study area. These include two earthquakes near the Swan Islands (2004 CE) and the Cayman Islands (2017 CE) with magnitudes of 7.5 and 6.8, respectively. However, the comparison with the United States Geological Survey (USGS) dataset implies a relatively low potential for such seismic event layers on the basis of longer return periods of approximately magnitude-seven earthquakes (>150 years) and only two potential matches within the historical record. Extrapolating the earthquake correlation over the entire core length, $7 \%$ of all recorded event beds can be theoretically attributed to seismic events. It is, however, questionable whether earthquakes follow such random patterns. The majority of the identified event layers derive, in accordance with the calibration of the historical record, likely from TC over-wash. The origin of six event layers remains unknown, but at least four of them occur in times of unreliable storm documentation without a clear TC track observation (<1950 CE). These additional event layers could also originate from undocumented or inaccurately tracked TCs.

\subsection{Proxy results: quantification of TC-frequency}

The return period of TC events averaged over 100 years ( $\left.\mathrm{T}_{100}\right)$ is a more quantitative indicator for TC frequency (Denommee et al. 2014) compared to the classical counting approach (activity $=\mathrm{n}_{\text {storm }} / 100$ ) (Fig. 3 b). We counted the number of event layers per 20-year period, calculated five individual 20-year event return periods $\mathrm{T}_{20}$

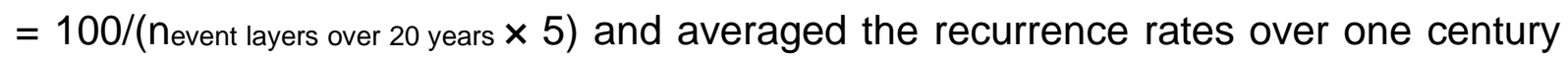
( $\left(T_{100}\right)$ to compare activity data with a previous Lighthouse Reef core (Denommee et al. 2014). The average frequency of TCs was relatively low ( $T_{100}=35 \pm 3$ years) during the Roman Warm Period (RWP) and seems rather constant from 100 to 500 CE. The Dark Ages Cold (DAC) is characterized from 500 to 900 CE by comparably 

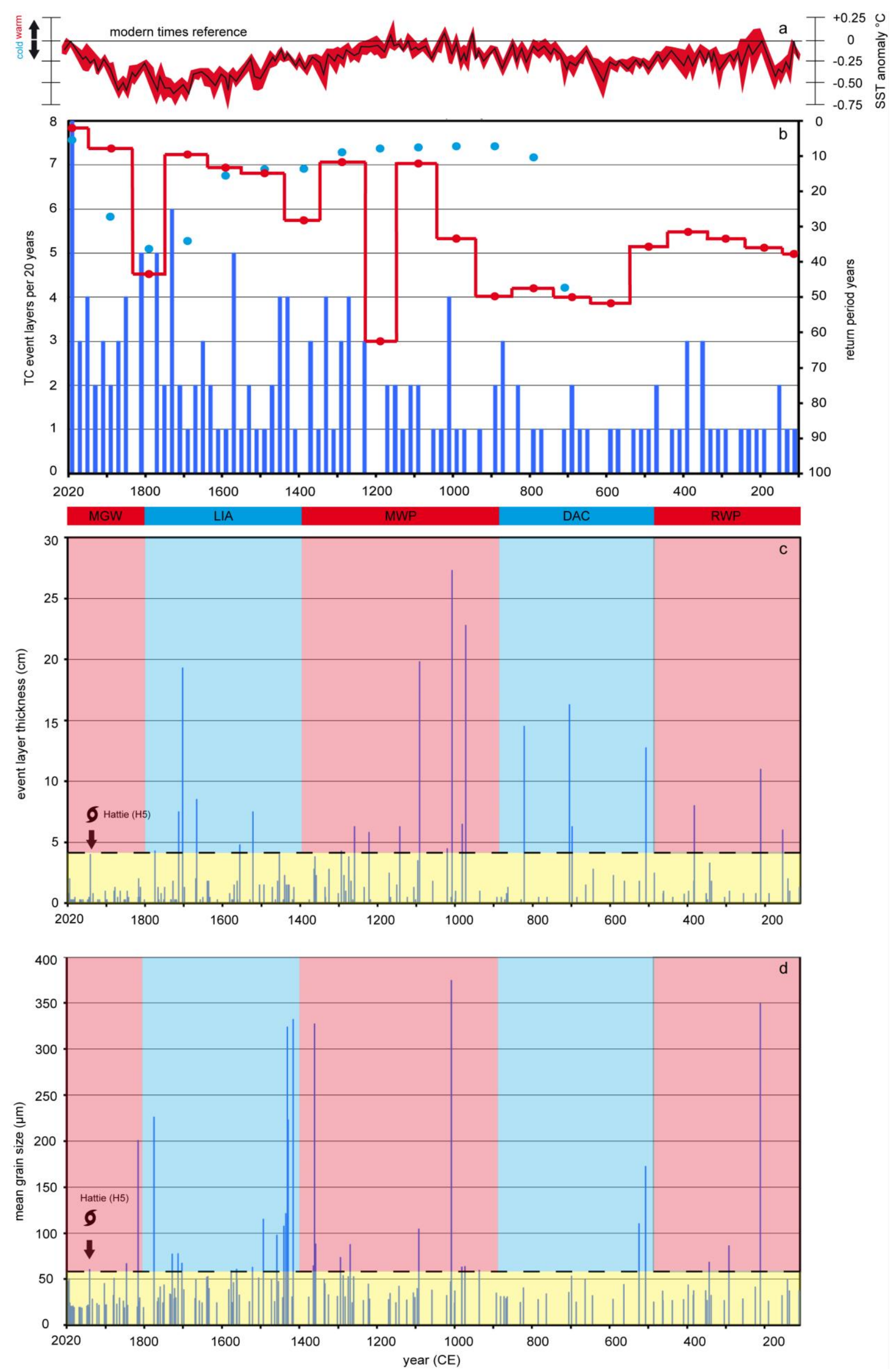
$\leftarrow$ Figure 3. (a) The synthesis data of a global SST reconstruction (Rosenthal et al. 2017) are based on cumulated global (Mann et al. 2008), Northern Hemisphere (Moberg et al. 2005) and western Pacific Warm Pool (Oppo et al. 2009) SST reconstructions. (b) Blue bars in histogram illustrate the total amount of all detected event layers per 20-year interval $(n=145)$. Red line is the 100-year average for TC return period as a quantitative proxy for TC frequency. The blue dots represent data from a previous study (Denommee et al. 2014). Blue bars in histogram represent (c) event-layer thickness $(\mathrm{cm})$ and $(\mathbf{d})$ mean grain sizes $(\mu \mathrm{m})$. Category 5 Hurricane "Hattie" (1961 CE) that passed over Lighthouse Reef was used as reference frame to determine textural outstanding event layers (yellow area).

constant but by even lower TC activity ( $\mathrm{T}_{100}=46 \pm 7$ years). The evidence from both periods suggests a constant TC regime and low TC activity in the south-western Caribbean. The beginning of the Medieval Warm Period (MWP), the most recent preindustrial warm period (900-1400 CE), seems to be the beginning of a 200-year transition (900-1100 CE) towards higher TC activity (1100 CE-modern). This transition to a more active state ( $T_{100}=12$ years) ceases in the mid-MWP. The average MWP recurrence rates ( $T_{100}=34 \pm 23$ years) are somehow comparable to that of the RWP, but the standard deviation illustrates a very high variability ranging from minimum $T_{100}=12(1100-1200 \mathrm{CE}$ and $1300-1400 \mathrm{CE})$ to maximum $\mathrm{T}_{100}=63$ recurrence years. The maximum activity intervals are comparable with previous results indicating extremely high and constant $T C$ activity ( $\mathrm{T}_{100}=4-7$ years) during the MWP (Denommee et al. 2014). Obvious differences are, however, the higher variability and the slightly longer return periods in our record, which probably results in parts from the annual as compared to the near-annual resolution (2 years; Denommee et al. 2014). A possible explanation for the significant drop between 1200 and $1300 \mathrm{CE}$ could be the fact that event beds do not cover the bottom of the sinkhole entirely. Missing event layers within individual 20-year periods have a large influence on calculating the quantitative $T_{100}$ average values, as seen impressively for this time interval. TC activity again decreases ( $T_{100}=28$ years) in the early Little Ice Age (1400-1500 CE) and then stabilizes ( $T_{100}=9-15$ years) from 1500 to 1700 CE during mid-end LIA. We observe the final drop in TC frequency back to the pretransition level ( $T_{100}=43$ years) at the end of the LIA starting around $1700 \mathrm{CE}$, which is 100 years later than previously described (Denommee et al. 2014). One possible solution for the temporal discrepancy could be problems of the previous study concerning the correlation between radiometric and varve counting data and related dating uncertainty (Denommee et al. 2014). The conspicuous 340-years age offset between both methods has been observed neither in the current $\mathrm{BH} 6$ core nor in the 
previous LOCO 1-core (Gischler et al. 2008). The weak linkage to an older carbon source (Denommee et al. 2014) is speculative and not supported by the other "Great Blue Hole" cores, which both indicate an extremely reliable core top dating as well as strong radiocarbon and varve age correlations. The decreasing trend in LIA TC activity obtained from core BZW-BH-SVC4 (Denommee et al. 2014) seems to be similarly influenced by missed event layers around $1720 \mathrm{CE}, 1840 \mathrm{CE}$ and $1900 \mathrm{CE}$. This argument may explain the differences regarding the onset and length of the decreasing period between this core and BH6. Nevertheless, there are still comparable sharp decreases of the TC return period in both cores at the end of the LIA followed by a 100-year (1900-2000 CE) increase in TC frequency $\left(\mathrm{T}_{100}=8\right.$ years), which extends until the present day $\left(T_{100}=2\right.$ years $\left.>2000 \mathrm{CE}\right)$. The average recurrence rate in the instrumental period is $T_{100}=5 \pm 4$ years (core data) and indicates thus the highest frequency in the $\mathrm{BH} 6$ record. This high activity interval also corresponds very accurately to data obtained from the historical TC-strike record for Lighthouse Reef ( $T_{100}=7$ years). $T C$ activity is generally higher in the second half ( $>1100 \mathrm{CE}$ ) than in the first half of the Common Era record, except for the short period from 1700 to $1900 \mathrm{CE}$. All these observations likely reflect a connection of TC activity with Common Era climate changes, which mainly control the underlying ocean-and atmosphere boundary conditions on longer time-scales. The comparison of quantitative $T_{100}$ values between cores of the same study site and data from other regional TC archives should be treated very carefully due to local coring-site differences, grain-size proxy limitation and the uncertainty arising from randomly distributed event layer gaps or seismic events. The general trends in cores $\mathrm{BH} 6$ and BZW-BH-SVC4 are in any case altogether comparable and thus well suited to reflect the changes in long-term south-western Caribbean TC patterns.

\subsection{Correlation between event bed texture and historical TC record}

A comparison of different historical record TC categories with event-layer thickness (Fig. $4 \mathrm{c}$ ) and grain size (Fig. $4 \mathrm{~d}$ ) did not indicate significant correlations between cyclone intensity/duration and textural characteristics. Relatively large, but rather porous Halimeda chips are the major event layer constituents. Even weak tropical storms can easily mobilize such particles under low critical stress and initiate event layer formation (Denommee et al. 2014). Another factor contributing to the lack of correlation is the path and the energy of storm systems, which cannot be considered 

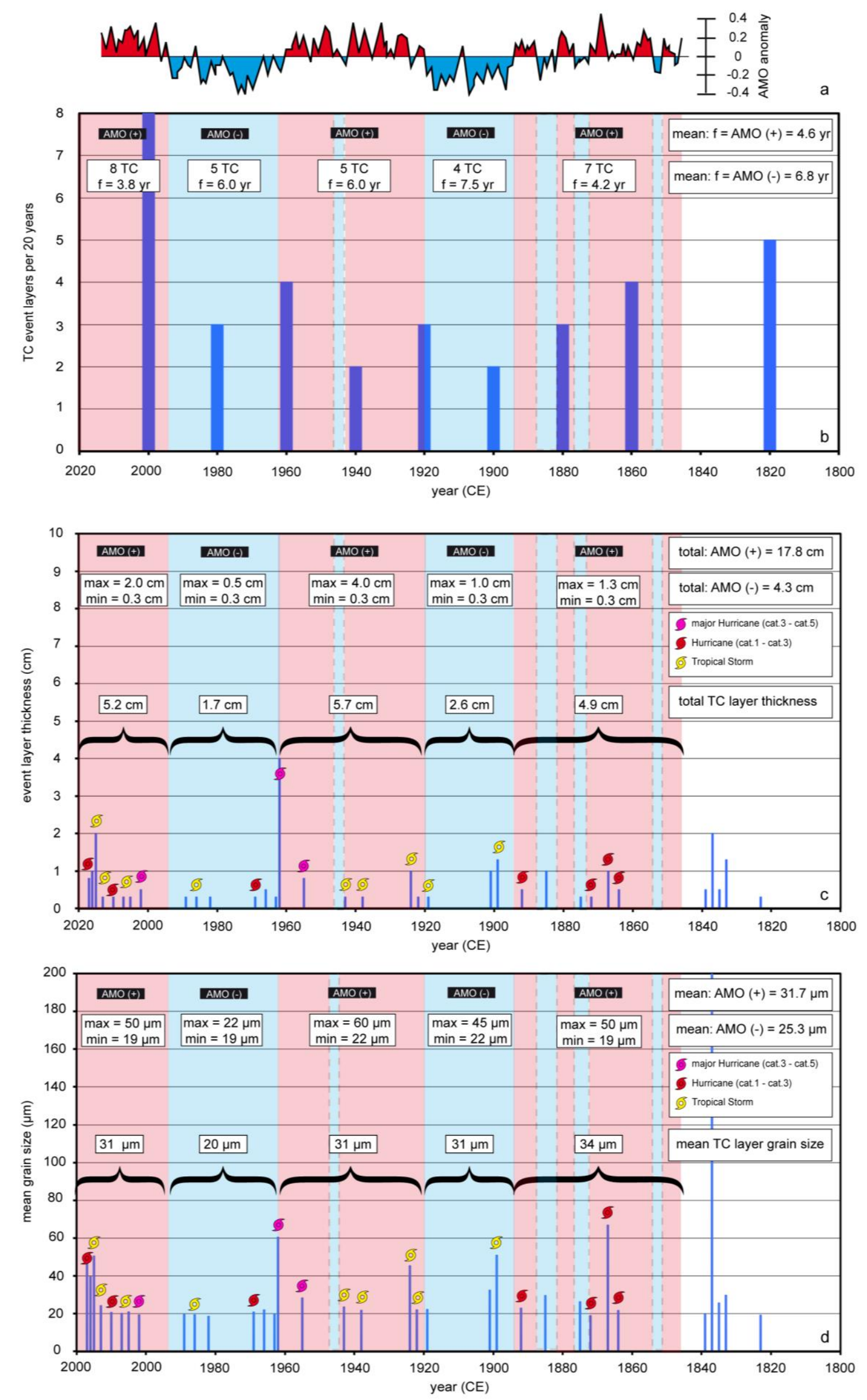
$\leftarrow$ Figure 4. (a) 50-70 years AMO anomaly (red = positive phase; blue = negative phase) plotted on basis of NOAA/ESRL/PSD raw data (1850-2000 CE). (b) Calibration of TC activity with AMO phases of the instrumental record. Calibration of (c) event-layer thickness (total) and (d) mean grain size (average) with AMO phases of the instrumental record.

on longer time scales. Long reef recovery time (decades) and high TC activity intervals ( $T_{100}<12$ years) are other important factors controlling the availability of source sediment and thus the textural characteristic of event layers. The importance of reef recovery time is expressed by a weak but nevertheless statistically significant correlation ( $r=0.22 ; p=0.0057)$ between layer thickness and time between individual TC strikes. As a result of the complex interplay of factors controlling thickness and grain size of event layers, a reconstruction of TC intensity/duration is not possible so that this study focuses only on the temporal pattern of TC frequency.

\subsection{Qualitative long-term patterns of textural characteristics}

It is, however, possible to observe some qualitative long-term patterns of textural data in the record (Fig. $3 \mathrm{c}, \mathrm{d}$ ). Average grain size of event layers appears to be finer from $100 \mathrm{CE}$ to $1100 \mathrm{CE}$, which is in particular illustrated by the occurrence of 10 outstanding event layers (referenced to the textural characteristics of Hurricane "Hattie") in comparison with 20 outstanding event layers in the upper part of the record. Event-layer thickness on the contrary seems to be higher $(6-27 \mathrm{~cm})$ in the lower part of the record as compared with the upper core part $(4-20 \mathrm{~cm})$ with an equal number of outstanding event layers in both cases $(n=12)$. Taking the lower TC frequency during the RWP and DAC into account, the enhanced event layer thickness of basal core parts supposedly reflects the relationship of higher abundance of erodible reef material and larger time intervals between individual TC strikes. In return, the lower abundance of erodible reef material during times of higher TC activity likely explains the lower event-layer thickness in upper core parts. It is anyway very difficult to fully exclude the other effects controlling event-layer thickness or grain size as a consequence of, e.g., storm distance, duration or wave energy. Our long-term textural data interpretation is, therefore, far from being complete, especially for event layer grain sizes.

\subsection{Climatological control of Maya civilisation decline}

Five event layers of the Common Era record are of particular interest (1113 CE, 1029 CE, 944 CE, 843 CE and 726 CE). Two of these five TC strikes coincide with 
major drought phases in the Mayan Lowlands (820-870 CE and 1020-1100 CE). Several $\mathrm{cm}$ thick event layers coinciding with such extremely dry periods might reflect a variation in the strength of the Caribbean Low-Level Jet (CLLJ) in response to an increase in pressure gradients between the North Atlantic High and the Pacific ITCZ (Wang 2007). Such "dry-period event layers" may theoretically be attributable to large swells associated with a strengthening of the CLLJ. There is, however, no direct correlation of dry phases, CLLJ strength and TC event-layer occurrence verifiable for the historical records, which makes it rather speculative to consider this linkage during MWP and DAC times. In general, swells caused by CLLJ strength variations are furthermore not comparable in terms of energy and over-wash potential with several kilometres long storm surges and storm waves. The CLLJ linkage offers, therefore, not a convincing explanation for individual event layers coinciding with major drought phases. The same event layers could equally just be sporadic TCs that stalled over the site despite drought periods. The DAC and MWP droughts were previously interpreted as a crucial factor of the Classical Maya culture demise (Kennett et al. 2012; Lachniet et al. 2013). The other three emphasized TC strikes occur directly prior to, during and after the drought periods. It could be speculated that TC landfalls in the Maya Lowlands caused heavy destruction and flooding and might have contributed to the stress during drought phases further pushing the Maya civilization towards their limits.

\subsection{TC-frequency modulation by SST and AMO variability}

The described long-term trends in TC activity precisely follow a Common Era global SST model (Rosenthal et al. 2017), based on cumulated global (Mann et al. 2008), Northern Hemisphere (Moberg et al. 2005) and western Pacific Warm Pool (Oppo et al. 2009) reconstructions (Fig. 3 a). The temperature curve indicates a strong connection of TC patterns with rising/high (active) and falling/low SSTs (inactive). Multi-decadal SST variations, which are of great importance to modulate the historical record TC activity, are not considered in such long-time comparisons. TC activity (Fig. 3 b), event-layer thickness (Fig. 3 c) and mean grain size (Fig. 3 d) apparently underlie multi-decadal variations over the Common Era. We compared a regional SST reconstruction (1750-2017 CE; Tierney et al. 2015) and AMO anomalies (Fig. 4 a) with historical record TC frequency core data to highlight the importance of such multi-decadal SST and TC variations. Three positive $\left(n_{\text {storm }}=19\right)$ 
and two negative $\left(\mathrm{n}_{\text {storm }}=9\right.$ ) AMO phases are correlated with high (>2000 CE, 1920-1960 CE, 1850-1900 CE) and low (1960-2000 CE, 1890-1920 CE) TC activity intervals and positive/negative SST anomalies, respectively. The average return period is shorter $\left(T_{20}=4.6\right.$ years) in positive $A M O$ phases than during negative phases $\left(T_{20}=6.8\right.$ years; Fig. 4 b). Similar results were obtained when comparing total event-layer thickness (Fig. $4 \mathrm{c}$ ) and grain-size averages (Fig. $4 \mathrm{~d}$ ) with AMO phases. The total thickness and mean grain size of event layers in $\mathrm{AMO}+$ phases are clearly higher and coarser $(17.8 \mathrm{~cm}, 31.7 \mu \mathrm{m})$, respectively than in negative ones $(4.3 \mathrm{~cm}, 25.3 \mu \mathrm{m})$. Within the instrumental record, there is clear evidence for coarser/finer and thicker/thinner event layers during AMO+/AMO- phases, in which higher/lower SST prevails in the tropical Atlantic. Based on this AMO/SST calibration, we propose the use of event-layer characteristics (mean grain size/layer thickness) and TC counts for AMO signal detection.

\subsection{Statistical wavelet analysis: AMO control of SST variability}

Wavelet analyses of event layer counts (Fig. 5 a), thickness (Fig. 5 b) and grain size (Fig. $5 \mathrm{c}$ ) data indicate a statistically significant cyclic signal over nearly the entire Common Era ranging from minimum 300-2017 CE. The mean cycle length varies in a $95 \%$ probability interval between 44 and 64 years and is either compatible with the periodicity of the AMO signal (50-70 years) or multi-decadal variations of ENSO amplitudes (Burn and Palmer 2015). The results from the wavelet analysis support the assumption, that secondary climate mode variations modulate the TC-activity not only during the Instrumental Era; they rather occur over the entire Common Era timeline. We suspect the AMO phase changes to be an appropriate driver for the secondary (multi-decadal) TC activity variation, because of a strong historical record correlation of AMO indices/anomalies with TC counts, textural parameters and tropical Atlantic SST variations (Fig. 4 a-d; Tierney et al. 2015). The lack of intradecadal (5-8 years) ENSO signals (Burn and Palmer 2015) is another indirect argument for the proposed AMO control. Intra-decadal ENSO variations are closely linked to the multi-decadal ENSO amplitude variation. If the observed multi-decadal signals were really attributed to ENSO amplitude variations, intra-decadal signals would have been detected also in the wavelet power spectra. For these reasons, the AMO influence appears to be an important long-term mechanism for understanding past TC activity patterns. The secondary (multi-decadal) AMO control likely works in 
a subsequent and supportive manner with regard to the primary (centennial/millennial scaled) long-term AMO mode forcing in response to Common Era climate variation (Crowley 2000).

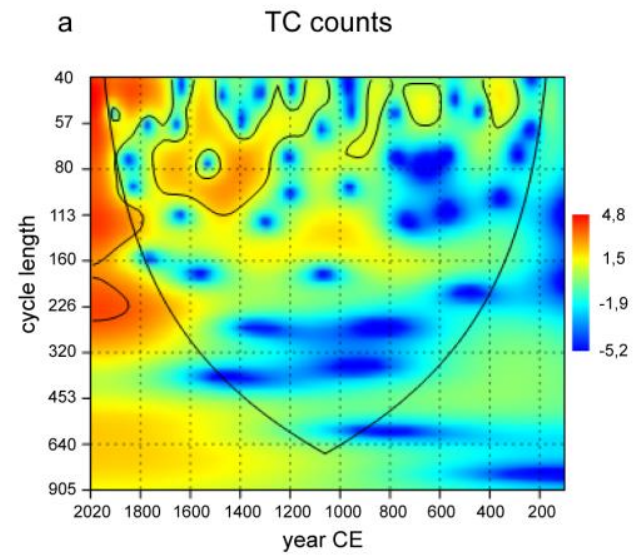

b TC layer thickness
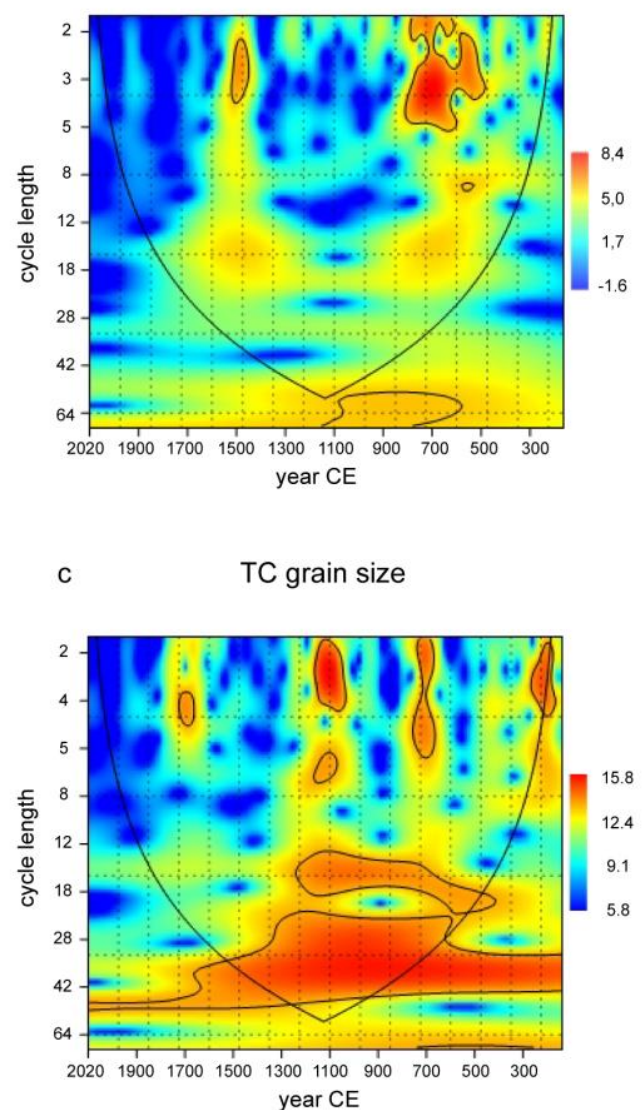

Figure 5. Wavelet power spectra comprising TC counts (a), TC layer thickness (b) and TC grain size (c). Statistically significant cycle lengths $(p<0.05)$ with confidence level $95 \%$ are contoured and coloured orange to red. (a) TC frequency is influenced statistically significant by AMO variation over the entire Common Era. The detected mean cycle length is around 44-64 years. Both layer thickness (b) and mean grain size (c) are also linked to periodicities of 44-64 years. 


\section{Discussion}

\subsection{Comparison with other TC records}

The record of core $\mathrm{BH} 6$ coincides quite well with previous ones from the same location (Gischler et al. 2008; Denommee et al. 2014) in an overlapping time window (800-2017 CE). All cores from Lighthouse Reef indicate the highest TC activity during the MGW (1900-2017 CE), a distinct decrease (medium activity) over the LIA (1400-1900 CE) and a high activity since the mid-MWP (1100 CE). The BH6 record adds an unprecedented period of 700 years of low TC activity that is attributable to the DAC (500-900 CE) and RWP (100-500 CE). The dating of rough trends and the calculated values of TC return periods, however, differ among the three Lighthouse Reef cores. Despite a general coincidence of broad TC activity patterns, there are some limitations in the previous studies. The previously used approaches to identify TCs are certainly less accurate because they are largely based on visual colour differences, quantitative event-layer thickness measurements and semi-quantitative grain-size estimations. The additional consideration of event-layer geometry, fine material abundance, quantitative background and event-layer grain-size measurements, a historical record grain-size calibration and innovative XRF scanning, as presented here, is an important step forward that ensures a more reliable TC layer identification. The two cores from the previous studies are also significantly shorter and exhibit only a 2-4-years resolution as compared to the annual resolution of the $\mathrm{BH} 6$ core. These methodological differences likely explain the observed variations between the calculated TC return periods. Another noteworthy limitation of one of the previous studies is the appearance of age dating problems and the occurrence of a 340-years age offset between varve and radiocarbon dating within the BZE-BH-SVC4 (Denommee et al. 2014) core. This age offset is likely to large parts responsible for the observed difference in dating of rough Common Era TC activity trends, as exemplified in the late LIA drop discussion. The continuous offshore atoll records, characterized by annual to multi-annual resolution, are unfortunately not comparable with some discontinuous and decadal-resolution records obtained from coastal lagoons (Adomat and Gischler 2017) and marshes (McCloskey and Keller 2009; McCloskey and Liu 2012) of the Belize mainland coast. These records indicate a higher TC activity during the LIA and RWP (100-500 CE) and lower TC activity within the MGW and MWP (900-1400 CE). The significance of these discontinuous TC activity reconstructions remains strongly restricted, because 
of an exceptionally low event-layer preservation potential, which is caused by erosional unconformities and other geomorphological processes related to changes of accommodation space, sediment supply and subsidence.

A continuous coastal lagoon record from Puerto Rico (Woodruff et al. 2008) with decadal resolution demonstrates a completely different behaviour of long-term TC patterns than the Belize offshore atolls, i.e. high activity during the MGW, the DAC and the RWP and low activity during the LIA and the MWP. The general difference to the Puerto Rico record can be best explained by the occurrence of four major Caribbean TC clusters (Suppl. 3 a; Kossin et al. 2010). Landfalls over Puerto Rico (north-eastern Caribbean) derive largely from a combination of cluster 3 and 4 TC tracks, which originate in the Western, Central and Eastern Atlantic (Suppl. 3 d, e). Landfalls over Belize are characterized by a general mixture of TC tracks belonging to clusters 2 and 4 (Suppl. $3 \mathrm{c}$, e). TC landfalls on the Yucatan Peninsula belonging to cluster 2 have due to their genesis region (Western Caribbean) no impact on sedimentary records obtained from Puerto Rico. TC tracks of cluster 3 are generally not attributable to Belizean archives. Their major track direction towards the northeast originating from the genesis region in the Central-Eastern Atlantic favours landfalls in the north-eastern Caribbean region and along the North American east coast. The discrepancy of the Common Era TC patterns between Belize and Puerto Rico records are best explained by these major differences of clusters 2 and 3 . This explanation is sound despite a possible overlap of cluster 4 TCs. Cluster 4 consists of two sub-clusters (Kossin et al. 2010) reflecting two major genesis regions of the same latitude, but different longitude (Caribbean Sea and Western Atlantic). TCs originating from these sub-clusters could exercise for one thing independent and different impacts on both sites considering the ordinarily given north-east-ward cyclone path.

Another continuous and low-resolution cyclone record from the northern Antilles (St. Martin; Malaize et al. 2013) indicates, however, a TC activity pattern, which is more comparable to the one of the south-western Caribbean. A rough accordance with the Belizean TC activity pattern is on the other hand also conceivable. Cluster 4 TCs originating from the Western Atlantic sub-cluster (genesis region east of the northern Antilles) may well migrate under appropriate atmospheric conditions initially westwards and cross the northern Antilles. The same TCs may secondarily move 
over the Yucatan Peninsula following the north-eastern migration path. The bipartite nature of cluster 4 is an admittedly weak, but satisfactory explanation for the observed general differences and similarities between our south-western and two north-eastern Caribbean records.

Two North American records (Massachusetts; Donnelly et al. 2015) and Florida (Lane et al. 2011; Brandon et al. 2013) are influenced due to their spatial distribution by practically all TC clusters, which makes a comparison really challenging. However, they all differ in general from the Belizean TC records. A common similarity between the individual annually to decadally-resolved North American archives is the low TC activity over the MGW and LIA, a higher TC activity within the MWP and DAC as well as a highly site-specific TC variability during the RWP. The continuous and multi-decadal (van Hengstum et al. 2013, 2016) to annually (Wallace et al. 2019) resolved Bahamas records are relatively similar to the North American archives with low TC activity during the MGW/LIA and high TC activity during the MWP/DAC.

TC activity patterns strongly depend on the different TC cluster, which cause in particular large local activity variations. This limitation makes a quantitative comparison and hazard assessments at basin-scale very difficult. A common feature seems to be, however, the occurrence of a general TC activity shift in the wake of the MWP climate change. All north-western Caribbean and North American records change from a more active TC regime $(<1100 \mathrm{CE})$ towards a more inactive state (>1400 CE). The south-western Caribbean records show a remarkably similar temporal, but reversed transition from a less active $(<1100 \mathrm{CE})$ to a more active state ( $>1400 \mathrm{CE}$ ). This latitudinal pattern can be explained by changes in the position of the ITCZ as the potential driver. The ITCZ shifted in the wake of this climate change from a relatively northern position (0-1000 CE) towards a more southern location (1000-1400 CE; van Hengstum et al. 2016). This southward ITCZ migration enhanced the potential for TC landfalls over the wider Yucatan Peninsula, which concurrently suppressed the landfall potential in the Northern Caribbean and along the North American east coast (latitudinal shift of genesis regions).

\subsection{Common Era TC activity: a conceptual and comparative view}

The annually-resolved "Great Blue Hole" TC record offers the great potential to review the connection of long-term TC activity patterns and Common Era climate 
variability. We provide, largely based on qualitative observations, a conceptual and comparative view of all involved tropospheric and oceanographic processes, which have likely shaped the TC activity patterns of the south-western Caribbean in response to Common Era climate variation (Fig. 6).

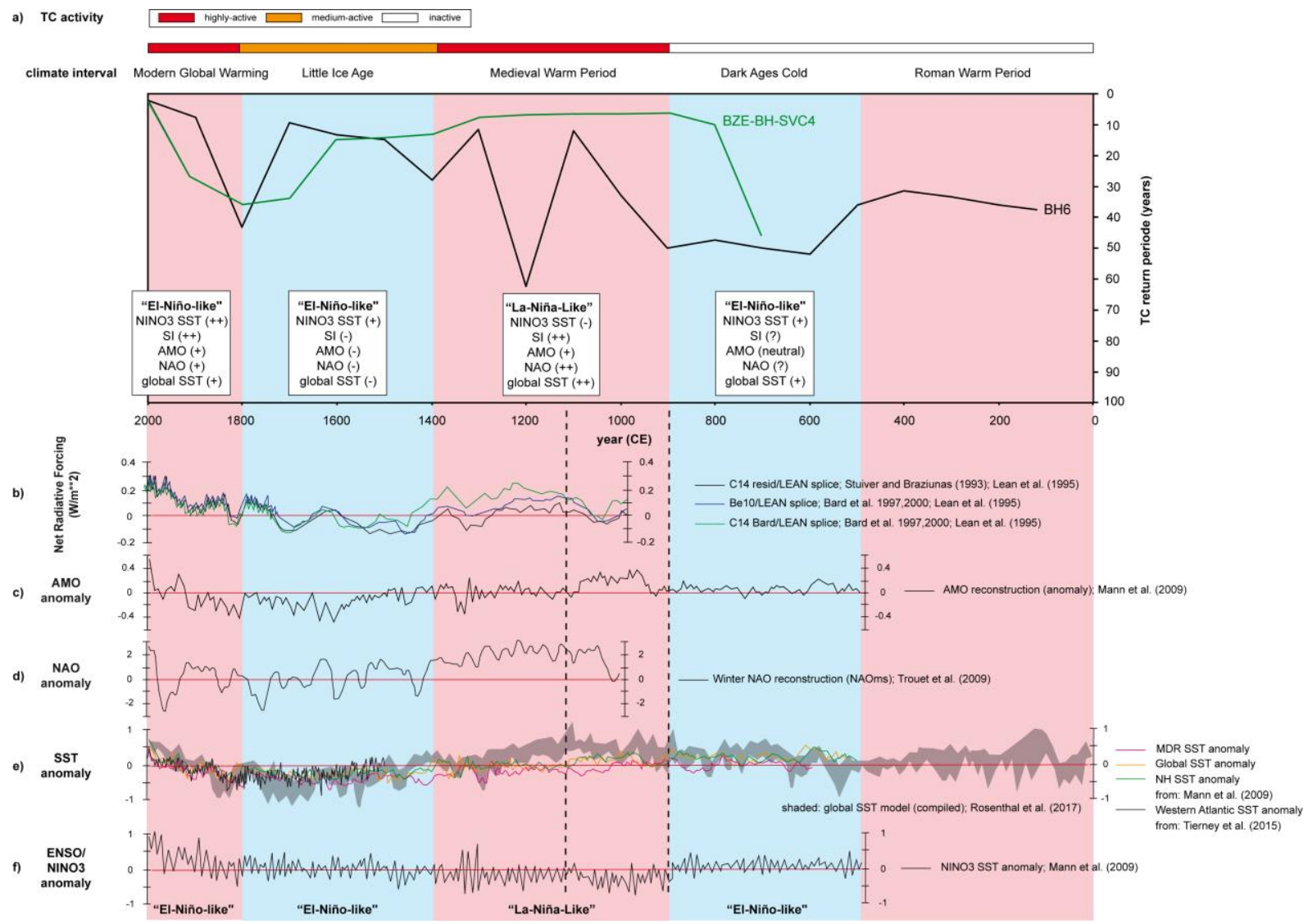

Figure 6. (a) Comparison of TC activity obtained from the BH6 (black line) and BZE-BH-SVC4 (Denommee et al. 2014) (green line) records in the wake of Common Era climate changes (red = warm interval; blue = cold interval). Climate phenomena and SST responses on Common Era climate changes triggered by a combination of solar irradiance (Stuiver and Braziunas 1993; Lean et al. 1995; Bard et al. 1997, 2000) (b) and volcanism (Miller et al. 2012; Sigl et al. 2015; Brönnimann et al. 2019). including AMO (Mann et al. 2009) (c), NAO (Trouet et al 2009) (d), individual global (Mann et al 2009), Northern Hemisphere (Mann et al. 2009), Western Atlantic (Tierney et al. 2015) and MDR (Mann et al. 2009) SST curves, a global synthesised Common Era SST model (Rosenthal et al. 2017) (e) as well as (f) ENSO/NINO3 reconstructions (Mann et al. 2009). The dashed lines roughly frame the transition interval of the changing Common Era TC activity in succession of a 200-year hydro-climate variation in response to the onset of the MWP climate anomaly.

Variations in solar irradiance (Fig. 6 b) have been previously considered as a main external driver for late Holocene climate changes (Crowley 2000). Volcanic forcing is another potential and closely linked natural driver of the Common Era climate variability as it may alter solar insolation. High volcanic forcing activity intervals induce enhanced sulfate aerosol injections into the stratosphere, which shield the earth surface from incoming solar radiation and consequently cause regional and 
global cooling tendencies (Robock 2000). The volcanic forcing effect on air- and surface ocean-temperature variability is, however, considering the past 2,500 years largely realised on inter-annual-to-decadal time scales (Sigl et al. 2015). Both climate driver mechanisms have in common that they cause subsequent feedbacks of important climate phenomena. Therefore, the climate phenomena of the ENSO (Mann et al. 2009) and AMO (Mann et al. 2009) as well as to some minor extent the NAO (Trouet et al. 2009) have been considered in our conceptual view as potential internal TC-controlling mechanisms, because they have likely modulated the boundary conditions for TC formation by exercising primary control on basin-scaled SST patterns (Fig. 6 e) and vertical wind shear stress dynamics. There is, however, also a relevant secondary/multidecadal AMO control apparent, which needs to be considered. We qualitatively compared relative long-term reconstructions of these climate modes with our TC activity reconstruction, in order to decipher possible key control mechanisms, and independently discussed four of the five Common Era climate intervals in this regard. The considered climate mode and SST reconstructions reach not far enough back in time to make the RWP subject of the discussion (Fig. 6).

A causative explanation for the onset of the DAC could be a temporal overlap with a phase of strong tropical and high-latitude volcanic activity (500-600 CE; Sigl et al. 2015). The related relatively high global aerosol injection would certainly have exercised control on regional and global SST patterns via attenuation of solar insolation. The compiled global SST curve (Rosenthal et al. 2017) supports this argument by indicating a global negative SST anomaly during the sixth century (Sigl et al. 2015). The reconstructed decrease of the south-western Caribbean TC recurrence rates ( $T_{100}=46$ years) relative to the RWP ( $T_{100}=35$ years) is probably attributable to this SST anomaly, hampering a frequent TC formation in the early DAC. However, the temporally limited effect of volcanic forcing and its feedback on SST is not sufficient to explain the persistent 400 -year trend of low TC activity. The continuation of the low activity trend may, however, satisfactorily explained by considering persistent "El-Niño-like" conditions in the mid and late DAC (Fig. 6 f). Such ENSO conditions hamper the TC formation potential as a result of strong vertical wind shear stress, stronger trade winds and an overall greater atmospheric stability (Gray 1984). Stable "El-Niño-like" conditions should concomitantly induce a 
regional positive SST anomaly in the tropical western Atlantic (Park and Li 2019). The MDR SST reconstruction (Mann et al. 2009) provides some evidence for slightly enhanced tropical Atlantic SST during the DAC, which would theoretically favour a more frequent TC formation. The results of a previous "Great Blue Hole" study (Denommee et al. 2014) indicate, however, that basin-scaled oceanographic variables and climate modes seem to be more important than local MDR SST conditions, with regard to TC-activity modulation. This argument in turn explains the weak effect of positive MDR SST on DAC TC-activity. A good explanation for the low internal variability, especially on multi-decadal time scales, may be the coincidence with a long-term stable and largely neutral AMO phase. For the outlined reasons, the early DAC drop of TC activity and the continuation of the low TC activity regime are best explained by a volcanically initiated global cooling and tropospheric ENSO conditions, which hampered frequent TC formation.

The onset of the MWP ( $900 \mathrm{CE})$ may be associated with a phase of increased solar activity (Crowley 2000) and reduced tropical and high-latitude volcanic activity (Sigl et al. 2015). Such preconditions could have been a potential trigger of extensive hydro-climate changes during the transition into the MWP climate anomaly. These changes in hydro-climate include a global ocean heating, as indicated by the outstanding positive SST anomaly in the compiled SST curve (Rosenthal et al. 2017), following high rates of radiative solar forcing (Fig. 6 b). A heating of the extra-tropical Pacific Ocean especially favours the development of long-term stable "La-Niña-like" conditions (Wu et al. 2017; Fig. 6 f), which should involve theoretically a negative western Atlantic SST anomaly (Park and Li 2019). The MDR SST reconstruction (Mann et al. 2009) supports the assumed "La-Niña" conditions effect on regional SST by indicating slightly decreasing tropical Atlantic temperatures. The reorganisation of the ENSO dynamics contains additionally important modifications in the North Atlantic atmosphere circulation such as lower vertical wind shear stress conditions, a strengthening of westerly winds and a weakening of the trade-wind system (Gray 1984). These atmospheric conditions would have favoured in general, and in combination with a positive basin-wide to globally-scaled SST anomaly, the development of a higher TC activity regime during the MWP. Long-term positive AMO (Fig. 6 c) and NAO (Fig. 6 d) modes would coevally contribute to develop suitable ocean and atmosphere conditions for a centennial-scaled enhanced 
TC activity and for a multi-decadal-scaled higher variability of TC activity, respectively.

The LIA climate change is the result of lower solar irradiance (Crowley 2000) two distinct phases of enhanced global volcanic activity or a combination of both, which caused global air- and sea surface temperature cooling, in particular at the beginning and at the end of the LIA (Brönnimann et al. 2019). The onset of the LIA cooling (1300-1400 CE) coincides with the most active volcanic half-century of the past millennium (Miller et al. 2012). Repeated explosive volcanism on its own may act as a trigger of climate change, independent of the precondition that the orbital configuration of the earth favours low solar insolation. The LIA climate change likely initiated by multi-decadally paced explosive volcanism and maintained by ocean and climate mode feedbacks (Miller et al. 2012) did therefore not mandatorily require a solar trigger. The reconstructed TC activity pattern of the LIA is characterised by a TC activity decrease (1300-1450 CE), a stabilisation back to MWP conditions (1450-1700 CE) and a considerable drop back to very low TC activity after $1700 \mathrm{CE}$. These rough trends accurately follow the two supposedly volcanically-induced cooling intervals (Miller et al. 2012; Brönnimann et al. 2019) and the climate-mode responses to the LIA climate change. Global (Rosenthal et al. 2017), northern hemisphere (Mann et al. 2008), MDR (Mann et al. 2009) and western tropical Atlantic (Tierney et al. 2015) SST reconstructions collectively indicate decreasing regional and global SST, however, with the specification of a step-wise, two-phase decline in the early and late LIA and an intercalated short warm interval. The gradual reorganisation of the ENSO dynamics towards "EI-Niño-like" conditions and the persistent negative $A M O$ and $N A O$ modes, following a volcanically initiated climate variation (Miller et al. 2012), apparently sustained the observed LIA TC-activity pattern as a combined result of inappropriate atmosphere and ocean conditions.

The MGW climate change ( $>1900 \mathrm{CE}$ ) is either the result of naturally increasing solar irradiance (Fig. 6 b) or caused by anthropogenic forcing, even though the second explanation is still a major point of the recent climate change debate. The high TC activity of the MGW climate interval is, however, in either case attributable to ocean heating processes, as indicated by an obvious temperature rise in all considered SST curves (Fig. 6 e) and climate-mode responses. Long-term stable "El-Niño-like" conditions should, however, hamper the TC formation potential from an atmospheric 
point of view. This disagreement is apparent but may be best explained by the amplification of the positive AMO mode that causes a relative weakening of local ENSO effects (Park and Li 2019). The discrepancy is, however, probably simply the result of an increasing significance of anthropogenic forcing, which originates from rising atmospheric carbon dioxide concentrations.

\section{Conclusions}

Our Common Era TC-activity study provides four key results: (1) The TC-activity of the south-western Caribbean generally shifted from a less active (100-900 CE) to a more active state (900 CE-modern). (2) We identified continuous and at least 1,700years-long multi-decadal signals of 44-64 years periodicity. These cyclic signals have been interpreted as an indicator for a multi-decadal AMO modulation of Atlantic TCactivity, which encompasses nearly the entire Common Era. (3) Climate-mode responses to external forcing mechanisms (solar irradiance and volcanism) have likely operated over the Common Era as the internal control mechanism for long-term TC activity. (4) The conceptual consideration of Common Era climate variability and climate-mode responses indicates a higher importance of basin-scaled ocean and atmosphere dynamics than variations in regional MDR boundary condition for shaping the long-term TC activity patterns.

\section{Methods}

\subsection{Fieldwork in Lighthouse Reef}

Seven sediment cores were collected from the bottom of the "Great Blue Hole" of Lighthouse Reef, Belize $\left(17^{\circ} 86^{\prime} \mathrm{N}, 87^{\circ} 32^{\prime} \mathrm{W}\right)$, along a W-E transect from a small boat using a portable Rossfelder P3 electrical vibrocore system and $6 \mathrm{~m}$ long aluminium tubes, equipped with copper core catchers. In order to extend core length to $9 \mathrm{~m}$, two aluminium pipes were glued together using $50-\mathrm{cm}$-long aluminium sleeves. Maximum core length ranges from $1.80 \mathrm{~m}$ (shortest core $\mathrm{BH} 1$ ) to $7.55 \mathrm{~m}$ (longest cores $\mathrm{BH} 6$ and $\mathrm{BH} 7)$. Coordinates at the coring sites were registered using a GPS instrument. After retrieval, cores were cut into 1.5 m-long sections, transported by air cargo from Belize City to Frankfurt am Main, Germany, and stored in a cold room at $4^{\circ} \mathrm{C}$.

\subsection{Core description: photo documentation and stratigraphy}

In the core laboratory, all tubes of $\mathrm{BH} 1, \mathrm{BH} 6$ and $\mathrm{BH} 7$ were opened and cut in halves lengthwise using an angle grinder and an ultra-thin copper sheet $(0.7 \mathrm{~mm})$. Photo 
documentations of the shortest core $\mathrm{BH} 1\left(17^{\circ} 18.943^{\prime} \mathrm{N}, 87^{\circ} 32.071^{\prime} \mathrm{W}\right)$ and the

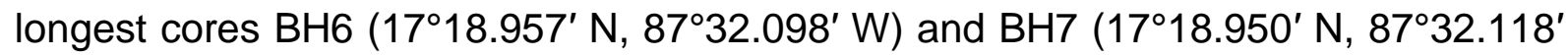
$W)$, the latter two from the approximate centre of the "Great Blue Hole", were carried out at the University of Bern using a Geotek-MSCL-S (Multi-Sensor Core Logger). Based on length and preservation, core BH6 was selected for sampling. During the coring process, the core top of $\mathrm{BH} 6$ had been lost due to liquefaction. Therefore, cores $\mathrm{BH} 6$ and $\mathrm{BH} 7$ were spliced together by means of prominent event layers to replace missing material. This led to a maximum core length of $8.55 \mathrm{~m}$ and achieves the highest possible temporal resolution from modern times throughout almost the entire Common Era. By using supportive high-resolution core pictures (Fig. 1 e), visual core description was done, including descriptions of different unconsolidated lithologies, measurements of mean annual layer thickness, differentiation of background versus event deposits, description of sedimentary structures, registration of macrofossils and characterization of sedimentary contacts (Suppl. 4).

\subsection{Systematic sampling}

Background sedimentation was characterized previously by an annual sedimentation rate of $2.5 \mathrm{~mm}$ per year (Gischler et al. 2008). Following the given sedimentation rate of constant background deposition and visual identification of annual layers, approximately 3,000 samples ( $5 \mathrm{~g}$ bulk material for quantitative textural analysis) and subsamples (400 mg bulk material for stable isotope analysis) were taken consequently and systematically over the entire spliced $8.55 \mathrm{~m}$ long core at $2.5 \mathrm{~mm}$ intervals (Suppl. 5).

\subsection{Age dating: varve counting and radiocarbon calibration}

To gain an age model for event-layer timing, varves were counted visually in the core sections and supportive by high-resolution core photos on basis of colour differences and measurements of laminae thickness. The mean sedimentation rate in $\mathrm{BH} 6$ core amounts to $2.55 \pm 0.05 \mathrm{~mm} /$ year confirming the results of earlier studies. Within deeper core sections, lamination is sometimes blurry and not as easy to identify as in younger core sections resulting in estimated varve counting errors of $5 \%$. The age to depth correlation was made on the basis of the varve counts and background sedimentation rates (Suppl. 6). As an independent age determination, five bulk samples enriched in entirely marine organic matter were selected from varved core sections at $5.75 \mathrm{~cm}, 87.25 \mathrm{~cm}, 336.50 \mathrm{~cm}, 586.50 \mathrm{~cm}$ and $852.00 \mathrm{~cm}$ core depth for 
${ }^{14} \mathrm{C}$ AMS geochronology (Suppl. 7). For our samples, Beta Analytic Inc., Miami, Florida provides average $\delta^{13} \mathrm{C}$ values of $-16.0 \%$. Organic residue was separated from bulk sediment by dissolving carbonate material with $\mathrm{HCl}$, washing the sample with $\mathrm{NaOH}$, and repeating until no carbonate material remained. The organic matter dating (Bard 1998) has been undertaken by Beta Analytic Inc., Miami, Florida with Accelerator Mass Spectrometry (AMS) in order to ensure the highest level of possible age-dating quality. The conventional radiocarbon ages from marine organic residue were converted to calibrated years before present using BetaCal3.21 MARINE13 calibration curves (High Probability Density Range Method; Reimer et al. 2013). All calibrated ages are presented with a 2- $\sigma$ error with $95.4 \%$ probability. The $\Delta R$ factors used in reservoir correction of marine carbonate sediment age are Delta- $R=-23 \pm 26$ from nearby Glovers Reef Atoll, as the best available site-specific $\Delta R$ value for the "Great Blue Hole" and global marine reservoir age of 405 years. A further calibration step (Fig. 2) was undertaken by regression lines between varve age (year $\mathrm{CE}$ ), calibrated radiocarbon age (year CE) and core depth $(\mathrm{cm})$, allowing the development of a consistent and robust anchored age-depth framework with determination coefficients of $r^{2}=0.98\left({ }^{14} \mathrm{C}\right)$ and $r^{2}=0.99$ (varves). Towards the lowermost core section, an increasing age offset between both age determination methods occurs. The uncertainties between layer counting and AMS dating in deeper core sections represent a minor data limitation. Independent ${ }^{14} \mathrm{C}$ age determination helps not only to constrain the absolute timing of $\mathrm{TC}$ events over the entire $\mathrm{BH} 6$ sediment core, but also to document that there are no gaps at the core top or within core sections. There appears to be no hiatus at the top of the sedimentary record of $\mathrm{BH} 6$ core as evidenced by (1) a very thick and coarse-grained event layer at $21 \mathrm{~cm}$ core depth correlated with great certainty to category 5 -hurricane "Hattie" that struck Lighthouse Reef in $1961 \mathrm{CE}$ (Stoddart 1963), and (2) a ${ }^{14} \mathrm{C}$ radiocarbon age near the core top $(5.75 \mathrm{~cm})$ indicating post "Bomb Effect" conditions.

\subsection{Quantitative textural analysis and sediment characterization}

Textural data that have previously been obtained in much lower resolution and by visual estimation only (Gischler et al. 2008; Denommee et al. 2014), now have been collected in a quantitative way and analysed comprehensively over the entire core length at annual resolution level. For textural analyses, a total of 2,915 samples with $2.5 \mathrm{~mm}$ sampling intervals, ensuring sufficient material $(5 \mathrm{~g})$ for all necessary 
processing steps, have been first washed and sieved through standard grain-size sieves of $2 \mathrm{~mm}, 1 \mathrm{~mm}, 500 \mu \mathrm{m}, 250 \mu \mathrm{m}, 125 \mu \mathrm{m}$ and $63 \mu \mathrm{m}$. Two recent studies (Toomey et al. 2013; Isaack et al. 2016) have demonstrated, that the fine fraction $(<63 \mu \mathrm{m})$ alone may be sufficient to identify event beds in reefal lagoon settings. To guarantee reliable quantitative grain size and sorting measurements, a more detailed analysis of fine material $<63 \mu \mathrm{m}$ was performed by using a laser-optical particle analyser (HORIBA Laser Particle Analyser-950), which runs with $2 \mathrm{~g}$ fine material $(<63 \mu \mathrm{m})$ suspended in $0,4 \mathrm{~N} \mathrm{Na} \mathrm{P}_{2} \mathrm{O}_{7}$ and demineralized water (Suppl. 8). Sediments were categorized by determination of classical sedimentary parameters (mean grain size, sorting, skewness and kurtosis), following the "Geometric and Logarithmic Folk \& Ward method" using the software package gradistat (Blott and Pye 2001). Poorly (1-2 Ф) to very poorly sorted (2-4 Ф), medium to coarse silt-sized couplets with absolute grain sizes ranging from 12 to $24 \mu \mathrm{m}$ and layer thicknesses $<2.5 \mathrm{~mm}$ represent the annual background sedimentation of biogenic fine material. The mean grain size of the background sediments is $20 \mu \mathrm{m} \pm 4 \mu \mathrm{m}$. Both poorly $(1-2 \Phi)$ to very poorly $(2-4 \Phi)$ sorted TC event layer units are several $\mathrm{mm}(>0.3 \mathrm{~mm})$ to $28 \mathrm{~cm}$ thick, depending on sediment source, cyclone strength, cyclone track direction, proximity to sample site and residence time. Mean grain sizes of different event-layer lithologies range from 20-30 $\mu \mathrm{m}$ (coarse silt), 31-61 $\mu \mathrm{m}$ (very coarse silt), 62-121 $\mu \mathrm{m}$ (very fine sand), 133-226 $\mu \mathrm{m}$ (fine sand) and 263-374 $\mu \mathrm{m}$ (medium sand).

\subsection{X-Ray fluorescence analysis: a new cyclone indicator}

The other intact core half has been completely scanned at $0.3 \mathrm{~mm}$ intervals using $20 \mathrm{~s}$ integration times with an X-ray fluorescence core scanner (XRF; COXITRAX equipped with a Cr-anode-X-ray tube set to $30 \mathrm{kV}$ and $40 \mathrm{~mA}$ ) at the University of Bern, in order to implement a new and innovative high-resolution method for TC detection in calcitic sinkhole environments. With more than 20,600 measuring points and a sampling interval of $0.3 \mathrm{~mm}$, XRF scanning can be a further high-resolution method for TC detection (Suppl. 9). Special attention was given in this context to peaks of the element ratio of $\mathrm{Sr} / \mathrm{Ca}$. Strontium is typically enriched in predominantly aragonitic marginal reef carbonate material, e.g., coral skeletons and Halimeda chips and depleted in lagoon sediments typically dominated by mollusc shells and foraminiferal tests (Gischler and Lomando 1999). Lagoonal sediment is the most likely source of background sediments in the "Great Blue Hole", whereas coarser- 
grained sedimentary particles from the reef margin with high $\mathrm{Sr}$ amounts will potentially be transported into the sinkhole sediment trap and deposited within event layers.

\subsection{Tropical cyclone identification}

We used, in contrast to the previous studies, a multi-proxy-approach to ensure a more reliable and quantitative TC identification. Our approach requires at best a match with all five different event layer identification criteria: (1) grain-size $(>20-24 \mu \mathrm{m})$; (2) amount of fine material <63 $\mu \mathrm{m} \mathrm{(<85 \% );} \mathrm{(3)} \mathrm{layer} \mathrm{thickness}$ (>2.5 mm); (4) colour (yellow/brown) and (5) composition (Sr/Ca-ratio >0.025). Precondition for a successful TC identification is a match with various criteria because mean grain size is difficult to use as single identification tool due to several limitations (e.g. internal variations, layer geometry, coring site, core splicing and hydro-dynamical particle properties).

\subsection{Statistical wavelet analysis}

TC counts, event layer thickness and mean grain size raw data (Suppl. 10) were used for statistical wavelet analyses (software package PAST version 3.14; Hammer et al. 2001). The full dataset was inspected at various scales simultaneously, detecting periodicities at different wavelength within the 2000-year time series. The square correlation strength with the mother wavelet ("Morlet" with wave number 6 ) is shown on a coloured scale. The underlying algorithm is based on fast convolution of signals with the Morlet wavelet using a "Fourier Transformation". Statistical significance level corresponding to $p=0.05$ is plotted as a contour line (chi-squared test). 


\section{CHAPTER 3:}

\section{QUATERNARY SCIENCE REVIEW MANUSCRIPT}

\section{"Great Blue Hole (Lighthouse Reef, Belize): a continuous, annually resolved record of Common Era sea surface temperature, Atlantic Multidecadal Oscillation and cyclone-controlled run-off"}

\section{Abstract}

The Holocene $(<11.7 \mathrm{kyr} \mathrm{BP})$ is characterized by several periods of distinct climate changes. Some of these climate variations had extensive effects on mankind and coincided with demises of extinct high civilizations. Annually-resolved climate reconstructions will certainly play an increasingly important role in public perception, when applying these past patterns to the recent climate debate. The future consequences of the ongoing climate crisis are still challenging to predict, due to the lack of comprehensive, annually-resolved and continuous sea-surface temperature (SST) data. Our $8.55 \mathrm{~m}$ long sediment core from the bottom of the "Great Blue Hole" (Lighthouse Reef, Belize) provides an annually-resolved, continuous and unique south-western Caribbean climate record for the last 1885 years. The varved, "lakelike" sinkhole successions of marine carbonates encompass approximately the entire Common Era (0 CE-modern), a time window, which is key for studying climatic variations and their effects on human society. Our SST record is based on stable isotopes $\left(\delta^{18} \mathrm{O}\right)$ and molecular proxy applications (TEX $\left.{ }_{86}\right)$. Throughout the Common Era, oxygen isotopes $\left(\delta^{18} \mathrm{O}\right)$ and TEX $\mathrm{X}_{86}$ data imply a general SST rise of $0.5^{\circ} \mathrm{C}$ and $1.3^{\circ} \mathrm{C}$, respectively, within the south-western Caribbean. The modulation of SST within the Common Era time series likely operated on two different time levels: (1) Solar (e.g., "Gleissberg Cycles") and volcanic activity triggered climate changes, which in turn induced responses of the Atlantic Multidecadal Oscillation (AMO), the North Atlantic Oscillation (NAO) and the El-Niño-Southern Oscillation (ENSO). Their changing mode of action has been identified as a likely origin of the primary, i.e., centennially scaled SST variability. We suspect long-term positive AMO and NAO modes as the primary key control mechanisms of the Dark Ages Cold and Medieval Warm Period SST patterns. ENSO mode modulation likely exerted primary control on regional SST variability during the Little Ice Age and the Modern Global 
Warming. (2) Our $\delta^{18} \mathrm{O}$ data further indicate a striking secondary control on multidecadal time scales: $\delta^{18} \mathrm{O}$ variations occur with $32-64$ years periodicity. This signal is clearly evidence of SST modulation controlled by AMO phase changes (50-70 years) over almost the entire Common Era. Our carbon isotope record $\left(\delta^{13} \mathrm{C}\right)$ exhibits two remarkable negative anomalies and a long-term up-core decreasing trend. The first excursion (drop of $0.5 \%$ ) occurred with the onset of the Medieval Warm Period, which is reconstructed to be a peak time in south-western Caribbean tropical cyclone (TC) activity. This overlap is stressing a potential context between TC activity, enhanced coastal run-off and increased soil-erosion reflected by ${ }^{13} \mathrm{C}$-depleted carbon isotopes. A second anomaly (>1900 CE) is more likely the result of the "Suess Effect" (anthropogenic impact of the Industrial Revolution on carbon isotopes composition) than another reflection of a TC peak activity interval.

\section{Introduction}

Reliable and high-resolution climate data are crucial prerequisites for a variety of climate modelling approaches. Such data are, however, only available for the last $\sim 150$ years of the Instrumental Era. In order to overcome the temporal limitation of the instrumental record, sufficiently longer, continuous and at the same time annually-resolved paleoclimate datasets need to be studied. The short instrumental record prevents, in particular, the detection of long-term changes in climate dynamics and their consideration and implementation in climate modelling approaches. Extracting millennial-scale proxy data from various paleoclimate archives provides the opportunity to consider climate variations far beyond the instrumental record and to gain the required long-term datasets for more reliable climate modelling approaches.

The past two millennia of Common Era climate history crucially sustained the society growth and development standards in the south-western Caribbean. The Medieval Warm Period (900-1400 CE) is one example for a naturally occurring Late Holocene climate change (Mayewski et al. 2004) far beyond the instrumental record that offers the unique potential to be considered as an analogue of the present-day climate crisis. The demise of the Classical Maya high civilization likely followed extensive hydro-climatic changes appearing with the onset of the Medieval Warm Period (Kennett et al. 2012). The south-western Caribbean region is overall very climatesensitive and well suited to study the causes of all Common Era climate variations 
and subsequent changing ocean-atmosphere dynamics maintained by responses of prominent climate phenomena.

The three major natural Caribbean climate drivers include the AMO (Atlantic Multidecadal Oscillation; Gray et al. 2004), the NAO (North Atlantic Oscillation; Trouet et al. 2009) and the ENSO (El-Niño-Southern Oscillation; Li et al. 2013). The AMO phenomenon is a major oceanographic feature of climate variability in the North Atlantic region (Enfield et al. 2001) and multi-decadal modulation of Atlantic (Knight et al. 2005) and Caribbean SST patterns (Hetzinger et al. 2008). The NAO is a key mechanism of North Atlantic atmospheric circulation and in general a measure for air pressure gradient fluctuations between the Icelandic Low and the Azores High (Elsner et al. 2006), which was previously considered to explain long-term patterns in Atlantic cyclone activity (Denommee et al. 2014). The ENSO mode describes a coupled ocean and atmosphere circulation phenomenon that primarily works in the equatorial Pacific. Despite this fact, there are also important tele-connections with the tropical western Atlantic (Burn and Palmer 2015). These include a multi-annual to decadal modulation of regional SST patterns, tropospheric vertical wind shear stress dynamics and the strength of the trade wind system as well as cyclone activity (Gray 1984). The development of millennial-scale and high-resolution climate records is a crucial prerequisite to understand the underlying control mechanisms of Caribbean climate dynamics on much longer time scales than the instrumental record.

A compilation of global multi-proxy data (Emile-Geay et al. 2017) allows an impressive overview of a high number of previously investigated climate records. Such records are typically based on ice core, tree, organism (shells, skeletons, tests), speleothem and sediment archives. However, the available Caribbean climate records for the above-described purpose are still scarce and not sufficient, particularly when considering the marine realm of the south-western Caribbean region and the entire Common Era time series. Most Caribbean records derive from continental Mesoamerican lakes (Metcalfe et al. 2000; Hodell et al. 2008) such as Petén-Itzá (Guatemala), Chichanancanab (Mexico) or Miragoane (Haiti). Unfortunately, all these records have, however, only decadal resolution, target Pleistocene-to-Holocene time scales and focus primarily on atmospheric elements of the climate system. The extracted precipitation records reflect a transition from arid to 
more humid conditions during the Early Holocene (11-8 kyrs BP), followed by a relatively persistent humid period during the Holocene Climate Optimum (8-7 kyrs BP; Hillesheim et al. 2005) and a return to drier conditions from $~ 7$ kyrs BP (Hodell et al. 1991; Curtis et al. 1998; Wooller et al. 2009). Only few regional and annually resolved Caribbean speleothem records allow detailed insights into the Common Era climate history (Kennett et al. 2012), but they mostly reflect, equally to the lake sediment archives, changes in precipitation patterns and lack information with respect to changes of ocean dynamics. The sedimentary archive from the anoxic Cariaco Basin (Haug et al. 2001, 2003) is the only available marine long-term record of the western Caribbean realm, however with the same focus on precipitation changes only. Although the abovementioned approaches display a satisfactory representation of Holocene precipitation patterns in the Caribbean realm, there is an urgent need for establishing Common Era climate records, which target in particular oceanic (SST) and atmospheric dynamics (cyclone activity) at the same time.

Instrumental data from the tropical Western Atlantic particularly display a strong natural connection of ocean and atmosphere dynamics regarding SST variations and tropical cyclone activity (Goldenberg et al. 2001). The current variation of the tropical Atlantic SST between $26^{\circ} \mathrm{C}$ and $29^{\circ} \mathrm{C}$ (Gray 1986; DeMaria and Kaplan 1994) exerted a major control within the Instrumental Era, which mainly regulated the TC activity in addition to ENSO-controlled tropospheric modulations (Murakami et al. 2018). The latter include the control of vertical wind shear-stress dynamics and the creation of steady vertical temperature gradients (McTaggart-Cowan et al. 2015). This interplay of ocean and atmosphere dynamics facilitates a deep atmospheric convection over wide tropical Atlantic regions and, thus, exerts influence on the thermodynamic modulation of TC activity. However, conceptual and numerical TCactivity prediction models (Webster et al. 2005; Bender et al. 2010; Knutson et al. 2010) are either anchored on the short Instrumental Era dataset or consider largescaled and globally compiled climate records due to a lack of appropriate regional alternatives. It is consequently essential to feed the available climate and TC activity models with continuous and annually-resolved Common Era SST data obtained from a sufficiently long and self-contained tropical Atlantic SST archive.

Most of the tropical Atlantic SST records have been primarily obtained from sclerosponge (Haase-Schramm et al. 2003), foraminifer (Black et al. 2007) and coral 
(Kuhnert et al. 2002; DeLong et al. 2014; Tierney et al. 2015) archives. Unfortunately, all these climate records encompass only shorter time periods (centuries) compared with those extracted from "lake-like" sediment successions in marine sinkholes (millennia). SST reconstructions, covering approximately the last two millennia (Common Era), are largely smoothed synthesis approaches, compiling several of the short and regional records to a single and "continuous" SST curve (e.g., Mann et al. 2008; Rosenthal et al. 2017).

Shinn et al. (1996) first highlighted the huge potential for obtaining millennial-scale climate and SST records from flooded sinkholes. Some former studies investigated an anoxic and "lake-like" Blue Hole with stratified water column, situated in Lighthouse Reef Atoll (Belize), with regard to multi-annual climate (Gischler et al. 2008, 2013) and TC activity (Denommee et al. 2014) reconstructions. The great potential offered by this flooded Pleistocene karst cavity has not yet been fully exploited in terms of climate and SST research. For these reasons it is essential to review and improve the Lighthouse Reef sinkhole archive, especially with regard to the role of the major Caribbean climate drivers. In this context, emphasis is placed on reliable AMO signal detection and evidence for a multi-decadal control of Caribbean SST patterns. We are confident that the varved sinkhole-sediment succession of the "Great Blue Hole" will provide a valuable marine archive for the detection of AMO signals and its control on Common Era SST variability. Other available AMO reconstructions are still solely based on continental approaches (tree ring archives; Gray et al. 2004) or do not continuously record the AMO signal over the past two millennia (Delworth and Mann 2000). To date, our study provides the longest continuous and concurrently only annually-resolved tropical Atlantic SST $\left(\delta^{18} \mathrm{O}\right.$, TEX $\left.{ }_{86}\right), A M O$ variability and cyclone-controlled run-off $\left(\delta^{13} \mathrm{C}\right)$ reconstruction, which builds on the results of an annually-resolved TC activity study (Schmitt et al. 2020a).

\section{Setting}

\subsection{Geography and geomorphology}

Belize ( $16^{\circ} \mathrm{N}$ to $18^{\circ} 30^{\prime} \mathrm{N}, 87^{\circ} 30^{\prime} \mathrm{W}$ to $89^{\circ} 30^{\prime} \mathrm{W}$ ) is located in Central America (Fig. 7 a), bordered by the Mexican Yucatan Peninsula (north), the Caribbean Sea (east), Honduras (south) and Guatemala (west). The Belize barrier and atoll reef system (Fig. 7 b) forms the longest modern tropical reef system in the Atlantic Ocean with a north-south extension of about $250 \mathrm{~km}$. It is located $20-80 \mathrm{~km}$ offshore the Belize 
mainland coastline and runs roughly parallel to the passive continental margin. The classical barrier reef geomorphology merges in the northern reef section into a fringing reef. At the southern end, abundant patch reefs, shelf atolls and drowned reefs are found and the barrier reef proper shows a peculiar hook-shaped morphology. The three offshore atolls (Turneffe Islands, Lighthouse Reef and Glover's Reef) vary in size from 200 to $525 \mathrm{~km}^{2}$ and exhibit different geomorphological expressions (Stoddart 1962; Gischler and Lomando 1999). A continuous seaward and a discontinuous leeward surface-breaking reef rim characterize Lighthouse Reef, the smallest offshore atoll $\left(200 \mathrm{~km}^{2}\right)$. The eastern lagoon of Lighthouse Reef is up to $9 \mathrm{~m}$ deep, whereas the western lagoon is only $3 \mathrm{~m}$ deep. Both lagoon sections are separated by an almost $20 \mathrm{~km}$ long patch reef chain (“middle reef").
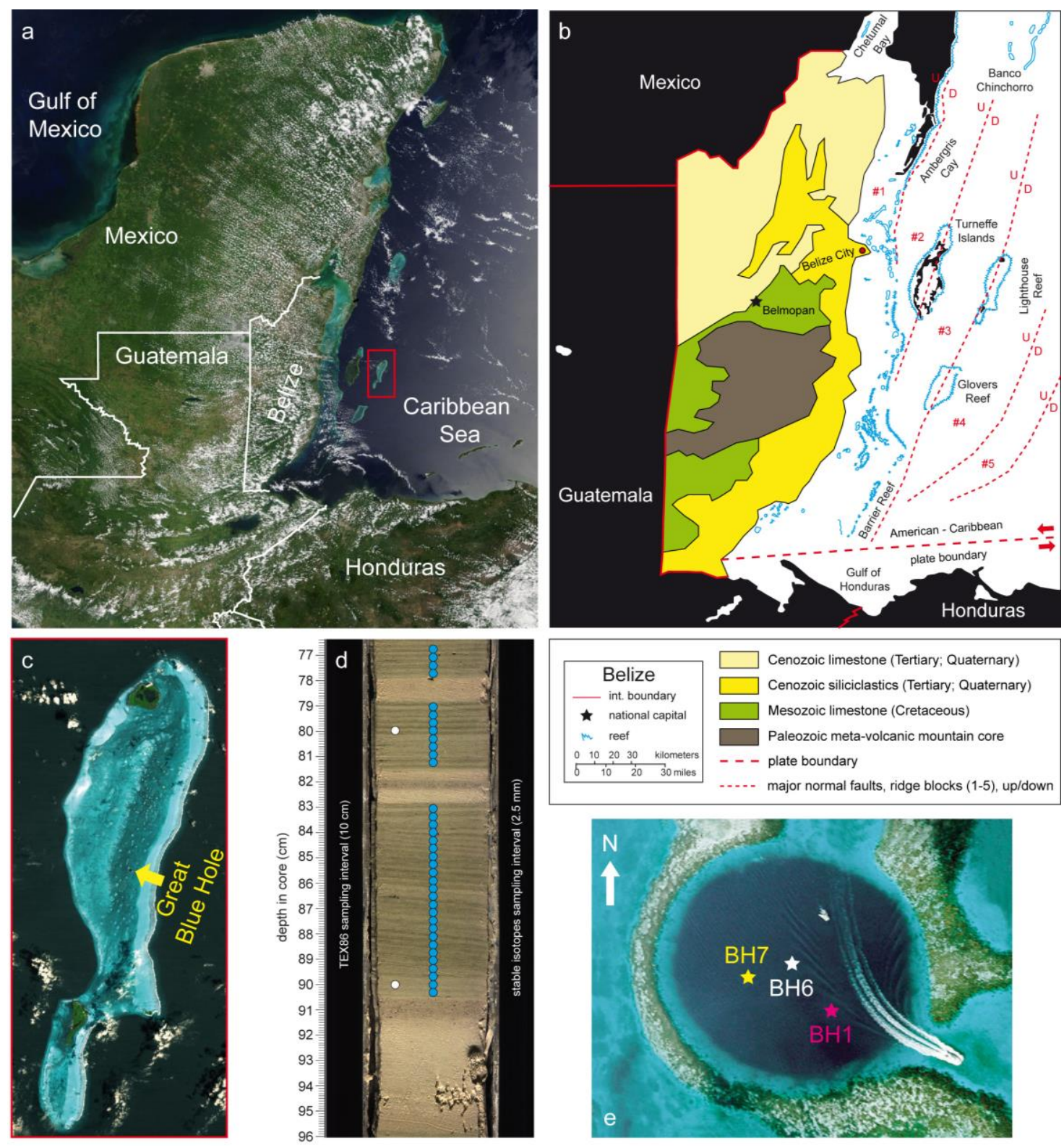
$\leftarrow$ Figure 7. (a) Geographical overview of the Yucatan Peninsula illustrating the position of Belize and offshore atoll Lighthouse Reef (small red box) in the south-western Caribbean region. (b) Simplified geological and tectonic map of Belize and its structural influence on reef formation. The maps were produced digitizing open access satellite images using the vector graphic software Adobe lllustrator CS4 V.14.0. We acknowledge the use of imagery from the NASA Worldview application (https://worldview.earthdata.nasa.gov), part of the NASA Earth Observing System Data and Information System (EOSDIS). (c) Open access ASTER satellite image of Lighthouse Reef (https://asterweb.jpl.nasa.gov) supplied by Japan Space Systems, and U.S/Japan ASTER Science TEAM (NASA/METI/AIST/). The position of the "Great Blue Hole" is highlighted within the eastern lagoon. (d) Core photograph (interval BH1: $76.5-96.0 \mathrm{~cm}$ ) of the sediment succession from the bottom of the "Great Blue Hole" comprising fine-grained, yellow/brown-green laminated couplets and three intercalated coarser sandy TC-strike event beds. The blue (middle) and white (left) dots illustrate the sampling intervals of stable isotopes $(2.5 \mathrm{~mm})$ and TEX ${ }_{86}(10 \mathrm{~cm})$, respectively. (e) Aerial view taken from a previous study (Gischler et al. 2008) indicating the position of the cores BH1 $\left(17^{\circ} 18.943^{\prime} \mathrm{N}\right.$, $\left.87^{\circ} 32.071^{\prime} \mathrm{W}\right)$, BH6 $\left(17^{\circ} 18.957^{\prime} \mathrm{N}, 8^{\circ} 32.098^{\prime} \mathrm{W}\right)$ and $\mathrm{BH} 7\left(17^{\circ} 18.950^{\prime} \mathrm{N}, 87^{\circ} 32.118^{\prime} \mathrm{W}\right)$ in the "Great Blue Hole".

The "Great Blue Hole" is a $125 \mathrm{~m}$ deep and $320 \mathrm{~m}$ wide, inundated Pleistocene sinkhole within the eastern Lighthouse Reef lagoon (Fig. 7 c). Several giant 2-3 m long stalactites formed subaerially during Pleistocene sea-level lowstands (Dill et al. 1998). They continued to accrete after marine flooding and represent impressive evidence for the former karst and flooding history (Gischler et al. 2017b). The cylindrical shape of the "Great Blue Hole" results from a roof collapse (Dill 1977). Its upper edge is almost completely surrounded by coalesced coral patch reefs except for two channels in the north and east connecting the interior with the eastern lagoon. Inside the reef rim, there is a $30^{\circ}$ inclined coarse sediment slope transitioning at $10 \mathrm{~m}$ depth to an almost vertical wall. The water conditions below $90 \mathrm{~m}$ depth (thermocline and pycnocline) are anoxic (Dill 1977). Consequently, the sediment succession is not disturbed by bioturbation, allowing its use as unique "lake-like" climate archive with annual resolution. The annual couplets (varves) of the "Great Blue Hole" sediment succession most likely reflect seasonal changes in productivity within the surface waters of the Lighthouse Reef lagoon (Gischler et al. 2008, 2013). As a result, there is a difference in organic matter content between summer (yellow/brown layer) and winter season (green layer). The organic-rich greenish laminae form during winter months, when the wind blows towards the east and southeast causing an upwelling of deeper, nutrient-rich water masses and an associated increase of productivity. Coarse-grained event layers interrupt this constant background sedimentation (Fig. 7 d). TCs passing the "Great Blue Hole" cause either a sediment slope collapse at the top of the sinkhole (downslope density flows), or physically initiate a suspension and settling out of coarse-grained carbonate particles 
(>63 $\mathrm{mm}$ ) from the surrounding lagoon floor and marginal reef through storm wave and surge impact (Brown et al. 2004; Schmitt et al. 2020a).

\subsection{Mainland geology and reef development}

Belize mainland geology is divided into three large-scale tectono-morphological units:

(1) Cenozoic limestones and siliciclastics cover large parts of the northern Maya Lowlands and the coastal areas, (2) Palaeozoic sediments (shales/schists) and igneous rocks (granites/porphyries) form the core of the southern 1124 m.a.s.l. high Maya Mountain belt, and (3) Mesozoic limestones and dolostones surround the southern meta-volcanic mountain core (Fig. 7 b). Owing to the geological situation, the Mesoamerican Barrier Reef system is a mixed carbonate-siliciclastic sedimentation system (Purdy 1974; Purdy and Gischler 2003).

NNE-trending major normal faults are key tectonic features, which structurally shape the Belize passive continental margin. The hanging walls of five elongated NNEstriking ridges of fault blocks (Dillion and Vedder 1973) provide the pedestal for reef development (Fig. 7 b). In detail, the westernmost block (\#1) is the basement of the northern Belize Barrier Reef ranging from Chetumal Bay south to approximately Belize City. The middle barrier reef section and offshore atoll Turneffe Islands are located on top of the eastward following fault block (\#2). The next block (\#3) forms the basement of the southernmost barrier reef section and offshore Glover's as well as Lighthouse Reef atolls.

The antecedent topography of modern reef development was mainly formed during Pleistocene sea-level lowstands by fluvial channels, river bars and karst dissolution producing deeply incising valleys (Purdy 1974). Postglacial reef growth started in the early Holocene on top of Pleistocene reefs and topographic highs of mixed siliciclastic-carbonate sediments of marine isotope stage 5e time (Choi and Ginsburg 1982); as a consequence of a transgressive sea-level rise (Esker et al. 1998; Ferro et al. 1999). According to subsurface core data, initial reef growth started approximately 8.2 kyr BP in the Belize Barrier Reef area and 7.8 kyr BP on the offshore atolls (Gischler and Hudson 1998). Lagoonal inundation in the atolls began during 8.5-6.0 kyr BP (Gischler 2003). 


\subsection{Climate and oceanography}

Belize is located in the subtropical climate zone with mean annual air temperatures ranging from $24{ }^{\circ} \mathrm{C}$ (winter) to $30^{\circ} \mathrm{C}$ (summer). For most of the year, trade winds dominate the atmospheric circulation system blowing from east (January-April) to north-east (July-December). The trade winds consequently establish a mean surface wave direction to the west and south-west (Burke 1982). Two kinds of interruptions occur in contrast to the normal trade-wind regime. From November to February, atmospheric circulation is mainly affected by the influence of North American highpressure systems, inducing northerly winter storms and an overall cold and stormy weather pattern (Adomat and Gischler 2015). From July to October, cyclones approaching from east to south-east are the most remarkable atmospheric phenomenon. TCs repeatedly made landfall over Belize with an average of one cyclone every 5 years in the twentieth century (www.nhc.noaa.gov).

Another important climatic feature is the latitudinal change of the intertropical convergence zone (ITCZ), which is located relatively north over the wider Belize area in summer to fall (Haug et al. 2001). The northward ITCZ migration causes both elevated rainfall and higher TC development potential. The migration of the ITCZ towards a more southern winter and spring position results in lower precipitation. Belize mainland precipitation increases from $150 \mathrm{~cm} / \mathrm{yr}$ in the north to more than $400 \mathrm{~cm} / \mathrm{yr}$ in the mountainous south, reflecting the two general mainland topography units (Purdy 1974). The average rainfall on the offshore atolls is estimated to be 175 $\mathrm{cm} / \mathrm{yr}$ (Stoddart 1962).

The northwards directed Caribbean Current dominates both deep and surface circulation of the south-western Caribbean region (James and Ginsburg 1979). Belize is a micro-tidal area with tidal ranges of $<0.3 \mathrm{~m}$ (Stoddart 1962). Modern SST variations occur in the wider Belize area according to the GISST2.3b dataset within a $24-32^{\circ} \mathrm{C}$ range (Wantland and Pusey 1975; Woodruff et al. 1998). Sea-surface salinity (SSS) is $35 \%$ around the barrier reef and significantly decreased close to the coast $(18 \%)$ and within the northernmost "fringing reef" shelf around Chetumal Bay (Purdy and Gischler 2003; Purdy et al. 2003). In offshore atoll lagoons of Glover's and Lighthouse Reef, SSS is slightly increased (annual fluctuations of $37-41 \%$ ), with the highest salinities in winter and spring. Salinity values of up to $70 \%$ occur in Turneffe Island lagoon due to restricted circulation conditions (Hauser et al. 2007). 


\section{Material and methods}

Seven sediment cores $(\mathrm{BH} 1-\mathrm{BH} 7)$ were collected from the bottom of the "Great Blue Hole" (Lighthouse Reef, Belize) in August 2017 along a W-E transect. The coring process was carried out from a small vessel using a portable Rossfelder P3 electrical vibrocore system (floating unit, vibrator head, baseplate) and $6 \mathrm{~m}$ long aluminium tubes of $7.5 \mathrm{~cm}$ diameter, prepared with copper core catchers. In order to extend core length to $9 \mathrm{~m}$, two aluminium pipes were glued together using $50-\mathrm{cm}$-long aluminium sleeves and epoxy-adhesive. A second core catcher was added to balance the higher sediment load. The maximum core length of all cores ranges from $1.80 \mathrm{~m}$ (shortest core $\mathrm{BH} 1$ ) to approximately $7.70 \mathrm{~m}$ (longest cores $\mathrm{BH} 6$ and $\mathrm{BH} 7$ ). The coordinates at the coring sites were registered using a GPS instrument (e.g., BH1: $17^{\circ} 18.943^{\prime} \mathrm{N}, 87^{\circ} 32.071^{\prime} \mathrm{W}$; BH6: $17^{\circ} 18.957^{\prime} \mathrm{N}, 8^{\circ} 32.098^{\prime} \mathrm{W}$ and $\mathrm{BH} 7$ : $17^{\circ} 18.950^{\prime} \mathrm{N}, 8^{\circ} 32.118^{\prime} \mathrm{W}$; Fig. 7 e). The core BH6 derives approximately from the centre of the sinkhole (Fig. 7 e). After retrieval, cores were cut in-situ into $1.5 \mathrm{~m}$-long sections, transported by air freight from Belize City to Frankfurt am Main, Germany, and stored in a cold room at $4{ }^{\circ} \mathrm{C}$ to avoid dehydration.

All 1.5 m-long core sections of $\mathrm{BH} 1, \mathrm{BH} 6$ and $\mathrm{BH} 7$ have been opened in the laboratory and cut in halves lengthwise using an angle grinder and an ultra-thin copper sheet $(0.7 \mathrm{~mm}$ thickness). To avoid contamination of the core material with hydrated double sulphate aluminium salt, core catchers were immediately removed from the basal core tubes. High-resolution line-scan images of the shortest core $\mathrm{BH} 1$ (Fig. $7 \mathrm{~d}$ ) and the two longest cores $\mathrm{BH} 6$ and $\mathrm{BH} 7$ were acquired at the University of Bern using a Geotek-MSCL-S (Multi-Sensor Core Logger). A stratigraphic and sedimentological core description was done by visual core observation and the use of high-definition photographs of the cores. This approach allowed (1) a highresolution differentiation of background and cyclone depositions, (2) to monitor varve thickness precisely, and (3) a straightforward description of sedimentary structures and layer contacts. Based on its length and an exceptionally good preservation, core BH6 was selected for sampling even though the core top had been lost due to liquefaction during the coring process. Because core $\mathrm{BH} 7$ shows a remarkably similar succession, it has been spliced together with core $\mathrm{BH} 6$ to replace the missing material of $86 \mathrm{~cm}$ length at the core top of $\mathrm{BH} 6$ by means of correlating prominent cyclone event-layers. The distance between both cores within the W-E transect is 
$35 \mathrm{~m}$ (Fig. 7 e). For the sake of simplicity, we refer to the spliced core as "BH6". Splicing leads to a maximum core length of $8.55 \mathrm{~m}$.

The previously estimated constant sedimentation rate of $2.5 \mathrm{~mm} / \mathrm{yr}$ (Gischler et al. 2008) was reviewed and confirmed (2.55 $\pm 0.5 \mathrm{~mm} / \mathrm{yr})$ by varve-thickness measurements and age model comparison. In total, 76 TEX 86 samples $(5 \mathrm{~g}$ bulk material) and 1707 stable isotopes subsamples (500 mg bulk material) were taken systematically over the entire core length, following the constant background sedimentation rate. The bulk material for stable isotope analyses was continuously sampled at annual resolution in $2.5 \mathrm{~mm}$ intervals throughout all varved background sections (Fig. 7 d). A $2.5 \mathrm{~mm}$ slab of TEX 86 bulk material was discretely sampled every $10 \mathrm{~cm}$ within the background sediments, to achieve a 40-years resolution of absolute SST data (Fig. 7 d). For textural analyses, a total of 2915 samples with 2.5 $\mathrm{mm}$ sampling intervals, ensuring sufficient material $(4.5 \mathrm{~g})$ for all necessary processing steps, have been washed and sieved through standard grain-size sieves of $2 \mathrm{~mm}, 1 \mathrm{~mm}, 500 \mathrm{~mm}, 250 \mathrm{~mm}, 125 \mathrm{~mm}$ and $63 \mathrm{~mm}$ (Schmitt et al. 2020a). To guarantee reliable quantitative grain size and sorting measurements, a more detailed analysis of the fine material $<63 \mathrm{~mm}$ was performed by using a laser-optical particle analyser (HORIBA Laser Particle Analyser-950), which runs with $2 \mathrm{~g}$ fine material (<63 mm) suspended in $0.4 \mathrm{~N} \mathrm{Na}_{4} \mathrm{P}_{2} \mathrm{O}_{7}$ and demineralized water. Sediments were categorized by determination of classical sedimentary parameters (mean grain size, sorting, skewness and kurtosis), following the "Geometric and Logarithmic Folk and Ward method" and by using the software package gradistat (Blott and Pye 2001).

The chronology of the sediment core "BH6" is anchored on two well-established and independent age/depth frameworks (Fig. 2). We used a combination of radiocarbon and varve age-models that is robust enough for data interpretation at annual resolution (Suppl. 11). Two laminae $(1.25 \mathrm{~mm})$, yellow/brown- and green-coloured, form a couplet (varve) of medium-coarse silt-sized and $2.5 \mathrm{~mm}$ thick sediment layers (Fig. 7 d). These varves represent the constant annual background sedimentation. The annual sediment layers were counted in the intact core half to gain the primary age model for the analyses (Fig. 2). The varve counting of such couplets, back to $130 \mathrm{CE}$, is, however, not fully straightforward within deeper core sections, because the lamination becomes blurry in cases and the boundaries between green and yellow/brown laminae are therefore not as easy to identify as in younger core 
sections. This resulted in average estimated varve counting errors of $5 \%$. TC layers have been in general omitted in the varve age model, which produces minor continuation gaps and apparently causes changes of linear slopes (Fig. 2). As an independent age determination, radiocarbon geochronology was generally used to check the quality of the applied varve counting approach. For this, five bulk samples $(3 \mathrm{~g})$ enriched in organic matter $(>7 \%)$ were selected from the sampled core half at $5.75 \mathrm{~cm}, 87.25 \mathrm{~cm}, 336.50 \mathrm{~cm}, 586.50 \mathrm{~cm}$ and $852.00 \mathrm{~cm}$ depth (Fig. 2). The green amorphous organic residue $\left(\delta^{13} \mathrm{C}\right.$ avg $\left.=-16.0 \%\right)$ was separated from bulk sediment by dissolving carbonate material with $\mathrm{HCl}$, washing the sample with $\mathrm{NaOH}$, and repeating until all carbonate material dissolved. Beta Analytic Inc. (Miami, Florida) conducted the radiocarbon dating with Accelerator Mass Spectrometry (AMS; Bard 1998). The conventional radiocarbon ages were converted to calibrated years before present using the BetaCal3.21 MARINE13 calibration curve (High Probability Density Range Method; Reimer et al. 2013). All calibrated ages are presented with a 2- $\sigma$ error with $95.4 \%$ probability. The $\Delta R$ factor used for reservoir correction of marine carbon age is Delta- $R=-23 \pm 26$ from nearby Glover's Reef, as the best available site-specific $\Delta R$ correction for the "Great Blue Hole" water mass. The AMS dating of the amorphous organic residue produced five radiometric ages calibrated to calendar years ranging from $1950 \pm 99 \mathrm{CE}$ near the core top to $171 \pm 125 \mathrm{BCE}$ (Table 1). Both age models explicitly show an extraordinarily strong linear correlation $(r=0.99$; $p<0.05)$ without any significant age offset between the counts of annual couplets and ${ }^{14} \mathrm{C}$ ages in upper core parts. For example, at $87 \mathrm{~cm}$ depth, the varve age of $1787 \pm 12 \mathrm{CE}$ lies perfectly within the error range of radiocarbon dating of $1830 \pm 120 \mathrm{CE}$ (Table 1). Towards the lowermost core section, an increasing age offset occurs between the two age determination methods. The offset between layer counting and AMS dating in deeper core sections represents a minor data limitation, however, they are the best chronometers available. The ${ }^{14} \mathrm{C}$ age determination helps, thus, to document that there are no major gaps within the seven core subsections. No hiatus occurs, furthermore, at the top of "BH6" core as evidenced by (1) a very thick and coarse-grained event layer at $21 \mathrm{~cm}$ core depth (varve age: $1962 \mathrm{CE}$ ) correlated with great certainty to category 5 -hurricane "Hattie" that stroke Lighthouse Reef in 1961 CE (Stoddart 1963), (2) a ${ }^{14} \mathrm{C}$ radiocarbon age near the core top $(5 \mathrm{~cm})$ indicating post "Bomb Effect" conditions (aberrantly old age without correction), and (3) indirectly by using our high-resolution stable isotope curves, which include the 
prominent $0.5 \%$ drop in $\delta^{13} \mathrm{C}$ values related to the "Suess Effect" and the substantial decrease of $\delta^{18} \mathrm{O}$ values $\left(0.25 \%=1.3^{\circ} \mathrm{C}\right)$ within the past 150 years characteristic of the Industrial Era warming.

Thereupon, the archive core half was continuously scanned at $0.3 \mathrm{~mm}$ intervals with a $20 \mathrm{~s}$ integration time using a non-destructive $\mathrm{X}$-ray fluorescence core scanner (XRF; COX-ITRAX equipped with a Cr-anode-X-ray tube set to $30 \mathrm{kV}$ and $40 \mathrm{~mA}$ ) at the University of Bern. More than 23,000 raw data (total counts) have been first converted, dividing the raw data with the integration time, to counts per second (cps) and then used to check the potential of several previously conducted proxy techniques. For this purpose, special attention was given to the elements $\mathrm{Al}, \mathrm{Cl}, \mathrm{Ca}$, $\mathrm{Ti}, \mathrm{Fe}, \mathrm{Cu}$ and $\mathrm{Sr}$. The Ca-content was previously used as a long-term indicator for carbonate availability (Croudace and Rothwell 2015). Isaack et al. (2016) discussed the application of $\mathrm{Cl}$-content for evaluating lagoon salinity or sediment water content. Böning et al. (2012) described the application of $\mathrm{Cu} / \mathrm{Al}$ ratios as a possible indicator for primary productivity changes. $\mathrm{Fe} / \mathrm{Ca}$ and $\mathrm{Ti} / \mathrm{Ca}$ ratios are useful proxies to reconstruct mainland run-off/soil erosion processes according to Gregory et al. (2015). Schmitt et al. (2020a) introduced the application of $\mathrm{Sr} / \mathrm{Ca}$ ratios as a potential cyclone detection tool in sinkholes with calcitic background sedimentation.

$100 \mathrm{mg}$ of pulverised bulk material was subsequently analysed for carbon $\left(\delta^{13} \mathrm{C}\right)$ and oxygen $\left(\delta^{18} \mathrm{O}\right)$ stable isotope compositions using a ThermoFinnigan MAT253 mass spectrometer with Gas Bench II according to the method of Spötl and Vennemann (2003). The analytical precision is better than $0.02 \%$ for $\delta^{13} \mathrm{C}$ and $0.03 \%$ for $\delta^{18} \mathrm{O}$ values. Isotope values are reported in parts per thousand (\%o) relative to the Vienna Peedee belemnite standard (VPDB). The oxygen isotopes data $\left(\delta^{18} \mathrm{O}\right)$ form the basis for a regional SST reconstruction. Carbon isotopes variation $\left(\delta^{13} \mathrm{C}\right)$ is interpreted to reflect, in combination with preceding vegetation and land use changes, signals of run-off/erosion processes, probably as the result of cyclone peak activity intervals.

Glycerol dibiphytanyl glycerol tetraethers (GDGTs) were analysed to calculate the TEX 86 (tetraether index of lipids consisting of 86 carbon atoms) index. The powdered samples were extracted by ultrasonication with a mixture of dichloromethane and methanol (3:1, v:v). An aliquot of the resulting total lipid extract was cleaned and analysed by high-performance liquid chromatography/atmospheric pressure positive 
ion chemical ionization mass spectrometry (HPLC/APCI-MS) at the University of Hamburg, as described in Baumann et al. (2018). Relative abundances of GDGTs have been successfully used to obtain TEX $\mathrm{T}_{86}$ as salinity independent proxy for absolute SST values using the TEX ${ }_{86}$ calibration of Kim et al. (2010), calibrated for (sub)tropical environments. This calibration is valid for temperatures from $10^{\circ} \mathrm{C}$ to $40^{\circ} \mathrm{C}$ and especially above $>15^{\circ} \mathrm{C}$ ( $\mathrm{Kim}$ et al. 2010). The $\mathrm{TEX}^{\mathrm{H}}{ }_{86}$ calibration is including the Crenarchaeol isomer, which cannot be found in (sub)polar regions. Therefore, in cold regions only the TEX ${ }^{L_{86}}$ calibration is applicable (Kim et al. 2010).

$$
\text { TEX }{ }_{6}=\log \frac{([\text { GDGT }-2]+[\text { GDGT }-3]+[\text { Crenarchaeol isomer }])}{([\text { GDGT }-1]+[\text { GDGT }-2]+[\text { GDGT }-3]+[\text { Crenarchaeol isomer }])}
$$

The SSTs can be calculated by the following equation:

$$
\text { SST }=68.4 \times(\text { TEX } 56)+38.6
$$

The residual standard error for the $\operatorname{TEX}^{\mathrm{H}}{ }_{86}\left({ }^{\circ} \mathrm{C} \pm 1 \sigma\right)$ was $2.5^{\circ} \mathrm{C}$. Sampling resolution is limited to relatively large intervals $(10 \mathrm{~cm})$, because of the extensive preparation (Wuchter et al. 2004). Furthermore, about 3-5 g of bulk material is needed for TEX 86 analyses, resulting in shortage of material for other analytical approaches. All datasets were used and analysed for cyclic periodicities with wavelet analyses of power spectra (Hammer et al. 2001), in order to statistically check a potential influence of the major Caribbean climate drivers on SST variability. The full dataset was in each case inspected with the software PAST at various time scales simultaneously, detecting periodicities at different wavelengths within the 2000-year time series. The square correlation strength with the mother wavelet ("Morlet" with wave number 6) is shown on coloured power spectra. The underlying algorithm is based on fast convolution of signals with the "Morlet" wavelet using a "Fourier transformation". Statistical significance level (corresponding to $p=0.05$ ) is plotted as a contour line (chi-squared test) within the cone of significance. 


\section{Results}

\subsection{Sedimentology}

The sediment successions covering the bottom of the "Great Blue Hole" consist almost entirely of fine-grained calcium carbonate material ( $>93 \%)$. The major noncarbonate constituent is green, amorphous organic matter that makes up on average 6-7\% of bulk sediment material (Gischler et al. 2008). The remainder includes low silica contents derived from sponge needles, diatom and radiolarian tests. The carbonate fraction is composed on average of $75 \%$ aragonite, $23 \%$ high-magnesium calcite and $2 \%$ low magnesium calcite (Gischler et al. 2008).

The core stratigraphy is genetically separated and characterized by varved yellow/brown-greenish fair-weather sedimentation and yellow/brown storm-induced event-layer deposition. Thin-section analysis from the "Great Blue Hole" bottom sediments show that varying amounts of skeletal debris including Halimeda, coralline red algae, molluscs, foraminifers, corals and echinoderms are the major constituents besides minor constituents of organic and non-skeletal particles (peloids) both in background and event layers. Surface sediments of the Lighthouse Reef lagoon exhibit similar compositions (Gischler and Lomando 1999).

The sinkhole-sediment succession predominantly consists of poorly to very poorly sorted (1-4 $\Phi)$ sequences $(<2.5 \mathrm{~mm}$ ) of medium to coarse silt-sized deposits (12-30 $\mathrm{mm}$ ). These annual layered sequences represent the varved background sedimentation of skeletal material that is produced in the marginal reef, transported as suspended load by surface currents towards the west, and finally deposited in the "Great Blue Hole" sediment trap under fair weather conditions. The measured average grain size of the varved background sediment sequences is $20 \pm 4 \mathrm{~mm}$. TCs passing the "Great Blue Hole" cause an interruption of the fair-weather sedimentation dynamics. The formation of the intercalated event beds is attributable either to downslope density flows or coarser material settling out of suspension (Brown et al. 2014). The contacts between the varved sections and the coarser storm-induced event layers are therefore either sharp and erosive (downslope density flow) or gradual (settling out of suspension). In total, five poorly (1-2 $\Phi)$ to very poorly (2-4 $\Phi)$ sorted TC event layer categories occur in the "BH6" core stratigraphy. These units are several $\mathrm{mm}$ up to $28 \mathrm{~cm}$ thick and consist of over-washed skeletal debris more similar to the marginal reef sediment composition (increased coral and 
Halimeda contents). The grain sizes of the five different event layer lithologies range from 24-30 mm (coarse silt), 31-61 mm (very coarse silt), 62-121 mm (very fine sand) and $133-226 \mathrm{~mm}$ (fine sand) up to $263-374 \mathrm{~mm}$ (medium sand). All textural and sedimentological characteristics of background and event bed sections and their unequivocal differentiation originate from the multi-proxy-TC-identification approach shown in the supplementary material of Schmitt et al. (2020a).

\subsection{Inorganic geochemistry}

Oxygen isotope values of bulk samples from core "BH6" range from $-1.28 \%$ o to $-1.99 \%$ VPDB (Fig. 8; Suppl. 12). An up-core trend towards lower/more negative values and an underlying multi-decadal oscillation ( 50 years) occurring along the entire time series are apparent.

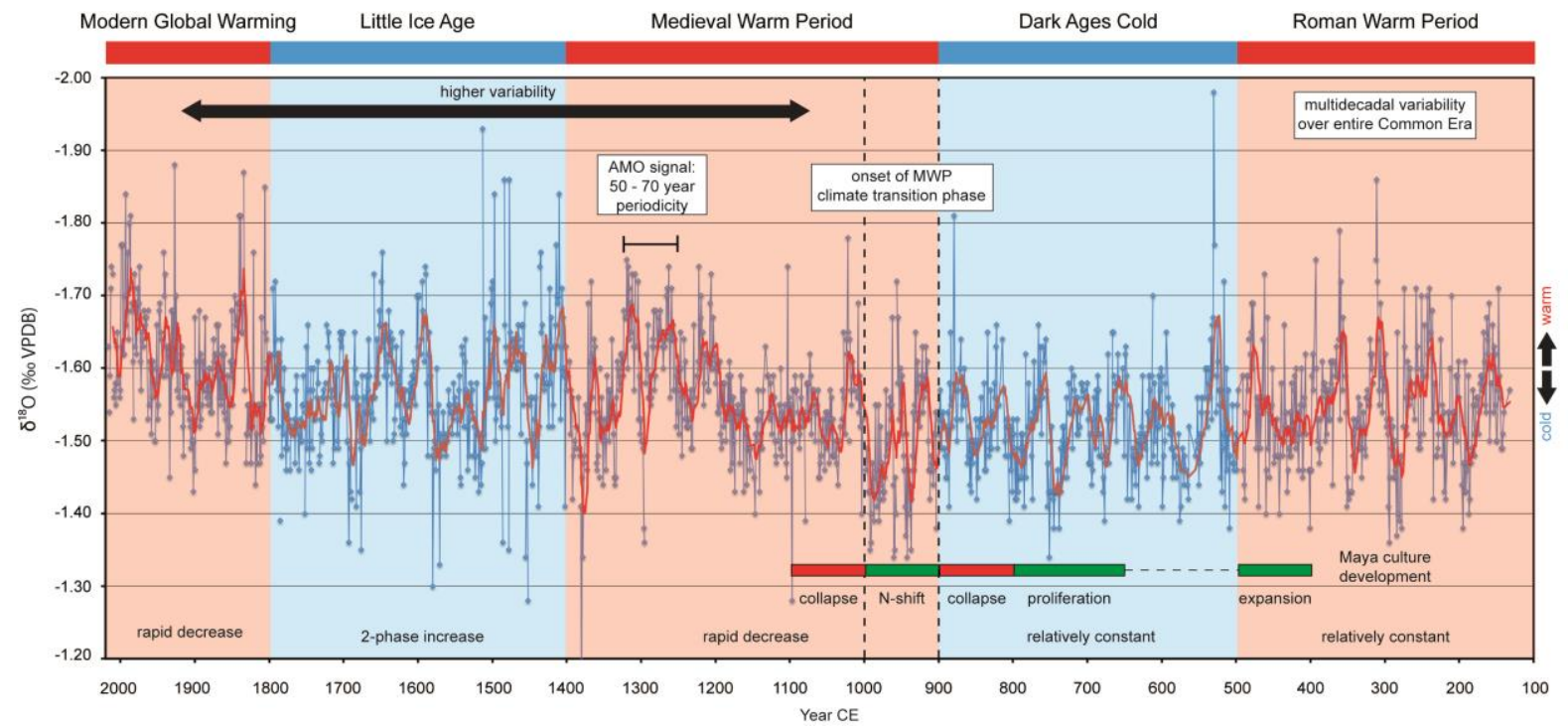

Figure 8. 2000-year $\delta^{18} \mathrm{O}$ time series of core "BH6" (event layers excluded). Note that the $\mathrm{y}$-axis is reversed. The red line is a 50-year running average. Oxygen isotopes have been correlated with Common Era climate variations ( $\mathrm{red}=$ warm climate interval; blue = cold climate interval). The $2.5 \mathrm{~mm}$ sampling interval is equal to annual resolution (background sedimentation rate $=2.5 \mathrm{~mm}$ ). The sample dating is based primarily on varve counting results and supportive on ${ }^{14} \mathrm{C}$ age dating. Strong positive peaks in the curve are caused by high aragonite content (compositional artefact). The dashed lines frame the onset of the Medieval Warm Period (MWP) climate transition phase. The timing of Maya culture development status (bar chart) is based on the study of Kennett et al. (2012).

$\delta^{18} \mathrm{O}$ values decrease over the last 2000 years on average from $-1.50 \%$ to $-1.60 \%$ o VPDB. In detail, the oxygen isotope values fluctuate in a relatively constant manner from 100 to $500 \mathrm{CE}$. From 500 to $900 \mathrm{CE}$, oxygen isotopes still show relatively constant fluctuations, but indicate a slight increasing trend towards higher/more positive values. From 900 to $1400 \mathrm{CE}$ a prominent decreasing trend towards 
lower/more negative values (from $-1.50 \%$ o to $-1.70 \%$ ) occurs concurrently with a rise of overall variability posterior to $1100 \mathrm{CE}$. The most negative values are reached from 1200 to $1350 \mathrm{CE}$. Two phases of $\delta^{18} \mathrm{O}$ increase characterize the time window from 1400 to $1800 \mathrm{CE}$, which end around $1570 \mathrm{CE}$ and $1770 \mathrm{CE}$, respectively. Since $1800 \mathrm{CE}$, again a conspicuous decreasing trend to more negative values are apparent. The most recent decrease in isotopic composition $(-1.50 \%$ o to $-1.75 \%$ ) is remarkably similar to the previous decreasing interval (900-1400 CE).

Bulk carbon stable isotope values vary from $+2.20 \%$ to $+4.30 \%$ VPDB (Fig. 9; Suppl. 12). There is an overall up-core decreasing trend from $+3.50 \%$ to $+2.50 \%$ ond several centennial-scaled patterns, reminiscent to the oxygen isotope curve.

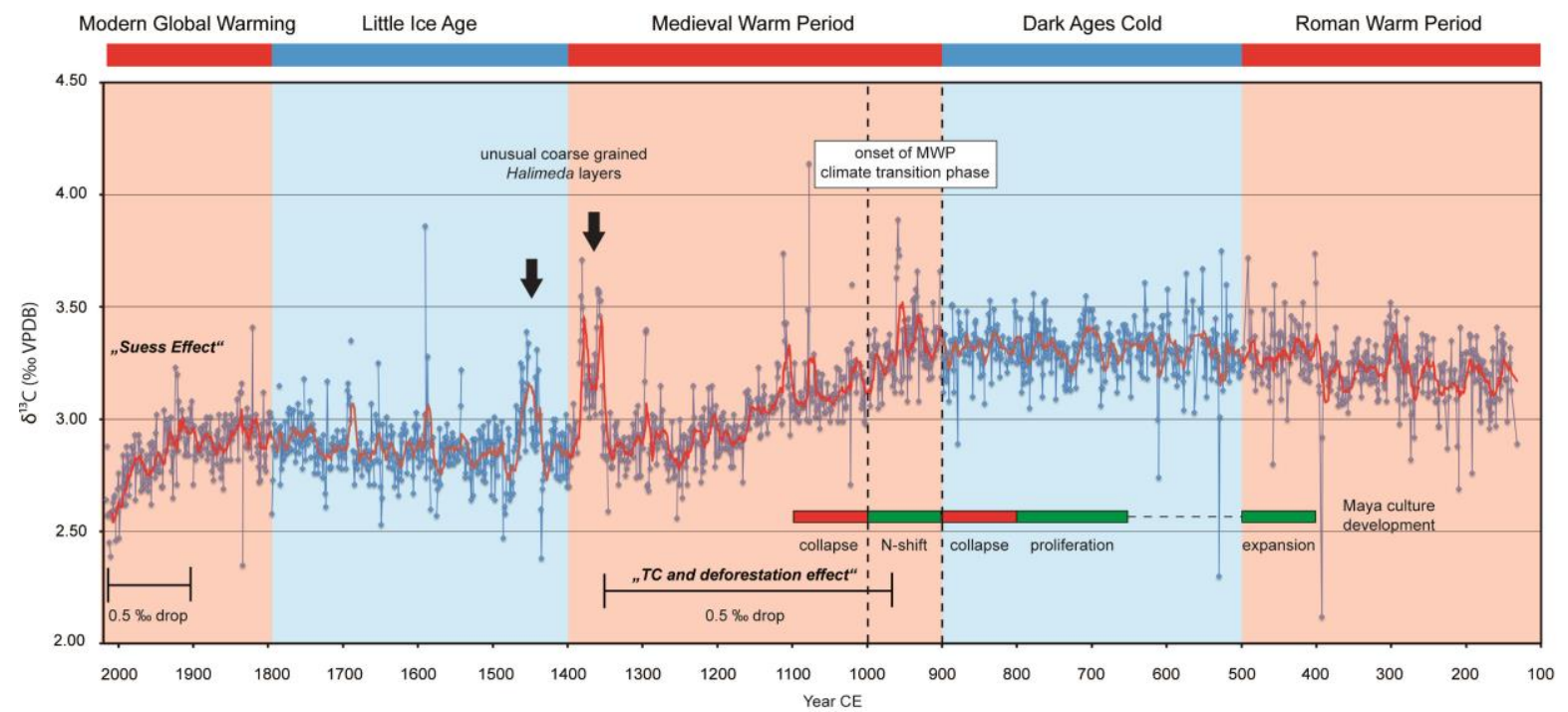

Figure 9. 2000-year $\delta^{13} \mathrm{C}$ time series of core "BH6" (event layers excluded). The red line is a 50-year running average. Carbon stable isotopes have been correlated with Common Era climate variations ( red = warm phase; blue = cold phase). The $2.5 \mathrm{~mm}$ sampling interval is equal to annual resolution (background sedimentation rate $=2.5 \mathrm{~mm}$ ). The sample dating is based primarily on varve counting results and supportive on ${ }^{14} \mathrm{C}$ age dating. Strong positive peaks in the curve are caused by high aragonite content (compositional artefacts, e.g., $1350 \mathrm{CE}$ and $1450 \mathrm{CE}$ ). The dashed lines frame the onset of the Medieval Warm Period (MWP) climate transition phase. The timing of Maya culture development status (bar chart) is based on the study of Kennett et al. (2012).

$\delta^{13} \mathrm{C}$ and $\delta^{18} \mathrm{O}$ values show a weak and statistically significant positive correlation $(r=0.48 ; p<0.05)$. The $\delta^{13} \mathrm{C}$ values increase between 100 and $500 \mathrm{CE}$ from $+3.20 \%$ to $+3.40 \%$. Afterwards, $\delta^{13} \mathrm{C}$ values fluctuate in a constant manner from 500 to 900 CE. From 900 to $1400 \mathrm{CE}$, the carbon stable isotope curve shows a significant $0.5 \%$ drop from $+3.30 \%$ to $+2.80 \%$. Particularly striking are the two positive excursions back to prior-drop composition around $1350 \mathrm{CE}$ (double peak) and $1450 \mathrm{CE}$. From 1400 to $1800 \mathrm{CE}$, another interval of constant fluctuation occurs, however, with a 
very weak increasing trend. From 1900 CE until present days, another significant $\delta^{13} \mathrm{C}$ drop $(0.5 \%$ ) from $+3.00 \%$ to $+2.50 \%$ is visible.

\subsection{Organic geochemistry}

TEX $X_{86}$ values show an up-core and statistically significant $(r=0.283 ; p=0.01)$ increasing trend of SSTs from $27.4 \pm 0.9^{\circ} \mathrm{C}$ to $28.7 \pm 0.8^{\circ} \mathrm{C}$. This primary increasing trend seems to be additionally influenced by an underlying multi-decadal temperature variability (Fig. 10 a; Suppl. 12).
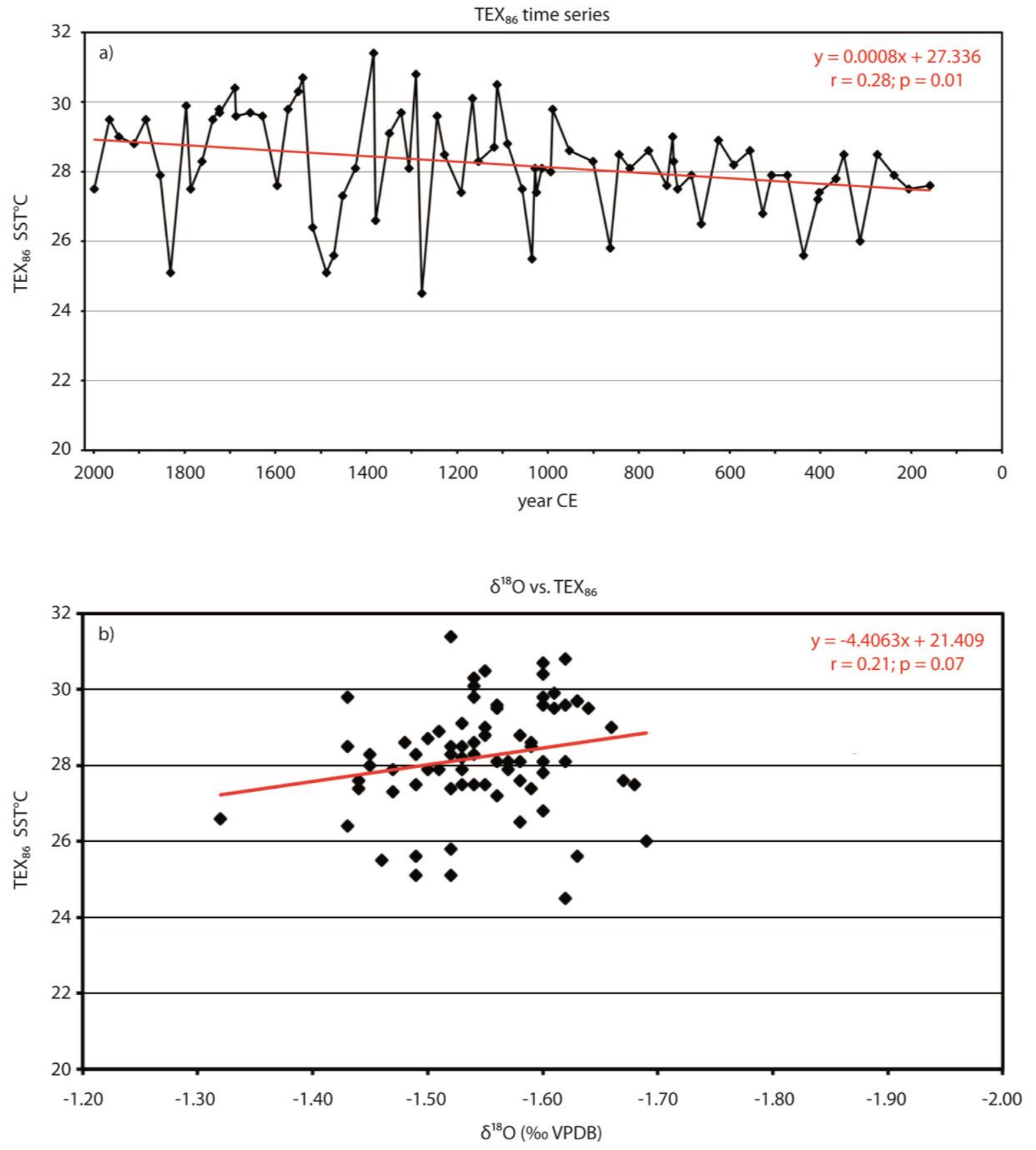
$\leftarrow$ Figure 10. (a) Absolute south-western Caribbean SST curve reconstructed from a 2000-years TEX 86 time series (event layers excluded). The red line indicates a linear and statistically significant primary SST rise over Common Era times. This long-term increase of SST underlies secondary a cyclic/multi-decadal variation (black curve). The $10 \mathrm{~cm}$ sampling interval of $2.5 \mathrm{~mm}$ thick slabs is equal to a 40-year TEX ${ }_{86}$ SST resolution. The sample dating is based primarily on varve counting results and supportive on ${ }^{14} \mathrm{C}$ age dating. (b) Statistical correlation between $\delta^{18} \mathrm{O}$ and $T E X_{86}$ data. The red line shows a weak linear, but statistically insignificant correlation between the two temperature proxies.

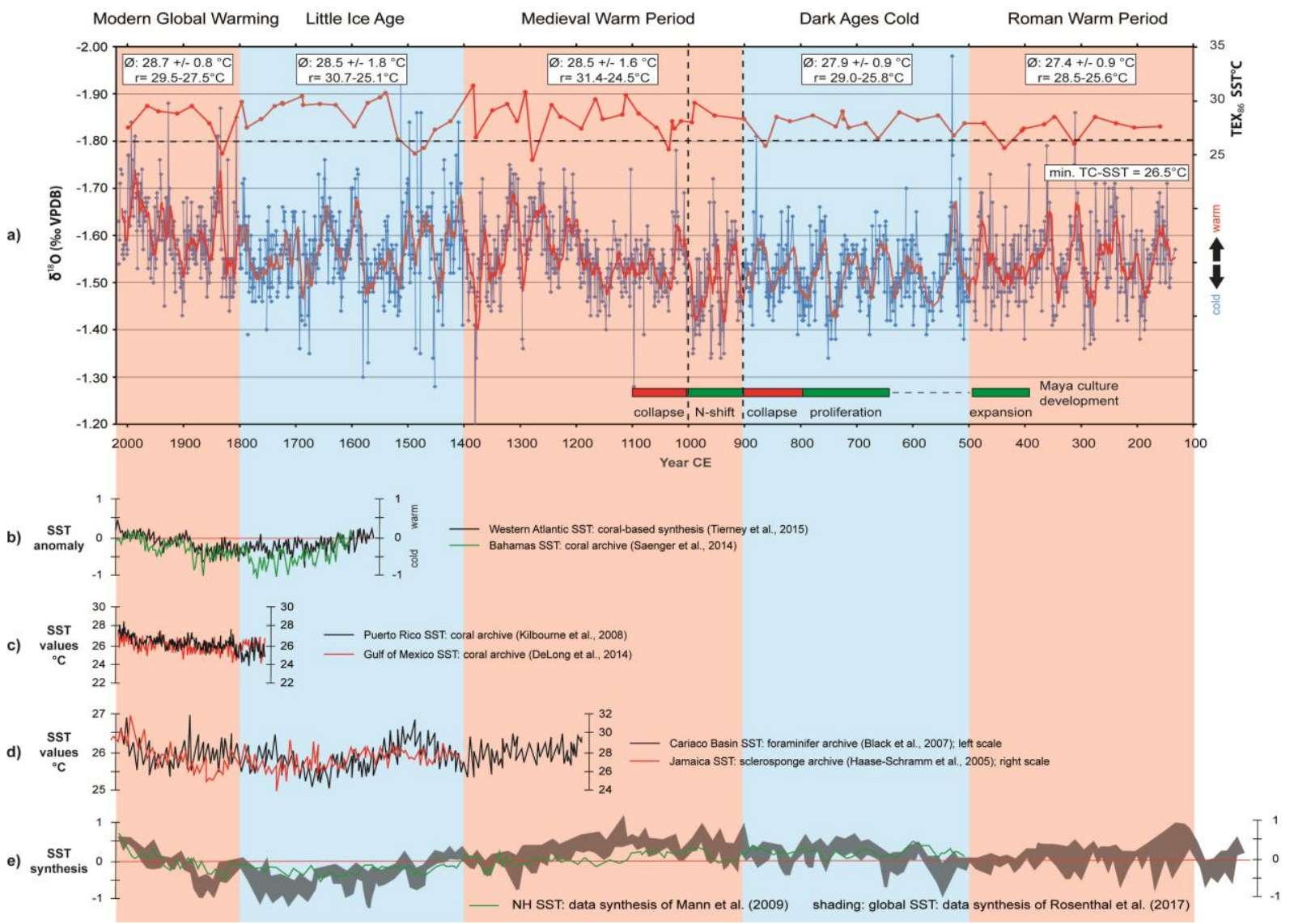

Figure 11. (a) Combination of $\delta^{18} \mathrm{O}$ (relative SST curve) and TEX 86 (absolute SST curve) time series. Note that the $y$-axis is reversed. The horizontal dashed black line indicates the boundary condition of $26.5^{\circ} \mathrm{C}$, which is of great importance for tropical cyclone formation and a further quality assurance of the presented TEX ${ }_{86}$ SST reconstruction. The timing of Maya culture development status (bar chart) is based on the study of Kennett et al. (2012). The TEX 86 SST values in the white boxes are averages $(\varnothing)$ over the individual Common Era climate intervals. The appearing SST range $(r)$ is shown in the same boxes with regard to $\mathrm{min} / \mathrm{max}$ temperatures. (b) Coral-based relative reconstructions of tropical Atlantic SST patterns including a Western Atlantic proxy synthesis (Tierney et al. 2015) and a coral archive record from the Bahamas (Saenger et al. 2014). (c) Absolute SST reconstruction on the basis of coral archives including Puerto Rico (Kilbourne et al. 2008) and Florida/Gulf of Mexico (DeLong et al. 2014). (d) Absolute SST reconstruction considering a foraminifer archive from the Cariaco Basin (Black et al. 2007) and a sclerosponge archive from Jamaica (Haase-Schramm et al. 2005). (e) Northern Hemisphere (NH) SST reconstruction following the synthesis approach of Mann et al. (2009). A compiled Common Era global SST synthesis (Rosenthal et al. 2017) is shaded in black. The curve of Rosenthal et al. (2017) consists of different cumulated global, Northern Hemisphere and western Pacific Warm Pool SST reconstructions. 
The TEX 86 -based SST record, averaged over the five Common Era climate intervals, would be equivalent to the decrease in oxygen isotope values if $\delta^{18} \mathrm{O}$ were taken as purely SST-derived $\left(0.25 \%\right.$ or $\left.1.3^{\circ} \mathrm{C}\right)$, but the mutual relation between both datasets (Fig. $10 \mathrm{~b})$ is statistically insignificant $(r=0.21 ; p=0.07)$. The up-core trend in TEX 86 SST, however, still qualitatively follows the rough pattern of oxygen isotope variations (Fig. 11). From 100 to 500 CE (Roman Warm Period), TEX 86 SST is less variable, (min: $25.6^{\circ} \mathrm{C}$; $\max : 28.5^{\circ} \mathrm{C}$ ) and fluctuates relatively constant around a mean value of $27.4 \pm 0.9^{\circ} \mathrm{C}$. From 500 to $900 \mathrm{CE}$ (Dark Ages Cold), TEX ${ }_{86}$ SST values again fluctuate in a relatively constant manner (min: $25.8^{\circ} \mathrm{C}$; max: $29.0^{\circ} \mathrm{C}$ ) around a mean value of $27.9 \pm 0.9^{\circ} \mathrm{C}$. The averaged TEX ${ }_{86}$ SST $\left(28.5 \pm 1.6^{\circ} \mathrm{C}\right)$ obviously increases from 900 to $1400 \mathrm{CE}$ (Medieval Warm Period). A concurrent rise of surface ocean temperature variability, indicated by a higher range of minimum $\left(24.5^{\circ} \mathrm{C}\right)$ and maximum temperatures $\left(31.4^{\circ} \mathrm{C}\right)$, is also noteworthy. The subsequent period from 1400 to $1800 \mathrm{CE}$ (Little Ice Age) is relatively similar in terms of mean TEX 86 SST $\left(28.5 \pm 1.8^{\circ} \mathrm{C}\right)$, but not as variable as the Medieval Warm Period with regard to minimum and maximum SSTs ranging from 25.1 to $30.7^{\circ} \mathrm{C}$. From $1800 \mathrm{CE}$ (Modern Global Warming), the mean TEX ${ }_{86}$ SST increases to $28.7 \pm 0.8^{\circ} \mathrm{C}$, however, surface ocean temperature variability decreases again in comparison to the two previous climate intervals. Obviously, enhanced minimum temperatures $\left(27.5^{\circ} \mathrm{C}\right)$ but in turn slightly reduced maximum temperatures $\left(29.5^{\circ} \mathrm{C}\right)$ generally characterize this time interval.

\subsection{Time series analysis}

Time series analysis of the $\delta^{18} \mathrm{O}$ values allows to identify two statistically significant spectral peaks with multi-decadal to centennial scales including 32-64- and 128-256year periodicities (Fig. 12 a). These clearly separated cycle lengths encompass the $\delta^{18} \mathrm{O}$ time-line back to $300 \mathrm{CE}$. Wavelet power spectra of $\delta^{13} \mathrm{C}$ measurements indicate a similar cyclicity (Fig. 12 b), however, with some important limitations. In contrast to the $\delta^{18} \mathrm{O}$ wavelet, it is not possible to fully distinguish the different periodicities from each other. Furthermore, it is also impossible to trace them back over the entire timeline. The longer 128-256-year cycle occurs over the entire time series, but the signal is discontinuous along the wavelet power spectrum. The shorter 32-64-year periodicity is limited to the time interval from 1300 to $1500 \mathrm{CE}$ and is more likely an artefact than a periodic feature. Two striking positive carbon isotope 
anomalies, caused by high Halimeda abundances, occur exactly during this time interval. The first positive double peak appears from 1360 to $1392 \mathrm{CE}$, followed by a 40-year intermediate interval (1392-1432 CE) leading over to the second peak around 1432-1482 CE (Fig. 9). These two positive excursions appear consequently within an imaginary periodicity of 30-60 years and cause, thus, the temporal limited multi-decadal signal in the $\delta^{13} \mathrm{C}$ power spectrum.

a) $\quad \delta^{18} \mathrm{O}$

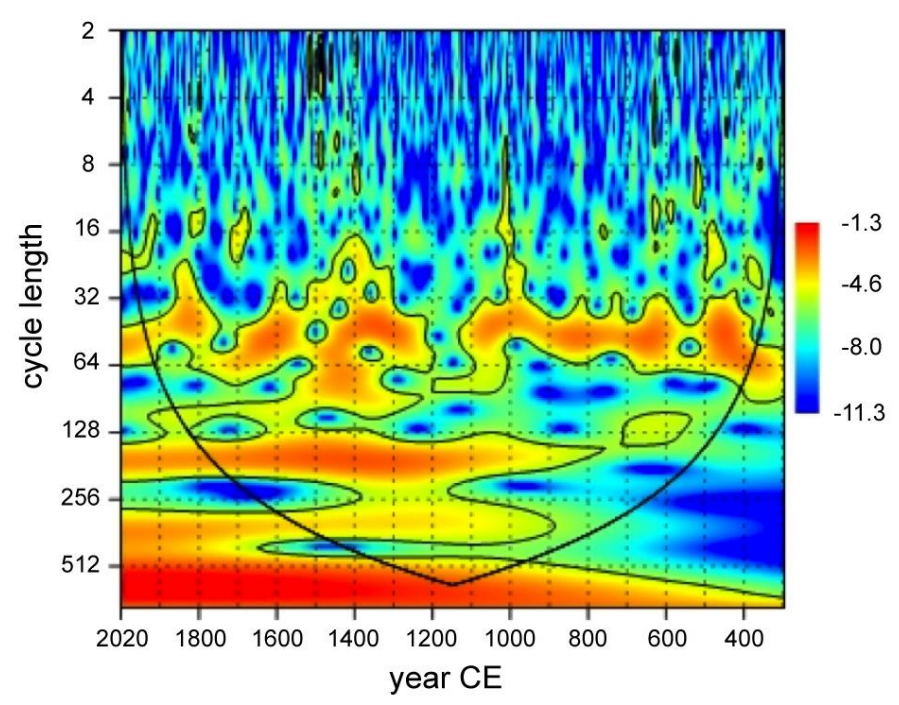

b) $\quad \delta^{13} \mathrm{C}$

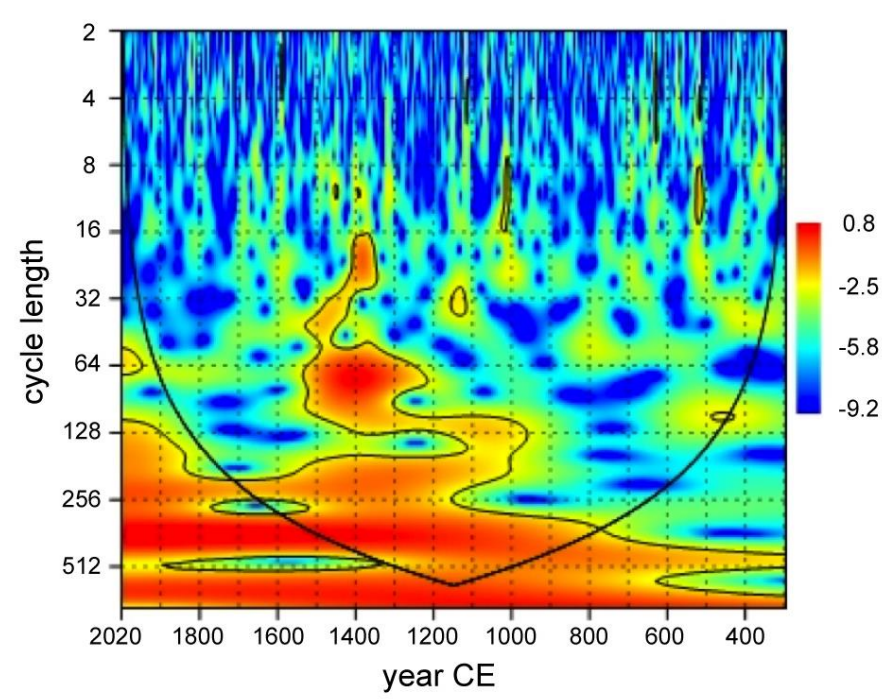

Figure 12. (a) Wavelet power spectrum of $\delta^{18} \mathrm{O}$ illustrating $\mathrm{AMO}(32-64 \mathrm{yr})$ and solar forcing (128-256 yr) cycles. (b) Power spectrum of $\delta^{13} \mathrm{C}$ indicating an unsolvable signal overlap. Statistically significant cycle lengths $(p<0.05)$ have a confidence level of $95 \%$ within the cone of significance, contoured and coloured orange to red. 


\subsection{XRF data}

Even though many of the investigated signals are close to the standard deviation, some patterns of the XRF signals indicate noticeable qualitative trends. The $\mathrm{Ca}$ content of the core "BH6" fluctuates in a constant manner around $125000 \pm 21000$ cps (Fig. 13 a). The fluctuation, however, operates to large parts within the standard deviation. This fact largely prevents a quantitative detection of carbonate availability oscillation. Detailed statements with regard to long-term carbonate availability variations are limited for this reason. In any case, the constant fluctuation would indicate more or less constant carbonate availability throughout the Common Era time series. There seems to be a qualitatively separated three-part $\mathrm{Cl}$ pattern within the time series verified by generally lower $\mathrm{Cl}$ counts from 100 to $1200 \mathrm{CE}$ (500-1000 cps), higher $\mathrm{Cl}$ counts from 1200 to $1800 \mathrm{CE}$ (1000-2000 cps) and again lower $\mathrm{Cl}$ counts from $1800 \mathrm{CE}$ towards present day (1000-1500 cps). But again, as seen for $\mathrm{Ca}$ content, the internal variation of the $\mathrm{Cl}$ counts lies to large parts within the error bars (SD $300 \mathrm{cps}$ ), which makes it hardly possible to quantify a distinct trend or periodicity apart from the qualitative observation. The $\mathrm{Sr} / \mathrm{Ca}$ ratio shows a relatively constant fluctuation around a mean value of $0.021 \pm 0.005$ (Fig. $13 \mathrm{~b}$ ). The $\mathrm{Sr} / \mathrm{Ca}$ ratio is generally not appropriate to identify long-term trends. But the numerous outstanding high peaks of $\mathrm{Sr} / \mathrm{Ca}$ ratios $>0.03$ are clearly attributable to event layers caused by Common Era cyclone strikes (Schmitt et al. 2020a). The obviously higher $\mathrm{Sr} / \mathrm{Ca}$ ratios in TC event layers result from an increased abundance of over-washed aragonitic Halimeda chips and coral fragments in contrast to a depletion of aragonitic grains within fair weather background sediments. The $\mathrm{Cu} / \mathrm{Al}$ ratio fluctuates constantly and without any noticeable patterns around a mean ratio of $1.5 \pm 1.0$. Such a constant fluctuation indicates probably relatively constant productivity conditions that appear without significant changes throughout the Common Era time series. Owing to the overall high carbonate content and the specific protected offshore setting of the sinkhole, the input of lithogenic elements derived from soil erosion over mainland run-off and dust transport is very low, which is also suggested by extremely low $\mathrm{Fe} / \mathrm{Ca}$ ratios (mean 0.003; Fig. $13 \mathrm{c}$ ). Long-term fluctuations of the $\mathrm{Fe} / \mathrm{Ca}$ ratio are not noticeable, because of the relatively high standard deviation (0.008) and the extensively low $\mathrm{Fe}$ abundances in relation to the $\mathrm{Ca}$ amount. However, there is a pattern of elevated Fe/Ca ratios around 1300-1600 CE, during the Dark Ages Cold (500-900 CE) and in the Roman Warm Period (100-500 CE). 

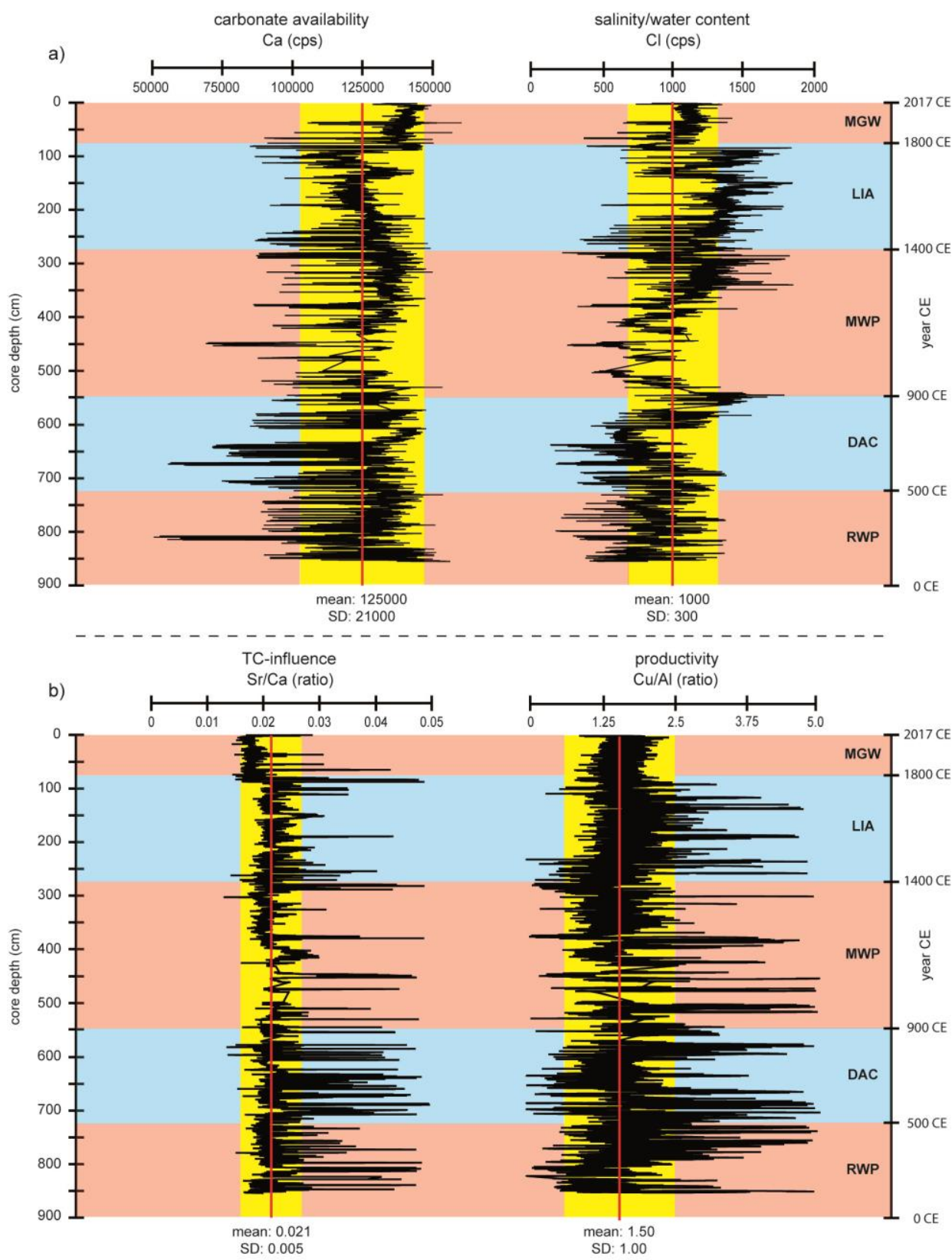

errestrial run-off/soil-erosion

terrestrial run-off/soil-erosion

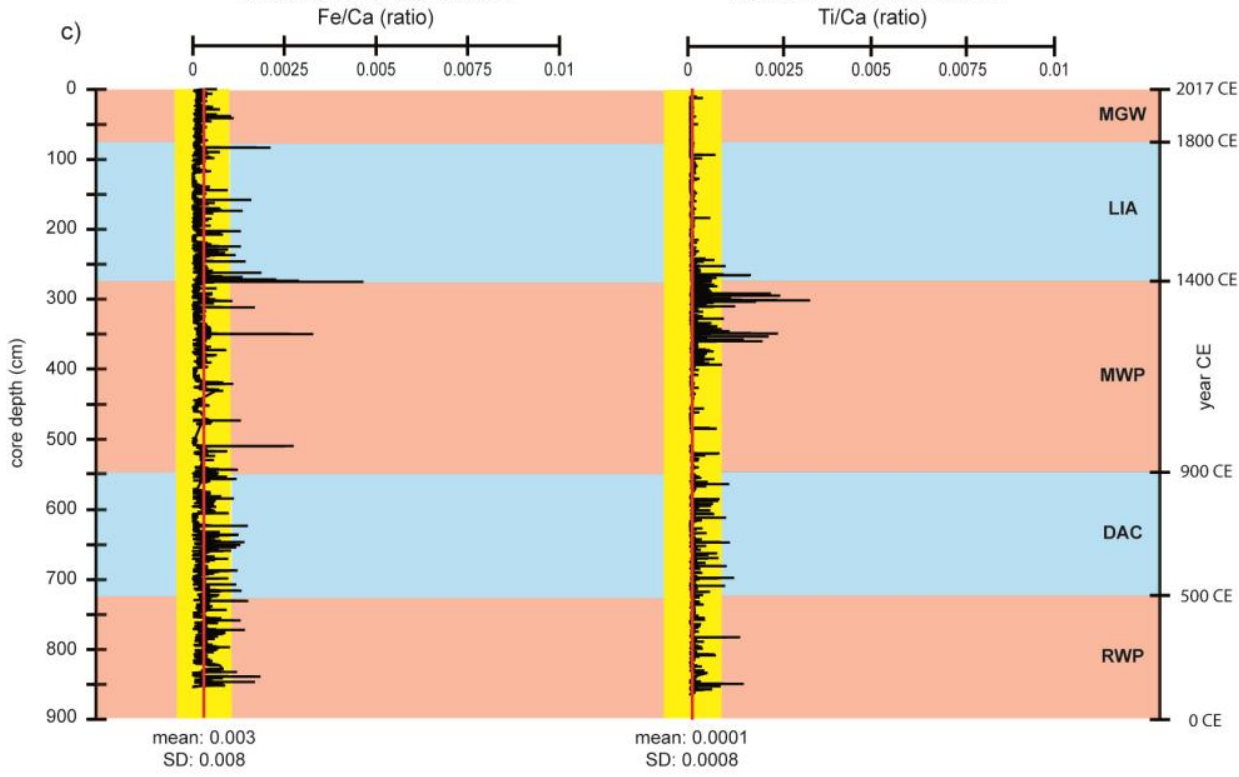


$\leftarrow$ Figure 13. (a) $\mathrm{Ca}$ and $\mathrm{Cl}$ contents as proxies for carbonate availability and salinity/water content. (b) $\mathrm{Sr} / \mathrm{Ca}$ and $\mathrm{Cu} / \mathrm{Al}$ ratios as proxies for tropical cyclone influence and primary productivity changes. (c) $\mathrm{Fe} / \mathrm{Ca}$ and $\mathrm{Ti} / \mathrm{Ca}$ ratios as proxies for terrestrial run-off and soil erosion. All element contents are shown as counts per seconds (cps). The red lines represent the average values (mean); the yellow box the standard deviation (SD).

The proxy application of the $\mathrm{Ti} / \mathrm{Ca}$ ratio signals underlies similar limitations, which include generally extremely low element ratios (mean: 0.0001) and high standard deviation values (SD: 0.0008). However, compared with $\mathrm{Fe} / \mathrm{Ca}$ ratios, the $\mathrm{Ti} / \mathrm{Ca}$ ratios show the same, but more pronounced pattern of elevated ratios from 1200 to 1500 CE and comparable patterns of elevated Ti/Ca ratios during the Dark Ages Cold (500-900 CE) and in the Roman Warm Period (100-500 CE). Highest excursions in both $\mathrm{Fe} / \mathrm{Ca}$ and $\mathrm{Ti} / \mathrm{Ca}$ ratios occur during the late Medieval Warm Period.

\section{Discussion}

\subsection{Quality check: $\delta^{18} \mathrm{O}$ and TEX $\mathrm{X}_{86}$ applications as SST proxies}

Measuring $\delta^{18} \mathrm{O}$ values of calcareous skeletons, shells and tests of marine organisms such as corals, foraminifera, molluscs and calcareous algae is a common tool for past environment reconstruction with focus on SST (Wefer and Berger 1991). A change of $0.2 \%$ in $\delta^{18} \mathrm{O}$ composition approximates a one-degree temperature change in surface oceanwater. However, oxygen isotopes cannot be used as a simple quantitative temperature proxy. $\delta^{18} \mathrm{O}$ values of carbonates depend on several environmental factors that control the isotopic composition of seawater. In addition to temperature change, evaporation and salinity modulate the initial seawater composition from which organisms form their skeletons, shells and tests. Altogether, the effects of evaporation and salinity on $\delta^{18} \mathrm{O}$ values cannot be completely excluded within this study. The sampling interval of $2.5 \mathrm{~mm}$, i.e., the annual sediment accumulation, prevents that inter-annual salinity fluctuations, which presently amount to $37-41 \%$ in the Lighthouse Reef lagoon, are recorded. Chlorine data certainly demonstrate a qualitative pattern, i.e., significant elevated $\mathrm{Cl}$ counts from 1200 to $1800 \mathrm{CE}$ and decreased $\mathrm{Cl}$ counts from 100 to $1200 \mathrm{CE}$ (Fig. $13 \mathrm{a}$ ), but they are overall not a suitable indicator for long-term salinity changes in the "Great Blue Hole" setting. The qualitative chlorine pattern more likely reflects differences in water content and porosity between sections near the core top (wet/high porosity) and deeper and compacted core parts (dry/low porosity). As another important control factor, different groups of organisms come along with different degrees of oxygen 
isotope fractionation during biomineralization. This is a minor limitation of the applied approach, because the presented $\delta^{18} \mathrm{O}$ values are bulk measurements, representing a mixture of different skeletal isotopic compositions. However, in order to invalidate larger fractionation and bulk effects, Wefer and Berger (1991) demonstrated that the isotopic composition of different organism groups such as corals, molluscs, foraminifers and calcareous algae exhibit a similar sensitivity to temperature variations. Even though, that all these groups of organisms are characterized by hugely different absolute $\delta^{18} \mathrm{O}$ values, their records indicate similar decreasing tendencies to isotopic lighter compositions with increasing temperatures. Gischler et al. (2009) measured bulk $\delta^{18} \mathrm{O}$ values of 330 surface sediment samples from the three Belize offshore atolls, which yielded an isotopic range from $-2.50 \%$ to $0.00 \%$ o VPDB. These values agree well with the $\delta^{18} \mathrm{O}$ bulk variations observed in the present study $(-1.28 \%$ to $-1.99 \%$ ). The occurrence of different material mixtures between aragonite and magnesium calcite, which could potentially cause a high variability in bulk $\delta^{18} \mathrm{O}$ data, can be excluded, based on $36 \mathrm{X}$-ray powder diffraction (XRD) samples covering the past 1500 years (Gischler et al. 2008), and 20 thin-section point counting analyses of background sediment sections. The aragonite content indeed varies between event-layer and background samples (67-82\%) but is largely constant (mean: $75 \%$ ) within the background sections sampled for stable isotope analyses. Compositional variations in the abundance of major skeletal particles have also not been observed in quantitative thin-section analyses of background sediment samples. Overall, there is no strong evidence for a connection between compositional mixture variations and the distinct multi-decadal cyclicity, which is particularly apparent in the $\delta^{18} \mathrm{O}$ curve.

TEX 86 data, which are independent of salinity, evaporation and fractionation influence, are used to quantify SST variations in the "Great Blue Hole". The reconstructed TEX ${ }_{86}$ SST values using the calibration for (sub)tropical environments (TEX $\mathrm{H}_{86}$ ) range only slightly above the detection uncertainty of $\pm 2.5^{\circ} \mathrm{C}$ (see methods and material section), however, they are overall realistic considering the general south-western Caribbean SST of $>26^{\circ} \mathrm{C}$ as a potential reference frame. The TEX ${ }_{86^{-}}$ based SST reconstruction of the last 150 years agrees with the measured Instrumental Era temperature range (GISST2.3b) and in situ measurements in the upper water column of the "Great Blue Hole" (Gischler et al. 2013), which is a further 
validation and satisfactory indicator for the quality of the provided TEX 86 -based SST temperature reconstruction.

The lack of a strong statistically significant correlation between TEX $\mathrm{X}_{86}$ temperature data and $\delta^{18} O$ values $(r=0.207 ; p=0.07$; Fig. $10 b)$ is either the result of the above described "bulk-problem", or more likely the result of methodological limitations. It is in this context impossible to compare TEX $\mathrm{X}_{86}$ and $\delta^{18} \mathrm{O}$ data directly, because of the lack of analytical material after TEX ${ }_{86}$ measurements. For the comparison of $\delta^{18} \mathrm{O}$ and TEX ${ }_{86}$ data, $\delta^{18} \mathrm{O}$ values had to be averaged over a period of five years around the respective $\mathrm{TEX}_{86}$ samples, thereby smoothing highly variable annual $\delta^{18} \mathrm{O}$ fluctuations to a single theoretical $\delta^{18} \mathrm{O}$ value. This limitation may be the critical issue for the lack of correlation between both temperature proxies. The strongest argument against any obliteration by bulk-effects is the observation that Belize coral records show very similar isotopic trends for the Instrumental Era, i.e., a decrease in $\delta^{18} \mathrm{O}$ values of coral skeletons, which amounts to $0.2 \%$ (Gischler and Oschmann 2005). This Instrumental Era trend is equal to the decreasing tendency of the $\delta^{18} \mathrm{O}$ values obtained from the "BH6" bulk sediment analyses during the same time interval. For all these reasons, we regard it appropriate to use bulk $\delta^{18} \mathrm{O}$ values as an annuallyresolved and relative SST indicator allowing a comparison of Common Era SST trends with other circum-Caribbean proxy-based SST reconstructions. The consideration of quantitative TEX ${ }_{86}$ SST data enables an additional utilization of an absolute SST curve (Fig. 10 a) for the south-western Caribbean region, however, with the limitation of only multi-decadal resolution.

\subsection{Comparison: SST records and Common Era climate variability}

The new south-western Caribbean $\delta^{18} \mathrm{O}$ record from core "BH6" is longer, and in the overlapping time interval largely similar to core data from a previous study from the same sinkhole (Gischler et al. 2008). The Lighthouse Reef sinkhole record resembles also known patterns from other proxy-based circum-Caribbean SST reconstructions and coral-based tropical Western Atlantic synthesis approaches (e.g., Tierney et al. 2015; Fig. 11). These regional SST records have been mainly obtained from temporally shorter coral (Fig. 11 b, c), foraminifer and sclerosponge (both: Fig. 11 d) archives. All the various records from the Bahamas (Saenger et al. 2014), Puerto Rico (Kilbourne et al. 2008), the Gulf of Mexico (DeLong et al. 2014), Jamaica 
(Haase-Schramm et al. 2005) and the Cariaco Basin (Black et al. 2007) reach consequently not far enough into the past, to compare them especially on centennial up to millennial time scales with the presented 1885-years long $\delta^{18} \mathrm{O}$ and TEX $\mathrm{X}_{86}$ records from the Belize "Great Blue Hole". For this reason, we must compare our continuous Common Era temperature curve with substantially longer but compiled records of the northern hemisphere (Mann et al. 2008) and global (Rosenthal et al. 2017) SST curves (Fig. 11 e).

The oldest section of the Common Era time series (100-500 CE) is characterized by a warm climate interval, called the Roman Warm Period (RWP). The smoothed global SST record of Rosenthal et al. (2017) indicates an obviously positive global SST anomaly for the corresponding time interval, which is in terms of mean SST values, comparable to those of the present-day warm climate interval $\left(27-28^{\circ} \mathrm{C}\right)$. Our TEX 86 -based regional SST reconstruction displays for the RWP an average southwestern Caribbean SST of $27.4 \pm 0.9^{\circ} \mathrm{C}$. The reconstructed minimum $\left(25.6^{\circ} \mathrm{C}\right)$ and maximum $\left(28.5^{\circ} \mathrm{C}\right) \mathrm{SST}$ values (Fig. 11 a) do not record large surface ocean temperature variability within the RWP. The oxygen isotope values fluctuate equally in a relatively constant manner around a mean value of $-1.55 \%$ and indicate thus a similar pattern of constant surface ocean temperatures. The "Great Blue Hole" proxy records are only comparable with the broad Common Era global SST curve, compiled out of several northern hemisphere and Pacific warm pool reconstructions (Rosenthal et al. 2017), because of the lack of other regional records spanning the RWP.

The time interval from 500 to $900 \mathrm{CE}$ represents the subsequent Common Era cold climate interval of the Dark Ages Cold (DAC). This period is characterized by general global cooling effects, and compared with RWP times, fewer positive northern hemisphere (Mann et al. 2009) and global SST anomalies (Rosenthal et al. 2017). The small range of TEX 86 -based minimum $\left(25.8^{\circ} \mathrm{C}\right)$ and maximum $\left(29.0^{\circ} \mathrm{C}\right)$ temperatures supports a continuation of a generally low south-western Caribbean surface ocean temperature variability during the DAC. The oxygen isotope record from the Belize sinkhole indicates similar and relatively constant temperature fluctuations, but also a minor shift towards heavier isotopic compositions. The latter specifically suggests a weak regional cooling trend $\left(0.3^{\circ} \mathrm{C}\right)$, which is not traceable using the 40-year resolution TEX 86 data. The suspected local cooling trend is, 
however, satisfactorily verifiable considering the decreasing global SST tendencies from 500 to $700 \mathrm{CE}$ (Rosenthal et al. 2017) and a significantly less positive northern hemisphere SST anomaly in contrast to the RWP times, provided by Mann et al. (2009).

The Medieval Warm Period (MWP) is the most recent past warm climate interval of the Common Era time series (900-1400 CE). Both the global (Rosenthal et al. 2017) and northern hemisphere (Mann et al. 2009) SST compilations display obvious positive SST anomalies during the MWP that even exceed the present-day surface ocean temperatures. These basin-scale if not global patterns of outstanding high SST coincide on a local scale with the occurrence (>1100 CE) of an apparent isotopic decreasing trend towards lower $\delta^{18} \mathrm{O}$ values (from $-1.50 \%$ to $-1.70 \%$ ), which indicate a $\sim 1^{\circ} \mathrm{C}$ temperature rise within the south-western Caribbean region. In addition to the $\delta^{18} \mathrm{O}$ record, the enhanced MWP average TEX $X_{86}$ temperatures $\left(28.5 \pm 1.6^{\circ} \mathrm{C}\right)$ and the increasing range of minimum $\left(24.5^{\circ} \mathrm{C}\right)$ and maximum $\left(31.4^{\circ} \mathrm{C}\right)$ temperatures underline not only a rising variability within the south-western Caribbean, but also support the assumption of regional surface ocean warming processes in response to extensive hydro-climate changes. Indeed, foraminiferalbased regional SST records demonstrate higher tropical Atlantic SSTs for the end of the MWP as well (Nyberg et al. 2002; Lund and Curry 2006; Black et al. 2007). It has to be noted that these $\mathrm{Mg} / \mathrm{Ca}$-based SST reconstructions overlap only from 1200 to 1400 CE with the "Great Blue Hole" record. Richey et al. (2007) reconstructed equally high SSTs in the Gulf of Mexico, for the time interval of 600-1000 CE, by using $\mathrm{Mg} / \mathrm{Ca}$ and $\delta^{18} \mathrm{O}$ records obtained from foraminiferal tests. Their data reach only into the early part of the MWP, however, also support the temperature rise that occurs in the wake of extensive hydro-climate changes during 900-1100 CE, based on our proxy records.

The Little Ice Age (1400-1800 CE) is the youngest Common Era cold climate interval that comes along with major changes of basin-scaled if not global climate dynamics. The northern hemisphere (Mann et al. 2009) and global SST syntheses curves (Rosenthal et al. 2017) proclaim for the LIA significant negative global and northern hemisphere SST anomalies with surface ocean temperatures that lie obviously below the present-day conditions. An apparent trend reversal back to cooler water temperatures occurs, especially for LIA times, also in our south-western Caribbean 
$\delta^{18} \mathrm{O}$ curve. This regional cooling trend $\left(\sim 1^{\circ} \mathrm{C}\right)$ is realized by two phases of $\delta^{18} \mathrm{O}$ increase to $-1.50 \%$ and characterized by two positive (1570 CE and $1770 \mathrm{CE}$ ) and negative isotope peaks (1450 CE and 1600 CE). The TEX 86 SST curve (Fig. 10 a) shows at the same time a relatively cooling trend with intercalated warm intervals, in particular, in the early LIA. As a result of these temperature fluctuations, the average LIA SST seems to remain relatively high $\left(28.5 \pm 1.8^{\circ} \mathrm{C}\right)$. The surface ocean temperature was, however, somewhat less variable (minimum: $25.1^{\circ} \mathrm{C}$ and maximum: $30.7^{\circ} \mathrm{C}$ ) as compared to the MWP. Other tropical Atlantic records provide similar evidence for a regional tropical Atlantic LIA cooling, even though this climate change is mainly suspected to be a typical North Atlantic and European feature (Fig. 11). Black et al. (2007) and Saenger et al. (2009) reported a substantial decrease of tropical Atlantic SST posterior to 1500 CE with comparable fluctuations back to warm intercalated periods, remarkably similar to those observed in the "BH6" record. The negative tropical Atlantic SST anomaly during the LIA becomes even more pronounced when considering the data of Haase-Schramm et al. (2005), who found a general SST decrease from $28.5^{\circ} \mathrm{C}$ to $26.0^{\circ} \mathrm{C}$. The stable isotope record of Kuhnert et al. (2002) is a relatively short coral record (1520-1600 CE) but highlights a comparable shift towards lighter oxygen isotope compositions (cooler conditions) during the early-mid LIA.

In general, the Modern Global Warming (MWP) warm climate interval is characterized by positive northern hemisphere (Mann et al. 2008) and global (Rosenthal et al. 2017) SST anomalies. With the beginning of the Industrial Revolution (>1800 CE), an obvious increasing trend in south-western Caribbean SST appeared $\left(\sim 1.3^{\circ} \mathrm{C}\right)$, as reflected by lower $\delta^{18} \mathrm{O}$ values (decrease from $-1.50 \%$ o to $-1.75 \%$ ) and the highest Common Era average TEX ${ }_{86}$ temperatures $\left(28.7 \pm 0.8^{\circ} \mathrm{C}\right)$. All other regional SST records confirm this striking SST rise of tropical Atlantic surface ocean temperatures in succession to the LIA cooling (Fig. 11). Black et al. (2007) and Hetzinger et al. (2008) showed a significant increasing trend since $1900 \mathrm{CE}$. The records of Haase-Schramm et al. (2005), Saenger et al. (2009), DeLong et al. (2014) and Kilbourne et al. (2008) propose a more gradual SST rise starting already around 1800 CE. An interesting difference between the MGW and its most recent past analogue (MWP) is the fact that the maximum surface ocean temperatures of the MGW are lower $\left(29.5^{\circ} \mathrm{C}\right)$, but both 
MGW average $\left(28.7 \pm 0.8^{\circ} \mathrm{C}\right)$ and minimum SSTs $\left(27.5^{\circ} \mathrm{C}\right)$ exceed those of the MWP $\left(28.5 \pm 1.8^{\circ} \mathrm{C}\right.$ and $\left.24.5^{\circ} \mathrm{C}\right)$, respectively. The higher minimum and average MGW temperatures may have resulted from increasing anthropogenic atmospheric greenhouse gas $\left(\mathrm{CO}_{2}\right)$ emissions and related global ocean warming. On a future long-term perspective, the MGW maximum temperatures will certainly exceed those from the MWP, given an ongoing and unchanged anthropogenic influence, even though this hypothesis is still a major topic of the present-day climate debate.

\subsection{Quality check: $\delta^{13} \mathrm{C}$ application as climate proxy}

$\delta^{13} \mathrm{C}$ values of calcareous skeletons are even more challenging to use for past environmental reconstructions than the $\delta^{18} \mathrm{O}$ data. Vital effects, the influence of skeletal growth rates and photosymbionts are for example not assessable within this study, even though these parameters exert a potential important control on $\delta^{13} \mathrm{C}$ values (Wefer and Berger 1991). The carbon isotopic composition may reflect further a mixture of several different climatic and oceanographic signals (e.g., cloudiness, productivity, water depth, cyclone activity, soil-erosion or coastal run-off). The $\delta^{13} \mathrm{C}$ values measured for the "BH6" bulk material vary in the same range $(+2.20 \%$ to $+4.30 \%)$, as expected from modern Belize offshore atoll surface sediments $(+1.00 \%$ and $+5.50 \%$; Gischler et al. 2008$)$, and are thus assuredly applicable as climate and ocean dynamics proxy. Consequently, the discussion of the $\delta^{13} \mathrm{C}$ dataset represents largely a qualitative improvement of previous sitespecific carbon isotope interpretations with a more detailed focus on Common Era climate and ocean dynamics (Anselmetti et al. 2007; Gischler et al. 2008).

\section{4. $\delta^{13} \mathrm{C}$ signals: proxy for TC modulation of soil-erosion/run-off}

The new carbon isotope record, obtained from the "Great Blue Hole" sinkhole archive, shows an overall up-core decreasing trend with three plateaus of constant isotopic composition fluctuations during the RWP (100-500 CE), the DAC (500-900 CE) and the LIA (1400-1800 CE) as well as two distinct intervals of negative $\delta^{13} \mathrm{C}$ trends (Fig. 9). The two prominent $0.5 \%$ drops of $\delta^{13} \mathrm{C}$ values occur during the MWP (900-1400 CE) and the MGW (>1800 CE). Some previous studies (Anselmetti et al. 2007; Gischler et al. 2008) explained such negative excursions and stable plateaus with human deforestation (increased ${ }^{12} \mathrm{C}$ export through soil erosion) and later forest re-growth (attenuated ${ }^{12} \mathrm{C}$ export). However, the cultural rise 
(400-800 CE) of the classical Maya culture and its proliferation phase (650-800 CE), which certainly involved deforestation, are not expressed in the $\delta^{13} \mathrm{C}$ time series. The first negative trend in $\delta^{13} \mathrm{C}$ does, however, in parts overlap with the demise of classical Maya culture (Kennett et al. 2012, Fig. 9), and it could be argued that enhanced deforestation and soil erosion occurred during the final cultural phases, e.g., to increase acreage during crisis. However, the $\delta^{13} \mathrm{C}$ sinkhole sediment signals allow another possible explanation. The two conspicuous negative $\delta^{13} \mathrm{C}$ excursions also overlap, in particular, with times of increased TC activity, whereas the three plateaus coincide with times of decreased Caribbean TC activity (Schmitt et al. 2020a). TC landfalls come with increased precipitation and concurrently enhanced soil erosion and transport of excess ${ }^{12} \mathrm{C}$ to the adjacent marine realm.

Previously investigated multi-annual to annually-resolved south-western Caribbean cyclone archives (Gischler et al. 2008; Denommee et al. 2014; Schmitt et al. 2020a) indicate the highest TC activity during the MGW, medium activity over the LIA, high activity during the MWP and generally low activity throughout the DAC and the RWP times. Other tropical Atlantic cyclone archives from the Bahamas (van Hengstum et al. 2013, 2016; Wallace et al. 2019), North America (Donnelly et al. 2015) or the Lesser Antilles (Woodruffe et al. 2008; Malaize et al. 2013) demonstrate different cyclone activity patterns for the Common Era. Four major TC clusters (Kossin et al. 2010) with different genesis regions, cyclone tracks and landfall sites affect these various circum-Caribbean localities to large parts independently from each other (Schmitt et al. 2020a). This framework causes large spatial and temporal TC activity variations between south-western Caribbean, north-western Caribbean, North American and Lesser Antilles cyclone archives. It is, therefore, not meaningful to consider archives that do not belong to the wider Belize area, in order to verify a connection of enhanced south-western Caribbean storminess during the MWP and MGW climate intervals and site-specific negative carbon isotope excursions. Still, future projects may confirm the hypothesis of high TC activity intervals causing carbon isotope composition drops in sinkhole archives by establishing similar records in other tropical Atlantic regions with temporally different high activity intervals.

Based on our observations in the south-western Caribbean Blue Hole record, we suggest that intensified Atlantic storminess could have led to a substantial terrestrial 
carbon export into coastal ocean regions. Cherubin et al. (2008) discussed that the Belize offshore atolls are only influenced by low amounts of fluvial input and dust deposition of terrestrial material due to the great distance to the coast $(60-80 \mathrm{~km})$ and the protected offshore position behind the Mesoamerican Barrier Reef System. The generally low $\mathrm{Fe} / \mathrm{Ca}$ and Ti/Ca ratios $(<0.0025)$ measured in the "BH6" sediment core support both a weak river-run-off sinkhole connection and low rates of dust accumulation. At times of especially high TC-activity, extensive storm waves and surges cause severe disturbance on the flat coastal areas. This destructive reworking of terrestrial material in combination with large amounts of precipitation likely induces an elevated rate of soil erosion, a strengthening of coastal run-off processes and a higher terrestrial material input into and transport throughout the coastal ocean. The accompanying increased input of ${ }^{13} \mathrm{C}$-depleted terrestrial carbon and soil material is, as a result of cyclone activity variations, likely reflected in carbon stable isotope and XRF records by significant negative carbon excursions and positive Fe and Ti peaks, respectively.

The two plateaus with constant fluctuating $\delta^{13} \mathrm{C}$ values spanning the RWP and DAC could be best explained following this argumentation by a low TC activity regime that occurred during the first half of the Common Era (Schmitt et al. 2020a). The first $0.5 \%$ decrease of $\delta^{13} \mathrm{C}$ values is assuredly attributable to an increase of southwestern Caribbean cyclone activity that appeared in succession to the onset of the MWP climate variation (Schmitt et al. 2020a). The effect of enhanced soil-erosion rates and stronger run-off processes onto carbon stable isotope signatures was likely reinforced by previously occurring changes of vegetation and agriculture in response to Maya culture development. Basin-scale climate variations are certainly more effective to cause such a striking signal than spatially restricted deforestation effects. The negative carbon isotopes excursion during the MWP was certainly not caused by changes in productivity (Fig. $13 \mathrm{c}$ ), considering the measured $\mathrm{Cu} / \mathrm{Al}$ ratios, which lack distinct evidence for related productivity variations. The sediment composition and structure of the core does also not support a significant change in trophic state, carbon recycling and methanogenesis in the "Great Blue Hole". We also can rule out substantial changes in deep water upwelling and introduction of isotopic light carbon from depth. The positive peaks in the $\mathrm{Ti} / \mathrm{Ca}$ and $\mathrm{Fe} / \mathrm{Ca}$ ratios around 1200-1500 CE and 1300-1600 CE could be a further evidence for higher input of terrestrial soil 
material, associated with increased export of isotopically light organic carbon from the adjacent continent during frequent cyclone landfalls (Fig. $13 \mathrm{c}$ ). The $\mathrm{Fe} / \mathrm{Ca}$ and Ti/Ca proxy signals could be, however, overprinted by Saharan dust input. The transport of Saharan dust into the Caribbean region is primarily controlled by tele-connections to the Azores and Hawaiian Highs (Doherty et al. 2008). In particular, the boreal winter connection to the NAO mode is a potential explanation for the obvious peaks in the $\mathrm{Fe} / \mathrm{Ca}$ and $\mathrm{Ti} / \mathrm{Ca}$ records during the MWP. The persistent and simultaneous incredibly positive NAO anomaly during the MWP (Trouet et al. 2009) could have been the control mechanism, which created a suitable trade wind strength and trajectory for enhanced Saharan dust transport and thus higher $\mathrm{Fe}$ and $\mathrm{Ti}$ abundances. With the available data, we can only propose this qualitative model, but future work could explore this possible link using more targeted analytical approaches capable of tracing dust sources. The subsequent $\delta^{13} \mathrm{C}$ plateau with constant fluctuating values is probably the result of the LIA climate variation that includes a weakening of the cyclone influence back to moderate activity. The two positive excursions around $1350 \mathrm{CE}$ and $1450 \mathrm{CE}$ are interpreted as artefacts caused by the atypical sediment characteristics of two very thick erosional TC-strikelayers rich in Halimeda fragments. The positive $\delta^{13} \mathrm{C}$ values likely reflect increased aragonite contents due to more than $60 \%$ coral and Halimeda constituents. We attribute the second drop of $0.5 \%$, starting around $1900 \mathrm{CE}$, with regard to the previous work (Gischler et al. 2008), to the "Suess effect". The high cyclone activity during the MGW and inherent precipitation and coastal run-off could be an additional, plausible explanation for the second $0.5 \%$ decline of carbon isotope compositions, following our argumentation above.

\subsection{Cyclicity in time series and AMO control on SW-Caribbean SST}

Decadal to centennial cycles have been identified previously in the Cariaco Basin (Haug et al. 2003), in lakes of the northern Yucatan Peninsula (Hodell et al. 2001) and on Great Bahama Bank (Roth and Reijmer 2005). These results illustrate, together with periodicities obtained by Gischler et al. (2008), that periodic proxy signal fluctuations may reflect cyclic changes of the major Caribbean climate drivers. The $\delta^{18} \mathrm{O}$ time series of the core "BH6" exhibits an obvious secondary multi-decadal cyclicity ( 50 year; Fig. 8 ). We analysed our data sets by means of wavelet power spectra to identify such climate mode periodicities. The climate phenomena of AMO 
and ENSO seem to be appropriate drivers for the multidecadal south-western Caribbean $\delta^{18} \mathrm{O} / \mathrm{SST}$ variation. The multidecadal cyclicity of 32-64 years detected in the $\delta^{18} \mathrm{O}$ power spectra are either the result of AMO mode variations, or the result of 50-70 years long ENSO amplitude changes (Klotzbach 2011). The periodic 40-70 years AMO cycles are attributable to velocity fluctuations of the thermohaline circulation (Latif et al. 2004; Dijkstra et al. 2006). The thermohaline circulation exerts thus not only a control on heat-transfer rates between the tropical Atlantic $\left(0^{\circ}\right)$ and the north Atlantic $\left(60^{\circ}\right)$, but also induces multi-decadal patterns and anomalies of regional SSTs in response to its periodic fluctuation (Kerr 2000). The connection of SST and AMO mode variations is verified and well understood as a natural driver of multi-decadal temperature variability (Frajka-William et al. 2010) and TC activity (Schmitt et al. 2020a) within the Instrumental Era. The variation in the strength of the thermohaline circulation during positive/negative AMO phases (AMO+/AMO-) could be also an important control mechanism on longer timescales, which causes the multi-decadal occurring secondary $\delta^{18} \mathrm{O}$ fluctuations in the Belize sinkhole records. The lack of intra-decadal (5-8 years) ENSO signals (Burn and Palmer 2015) is another indirect argument for the proposed AMO control. Intra-decadal ENSO variations are closely linked to the multi-decadal ENSO amplitude variation. If the observed multi-decadal signals were really attributed to ENSO amplitude variations, then intra-decadal signals would have been detected also in the $\delta^{18} \mathrm{O}$ time series by using a wavelet analysis. The apparent multi-decadal composition changes of oxygen isotopes are for these reasons at best an unprecedented perspective of AMO control spanning nearly the Common Era. Solar irradiance cycles, detected in the "Great Blue Hole" record (Gischler et al. 2008), seem to be more important shaping the primary long-term signal (centennial/millennial) and rough SST trends and anomalies in coherence with Common Era climate variability and climate phenomena responses. The longer periodicity of 128-256 years, detected in the $\delta^{18} \mathrm{O}$ time series, indicates a possible connection to centennial-scale solar cycles. It likely corresponds to the 80-120 year "Gleissberg Cycle" detected by Roth and Reijmer (2005) in Great Bahama Bank slope sediments.

\subsection{Conceptual Common Era climate model: a comparative view}

External changes in solar irradiance have been identified as a potential trigger of Common Era climate variations (Crowley 2000) and considered as a major driver for 
global air and surface ocean temperature modulation (Biktash 2017). The knowledge about volcanic forcing as another potential natural driver of Common Era climate variability has increased over the last years of climate research. Both climate forcing mechanisms are closely affiliated with each other. Volcanic forcing may alter solar insolation during high activity intervals by enhanced sulphate aerosol injections into the stratosphere, which shield the earth surface from incoming solar radiation (Robock 2000). The interplay of solar and volcanic forcing consequently causes global and regional cooling tendencies and modulates thus air- and surface oceantemperature variability from inter-annual to centennial time scales (Sigl et al. 2015). Both climate driver mechanisms have in common that they cause subsequent feedbacks of several climate phenomena (Velasco and Mendoza 2008). The development of a conceptual model, in which we consider a coherence of coupled solar and volcanic forcing mechanisms as well as the caused responses of climate modes (e.g., AMO, NAO, ENSO), is a meaningful way to decipher the causes and characteristics of the Common Era SST variability. We qualitatively compared longterm patterns of these climate modes (Fig. $14 \mathrm{c}, \mathrm{d}$, e) with our two SST records (Fig. $14 \mathrm{a}$ ) back to the onset of the DAC (500 CE), in order to identify the key mechanisms, which maintain the dynamic changes of the externally initiated climate variations.

A phase of strong tropical and high-latitude volcanic activity (500-600 CE) likely triggered the onset of the DAC (Sigl et al. 2015). The compiled global SST reconstruction of Rosenthal et al. (2017) indicates a global negative SST anomaly during the $6^{\text {th }}$ century, in all likelihood forced during this century of highly active volcanism. High amounts of global aerosol injections would certainly have exercised also control on regional SST patterns. Our oxygen isotope record provides evidence for a south-western Caribbean cooling of $0.3^{\circ} \mathrm{C}$ from 500 to $600 \mathrm{CE}$, emphasized by a $0.05 \%$ shift towards a heavier isotopic composition. A temporally limited and volcanically forced cooling at the beginning of the DAC is not sufficient to explain the subsequent fluctuation of the $\delta^{18} \mathrm{O}$ values with constant amplitudes around $-1.50 \%$ and persistently decreased SSTs until $900 \mathrm{CE}$. The continuation of a regional negative SST anomaly may, however, be satisfactorily explained by considering climate mode responses in the mid and late DAC. The DAC coincides with a slightly 


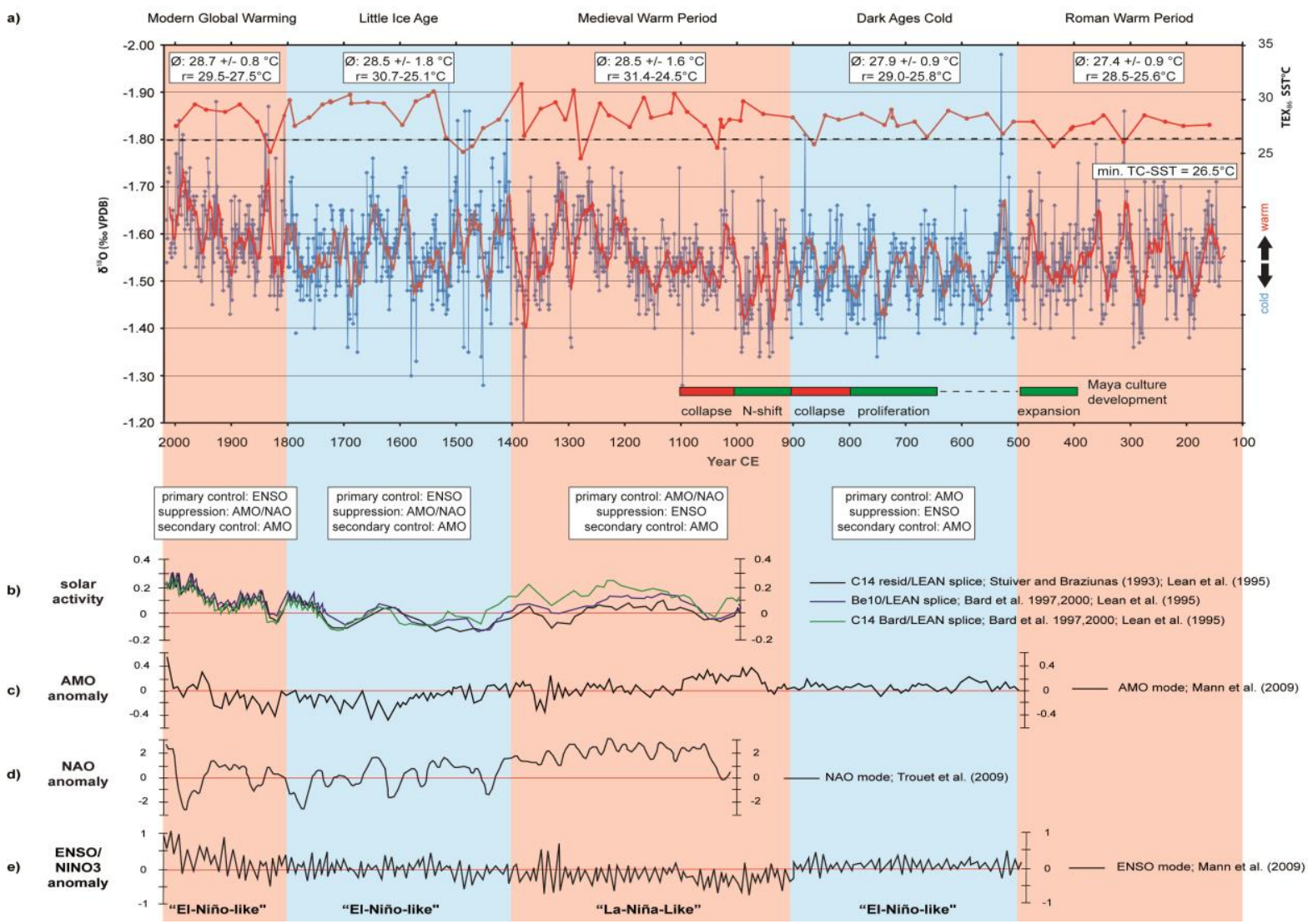

Figure. 14. (a) Combination of $\delta^{18} \mathrm{O}$ (relative SST curve) and TEX $\mathrm{X}_{86}$ (absolute SST curve) time series. Note that the $y$-axis is reversed. The horizontal dashed black line indicates the boundary condition of $26.5^{\circ} \mathrm{C}$, which is of great importance for tropical cyclone formation and a further quality assurance of the presented TEX ${ }_{86}$ SST reconstructions. The timing of Maya culture development status (bar chart) is based on the study of Kennett et al. (2012). The TEX ${ }_{86}$ SST values in the upper white boxes are averages $(\varnothing)$ over the individual Common Era climate intervals. The observed SST range $(r)$ is shown in the same boxes with regard to $\mathrm{min} / \mathrm{max}$ temperatures. The white boxes beneath the SST record include a conclusion of the primary climate modes control, shaping the SST pattern on centennial scales, the suppressed climate modes influence and the secondary control of climate modes affecting the SST pattern on a multi-decadal time scale. (b) Solar activity reconstructions including C14 resid/LEAN splice (Stuiver and Braziunas 1993; Lean et al. 1995), Be10/LEAN splice (Lean et al. 1995; Bard et al. 1997, 2000) and C14 Bard/LEAN splice (Lean et al. 1995; Bard et al., 1997, 2000). (c) Reconstruction of Atlantic Multidecadal Oscillation (AMO) following Mann et al. (2009). (d) North Atlantic Oscillation (NAO): boreal winter reconstruction following Trouet et al. (2009). (e) El-NiñoSouthern Oscillation (ENSO)/NINO3 SST reconstruction following Mann et al. (2009).

positive long-term AMO phase (Fig. 14 c) and persistent "El-Niño-like" conditions (positive NINO3 region SST anomaly; Fig. 14 e). In particular, such long-time stable "El-Niño-like" conditions should actually induce a positive regional SST anomaly in the tropical western Atlantic as suggested by Park and Li (2019). These authors discussed in detail an interacting teleconnection between Pacific ENSO and Atlantic AMO modes, which could help to solve the SST-related discrepancy. A major point of their discussion includes an ENSO influence weakening in the tropical western 
Atlantic during positive AMO phases. A possible explanation for the maintenance of a decreased SST pattern could be a primary control of a long-term positive AMO mode, which accompanies a suppression of the ENSO modulation and constantly low SSTs. Multi-decadal oscillations between positive and negative AMO phases within this long-term positive AMO mode are likely the reason for the multi-decadal fluctuations of the oxygen isotopes composition, which indicate multi-decadal temperature variability modulation. The related strong impacts of a high volcanic activity interval, which certainly caused significant changes in the Caribbean hydroclimate, could probably have been one prerequisite for an unfavourable climate situation and the reason for a minor decline of the Classic Maya Culture (500-600 CE), subsequently to a first expansion phase (400-500 CE; Kennet et al. 2012). A more favourable climate situation posterior to $600 \mathrm{CE}$, indicated by stable surface ocean temperatures, low amplitude SST fluctuations, a low and constant TC activity regime (Schmitt et al. 2020a) and generally higher precipitation rates (Kennett et al. 2012), could be a causative explanation for the following proliferation phase of the Classic Maya Culture (650-800 CE).

The onset of the MWP ( $>900 \mathrm{CE}$ ) was likely associated with high rates of positive net radiative forcing (Fig. 14 b), increased solar activity (Crowley 2000) and reduced tropical and high-latitude volcanic activity (Sigl et al. 2015). Such conditions could have been the origin of extensive hydro-climate changes, including both a global ocean heating, as for example indicated by outstanding high positive global (Rosenthal et al. 2017) and northern hemisphere (Mann et al, 2008) SST anomalies. On a regional scale, a positive western tropical Atlantic SST anomaly is verifiable by several circum-Caribbean proxy records (see Fig. 11 b-d) including those from the "Great Blue Hole". Decreasing $\delta^{18} O$ values towards an isotopically heavier composition and increasing $\mathrm{TEX}_{86}$ temperatures reflect a positive regional SST anomaly that comes along with a temperature rise of $0.6^{\circ} \mathrm{C}-1^{\circ} \mathrm{C}$ and a concurrently higher temperature variability. A particularly strong heating of the extra-tropical Pacific Ocean favours long-term stable and strong "La-Nina-like" conditions (Fig. 14 e), which in turn should theoretically induce a negative tropical western Atlantic SST anomaly, following the argument of Park and Li (2019). The reorganisation of the ENSO dynamics contains, however, additionally other important modifications in the northern hemisphere atmosphere circulation (e.g., strengthening of westerly winds; 
weakening of the trade wind system) that exerted control on south-western Caribbean SST (Gray 1984). These modifications interacted over an Atlantic airpressure gradient feedback with velocity variations in the North Atlantic thermohaline circulation (Denommee et al. 2014). The occurrence of substantially positive longterm NAO and AMO modes elucidates this crucial ocean-atmosphere feedback and ENSO tele-connection (Fig. $14 \mathrm{c}$, d). The positive tropical Atlantic SST anomaly during the MWP was for this reason maintained by the dominance of obviously positive AMO (Wang et al. 2017) and NAO (Trouet et al. 2008) modes (positive SST anomaly), which superimposed the ENSO modulation (negative SST anomaly) in an even stronger manner as observed during the DAC climate interval. The secondary level of SST variability is continuously controlled by multi-decadal AMO phase oscillations, however, characterized through larger amplitudes. Rising SSTs, enhanced surface ocean temperature variability and an overlap with a high TC activity regime (Denommee et al. 2014; Schmitt et al. 2020a) apparently had strong impacts on the Maya culture, in addition to a general aridification trend (800-1100 CE; Kennett et al. 2012). Repeated droughts between 800 and $1100 \mathrm{CE}$ have been previously blamed as one possible explanation for the first major collapse of the classic Mayan civilization (800-900 CE) and the subsequent northward migration period (900-1000 CE; Hodell et al. 1995, 2001; Rosenmeier et al. 2002; Haug et al. 2003; Kennett et al. 2012). A more active south-western Caribbean TC activity regime may be, in accordance with the above-described ocean and climate dynamic changes, another plausible and supplementary explanation in addition to the drought periods model. The TC activity shifted within the early MWP (900-1100 CE) from an inactive towards an active state (Schmitt et al. 2020a). More frequent TC landfalls in the Maya Lowlands likely caused heavy destruction and flooding and might have contributed to the stress during drought phases further pushing the Maya civilization towards its final decline (1000-1100 CE).

The LIA climate change is presumably a response to lower solar irradiance (Crowley 2000) or two distinct phases of enhanced global volcanic activity (Miller et al. 2012). Both mechanisms are causative with regard to global cooling effects in particular at the beginning and at the end of the LIA (Brönnimann et al. 2019), which is also indicated by negative global and northern hemisphere SST anomalies (Mann et al. 2009; Rosenthal et al. 2017). Enhanced volcanic activity on its own may have acted 
as a trigger of the LIA climate change, independent of the precondition that the orbital configuration of the earth favours also low solar insolation. The latter assumption is supported by a coincidence of the LIA onset with the most active volcanic halfcentury of the past millennium (Miller et al. 2012). The LIA climate variation was, considering the importance of periodic solar cycles, likely initiated by a combination of both forcing mechanisms and again maintained by ocean and climate mode feedbacks. Several circum-Caribbean SST records (e.g., Haase-Schramm et al. 2007; Black et al. 2007; Saenger et al. 2014; Tierney et al. 2015) collectively verify a conspicuously negative tropical Atlantic SST anomaly. Such an explicit LIA cooling is at first glance however, not detectable in the "Great Blue Hole" SST records. The $\delta^{18} \mathrm{O}$ record indicates still a distinct multi-decadal fluctuation and demonstrates in fact two phases of cooling $\left(\sim 0.2 \%=\sim 1^{\circ} \mathrm{C}\right)$ interrupted by erratic warm intervals with similarly increasing SSTs back to the initial conditions. Such ups and downs certainly contribute to an obliteration of a distinct LIA cooling trend, as seen in some of the above cited studies. The obliteration of the cooling trend could also be the result of another reorganisation of ocean-atmosphere dynamics towards more "El-Niño-like" conditions, considering the tele-connection to persistent negative AMO and NAO modes (Mann et al. 2009; Trouet et al. 2009). A weaker AMO and NAO control reinforces the influence of the ENSO modulation (Park and Li 2019), which in turn favours the potential of positive tropical western Atlantic SST anomalies despite a global cooling trend. This reinforced ENSO overprint may thus have affected the long-term SST pattern as a primary control mechanism during the LIA and likely contributed to diminish the stronger global cooling trends. The previously enhanced roles of the AMO and NAO modes conversely decreased, through the described ENSO modulation. The secondary multi-decadal temperature variability is, however, still largely controlled over AMO phase variations.

The MGW climate variation (>1800 CE) is either the result of natural, high solar irradiance rates (Fig. 14 b) and climate mode maintenance or caused by anthropogenic forcing and the amplification of climate mode influence. In either case, both scenarios cause strong ocean heating processes, as indicated by obvious positive SST anomalies obtained from all considered global, northern hemisphere and regional SST records (Fig. 11). If we assume a natural control of SST patterns, then strongly positive "El-Niño-like" conditions would favour the development of a 
substantially positive tropical western Atlantic SST anomaly. A simultaneously occurring negative $\mathrm{AMO}$ anomaly would then underline the importance of an ongoing primary ENSO control. The present situation is, however, probably simply a result of anthropogenic forcing considering the conspicuous amplification of AMO, NAO and ENSO indices during the 20th century. Following the second scenario of anthropogenic forcing, the positive SST anomaly would be attributable to global ocean heating and subsequent strengthening of climate-mode influence, which originates from a reinforcement of solar insolation by rising atmospheric carbon dioxide concentration.

\section{Conclusions}

We created a south-western Caribbean SST reconstruction by a combination of relative $\delta^{18} \mathrm{O}$ and absolute TEX $\mathrm{X}_{86}$ values and suggest that long-term SST patterns and short-term temperature variability were modulated on two temporal levels during the Common Era. Changes in solar and volcanic activity triggered climate changes, which in turn caused climate phenomena responses of ENSO, NAO and AMO modes. Their changing mode of action has been identified as the origin of the primary and centennially scaled SST changes visible in the $\delta^{18} \mathrm{O}$ and TEX 86 records. We identified long-term positive AMO and NAO modes as the primary key control mechanisms of the regional conditions during the DAC and the MWP and determined the ENSO mode modulation as the primary natural control of those during the LIA and the MGW. The new data obtained from the Belize "Great Blue Hole" indicate further a striking secondary control of south-western Caribbean SSTs on multidecadal time scales, which is apparent in the $\delta^{18} \mathrm{O}$ curve. SST variations occur with 32-64 years periodicity and are best described by the cyclic AMO phase variation of 50-70 years. The study enhances thus the understanding of AMO as an important multi-decadal control factor of Caribbean SST over the Common Era, which has not been identified in this resolution and length in all previous studies. The presented $\delta^{13} \mathrm{C}$ curve provides first evidence to use the long-term carbon stable isotope record of the "Great Blue Hole" as a south-western Caribbean ocean-atmosphere dynamics proxy, in response to storm-enhanced coastal run-off/soil erosion processes. However, more research on $\delta^{13} \mathrm{C}$ signals is necessary in sinkhole settings to validate this approach. If we consider the Common Era as reference frame to demonstrate climate variability effects on the modern human society, the MWP will be the best 
available natural reference. Interestingly, the $\delta^{18} \mathrm{O}$ values are characterized in both the MWP and the MGW by a remarkably similar range. The MWP obviously exceeded its present-day analogue in terms of maximum south-western Caribbean SST and natural temperature variability. Cyclone activity was likely the same comparing both climate intervals. However, the average and minimum SSTs were higher within the MGW. We expect a future increase of maximum SST to the MWP level and possibly beyond, a further increase of average surface ocean temperatures and even a further decrease of temperature variability, all because of the modern global climate crisis. The temporal and spatial coincidence of Classical Maya culture demise and the occurrence of extensive environmental changes during that time (e.g., first peak cyclone activity, maximum SST, highest SST variability and dry conditions) remind us not to underestimate global hazards and societal risks of the MGW crisis especially for Caribbean and adjacent populations. 


\section{CHAPTER 4:}

\section{FAZIES MANUSCRIPT}

\section{"Holocene sediments of an inundated sinkhole - facies analysis of the Great Blue Hole, Lighthouse Reef, Belize"}

\section{Abstract}

Anoxic sinkholes are unique geomorphological features of modern reef systems and in terms of "lake-like" sediment successions very special marine depositional environments. This study presents results of a sedimentological survey, which focuses on the "Great Blue Hole", a circular Pleistocene karst cavity, situated in the shallow eastern lagoon of Lighthouse Reef Atoll (Belize, Central America). The investigated Blue Hole is located within the tropical cyclone belt and acts as consequence of its unique geomorphology as a giant sediment trap for both fairweather and storm sedimentation. As an important innovation step, we applied a multi-proxy approach based on textural, compositional and geochemical data to ensure a more reliable differentiation between sediments with fair-weather and storm condition affiliation. Sediments having formed under both conditions were texturally categorized by determination of classical sedimentary parameters such as mean grain size and sorting. Sediment composition has been quantified in thin-sections based on 40 samples discretely taken along a core from the bottom of the $125 \mathrm{~m}$ deep and $320 \mathrm{~m}$ wide cavern. Classification of sedimentary facies follows a modified scheme for unconsolidated carbonate sediments based on the Dunham nomenclature. Fair-weather sediments are generally finer than $20 \mu \mathrm{m}$ and consist on average of $81 \%$ carbonate fine material, $12 \%$ Halimeda platelets, $3 \%$ coral fragments, $2 \%$ organic material, $1 \%$ mollusc shells, $1 \%$ foraminifer tests, and minor portions of coralline red algae and echinoderm plates (0-1\%). Intercalated event bed sediments are coarse-silt to sand-sized $(>20 \mu \mathrm{m})$ and differ in terms of generally lower fine carbonate material amounts $(50 \%)$ and increased abundances of overwashed Halimeda platelets (28\%) and coral fragments (6\%). Combined analyses of this study have revealed four primary sedimentary facies with affiliation either to the background (mudstone) or cyclonic event sedimentation (Halimeda wackestone, algae-rich packstone, coralgal rudstone) as well as a transitional sub-facies indicating 
storm-induced background overprinting (background wackestone). The striking compositional and textural differences of the Halimeda wackestone, algae-rich packstone and coralgal rudstone facies are considered to be another helpful (semi)quantitative proxy to identify event beds of tropical cyclones in unconsolidated sinkhole sediment successions.

\section{Introduction}

Blue Holes are small-scaled inundated sinkholes characterized by "lake-like" sedimentary dynamics. Therefore, they are special and concurrently unique marine depositional environments (Yao et al. 2020). Anoxic sinkholes may include annually layered bottom sediments ("varves") well suited for a wide range of geo-scientific surveys addressing both sedimentary and paleoclimate objectives. Studies concerning sediment composition and temporal facies patterns of sinkhole sediment successions in reefal carbonate systems are largely lacking in the south-western Caribbean. Some previous studies of sinkhole sediment successions from the wider Yucatán region are generally of qualitative and descriptive nature and largely focus on their use as paleo-cyclone (Brown et al. 2014) and paleo-climate (Gischler et al. 2008) records. This sedimentological survey primary concentrates on quantification of sinkhole sediment components and identification of sedimentary facies.

The "Great Blue Hole" is a circular and inundated Pleistocene karst cavity, situated in the shallow eastern lagoon of Lighthouse Reef Atoll (Belize, Central America, Fig. $15 \mathrm{c}$ ). The sinkhole is located within the Atlantic tropical cyclone belt and acts due to its special geomorphological shape as a giant natural sediment trap for both fair weather and storm sedimentation. The available accommodation space of the $125 \mathrm{~m}$ deep, $320 \mathrm{~m}$ wide, and anoxic sinkhole (Fig. $15 \mathrm{f}$ ) is consequently filled with several meters $(>8 \mathrm{~m})$ of undisturbed Holocene and underlying, as yet unknown portions of Pleistocene carbonate sedimentary sequences (Gischler et al. 2013). A constant input of fine carbonate material with seasonally varying contents of organic material (varved background sedimentation) usually backfills the interior of the cave under fair-weather conditions (Gischler et al. 2008). Tropical cyclones repeatedly passing over Lighthouse Reef are a contrasting and profound disruption of the fair-weather background sedimentation. Such storm systems either mobilize coarser carbonate particles from the eastern marginal reef rim and the eastern lagoon floor (storm surge/wave suspension) or cause a sediment slope collapse at 
the top of the sinkhole (downslope density flow; Brown et al. 2014). This storminduced over-wash deposition results in the formation of coarse and yellow-brown coloured event beds, which sharply intercalate the annual-layered, greenish background sediment deposits (Fig. 15 e).
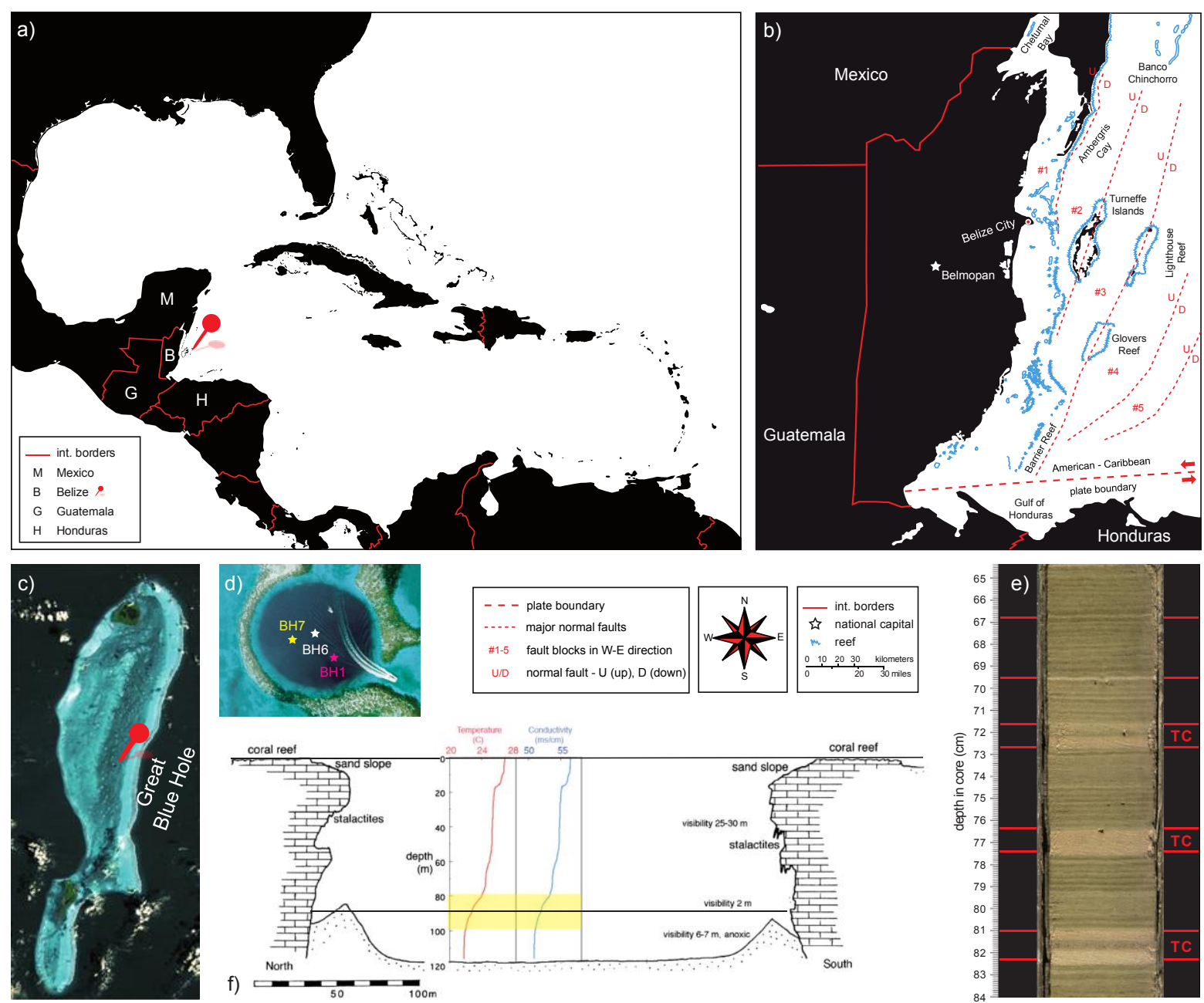

Figure 15. (a) Geographical overview illustrating the position of Belize in the south-western Caribbean. (b) Simplified geological and tectonic map of Belize and its structural influence on reef formation. (c) Open access ASTER satellite image of Lighthouse Reef (https://asterweb.jpl.nasa.gov) supplied by Japan Space Systems, and U.S/Japan ASTER Science TEAM (NASA/METI/AIST/). Location of the "Great Blue Hole" is highlighted within the eastern lagoon. (d) Aerial view taken from a previous study (Gischler et al., 2008) indicating the position of investigated "Great Blue Hole" sediment cores BH1 $\left(17^{\circ} 18.943^{\prime} \mathrm{N}, 87^{\circ} 32.071^{\prime} \mathrm{W}\right)$, BH6 $\left(17^{\circ} 18.957^{\prime} \mathrm{N}, 87^{\circ} 32.098^{\prime} \mathrm{W}\right)$ and $\mathrm{BH} 7\left(17^{\circ} 18.950^{\prime} \mathrm{N}\right.$, $87^{\circ} 32.118^{\prime} \mathrm{W}$ ). (e) Core photo (interval BH1: $65.0-84.0 \mathrm{~cm}$ ) of the undisturbed sediment succession comprising fine-grained, yellow-brown/green laminated couplets of fair-weather sediments and five intercalated coarser sandy cyclonic event beds (TC). (f) Schematic cross-section of the sinkhole with temperature and conductivity profiles (Gischler et al. 2008). Temperature and conductivity decrease significantly between $80-100 \mathrm{~m}$ depth; bottom water below ca. $90 \mathrm{~m}$ is anoxic (Gischler et al. 2013). All maps were produced by digitizing northward-directed open access satellite images and by using the vector graphic software Adobe Illustrator CS4 V.14.0. We acknowledge the use of imagery from the NASA Worldview application (https://worldview.earthdata.nasa.gov), part of the NASA Earth Observing System Data and Information System (EOSDIS). 
The Holocene sediment succession of the "Great Blue Hole" has been previously used successful, due to the lack of bioturbation, as a multi-annual climate (Gischler et al. 2008) and tropical cyclone archive (Denommee et al. 2014). Our sediment composition and facies analysis presented here is closely connected to two recently published studies, which provide continuous and annually-resolved cyclone activity (Schmitt et al. 2020a), sea surface temperature (SST) and Atlantic Multidecadal Oscillation (AMO) reconstructions (Schmitt et al. 2020b) for the past 1885 years of the Common Era (0 CE-present). The development of an annually resolved, multiproxy tropical cyclone identification approach is an important and innovative step in contrast to the previous and lower resolution studies (Gischler et al. 2008, Denommee et al. 2014).

A still disregarded element within the recent project is the lack of quantitative data with regard to sinkhole sediment composition, sedimentary facies identification and their long-term variation patterns over Common Era time-scales. All the abovementioned studies have described the bipartite stratigraphy of the "Great Blue Hole" sediment trap only qualitatively in terms of general differences (background vs. event) and superficially on the basis of quantitative textural data (grain size and layer thickness measurements). The majority of existing and comparable quantitative sediment facies analyses focuses on sediments of the classic tropical Atlantic research regions of the north-western Caribbean, i.e., the Florida Reef Tract (Ginsburg 1956; Enos 1974; Enos and Perkins 1977; Gischler et al. 2017a) and the Bahamas (Purdy 1963; Milliman 1967; Reijmer et al. 2009; Rankey and Reeder 2010). Quantitative sediment facies analyses related to the south-western Caribbean are, in addition to the above-mentioned studies, spatially limited to small and isolated carbonate platforms (Milliman 1969), the Mesoamerican Barrier Reef complex (Purdy and Gischler 2003) and Roatan Island, Honduras (Schmitt and Gischler 2017). The aim of all these studies was to focus on spatial facies patterns of modern surface sediments without considering temporal facies distributions obtained from subsurface sediments.

The investigation of temporal sediment composition and facies patterns presented here is not only an important aspect to understand the long-term sediment dynamics in under-explored sinkhole environments, but also an approach to better understand the connection of surface sediment composition and sediment trap deposition in 
closely linked depositional environments. Textural and compositional characteristics of event bed deposits have been additionally tested in this survey to be another proxy in the framework of tropical cyclone identification. As a general approach, it was presumed that the Holocene sediment succession of the "Great Blue Hole" is in terms of sediment composition very similar to the modern surface sediments of Lighthouse Reef atoll. Skeletal debris of Halimeda, coralline red algae, molluscs, foraminifers, corals and echinoderms are the major surface sediment components besides minor constituents of organic and non-skeletal particles (Gischler 1994; Gischler and Lomando 1999; Gischler and Zingeler 2002). Statistical analyses of various reefal carbonate sedimentation sites verified significant differences in marginal reef and lagoon sediment composition (Gischler and Lomando 1999; Schmitt and Gischler 2017). The average composition of the intercalated event beds likely differs in a similar way from those of the varved background sedimentation sections of sinkhole bottom deposits. Composition of storm-induced over-wash sediments should reflect more likely the marginal reef composition (increased content of coral and coralline algal fragments and Halimeda chips) than the adjacent lagoon composition (dominated by mollusc, foraminifer and Halimeda fragments), which is assumed to be more similar to the background sedimentation.

\section{Setting}

\subsection{Geography and geomorphology}

Lighthouse Reef $\left(17^{\circ} 17^{\prime} 56^{\prime \prime} \mathrm{N}, 87^{\circ} 32^{\prime} 34^{\prime \prime} \mathrm{W}\right)$ is located $80 \mathrm{~km}$ offshore of the coastline of the Central American country of Belize $\left(16^{\circ} \mathrm{N}\right.$ to $18^{\circ} 30^{\prime} \mathrm{N}, 87^{\circ} 30^{\prime} \mathrm{W}$ to $89^{\circ} 30^{\prime} \mathrm{W}$ ) (Fig. 15 a). Lighthouse Reef is the smallest offshore atoll $\left(200 \mathrm{~km}^{2}\right)$ and part of the longest modern tropical reef system in the Atlantic Ocean (Stoddart 1962). The Belize Barrier Reef covers a north-south distance of $\sim 250 \mathrm{~km}$ and runs roughly parallel to the passive continental margin (Fig. 15 b). Lighthouse Reef is characterized by a continuous seaward and discontinuous leeward surface-breaking reef rim (Fig. $15 \mathrm{c}$ ). The eastern lagoon is up to $9 \mathrm{~m}$ deep and separated from the shallower western lagoon $(3 \mathrm{~m})$ by an almost $20 \mathrm{~km}$ long patch reef chain.

In the "Great Blue Hole", an extensive flooded cave system, several giant 2-3 m long stalactites have been discovered below $50 \mathrm{~m}$ water depth by several diving explorations (Jones et al. 2002). The stalactites formed subaerially during Pleistocene sea-level lowstands, continued to accrete after transgressive marine 
flooding and thus represent impressive archives for the karst and flooding history of the former terrestrial cavern (Dill et al. 1998; Gischler et al. 2017b). The cylindrical shape of the sinkhole likely results from a roof collapse (Dill 1977). Its upper edge is currently almost completely surrounded by coalesced coral patch reefs (Fig. $15 \mathrm{~d}$ ) except for two channels in the north and east connecting the sinkhole interior with the eastern lagoon (Gischler et al. 2013). Inside the reef rim, there is a $30^{\circ}$ inclined coarse sediment slope transitioning at $10 \mathrm{~m}$ depth to a nearly vertical cave wall with several overhangs (Fig. 15 f). The water conditions below $90 \mathrm{~m}$ depth (thermocline and pycnocline) are anoxic (Dill 1977). As a consequence, the Holocene sediment succession is not disturbed by bioturbation, allowing its use as unique long-term climate archive with "lake-like" sedimentation continuity and annual resolution (varves).

\subsection{Quaternary reef formation}

Lighthouse Reef is situated next to an active strike-slip zone along the Caribbean and North American plate boundary (Fig. 15 b). Five NNE-trending major normal faults branch off from this active plate boundary and represent key tectonic elements that shape the basement of the passive Central American continental margin. The hanging walls of three of these fault blocks (Dillon and Vedder 1973) provide the pedestal for Quaternary reef formation.

Purdy (1974) described the important role of the antecedent topography for reef growth initiation, which was additionally influenced and formed by means of fluvial, siliciclastic sedimentation and karst processes during Pleistocene sea-level lowstands (Choi and Ginsburg 1982; Esker et al. 1998; Ferro et al. 1999). Holocene reef growth started at the Belize Barrier Reef and offshore atolls between 8.2-7.8 kyr BP (Gischler and Hudson 1998, 2004) on top of former Pleistocene reefs and topographic highs, as a consequence of Holocene sea-level rise. In the offshore atolls, lagoon inundation has been dated to 8.5-6.0 kyr BP (Gischler 2003).

\subsection{Climate and oceanography}

Belize is located in a subtropical and trade wind affected climate zone. The average annual air temperatures vary seasonally from $24^{\circ} \mathrm{C}$ (winter) to $30^{\circ} \mathrm{C}$ (summer). Trade winds blowing from east (January-April) to northeast (July-December) dominate the atmospheric circulation system and the climate for most of the year. Two important 
atmospheric phenomena disturb the normal trade-wind climate at the study site. North American high-pressure systems cause northerly winter storms and overall cold and stormy weather pattern from November to February (Adomat and Gischler 2015). Tropical cyclones repeatedly make landfall along the Yucatán Peninsula. Such storm systems induce large amounts of precipitation, flooding and massive destruction during the "hurricane season" (July to October). Belize is, with an average $20^{\text {th }}$ century strike rate of one landfall every 5 years (www.nhc.noaa.gov), highly susceptible to this short-term atmospheric interruption. Another important atmospheric feature closely linked to cyclone activity and precipitation is the latitudinal migration of the intertropical convergence zone (ITCZ). The ITCZ is located over the wider Belize area in summer to autumn (Haug et al. 2001) and causes elevated monthly precipitation of $\sim 250 \mathrm{~mm}$. A seasonal migration back towards a more southern position reduces monthly precipitation in winter and spring to $\sim 100 \mathrm{~mm}$. Belize mainland precipitation increases over a latitudinal transect from $150 \mathrm{~cm} / \mathrm{yr}$. in the north to more than $400 \mathrm{~cm} / \mathrm{yr}$. in the south. This pattern reflects the bipartite mainland topography of the flat northern Mayan Lowlands and the southern Maya Mountains (Purdy 1974).

The warm Caribbean Current controls both deep and surface ocean circulation of the south-western Caribbean region (James and Ginsburg 1979). Modern sea surface temperature (SST) fluctuates according to the GISST2.3b dataset and in-situ water temperature measurements within a $24^{\circ} \mathrm{C}-32^{\circ} \mathrm{C}$ range (Wantland and Pusey 1975; Woodruff et al. 1998). Sea surface salinity (SSS) is normal marine (35\%o) around large parts of the barrier reef structure. Significantly lower values have been measured close to the coast (18\%) and within the northernmost section around Chetumal Bay (Purdy and Gischler 2003; Purdy et al. 2003), presumably related to enhanced freshwater input throughout fluvial run-off and restricted ocean water circulation. In the offshore atoll lagoons of Glover's and Lighthouse Reef SSS values are slightly above normal marine (37-41\%). Salinity values of up to $70 \%$ occur in Turneffe Island lagoon due to a restricted lagoon circulation (Hauser et al. 2007).

\section{Methods}

Seven sediment cores (BH1-BH7) were collected from the bottom of the "Great Blue Hole" (Lighthouse Reef, Belize) along a W-E transect in August 2017. The coring process was performed from a small vessel using a portable Rossfelder P3 electrical 
vibrocore system (floating unit, vibrator head and baseplate) and $6 \mathrm{~m}$ long aluminium tubes of $7.5 \mathrm{~cm}$ diameter, prepared with two copper core catchers. In order to extend the core length to $9 \mathrm{~m}$, a $6 \mathrm{~m}$ long aluminium pipe was glued together with a sliced $3 \mathrm{~m}$ pipe using $50-\mathrm{cm}$-long aluminium sleeves and epoxy-adhesive. Core recovery amounts to $100 \%$, however, the youngest core sections at the core top contain considerable amounts of pore water, and sediment loss due to liquefaction is possible. The latter, i.e., the lack of the core top, can easily be identified though by correlating among different cores. The coordinates at the individual coring sites were registered using a GPS instrument. All cores were cut in-situ into $1.5 \mathrm{~m}$-long standardized core sections, transported by air freight from Belize to Germany, and stored in a cold room at $4^{\circ} \mathrm{C}$ to avoid sediment dehydration.

All $1.5 \mathrm{~m}$-long core sections were opened in the laboratory and cut in half lengthwise using an angle grinder and an ultra-thin copper sheet $(0.7 \mathrm{~mm}$ thickness). The sediment facies analysis is related to a spliced $8.55 \mathrm{~m}$ long sedimentary record. Core BH6 $(7.86 \mathrm{~m})$ was initially selected for sampling, because of its length and very good preservation. Some $85 \mathrm{~cm}$ of the core top were lost due to liquefaction during the coring process. The missing section was complemented by the upper $86.25 \mathrm{~cm}$ of core BH7. The cores BH6 $\left(17^{\circ} 18.957^{\prime} \mathrm{N}, 8^{\circ} 32.098^{\prime} \mathrm{W}\right)$ and $\mathrm{BH} 7\left(17^{\circ} 18.950^{\prime} \mathrm{N}\right.$, $87^{\circ} 32.118^{\prime} \mathrm{W}$ ) derive approximately from the centre of the sinkhole (Fig. $15 \mathrm{~d}$ ). There is a distance of $35 \mathrm{~m}$ between the two coring sites, and, consequently, both cores show very similar sediment successions. The two cores have been spliced together by means of prominent cyclone event bed correlation and age dating. This splicing created a temporally continuous and complete sedimentary record encompassing 1885 years of the Common Era ( 93\%). High-resolution line-scan images were acquired at the University of Bern using a Geotek-MSCL-S (Multi-Sensor Core Logger). A stratigraphic and sedimentological core description was completed by visual core observation and the use of these high-definition photographs. This approach allowed a preliminary qualitative assessment and visual pre-definition of background and event bed depositions (Fig. 15 e).

In total, 40 bulk samples have been extracted randomly over the entire core length to cover both visually separated sections of fair-weather (background) and storm (event) sedimentation (Table 2). For each of the four visually identified facies (background mudstone; event wackestone, packstone and rudstone), 10 samples 
(slabs of $2.5 \mathrm{~mm}$ thickness) were extracted randomly along the core every $80-90 \mathrm{~cm}$. We applied a multi-proxy-approach to ensure a reliable differentiation between background and event bed samples on the basis of (1) grain size $>20-24 \mu \mathrm{m}$, (2) fine material $(<63 \mu \mathrm{m})$ abundance $<85 \%$, (3) layer thickness $>2.5 \mathrm{~mm}$, (4) yellow/brown colour and (5) Sr/Ca ratios >0.025 (Schmitt et al. 2020a). In this manner, 23 samples were quantitatively allocated to event bed sedimentation; the remaining 17 samples belong to the background sedimentation.

For textural analyses, each bulk sample was weighed and separated using standard grain-size sieves of $2 \mathrm{~mm}, 1 \mathrm{~mm}, 500 \mu \mathrm{m}, 250 \mu \mathrm{m}, 125 \mu \mathrm{m}$ and $63 \mu \mathrm{m}$. To guarantee reliable quantitative grain size measurements, a more detailed analysis of the fine material $<63 \mu \mathrm{m}$ was performed by using a laser-optical particle analyser (HORIBA Laser Particle Analyser-950), which runs with $2 \mathrm{~g}$ fine material ( $<63 \mu \mathrm{m}$ ) suspended in $0.4 \mathrm{~N} \mathrm{Na}_{4} \mathrm{P}_{2} \mathrm{O}_{7}$ and demineralized water. The textural classification of the sediment samples follows a modified Dunham (1962) scheme for unconsolidated carbonate sediments (Schmitt and Gischler 2017). Grain size values were calculated for each sample using the textural raw data (Suppl. 13) and the software package GRADISTAT (Blott and Pye, 2001). Sediments were texturally categorized by determination of classical sedimentary parameters (mean grain size, sorting, skewness and kurtosis), following the geometrical and logarithmical Folk and Ward (1957) method. The corresponding grain-size scale refers to Udden (1914) and Wentworth (1922). For petrographic analysis, thin-sections were prepared from the recombined grain-size fractions $>63 \mu \mathrm{m}$.

The quantification of the main sediment components (Halimeda, coralline red algae, molluscs, foraminifers, corals, echinoderms and organics) was conducted with a polarizing microscope (10x-magnification) and point-counter (Prior-Model-G). A grid of 300 point-counts was chosen to systematically count the abundance of different constituents. The thin-section was fixed in an integrated mechanical module, which is movable in defined $0.3 \mathrm{~mm}$ steps over the $\mathrm{x}$-axis of the thin-section. The screening of the samples in y-axis-direction was performed manually in similar distances of 0.3 $\mathrm{mm}$ steps. 300 counts are sufficient enough to reduce the error of the point-counting method to a maximum of $4-6 \%$. The error estimation was undertaken on the basis of a chart for judging the reliability of such point-counting results (Van der Plas and Tobi 1965). In general, there are two possible ways of particle detection using the point- 
counting method: (1) grain-bulk measurements and (2) grain-solid measurements (Flügel 2004). The presented point-counting results are anchored on the second particle detection technique, which focuses on counting of skeletal particles, without a consideration of cement/matrix or debris filled cavities. The determined sediment composition reflects, however, only the grain size fraction $>63 \mu \mathrm{m}$. These data are calibrated with the sample-specific volume of the fine fraction $(<63 \mu \mathrm{m})$ and thus standardised to reflect the bulk sample texture.

Three multivariate statistical analyses (correlation, cluster and principal component analyses) were applied using the software package PAST (Hammer et al. 2001). Correlation analysis is well suited to quantify positive (synchronicity) and negative (non-synchronicity) correlations between different variables making up the sediment composition (e.g. texture and particle abundance). Cluster analysis was conducted to statistically decipher and verify similarities between the 40 samples using the unweighted pair group method with arithmetic mean (UPGMA algorithms). A dendrogram on the basis of the regulatory scheme of the Euclidean distance was used to delineate and statistically cluster different sedimentary facies types between and within the two main categories of background and event sedimentation. Principal component analysis (PCA) is another ordination method, which was primarily performed to verify and graphically underline the results of the cluster analysis.

\section{Results}

\subsection{Average sediment composition of the "Great Blue Hole"}

Halimeda platelets are the major coarse $(>63 \mu \mathrm{m})$ skeletal constituents of the Holocene sediment succession of the "Great Blue Hole" with an average (ø) abundance of $21 \%$ and a range $(r)$ of $5-53 \%$. Fragments of corals $(\varnothing=5 \% ; r=1$ $12 \%)$, coralline red algae $(\varnothing=3 \% ; r=0.3-9 \%)$, molluscs $(\varnothing=3 \% ; r=0.1-11 \%)$, foraminifers $(\varnothing=2 \% ; r=0-7 \%)$ and echinoderms $(\varnothing=0.3 \% ; r=0-2 \%)$ are the minor coarse skeletal components of the Holocene sinkhole sediments (Fig. 16 a). Marine organic material makes up another minor portion of the bulk sediment composition $(\varnothing=3 \% ; r=0.3-14 \%)$. The largest parts of the sediment consist of fine carbonate material $<63 \mu \mathrm{m}(\varnothing=63 \% ; r=16-91 \%)$. A conspicuous feature is the high variability of individual sediment component abundances, which is mainly attributable to the depositional mechanism differences between background and event bed sedimentation. 
a) av erage composition: sediment column

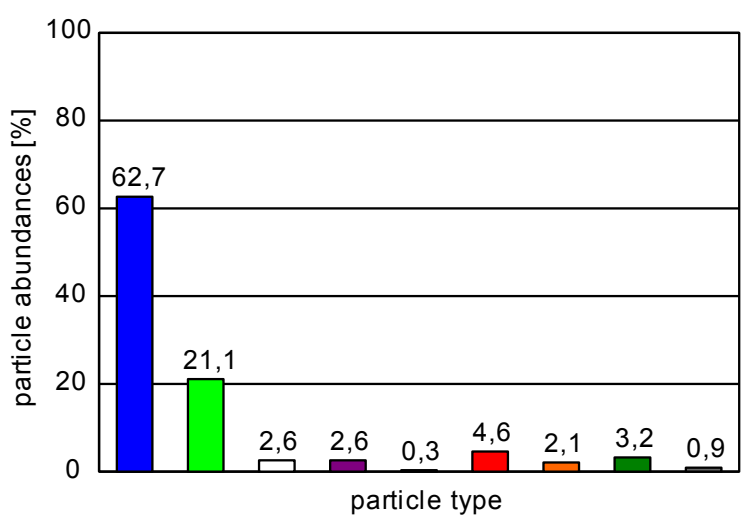

c) av erage composition: event sedimentation

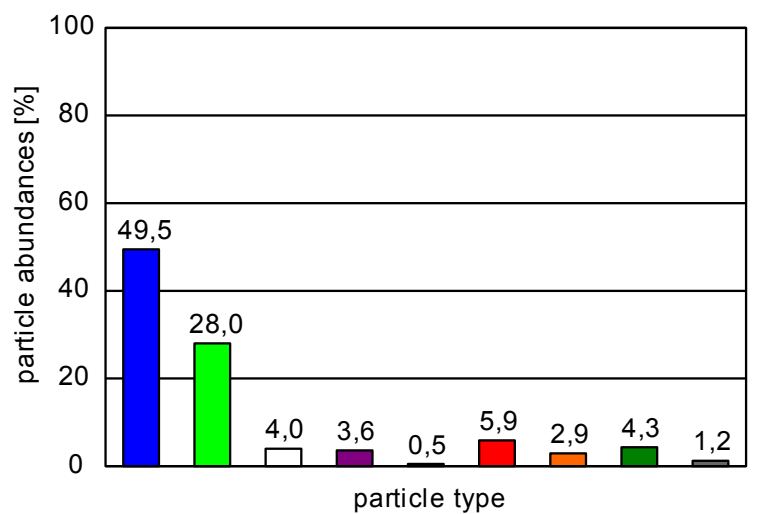

b) av erage composition: background sedimentation

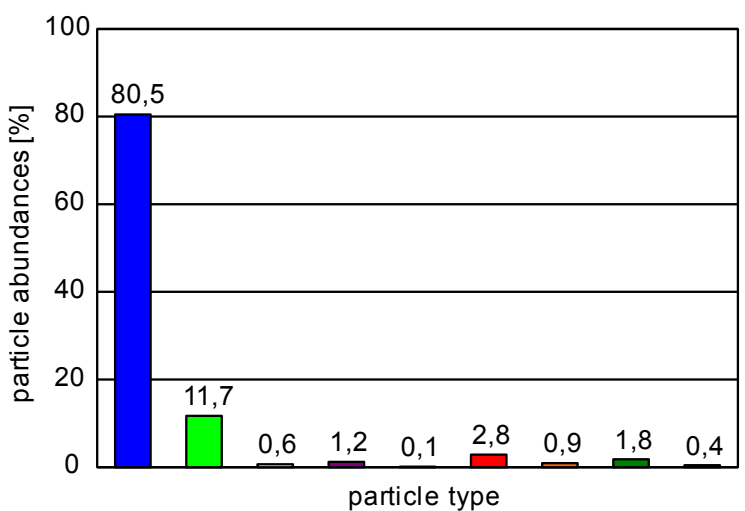

Figure 16. (a) Average sediment composition of the "Great Blue Hole" sinkhole (all samples). (b) Average composition of the background sedimentation (fair-weather conditions). (c) Average composition of the event sedimentation (storm conditions). All bar charts are standardised to the bulk sediment composition and include the major skeletal particles, the organic content and the abundance of fine carbonate material.

The correlation matrix considering abundances of all samples (Table 3) indicates a number of statistically significant correlations. The abundances of practically all types of coarse skeletal grains ( $>63 \mu \mathrm{m})$ show a statistically significant negative correlation with the abundance of the fine fraction $<63 \mu \mathrm{m}$. The abundances of mollusc and coralline red algae fragments have a statistically significant and positive correlation with the amount of the grain-size fraction $>2 \mathrm{~mm}$. The major skeletal sediment component Halimeda has a statistically significant positive correlation with the abundance of many other skeletal particles like corals, red algae, echinoderms and foraminifers. The majority of the minor skeletal particle abundances have statistically significant positive correlations among each other. Mean grain size values show both statistically significant and positive correlations to all skeletal and organic particles, to the grain size fraction $>2 \mathrm{~mm}$ and a negative and statistically significant correlation to the amount of the fine fraction $<63 \mu \mathrm{m}$. 


\subsection{Average background and event bed composition}

A more detailed comparison of the average background and event bed composition illustrates the striking compositional and textural differences between both depositional categories. The background sediments (Fig. 16 b) consist on average of $81 \%$ fine material, $12 \%$ Halimeda platelets, $3 \%$ coral fragments, $2 \%$ organic material, $1 \%$ mollusc shells, $1 \%$ foraminifer tests, and minor portions of coralline red algae and echinoderm plates $(0-1 \%)$. The grain-size range of the 17 background sedimentation samples varies between medium-very coarse silt and averages around $19 \mu \mathrm{m}$.

Event bed sediments (Fig. 16 c) are on average composed of 50\% fine material, $28 \%$ Halimeda platelets, $6 \%$ coral fragments, $4 \%$ organic particles, $4 \%$ red algae, $4 \%$ mollusc shells, $3 \%$ foraminifera tests and a small portion of echinoderm plates (1\%). The apparent differences to the background sediments are both obviously decreased amounts of fine material and increased abundances of coarse skeletal particles $(>63 \mu \mathrm{m})$, in particular Halimeda and coral fragments. The grain-size range of the 23 event bed samples fluctuates between very coarse silt and medium sand. As compared with the varved background sedimentation samples, average grain size of event bed sediments $(97 \mu \mathrm{m})$ is substantially higher.

\subsection{Textural facies classification}

Granulometric analysis of the 40 samples (Suppl. 13) reveals four broad primary depositional textures on the basis of the grain size distribution, following the modified Dunham (1962) classification for unconsolidated carbonate sediments used by Schmitt and Gischler (2017). Three samples with fine material $(<63 \mu \mathrm{m})$ amounts of around $90 \%$ are classified as textural mudstone facies. Twenty-seven samples are texturally related to the wackestone facies, which is mainly characterized by a fine fraction range of $50-90 \%$. Seven samples with fine material content below $50 \%$ are termed as textural packstone facies. Three other samples with fine material amounts lower than $50 \%$ have been termed as rudstone facies due to more than $10 \%$ abundances of $>2 \mathrm{~mm}$ grain size fraction. It should be emphasized that the use of fine material abundance as classification criterion provides only a soft boundary for facies determination of unconsolidated sediments. Average grain size $(\varnothing)$ as well as the internal grain size range $(r)$ of each textural group are additional and supportive criteria for characterizing the broad depositional textures of mudstone $(\varnothing=13.6 \mu \mathrm{m}$; 
$r=13-14 \mu \mathrm{m})$, wackestone $(\varnothing=25.6 \mu \mathrm{m} ; r=14-46 \mu \mathrm{m})$, packstone $(\varnothing=123.4 \mu \mathrm{m}$; $r=53-332 \mu \mathrm{m})$, and rudstone facies $(\varnothing=315.5 \mu \mathrm{m} ; r=223-374 \mu \mathrm{m})$.

\subsection{Combined textural and compositional facies classification}

The Holocene sediment succession of the "Great Blue Hole" is more accurately described considering the four identified textural facies separately with regard to their particle composition and within the framework of background (bs) and event bed (es) sedimentation (Fig. 17).

Mudstone.- The background sedimentation-related mudstone facies (Fig. 17 a) consist on average of $90 \%$ fine material, $6 \%$ Halimeda platelets and $2 \%$ coral fragments. The remaining $2 \%$ are attributable to a combination of coralline red algae, mollusc, echinoderm and foraminifer debris as well as to small amounts of organic particles. The mudstone facies is characterized by a strong dominance of fine material ( 90\%). A component-related specification of this textural facies is, therefore, not meaningful.

Wackestone.- The wackestone facies belongs either to background or event sedimentation (Fig. $17 \mathrm{e}$ ) and is composed on average (Fig. $17 \mathrm{~b}$ ) of a decreased content of fine fraction (72\%) as well as elevated amounts of skeletal debris (16\% Halimeda, $4 \%$ coral, $2 \%$ molluscs, $2 \%$ red algae and $2 \%$ foraminifer). Organic particles are relatively rare (2\%). Textural wackestone facies is comparably enriched in Halimeda platelets, however, a component-based classification is challenging due to the relatively high fine material abundance and the mixing of background and event sedimentation portions.

Packstone.- The event-sedimentation-related packstone facies (Fig. $17 \mathrm{c}$ ) comprises on average $33 \%$ fine material, 36\% Halimeda platelets, $7 \%$ coral fragments, $6 \%$ red algae, $5 \%$ mollusc shells, $4 \%$ foraminifer and $1 \%$ echinoderm plates as well as $2 \%$ miscellaneous skeletal debris. Organic content of this facies is around $6 \%$. Textural packstone facies is compositionally classified as an algae-rich packstone, because of substantially increased amounts of Halimeda and coralline red algae particles (42\%). 
a) mudstone facies (bs)

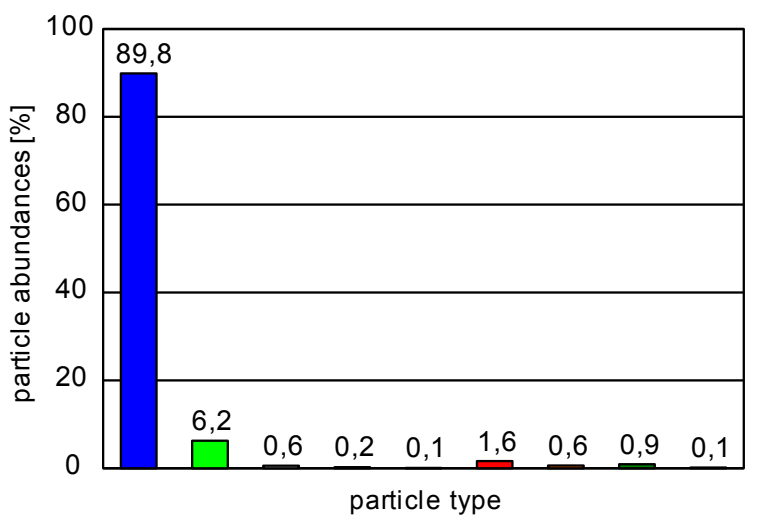

c) algae-rich packstone facies (es)

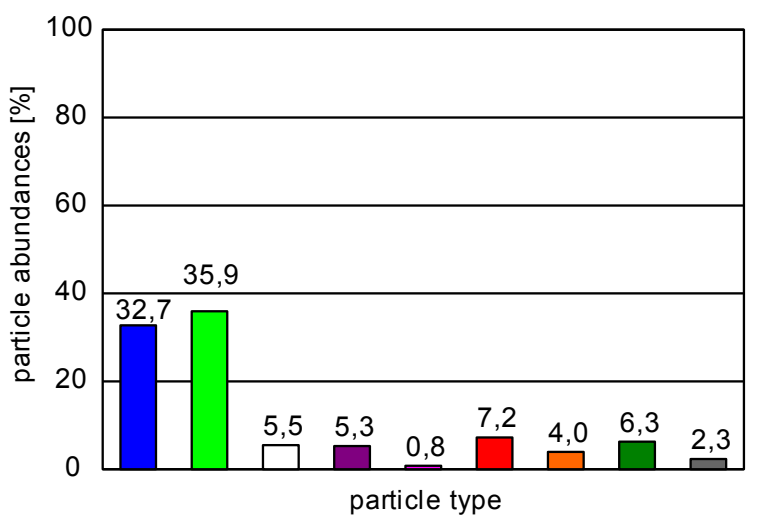

e) wackestone facies (bs) vs. Halimeda wackestone facies (es)
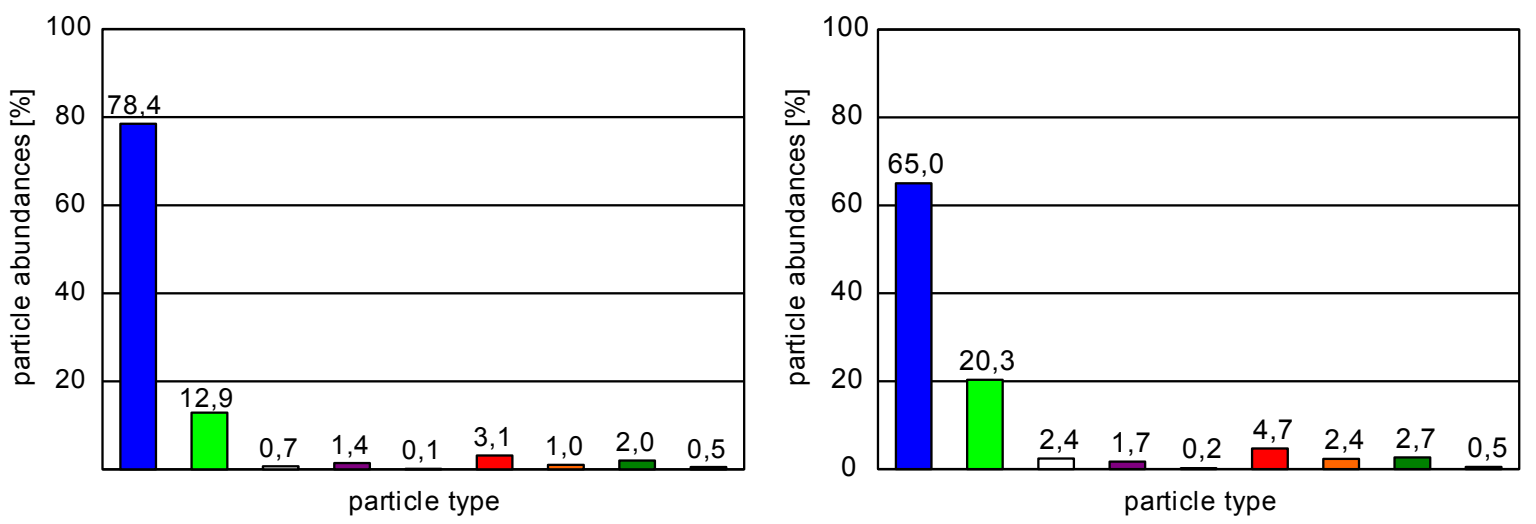

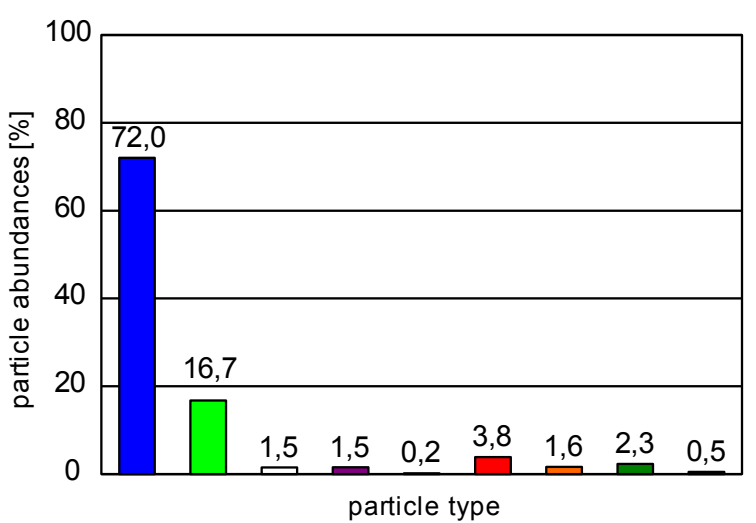

d) coralgal rudstone facies (es)

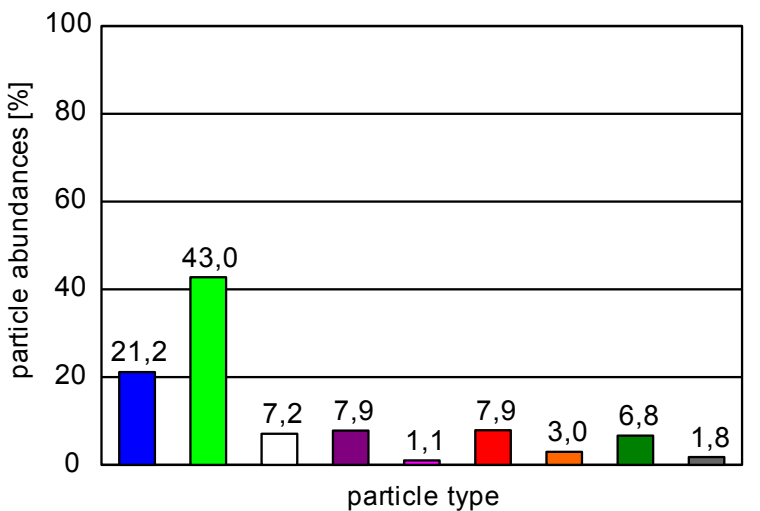

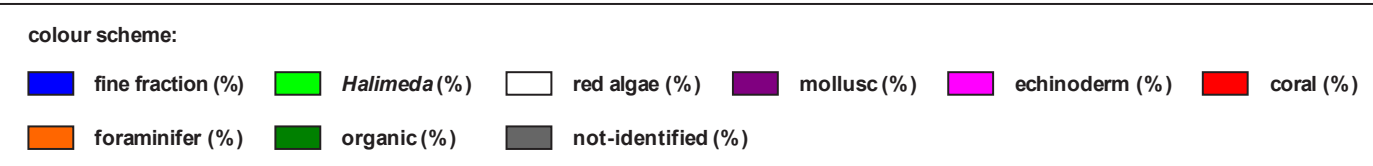

Figure 17. (a) Average sediment composition of the background sedimentation related mudstone facies. (b) Average sediment composition of the background and event sedimentation related wackestone facies. (c) Average sediment composition of the event sedimentation related algae-rich packstone facies. (d) Average sediment composition of the event sedimentation related coralgal rudstone facies. (e) The wackestone facies is further separated into a background sedimentation related transitional sub-facies (left) and an event sedimentation related Halimeda wackestone facies (right). All six bar charts are standardised to the bulk sediment composition and include the major skeletal particles, the organic content and the abundance of fine carbonate material. 
Rudstone.- The rudstone facies is part of the event sedimentation (Fig. $17 \mathrm{~d}$ ) and is characterized by the lowest amounts of fine fraction portions (21\%). Sediments of the rudstone facies mainly consist of skeletal debris with $43 \%$ Halimeda platelets, $8 \%$ coral fragments, $8 \%$ mollusc shells, $7 \%$ red algae, $3 \%$ foraminifer tests and $1 \%$ echinoderm plates as well as $2 \%$ miscellaneous skeletal debris. Organic material content is around $7 \%$ and comparable to the packstone facies. A combined compositional and textural classification as coralgal rudstone is appropriate, because Halimeda, red algae and coral fragments (58\%) comprise the most common skeletal sediment constituents.

\subsection{Statistical analysis - facies verification}

Facies types were delineated using multivariate statistics, i.e., through cluster analysis considering sediment composition, texture and the assignment to background and event sedimentation (Fig. 18). The dendrogram reveals a verification/clustering (coph.corr. $=0.96$ ) of four primary sedimentary facies: mudstone, wackestone, algae-rich packstone and coralgal rudstone. Event and background sediments are statistically separated in the cluster analyses from each other on the basis of varying textural and compositional parameters. Twenty-three event bed samples can be statistically aligned to two different event sediment clusters; the remaining 17 background section samples belong to another background sediment cluster. The only exception is sample 16 (background sedimentation), which clusters due to its textural and compositional similarity to event sedimentation within a section of event bed-related samples. The cluster analysis statistically verifies that rudstone, packstone and wackestone facies belong to the event beds, which are arranged within two very different event sedimentation subclusters (rudstone vs. packstone/wackestone). The classification of the mudstone and wackestone facies to a cluster of background sedimentation is statistically sound as well. An occurrence of soft boundaries and transitions between individual facies types is highlighted in the cluster analysis by an apparent overlap of background and event sedimentation samples in the wackestone facies and exceptional clustering of samples 16, 22, 23 and 26 within other facies types. Our summarized facies classification (Table 4) follows the results of this combined textural and compositional multivariate clustering. 


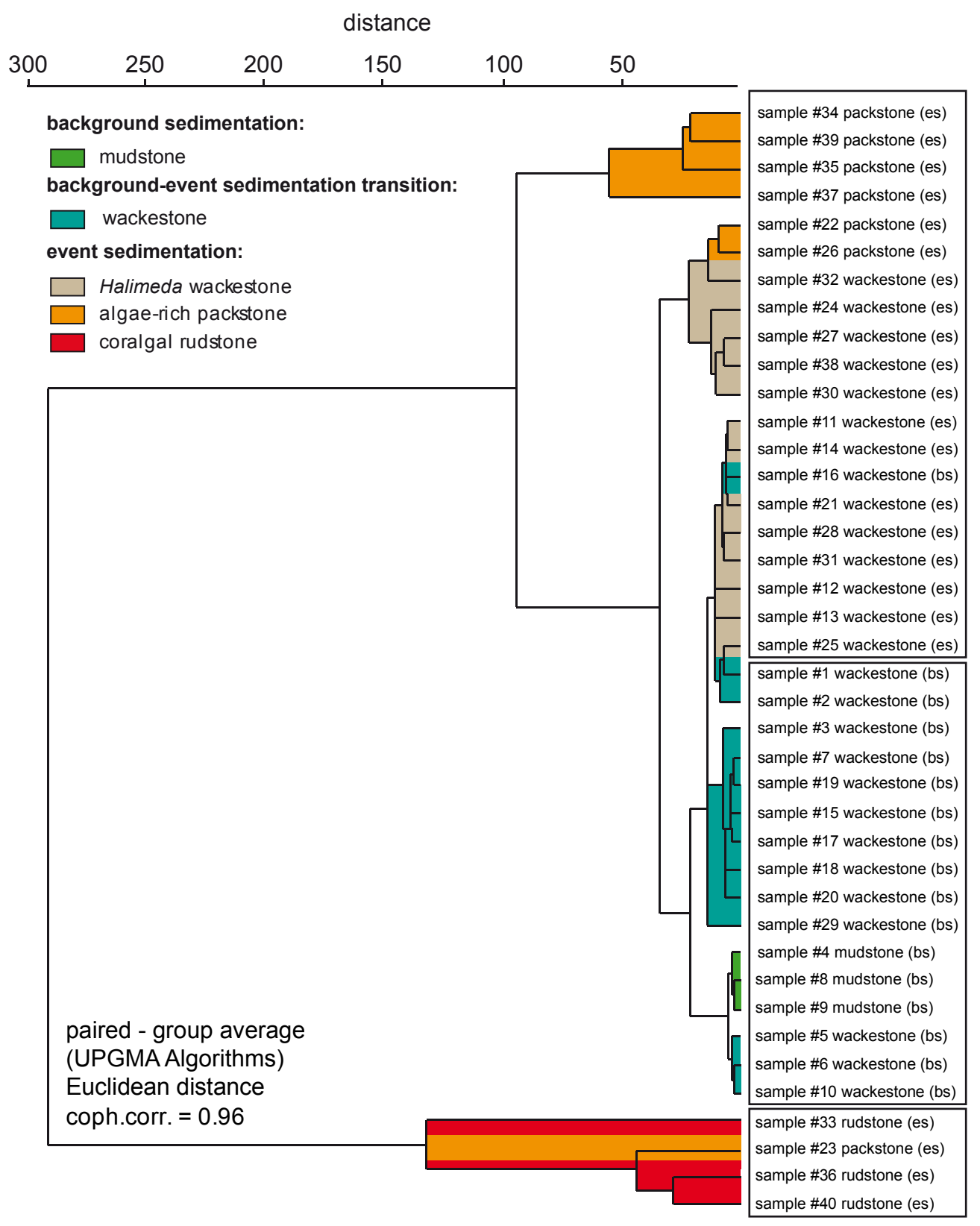

Figure 18. Dendrogram of the cluster analysis was used for the classification of sedimentary facies with affiliation to background and event sedimentation. For the most meaningful dendrogram entities, paired group average algorithm and Euclidean distance were used (coph.corr. $=0.96$ ). The cophenetic correlation (coph.corr.) is a measure of how faithfully a dendrogram preserves the pairwise distances between the original unmodeled data points. Ordination within the cluster analysis is based on combined relative abundances of sediment components and textural data.

The textural and compositional analyses alone do not fully permit a separation between the wackestone affiliation to either background or event sedimentation. A combination of both texture and composition data within the framework of the cluster analysis, however, satisfactorily deciphers small differences between both depositional categories and allows an allocation of wackestone-related samples to 
background and event sedimentation. The event bed-related wackestone facies (Fig. 17 e) consists of $65 \%$ fine material, $20 \%$ Halimeda, $5 \%$ coral fragments, $2 \%$ red algae, $2 \%$ foraminifer, $2 \%$ molluscs and $1 \%$ echinoderms (Table 4 ) and may be from now on better classified as Halimeda wackestone. The amount of organic particles is around $3 \%$. This facies is characterized by a mean grain size of $32 \mu \mathrm{m}$. The background sedimentation-related wackestone facies differs in particular through higher fine fraction abundances (78\%) and decreased Halimeda (13\%) as well as coral $(3 \%)$ particle abundances. The minor skeletal constituents and the organic material contents (2\%) are anyway relatively similar in both cases. Mollusc, foraminifer, red algae and echinoderm fragments together account for $4 \%$ of the sediment composition. On the basis of the compositional data, we propose a matrixbased classification as wackestone without component consideration. The substantially lower grain size $(20 \mu \mathrm{m})$ is, in addition, another conspicuous difference between both wackestone affiliations. The principal component analysis (Fig. 19) demonstrates and justifies a very similar facies grouping as obtained by the cluster analysis. All sediment samples have been arranged in the PCA plot with regard to background and event sedimentation separation in the same five sedimentary facies types, which were verified by using the cluster analysis: mudstone (bs), wackestone (bs), Halimeda wackestone (es), algae-rich packstone (es) and coralgal-rudstone (es).

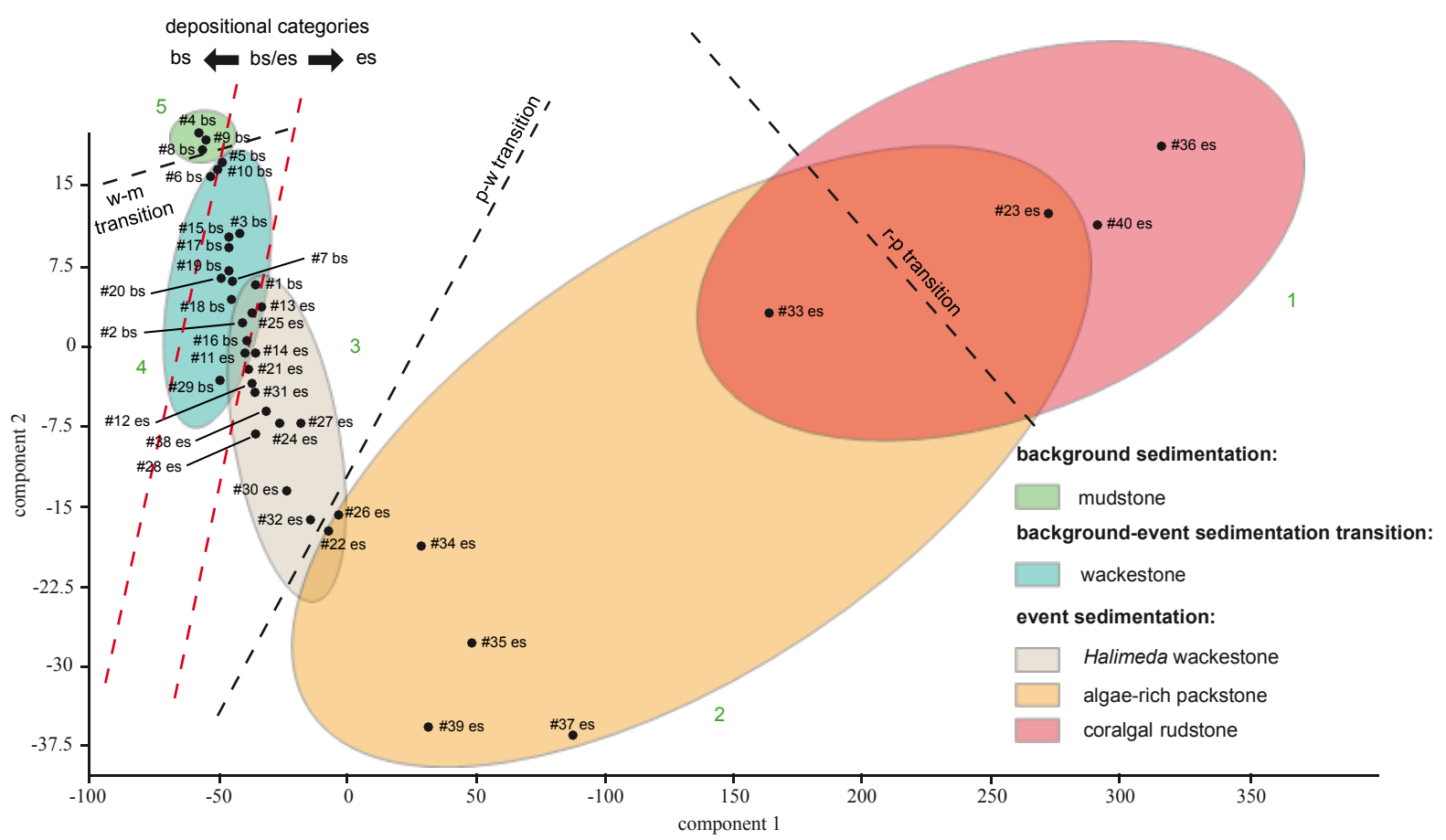


$\leftarrow$ Figure 19. Diagram of the principal component analysis (PCA) shows a comparably similar classification and arrangement of facies as obtained from the cluster analysis. The black dashed lines illustrate the transitional overlap between individual facies types. Two dashed red lines frame a zone, which is attributable to the transitional sub-facies (wackestone with background affiliation). All samples plotting on the right side of the transitional zone belong to the event sedimentation (Halimeda wackestone, algae-rich packstone and coralgal rudstone); the samples plotting at the left side in turn are attributable to the background sedimentation (mudstone). Abbreviations: bs (background sediments), es (event sediments), $r-p$ transition (rudstone/packstone transition), $p-w$ transition (packstone/wackestone transition), w-m transition (wackestone/mudstone transition).

\subsection{Key characteristics for facies identification and classification}

In combination, textural, compositional and statistical analyses demonstrate that the presence or absence of coarse skeletal components (allochems) represents a strong and quantitative distinction criterion for cyclonic and fair-weather sedimentation in anoxic sinkhole environments. A combined consideration of compositional and textural data allows further a reliable and statistically significant identification of different primary sediment facies and their genetic allocation to both sedimentation dynamics. Several key textural and compositional sediment characteristics have been determined in this study for the "Great Blue Hole", in order to identify and characterize the above-described five facies types. These key criteria for facies identification and classification include the volume of aragonitic fine material $(<63 \mu \mathrm{m})$, the abundance of skeletal components $(>63 \mu \mathrm{m} ;>2 \mathrm{~mm})$, the abundance of Halimeda platelets $(>63 \mu \mathrm{m})$, and both range and average grain size values (Table 5 b).

\subsection{Temporal changes of sediment composition}

There are no distinct temporal composition trends visible in the core $\mathrm{BH} 6$ considering all 40 samples, without differentiation between background or event sedimentation. The abundances of the major sediment components fluctuate without any visible trends over the entire core length. The lack of clear, linear trends is either related to the relatively low sample density considering the length of the core or originates from huge component abundance fluctuations between fair-weather and storm conditions. Only two linear trends appear to exist with regard to the total sediment composition of the sinkhole (Fig. $20 \mathrm{a}, \mathrm{b}$ ). The abundance of organic material shows a weak and statistically significant correlation ( $r=0.31 ; p=0.049)$ to core depth/time (Fig. $20 \mathrm{a}$ ) in that it increases in general in direction to the core top. The abundance of coral 
particles seems to increase in a similar way towards the core top (Fig. 20 b). The linear trend is, however, statistically not significant $(r=0.17 ; p=0.30)$.

Event and background sedimentation samples have to be considered independently from each other to overcome one of the above-mentioned limitations, i.e., the huge component fluctuations between both sedimentation mechanisms. The following section refers to the investigation of all event sedimentation-related samples (Fig. 20 $c-g)$. There is a statistically significant $(r=0.47 ; p=0.02)$ linear correlation between Halimeda abundances and core depth/time within the event bed samples (Fig. 20 c). The amount of Halimeda fragments obviously decreases towards the core top. Coralline red algae content seems to decrease in the same direction (Fig. 20 d). The correlation is, however, statistically not significant $(r=0.29 ; p=0.17)$. A further statistically significant $(r=0.49 ; p=0.02)$ correlation occurs between foraminifer abundances and core depth/time (Fig. 20 e) in that the amount of foraminifer particles decreases exactly like the Halimeda abundance towards the uppermost part of the core. Coral (Fig. $20 \mathrm{f}$ ) and organic (Fig. $20 \mathrm{~g}$ ) particle abundances seem to increase in a similar way towards the core top, as previously seen in the total sinkhole sediment composition investigation. The correlations are, however, not statistically significant within the event sedimentation samples $(r=0.16 ; p=0.47$ and $r=0.12 ; p=0.60)$, respectively. It is not possible to examine further temporal variability of the event sedimentation categories with regard to the three related facies (Halimeda wackestone, algae-rich packstone and coralgal-rudstone), because of the small sample size.

The fluctuations of the major sediment component abundances are generally smaller within the background sedimentation samples as compared with the event sedimentation samples (Fig. $20 \mathrm{~h}$-j). The main skeletal components of the background sediments display no temporal trends over the entire core depth. There is a strong correlation of organic particle abundances (Fig. $20 \mathrm{~h}$ ) with core depth/time indicated by a strong and statistically significant correlation $(r=0.72 ; p=0.001)$. The organic material abundance increases from the core base towards the core top. Two other noticeable, however, statistically insignificant trends include a decrease of coral fragments ( $r=0.35 ; p=0.16)$ towards the core top (Fig. $20 \mathrm{i}$ ) and an increase of foraminifer particles $(r=0.27 ; p=0.29)$ in the same direction (Fig. $20 \mathrm{j}$ ). 

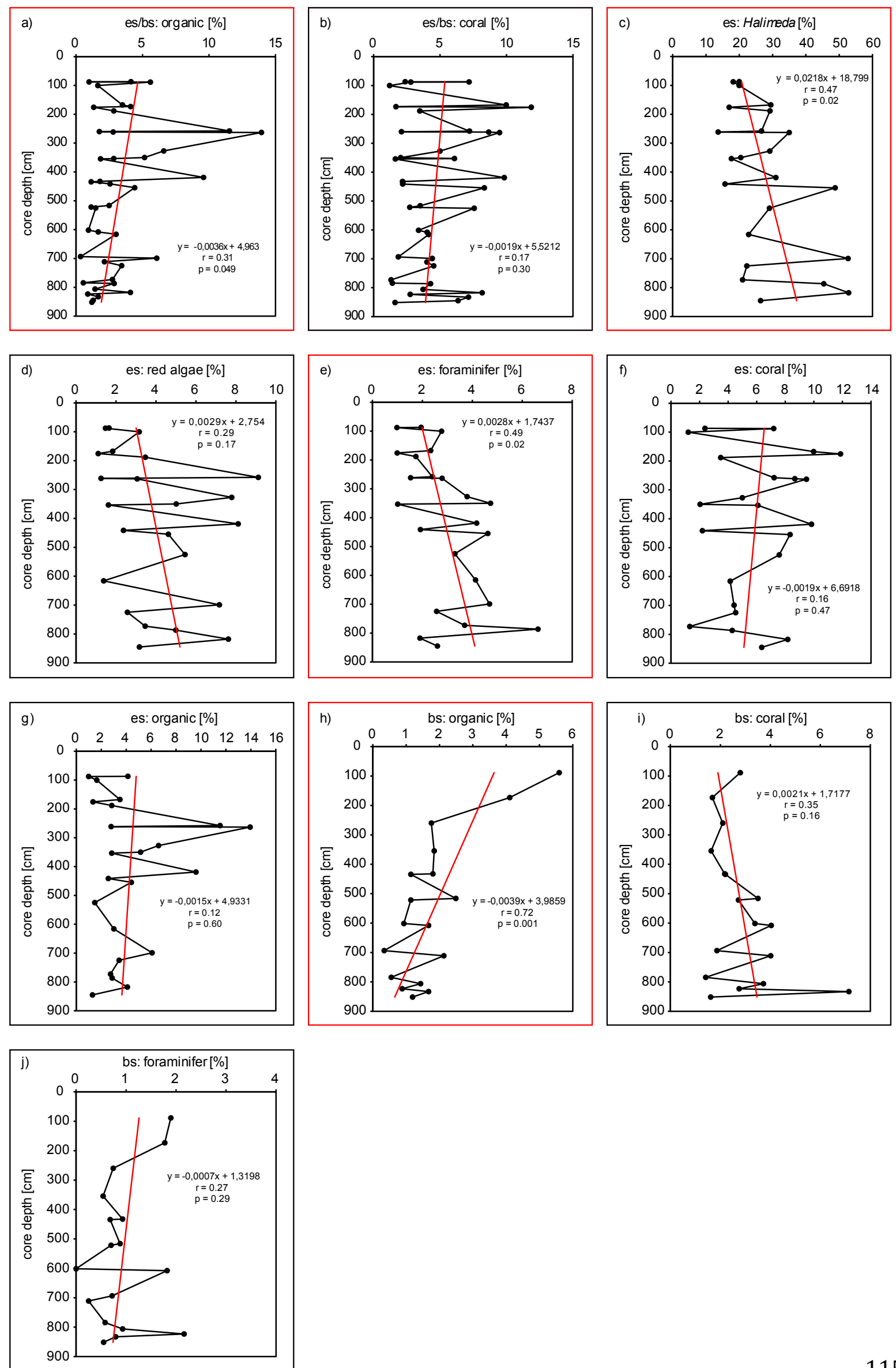
$\leftarrow$ Figure 20. Temporal trends in the sediment composition. (a-b) Combined consideration of background and event sedimentation samples (entire sediment succession). (c-g) Consideration of event sedimentation sections only. (h-j) Consideration of background sedimentation sections only. Statistically significant trends are highlighted with (red) boxes. All plots contain (red) regression lines including linear equations and $r$ - and $p$-values, respectively. Abbreviations: bs (background sediments), es (event sediments).

\section{Discussion}

\subsection{Major sediment constituents: surface-sinkhole feedback}

The data analysis of the 40 thin-section samples, both those with event bed and background affiliations, reveals a closely linked feedback between major surface sediment constituents and the average composition of the "Great Blue Hole" sediment succession. The surface sediments of Lighthouse Reef consist on average of $31 \%$ Halimeda, $16 \%$ molluscs, $15 \%$ corals, $8 \%$ red algae, $6 \%$ foraminifer, $17 \%$ fine material and $7 \%$ non-skeletal particles, organic material and non-identifiable components (Gischler 1994). In this context, special attention should be given to the green alga Halimeda, which occupies, in accordance with the presented correlation analysis, an important role with regard to sinkhole sediment formation. Because of their high abundance, Halimeda platelets have a statistically significant and positive correlation with practically all other involved sediment components. The Halimeda dominance is likely the result of the widespread ecological occurrence of green algae within the modern reef system of Belize. The identified and quantified sediment components correspond quite well with those recognized from the surface sediment investigation of Lighthouse Reef (Gischler 1994). However, certain compromises must also be admitted when comparing the mean sinkhole composition with averaged surface sediment compositions. Within the sinkhole, Halimeda fragments represent the major skeletal constituents; however, they occur with substantially lower abundance $(21 \%)$ compared to the surface sediments. The abundances of the other skeletal components, e.g., corals $(5 \%)$, coralline red algae $(3 \%)$, molluscs $(3 \%)$ and foraminifers $(2 \%)$ are similarly lower. The abundance of the fine fraction is on the contrary conspicuously increased in the sinkhole sediments $(63 \%)$ compared to the surface sediments. These differences can be partially explained by the fact that the surface sediment averages given above are obtained from open water, and environmentally and ecologically different reef zones (e.g., fore reef, reef rest, sand apron and lagoon). Therefore, this dataset should be only used to reflect the 
compositionally controlled surface-sinkhole sediment feedback with regard to the occurring major skeletal constituents.

\subsection{Reefal depositional environments and sedimentation dynamics}

Two major depositional environments with extremely different environmental conditions and sedimentation dynamics usually characterize modern coral reef systems, including marginal reef and lagoonal sections (Fig. 21).
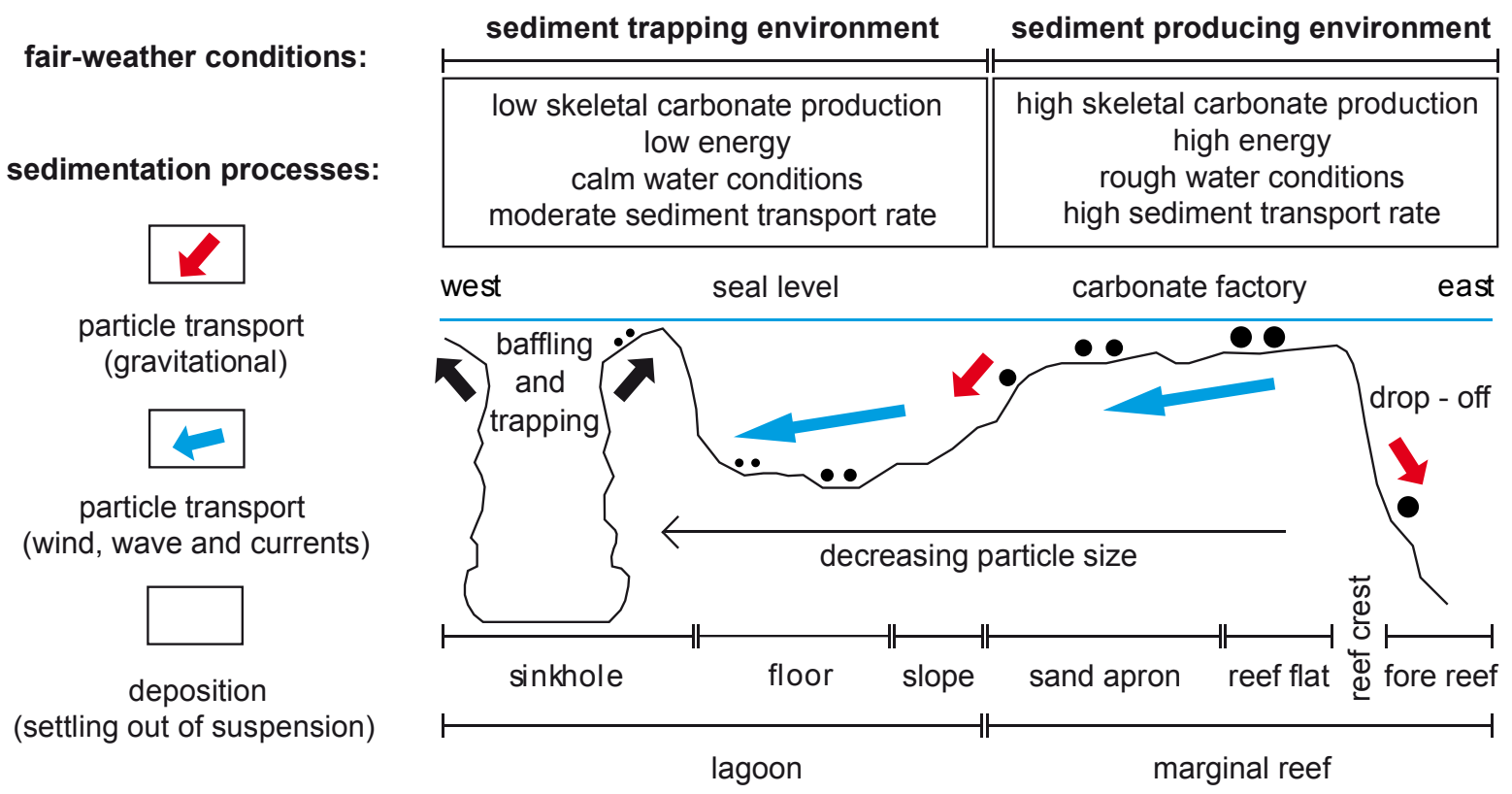

Figure 21. Schematic cross section through the eastern marginal reef and lagoon of Lighthouse Reef atoll, including all reef zones and the "Great Blue Hole" sinkhole. The simplified profile section is vertically exaggerated and indicates major sedimentation environments and primary/secondary sedimentation dynamics and deposition processes under fair-weather conditions.

An independent consideration of marginal reef and lagoon sediment composition data should be, therefore more appropriate to understand the role of the sinkhole within this bipartite sedimentation system. James (1979) described the marginal reef section as the carbonate factory of the system. This carbonate sediment-producing environment includes several shallow and high-energy marginal reef zones (e.g., fore reef, reef crest, reef flat and sand apron). Continuous wind and wave activity produces coarse carbonate fragments especially in the fore-reef, reef crest and reefflat setting (Chave et al. 1972) by physical destruction of the reef fabric (Scoffin 1992). For Lighthouse Reef, the produced material derives from the continuous eastern windward marginal reef setting. The emerging north-eastern surface currents induce a lateral transport of the skeletal debris towards the adjacent sand apron and 
initiate a gradual hydrodynamically controlled particle deposition. The surface currents carry the finer sediment particles onwards into the sediment-trapping environment, which is in case of Lighthouse Reef the eastern lagoon (Fig. 21). In the wake of this on-going transport process, carbonate particles are subjected to further physical and biochemical erosion and destruction (Perry 1996, 2000), which continuously reduces the particle grain size until final deposition.

\section{3. "Great Blue Hole", a lagoon-like deposition environment}

The accommodation space of the "Great Blue Hole" belongs to the sediment-trapping environment, which is characterized by low energy, calm water conditions, high water depth and low rates of carbonate production (Chave et al. 1972). The special sinkhole geomorphology includes restricted water circulation, a surrounding coalesced coral reef, two reef channels, and a $30^{\circ}$ inclined sediment slope at the top of the cavity (Fig. $15 \mathrm{~d}, \mathrm{f}$ ). These conditions create a very protected local sedimentation environment modulated by secondary sedimentation dynamics. The surrounding coalesced coral reef causes a baffling and trapping of coarser suspended particles (Fig. 21). The adjacent gentle slope at the top of the hole further supports particle deposition and grain-size reduction. These features represent a major barrier for coarse-grained particles and thus favour the accumulation of relatively high volumes of fines settling out of suspension. This contrasts to the surrounding lagoon floor characterized by a higher abundance of coarse skeletal particles. Increased fine material abundance in the "Great Blue Hole", in particular, dilutes the already rare coarse-grained skeletal particles, which are probably transported to a large extent through the two reef channels into the sinkhole. The sedimentation dynamics in the sinkhole are primarily governed by the outlined basic sedimentation dynamics shaping both major sedimentary environments in the reef system (Fig. 21) and secondary by the special sinkhole geomorphology. The composition of the sinkhole sediments, characterized by relatively increased volumes of fine material and relatively low skeletal grain abundances with Halimeda dominance, is an expression of these two controls.

Schmitt and Gischler (2017) compared various reefal carbonate sedimentation sites from the Atlantic, Pacific and Indian Oceans in order to highlight the compositional differences between lagoon and marginal reef sediment compositions. The three Belize offshore atolls and the Belize Barrier Reef belong to a group of algal- 
dominated marginal reef sediments. The average marginal reef sediment composition of Lighthouse Reef (Gischler 1994) consists of skeletal algae debris (34\% Halimeda and $12 \%$ red algae), coral fragments (28\%), mollusc shells (16\%), foraminifer tests (7\%) and low volumes of fine material (4\%). This sediment composition is similar to other locations such as Roatan (Schmitt and Gischler 2017), Bora Bora (Gischler 2011) and Hawaii (Harney et al. 2000; Calhoun et al. 2002). These algal-dominated marginal reefs clearly differ from coral-dominated marginal reef sediment compositions obtained from Jamaica (Boss and Liddell 1987), La Réunion (Gabrié and Montaggioni 1982), Kaledupa/Hoga, Indonesia (Madden et al. 2013), Moorea (Fodor 2014) and Mayotte (Masse et al. 1989).

Statistical analyses further decipher three fundamental groups of lagoon sediments within the considered reef systems. The Belize offshore atolls belong, together with the nearby site Roatan (Schmitt and Gischler 2017), to a cluster with high abundances of Halimeda. The lagoon sediments of Lighthouse Reef (Gischler 1994) consist on average of $27 \%$ Halimeda, $17 \%$ molluscs, $4 \%$ foraminifers, $4 \%$ red algae, $3 \%$ coral and contain fine material contents of $29 \%$. The lagoon sediments of the entire Belizean reef systems (Purdy and Gischler 2003) are in addition typically enriched in fine material content, which is a similarity with barrier reef lagoon systems of Bora Bora (Gischler 2011) and Moorea (Fodor 2014). Some lagoon sediments from, e.g., Mayotte (Masse et al., 1989) and Viti Levu (Gussmann and Smith 2002) are characterized by very high volumes of siliciclastic material (17\%-38\%). The quantified sinkhole sediment composition fits quite well within the framework of a lagoon-like sediment composition, simultaneously taking the special geomorphology into account. The marginal reef region acts as the source of the abundant Halimeda platelets. These particles are relatively large, but rather porous, chip-shaped and therefore hydro-dynamically more prone to the described transport and sedimentation processes than other, denser coarse-grained skeletal particles like mollusc shells or coral fragments. Within the sinkhole setting, the substantially increased volumes of fine fraction (63\%) are likely the result of the discussed special geomorphological characteristics, i.e., the secondary sinkhole sedimentation dynamics. The fine material consists almost entirely of aragonite mud and is, therefore very likely the product of Halimeda breakdown. 


\subsection{Background and event sedimentation - cyclone modulation}

Considering the sediment succession of the "Great Blue Hole" as a single sediment body is a simplified approach with regard to the bipartite stratigraphy of the sediment column. The sediment composition should be discussed with regard to background and event sedimentation compositions, i.e., in the framework of cyclone-modulated interruptions of the fair-weather sedimentation dynamics (Fig. 22). Large compositional variations between both sediment categories are best explained for the Lighthouse Reef sinkhole by such short-term interruptions (event bed sedimentation) of fair-weather sedimentation dynamics (background sedimentation).

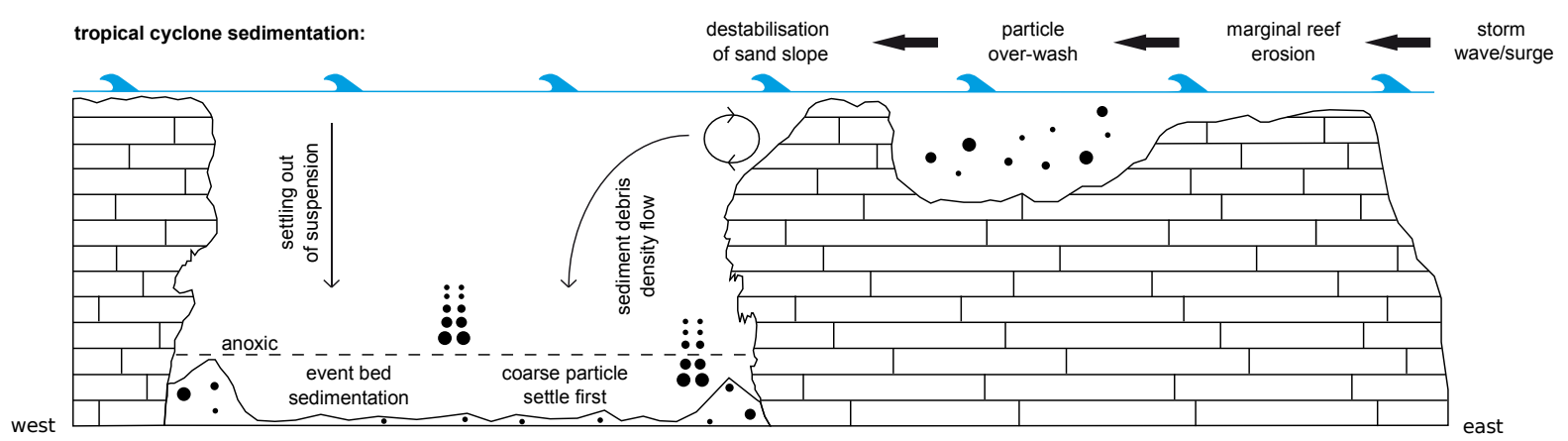

Figure 22: Conceptual model of event bed formation under tropical cyclone influence. The simplified cross section is vertically exaggerated and indicates potential cyclone-controlled sedimentation and depositional dynamics in the "Great Blue Hole". Visualisation was made following conceptualisation of Brown et al. (2014).

Storm-induced over-wash largely causes a mixing of reefal and lagoonal sediment characteristics, which are under fair-weather conditions typical for one of the two major reef environments. Results of the correlation analysis illustrate this component mixing by indicating positive correlation between practically all involved skeletal components. Storm surges and high waves provoke strong physical destruction of marginal reef structures, generate coarse reef-associated particles, and transport large amounts of suspended mixed coarse and fine material in a (north)-western direction into the sinkhole (Fig. 22). Storm systems also trigger instabilities on the sinkhole slope sediments, which have been deposited at this place under fairweather conditions (Brown et al. 2014). The effect of these storm systems leads to a general compositional and textural shift, described by the formation of more marginal reef-like and substantially coarser sediment layers with increased amounts of skeletal 
remains (in particular reef organisms: 28\% Halimeda and 6\% coral particles) and generally lower amounts of fine material (50\%).

\subsection{Texture and composition - a combined TC identification tool}

Compositional and textural differences between background and event sedimentation are sufficient to introduce a new tropical cyclone identification proxy. Combined granulometric and compositional analyses reveal four broad facies types, which are attributable to background and event sedimentation as well as to a transitional subfacies (Fig. 23 a). The background sedimentation-related mudstone facies (Fig. 23 b) reflects the fair-weather and more lagoon-like sedimentation conditions. The event sedimentation-related algae-rich packstone and coralgal rudstone facies (Fig. 23 b) reflect in contrast more marginal reef-like compositions caused by the cyclonemodulated interruptions of the fair-weather sedimentation dynamics. An ambiguous incorporation of the textural wackestone facies is on the basis of the considered samples more challenging. The event sedimentation-related Halimeda wackestone facies (Fig. 23 b) is compositionally very similar to the background-related wackestone facies. However, the event sedimentation-related Halimeda wackestone facies substantially differs from its background counterpart in terms of higher mean grain size values (Table 5). This small example highlights the need of a combined compositional and textural facies classification.

The cluster and PCA analyses verify the use of this combined facies classification and ensure the application as an additional cyclone identification proxy. Both analyses graphically present a categorical separation of background and event sedimentation facies on the basis of grain size values, composition and the ratio between fine carbonate material $(<63 \mu \mathrm{m})$ and skeletal component abundances (>63 $\mu \mathrm{m})$. The importance of considering both parameters can be additionally demonstrated discussing two further examples. Sample number 23 is part of the event sedimentation-related algae-rich packstone facies. The sample clusters, however, because of its high grain size $(332 \mu \mathrm{m})$, within a group of coralgal rudstone facies samples. Another example is sample number 16, which is part of the background-related wackestone facies. Sample 16 clusters as a single exception within a group of event sedimentation-related Halimeda wackestone facies. The mean grain size $(24 \mu \mathrm{m})$ as well as the Halimeda abundance (19\%) of sample number 16 are both significantly increased in contrast to the other wackestone (bs) 
samples. The sample is thus more similar to the event sedimentation-related Halimeda wackestone facies. Both examples show that it is challenging to estimate the ultimately decisive grouping parameter. The facies clustering is rather a combination of both compositional and textural key characteristics, which are of course closely connected to each other (Table $5 \mathrm{~b}$ ).

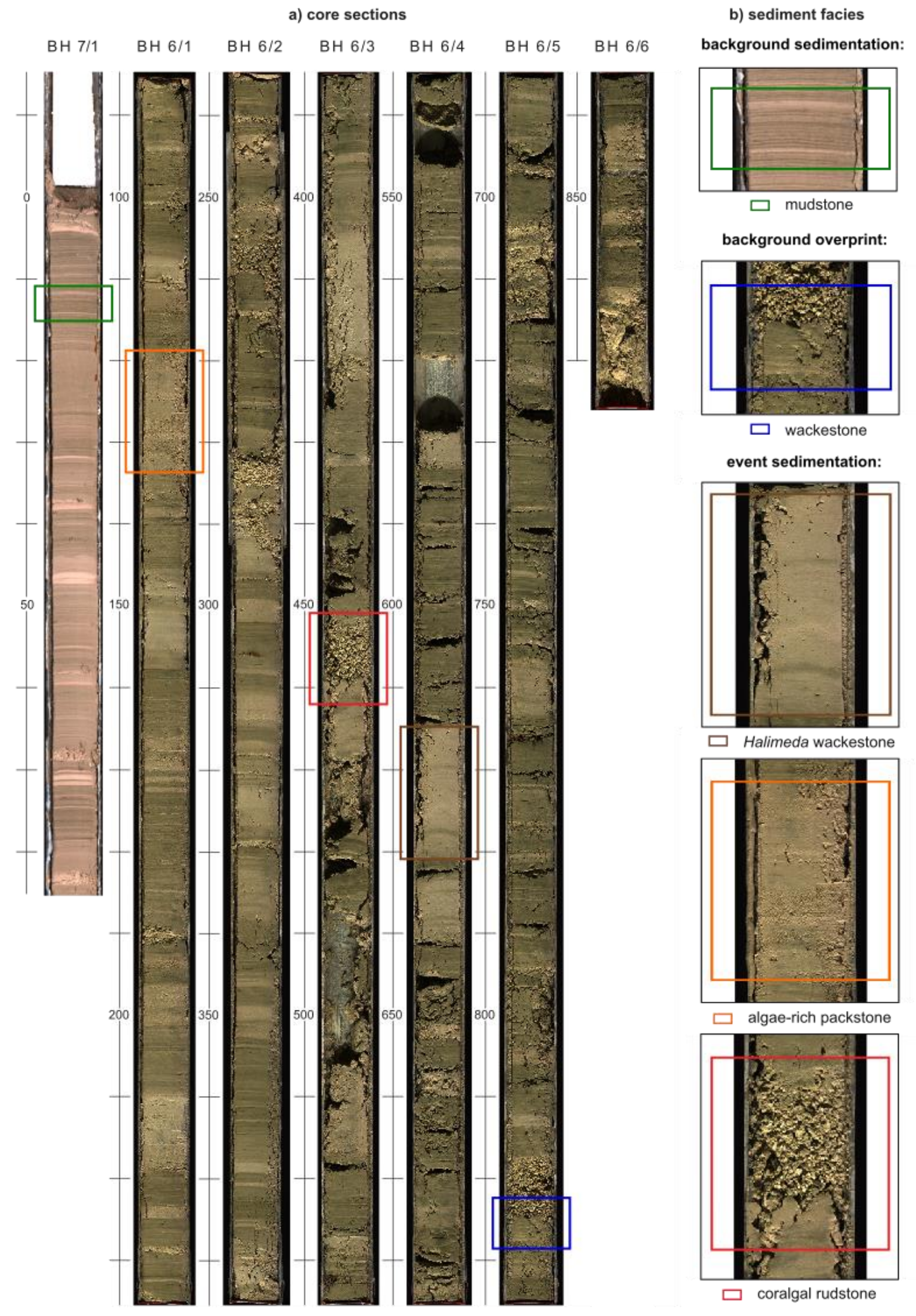


$\leftarrow$ Figure 23. (a) Core photos illustrating one section from core $\mathrm{BH} 7$ and six sections from core $\mathrm{BH}$. Core depth $(\mathrm{cm})$ is given in $50 \mathrm{~cm}$ (values) and $10 \mathrm{~cm}$ intervals (lines). No samples have been taken from the core section BH7/1 within this study. (b) Magnified core images of mudstone (bs), wackestone (overprinted-bs), Halimeda wackestone (es), algae-rich packstone (es) and coralgal rudstone (es) facies. Abbreviations: bs (background sedimentation); es (event sedimentation).

Our facies classification is only anchored on a limited amount of 40 randomly collected core samples. An application of the compositional and textural facies classification parameters is necessary over the entire core length, in order to create a more reliable facies differentiation between both sedimentation dynamics (Suppl. 14 a-g). The different panels of Suppl. 14 illustrate the performed extrapolation process in the corresponding "facies" column, in which the sample positions and different sedimentary facies are shown over the entire core length. Suppl. 14 also allows a comparison with other cyclone identification proxies (Schmitt et al. 2020a) and helps to solve the discussed limitations with regard to the wackestone facies affiliation to both background and event sedimentation. The extrapolation clearly indicates that large parts of the background sediments (72\%) are attributable on the basis of the presented key criteria (Table 5 a) to the mudstone facies. The remaining $28 \%$ of the background sedimentation may be described as background-related wackestone facies. This facies differs only in terms of lower grain sizes and reduced Halimeda abundances from the event sedimentation-related Halimeda wackestone facies, which in turn characterizes $83 \%$ of all event bed layers of the sediment core BH6. It is striking that the background-related wackestone facies occurs primarily beneath and among very thick and coarse-grained event beds of the algae-rich packstone and coralgal rudstone facies. We interpret the background-related wackestone facies as an overprinted background mudstone facies, which includes due to the storminduced overprinting some textural and compositional characteristics of event bed facies (Fig. 23 b). Such a facies may result either from an erosive reworking and mixing of the underlying varved material with event bed material or through rip-upclast deposition. This renders the transitional wackestone facies very different to the background-related mudstone facies. An additional occurrence of the background sedimentation-related wackestone facies is limited to short core sections with repeated occurrences of cyclone events involving probably a comparable material mixing during erosive event sedimentation. The abundance of this facies is, however, considerably lower in contrast to the mudstone facies, which is anyway a reliable indicator for background sedimentation conditions. Occurrences of the rudstone, 
packstone and wackestone facies are in turn a useful proxy to identify cyclone events in the wake of textural and compositional analyses, with the outlined limitation of the transitional facies. The multi-proxy tropical cyclone identification approach (Table 5 a) of Schmitt et al. (2020a) has been also used during the extrapolation process, in order to overcome this textural and compositional facies analyses-related limitation. Within this framework, a sample or core section of wackestone (bs) facies can be reliably excluded to be an event bed following five different criteria: (1) green, buffgreen colour, (2) fine material $(<63 \mu \mathrm{m})$ abundance $>85 \%$, (3) mean grain size $<20$ $24 \mu \mathrm{m}$, (4) layer thickness $=2.5 \mathrm{~mm}$ and (5) $\mathrm{Sr} /$ Ca ratios $<0.025$.

\subsection{Temporal composition changes}

A particularly striking and statistically significant decreasing trend of the organic matter abundance is visible towards the core base. This trend is valid for the combined consideration of event and background sedimentation as well as for the separate consideration of both categories, and is likely the result of organic matter content preservation. Two other significant trends occur only within the event sedimentation sections. Halimeda and foraminifer particle abundances decrease in direction to the core top. There seems to be on the contrary a general up-core increase of coral abundance in the combined sediment succession and within the event sedimentation sections. This trend is statistically insignificant, like the up-core decrease of coralline red algae abundance. Opposing trends of algae and coral abundances possibly reflect temporal ecology changes in the marginal reef environment. Algae are more resistant to changing environmental conditions than corals. Common Era SST reconstructions indicate, however, an increase of southwestern Caribbean (Schmitt et al. 2020b) and tropical Atlantic SST (Tierney et al. 2015), which should induce exactly opposite trends. Another control mechanism for the observed trends could be changing cyclone activity regimes (Schmitt et al. 2020a). Increasing frequency of cyclones involves a higher potential for the deposition of over-washed coarse and relatively dense coral fragments. Lower recurrence rates of tropical cyclones could also hamper the source material accumulation in the sedimentation system. Observed composition changes may be the result of rapid cyclone strikes, which probably induce a general decrease of Halimeda abundance, caused both by material mixing and dilution through changes in sediment sources. The second hypothesis also agrees with results from previous 
south-western Caribbean cyclone regime investigations, which indicate a generally high cyclone activity between 900-1400 CE (Gischler et al. 2008; Denommee et al. 2014). Halimeda abundance decreases significantly between $500 \mathrm{~cm}$ and $400 \mathrm{~cm}$ core depth, which is equivalent to the time interval of 1000-1200 CE. The amount of coral fragments seems to generally increase during the same time interval. This time corresponds to a proclaimed transition to higher cyclone activity (900-1100 CE; Schmitt et al. 2020a). The correlation of the compositional trends and cyclone activity variation is, however, largely speculative, in particular considering the weak correlation strength and the small sample size of 40 thin-sections in relation to the core length of $8.55 \mathrm{~m}$. A further limitation is the occurrence of several compositionally and hydrodynamically very different event sedimentation lithologies. In future surveys, sample size needs to be extended for a clear compositional trend evaluation including individual consideration of event sedimentation facies.

\section{Conclusions}

A comparison of surface sediment composition data with the quantified composition of average sinkhole sediment succession reveals a closely linked feedback mechanism between changing sedimentation dynamics (fair weather vs. cyclone conditions) of Lighthouse Reef Atoll and depositional processes within the "Great Blue Hole". The sinkhole sediment composition has been quantified in a combined compositional-textural facies analysis with regard to the two general sedimentation dynamics of fair-weather and storm induced sedimentation and the various sedimentation environments of Lighthouse Reef Atoll. The fair-weather sediments from the "Great Blue Hole" are relatively similar to typical surface lagoon sediments and consists on average of $81 \%$ carbonate fine material, $12 \%$ Halimeda platelets, $3 \%$ coral fragments, $2 \%$ organic material, $1 \%$ mollusc shells, $1 \%$ foraminifer tests, and minor portions of coralline red algae and echinoderm plates $(0-1 \%)$. The mean grain size of the background sediments is around $19 \pm 4 \mu \mathrm{m}$. The differences to the lagoon sediments may be best explained by the special geomorphology of the sinkhole allowing an enrichment of fine carbonate material. The event bed sediments differ from background sediments in terms of generally lower fine carbonate material amounts (50\%) and increased abundances of over-washed Halimeda chips (28\%) and coral skeletons (6\%) as well as substantially increased average grain sizes (97 $\mu \mathrm{m})$. Tropical cyclones interrupt the fair-weather sedimentation dynamics and induce 
a shift towards a more marginal reef-like sediment composition by source region material over-wash. Our granulometric, compositional and statistical analyses revealed four sedimentary facies with affiliation either to the background (mudstone) or event sedimentation (Halimeda wackestone, algae-rich packstone, coralgal rudstone) as well as an overprinted background sub-facies (wackestone). The latter one originates likely from storm-controlled modifications of varved background sections (e.g., erosive boundaries, material mixing, rip-up-clasts) and occurs primarily beneath and within thick and coarse event beds of the packstone and rudstone facies, which are ordinarily characterized on an erosive basis. Such sections of overprinted background sediments occur also among core section with temporally quick succession of several erosive event beds involving a comparable mixing of sediment characteristics. The striking compositional and textural differences of the Halimeda wackestone, algae-rich packstone and coralgal rudstone facies are a useful proxy to identify event beds of tropical cyclones in unconsolidated sinkhole sediment successions, however, with the limitation of given background sedimentation overprinting. The consideration of other independent cyclone identification proxies contributes to overcome this limitation. It seems entirely plausible that the different facies of the unconsolidated "Great Blue Hole" sediment succession could have been also preserved in similar and in terms of sedimentation dynamics comparable sinkhole or rock records, ensuring a wider application potential for identifying paleo-cyclonic events on the basis of these primary sedimentary facies. The discussed correlation of compositional event bed shifts and cyclone activity remains largely speculative, in particular considering the weak correlation strength and the small sample size of the study. The sample size needs to be extended in further studies, in order to connect variations in event bed composition with cyclone regime changes, including separate considerations of the three storm deposit facies. 


\section{CHAPTER 5:}

\section{CONCLUSIONS AND FORECAST}

\section{Ph.D. thesis: key objectives - summary}

\subsection{Summary (English)}

This Ph.D. thesis had three major objectives including (1) the development of an annually-resolved Common Era record for tropical cyclone activity, (2) the elaboration of annually-resolved SST and AMO datasets spanning the past two millennia and (3) a sedimentary facies identification, characterisation and compositional quantification of the "Great Blue Hole" sediment succession. All key questions and research hypotheses concerning the three major objectives have been completely answered and scientifically documented in three peer-reviewed articles, that form the main text body of this Ph.D. thesis. The two articles published by Scientific Reports and Quaternary Science Review journals contain scientifically outstanding cyclone frequency and climate (SST and AMO) records of the Common Era time series. Such long, continuous and annually-resolved records did not yet exist for the wider Atlantic in general and the circum-Caribbean region in particular. Comparison of historical record cyclone categories with grain size and layer thickness data did not indicate statistically significant correlations between cyclone intensity and textural proxies. As a result, the reconstruction of cyclone intensity was not possible, so that this Ph.D. thesis focused only on the temporal patterns of storm frequency. The most exciting and unexpected finding of the Ph.D. project was the detection of continuous AMO signals back to $300 \mathrm{CE}$ and a statistical proof over wavelet power spectra that the AMO climate phenomenon caused multi-decadal SST patterns over nearly the entire Common Era. This multi-decadal modulation exerts, besides ENSO dynamics, a primary control on long-term cyclone frequency variability in the south-western Caribbean. The third article, which was currently accepted by the Facies journal, contains a quantification of sediment components, the identification of four primary sedimentary facies with either fair-weather- or storm-sedimentation affiliation and enables thus valuable insights into the sinkhole sediment dynamics and the general sedimentology of event layer formation in sinkhole setting. This Ph.D. thesis also succeeded to implement a completely new sedimentary facies-based application for 
tropical cyclone event bed identification by using a textural and compositional evaluation of fair-weather and event sedimentation sections.

\subsection{Zusammenfassung (Deutsch)}

Mit der Durchführung dieser kumulativen Dissertation wurden drei unterschiedliche Ziele verfolgt: (1) die Entwicklung eines jährlich aufgelösten Datensatzes, der die Häufigkeit von tropischen Zyklonen über die letzten zwei Jahrtausende widerspiegelt, (2) die Erzeugung von jährlich aufgelösten SST und AMO Datensätzen für den gleichen Zeitraum und (3) die Ausarbeitung einer sedimentären Faziesanalyse, die eine kompositionelle Quantifizierung und Charakterisierung der Sedimentabfolgen im "Great Blue Hole" thematisiert. In dieser publikationsbasierenden Dissertation konnten die drei Forschungsziele vollständig erreicht und alle vorab aufgestellte Hypothesen, die mit diesen drei Aspekten im Zusammenhang stehen, beantwortet werden. Die Einzelergebnisse wurden zusätzlich zu dieser Doktorarbeit in Form von drei wissenschaftlichen Fachartikeln veröffentlicht, wobei letztere den eigentlichen Hauptteil dieser Dissertation darstellen. In den Fachartikeln, die bei den Journals Scientific Reports und Quaternary Science Review veröffentlicht wurden, sind mehrere einzigartige Klimadatensätze vorgestellt. Über den Zeitrahmen der vergangene zwei Jahrtausende reflektieren diese Datensätze für die süd-westliche Karibik Veränderungen in der Häufigkeit tropischer Zyklone, Variationen von SST und die AMO Variabilität. Für den tropischen Atlantik im Allgemeinen und die Karibik im Speziellen gab es bis zum Zeitpunkt dieser Dissertation noch keine vergleichbar lange, über mehrere Jahrtausende kontinuierlich erfasste und gleichzeitig jährlich aufgelöste gemeinsame Rekonstruktion von Sturmhäufigkeit, SST und AMO Variabilität. Der Vergleich von historischen Aufzeichnungen über Sturmstärken mit gemessenen Korngrößen und Schichtdicken der „Great Blue Hole“ Sturmlagen ergab keine statistisch signifikante Korrelation, so dass eine ursprünglich geplante Rekonstruktion von Sturmstärken nicht möglich war. Aus diesem Grund konzentrierte sich die vorgelegte Dissertation in erster Linie auf die hochauflösende Rekonstruktion von Sturmhäufigkeiten. Der Nachweis kontinuierlicher AMO Signale zurück bis in das Jahr 300 n.Chr. war ein wissenschaftlich äußerst relevantes und gleichzeitig vollkommen unerwartetes Ergebnis dieser Dissertation, das stattdessen erforscht wurde. Über Wavelet-Power-Spektren konnte der statistische Nachweis erbracht werden, dass das AMO-Klimaphänomen über fast die gesamte Neuzeit betrachtet 
multi-dekadische SST-Variationen erzeugt. In der süd-westlichen Karibik übt der multi-dekadische Einfluss des AMO Phänomens zusätzlich zu der gut erforschten ENSO-Dynamik eine starke Kontrolle auf die langfristige Steuerung der Sturmhäufigkeit aus. Der dritte wissenschaftliche Fachartikel, der kürzlich vom Facies Journal zur Veröffentlichung angenommen wurde, beschreibt eine Quantifizierung der Sedimentkomponenten, die Identifizierung von vier Sedimentfazies und deren Zugehörigkeit zur Schönwetter- oder Sturmsedimentation. Dieser Abschnitt der Dissertation ermöglichte auf der einen Seite wertvolle Einblicke in die Sedimentdynamik von „Blue Hole“ Ablagerungsräumen. Auf der anderen Seite ermöglich er eine detaillierte Einsicht auf die sedimentologischen Abläufe, die in diesem Setting zur Bildung von Sturmlagen führen. Im Kontext dieser Faziesanalyse konnte eine neue Proxy-Anwendung für die Identifikation von Sturmlagen etabliert werden. Diese basiert auf der Untersuchung und Charakterisierung von Sedimentfazies, indem texturelle und kompositionelle Unterschiede von Schönwetter- und Sturmsedimenten evaluiert und quantifiziert wurden.

\section{Ph.D. thesis: conclusive results}

\subsection{Conclusions (English)}

Tropical cyclone reconstruction.- The tropical cyclone archive (Chapter 2) extends in a remarkably way the limited knowledge of long-term cyclone dynamics and provides a detailed view of the causes and maintenance of late Holocene storm activity modulation over more than $1.8 \mathrm{kyrs}$. Quantitative data from the sediment core "BH6" largely confirm the results of previous studies (Gischler et al. 2008, 2013; Denommee et al. 2014) and add an unprecedented period of 700 years of low TC activity that is attributable to the DAC (500-900 CE) and the RWP (0-500 CE). In this Ph.D. project, a multi-proxy-approach was applied as an important advancement, to ensure a more reliable identification of storm layers, which requires at best match to fulfil five different criteria: (1) grain sizes $>20-24 \mu \mathrm{m}$; (2) $<85 \%$ of fine material $<63 \mu \mathrm{m}$; (3) layer-thickness $>2.5 \mathrm{~mm}$;(4) yellow-brown colour and (5) $\mathrm{Sr} / \mathrm{Ca}$ ratio $>0.025 .157$ coarse-grained (silt, sand; grain-size $>20 \pm 4 \mu \mathrm{m}$ ) event beds were interpreted as storm deposits. Historical storm record calibration suggests that the offshore cyclone archive of Lighthouse Reef is generally sensitive to all storm categories ranging from tropical storms up to major hurricanes of categories 4 and 5 . 
The cyclone record indicates the highest storm frequency during the Modern Global Warming ( $>1900 \mathrm{CE}$ ), a distinct decrease to medium activity over the Little Ice Age (1400-1800 CE) and again a high activity since mid-late Medieval Warm Period (1100-1400 CE). Enhanced cyclone frequency was generally expected to occur during times of elevated and/or rising SST (Saunders and Lea 2008). Large-scale climate and circulation patterns rather than local temperature variations have been also suspected to correlate with long-term cyclone occurrence (Mann et al. 2009; Denommee et al. 2014). This Ph.D. thesis confirmed a likely connection between long-term cyclone frequency patterns and at least basin-scale climate phenomena responses to Common Era climate variations and offered at the same time a conceptual and comparative view onto these dynamics considering several involved tropospheric and oceanographic control mechanisms, such as the El-Niño-Southern Oscillation (ENSO), the Atlantic Multidecadal Oscillation (AMO) and the North Atlantic Oscillation (NAO). These climate phenomena exercise a major control for enhanced/supressed storm formation, especially on centennial-millennial (primary) and multi-decadal (secondary) time scales by modulating the thermodynamic environment (SST and tropospheric wind shear dynamics) of large tropical areas. AMO phase changes were successfully correlated with periods of high (AMO+) and low (AMO-) frequency of tropical cyclone formation. During the past 1,700 years the AMO phenomenon modulated cyclone activity on multi-decadal time-scales. The beginning of the Medieval Warm Period (MWP) was identified as an important time interval of the Common Era timeline. There is a striking coincidence of considerably positive basin-wide/global SST anomalies and a noteworthy cyclone frequency variation, visible in the "Great Blue Hole" core records, during the MWP. The southward migration of the intertropical convergence zone (ITCZ) likely caused, in combination with extensive hydro-climate changes, a shift in the tropical Atlantic cyclone regime (van Hengstum et al. 2016). In the south-western Caribbean, cyclone frequency consequently changed from a stable and less active stage (100-900 CE) to a more active and variable state (>1100 CE).

Interestingly, five exceptionally thick storm deposits (up to $28 \mathrm{~cm}$ ) overlap with major drought phases that occur in the Mayan Lowlands around 1000 CE (Hodell et al. 2001; Haug et al. 2003; Kennett et al. 2012). It could be speculated that severe cyclone landfalls in the Mayan Lowlands caused heavy destruction, flooding and crop 
failure in coastal lowlands. Therefore, cyclone landfalls might have additionally contributed to the stress during such drought phases further pushing the Maya civilization towards their limits. If one compares the substantial current impacts of relatively frequent and intensive cyclone landfalls to life and property of the modern Caribbean populations, you can imagine that a shift to more frequent and maybe stronger cyclone strikes in succession of the transitioning MWP climate variation would likely induce severe problems to the ancient Maya culture.

SST and AMO reconstruction.- The SST and AMO reconstructions (Chapter 3) allow to expand well-known manifestations of climate dynamics during the short Instrumental Era up to an approximately two millennia-long perspective, which is key for studying long-term patterns of past climate variations and their effects on human society. The recovered continuous climate records are based on annually-resolved stable isotopes $\left(\delta^{18} \mathrm{O}, \delta^{13} \mathrm{C}\right)$ and decadally-resolved molecular proxy applications (TEX ${ }_{86}$ ), which both extend all available Caribbean SST records with increased quantitative sampling resolution 700 years back in time.

The studies of $\delta^{18} \mathrm{O}$ and $\delta^{13} \mathrm{C}$ has revealed that the sediments of the "Great Blue Hole" very reliably recorded late Holocene climate variability during five Common Era cold and warm climate intervals, including the Roman Warm Period, the Dark Ages Cold, The Medieval Warm Period, the Little Ice Age and the Modern Global Warming. While $\delta^{18} O$ was used as a relative temperature proxy for SST, TEX ${ }_{86}$ was successfully implemented in a marine sediment succession as a salinity independent proxy (Schouten et al. 2002; O'Brian et al. 2014), in order to receive absolute temperature values for the south-western Caribbean region. The $\delta^{13} \mathrm{C}$ signals of the "Great Blue Hole" sediments suggest control by run-off, the input of nutrients and primary production (Gischler et al. 2008). Patterns of $\delta^{13} \mathrm{C}$ signals have been identified in this Ph.D. project to best reflect mainland run-off/soil-erosion rates as response to cyclone activity regime variations.

Over Common Era time scales, oxygen isotopes and $\mathrm{TEX}_{86}$ data imply a general SST rise of $0.5^{\circ} \mathrm{C}$ and $1.3^{\circ} \mathrm{C}$, starting around $\sim 1000 \mathrm{CE}$ in the Caribbean Basin, respectively. Modulation of SST during the Common Era time frame likely operated on two different time levels. Solar (Hodell et al. 2001) and volcanic (Sigl et al. 2015) activities triggered climate changes, which in turn induced responses of the AMO 
(Black et al. 1999), the NAO (Trouet et al. 2009) and the ENSO (Frappier et al. 2002). Their changing mode of action was identified in this Ph.D. thesis as a likely origin of primary, or better, centennially-scaled SST anomalies. $\delta^{18} \mathrm{O}$ data further indicate a striking secondary control on multi-decadal time scales, occurring with a 32-64-years periodicity. This periodic fluctuation of SST was successfully correlated with cyclic AMO phase changes that control SST variation on multi-decadal orders (50-70 years). This positive feedback was successfully identified throughout nearly the entire Common Era.

The carbon isotope record exhibits two remarkable negative anomalies and a longterm up-core decreasing trend. Such negative excursions were previously correlated with intensive deforestation phases during high phases of Maya civilisation (Gischler et al. 2008). After the cultural demise and the related forest re-growth, which potentially prevented large amounts of soil erosion since $1 \mathrm{kyr} B P, \delta^{13} \mathrm{C}$ values should fluctuate in a relatively constant manner (Anselmetti et al. 2007). The stalling of the decreasing trend in $\delta^{13} \mathrm{C}$ beginning ca. $1400 \mathrm{CE}$ is, however, far ahead of the classical Maya Culture demise. Also, a previous cultural high phase (400-800 CE) of the classical Maya culture and its proliferation time (650-800 CE), which certainly involved severe deforestation, are, however, not expressed in the $\delta^{13} \mathrm{C}$ time series via negative excursions. This Ph.D. thesis suggests another plausible explanation, which better describes the $\delta^{13} \mathrm{C}$ pattern. The two conspicuous negative $\delta^{13} \mathrm{C}$ excursions overlap with times of significantly increased storm activity, whereas the three plateaus coincide with times of decreased Caribbean cyclone activity. Cyclone landfalls come also with increased precipitation and concurrently enhanced soil erosion and transport of excess ${ }^{12} \mathrm{C}$ to the adjacent marine realm. This huge effect onto carbon stable isotope signatures was, of course, reinforced by previously occurring changes of vegetation and agriculture in response to Maya culture development. Following this argumentation, the first anomaly ( 1000-1400 CE) is very likely attributable to the high activity cyclone regime that characterises the Medieval Warm Period. The second anomaly (>1900 CE) occurs during a further phase of high storm activity, but is most likely the result of the "Suess effect", i.e. the impact of the Industrial Revolution on the composition of carbon isotopes.

Facies analysis.- The sinkhole sediment composition has been successfully quantified in a combined compositional-textural facies analysis (Chapter 4). This part 
of the Ph.D. thesis describes in detail the two general sedimentation dynamics of fairweather and storm induced sedimentation and concentrates on the special sinkhole depositional environment within the lagoon of Lighthouse Reef Atoll. Sediments having formed under both conditions were texturally categorized by determination of classical sedimentary parameters such as mean grain size and sorting. Sediment composition was quantified in thin-sections. A comparison of surface sediment composition data with quantified composition data of the average sinkhole sediment succession revealed a closely linked feedback mechanism between changing sedimentation dynamics (fair weather vs. cyclone conditions) and depositional processes within the "Great Blue Hole". The fair-weather sediments of the sinkhole succession are relatively similar to typical surface lagoon sediments of Lighthouse Reef and consists on average of $81 \%$ carbonate fine material, $12 \%$ Halimeda platelets, $3 \%$ coral fragments, $2 \%$ organic material, $1 \%$ mollusc shells, $1 \%$ foraminifer tests, and minor portions of coralline red algae and echinoderm plates $(<1 \%)$. The mean grain size of the background sediments is around $19 \pm 4 \mu \mathrm{m}$. One obvious compositional difference to the lagoon sediments may be best explained by the special geomorphology of the sinkhole allowing a significant enrichment of fine aragonitic carbonate material. Tropical cyclones interrupt the fair-weather sedimentation dynamics and induce due to incoming storm surges and storm waves a shift towards a more marginal reef-like sediment composition, assured by marginal reef over-wash of coarse skeletal debris. The event bed sediments consequently differ from the fair-weather sediments in terms of generally lower fine carbonate material amounts $(50 \%)$ and increased abundances of over-washed Halimeda chips $(28 \%)$ and coral skeletons $(6 \%)$ as well as substantially increased average grain sizes $(97 \mu \mathrm{m})$.

Combined granulometric, compositional and statistical analyses, presented in the sedimentological part of this Ph.D. thesis, revealed four sedimentary facies with affiliation either to the background (mudstone) or event sedimentation (Halimeda wackestone, algae-rich packstone, coralgal rudstone) as well as an overprinted background sub-facies (wackestone). The latter one was interpreted to originate from storm-controlled modifications of varved background sections (e.g., erosive boundaries, material mixing, rip-up-clasts). The wackestone facies occurs primarily beneath and within thick and coarse event beds of the packstone and rudstone 
facies, which are ordinarily characterized on an erosive basis. Such sections of overprinted background sediments occur also among core section with temporally quick succession of several erosive event beds involving a comparable mixing of sediment characteristics. The striking compositional and textural differences of the Halimeda wackestone, algae-rich packstone and coralgal rudstone facies have been confirmed as a useful proxy application to identify event beds of tropical cyclones in unconsolidated sinkhole sediment successions, however, with the limitation of given background sedimentation overprinting.

\subsection{Schlussfolgerung (Deutsch)}

Rekonstruktion tropischer Zyklone.- Das Archiv für tropische Zyklone, dass im zweiten Kapitel dieser Arbeit ausführlich diskutiert wurde, erweitert in einer bemerkenswerten Art und Weise unser, durch die kurze instrumentelle Aufzeichnung, stark begrenztes Wissen über lang-zeitliche Klimadynamiken des späten Holozäns. Im Kapitel 2 wurde in diesem Kontext zunächst auf mögliche Ursachen von vergangenen Klimaschwankungen eingegangen. Hierauf aufbauend konnte mit dieser publikationsbasierenden Dissertation eindrucksvoll aufgezeigt werden, dass bestimmte Klimaphänomene über die letzten 1,885 Jahre einen entscheidenden Einfluss auf die Häufigkeit von tropischen Zyklonen hatten, vor allem auf multi-dekadischen und längeren Zeiträumen betrachtet. Die quantitativen Datensätze, die durch die vielfältigen Untersuchungen am Sedimentbohrkern „BH6“ gewonnen wurden, bestätigen im Wesentlichen die Ergebnisse vorheriger Studien (Gischler et al. 2008, 2013; Denommee et al. 2014). Diese werden mit Hilfe dieser Dissertation aber um ein 700 Jahre andauerndes und bis jetzt noch nicht dokumentiertes Zeitintervall ergänzt, das durch eine konstant niedrige Sturmaktivität charakterisiert wird und den beiden Klimaintervallen des Dunklen Zeitalters (500-900 n.Chr.) und der Römischen Warmzeit (0-500 n.Chr.) zuzuordnen ist. In der vorgelegten Doktorarbeit wurde ein innovativer Multi-Proxy-Ansatz aus geochemischen, texturellen und kompositionellen Daten verfolgt. Diese innovative Neuerung bei gleichzeitig jährlicher Auflösung ermöglichte eine sehr viel exaktere und zuverlässigere Identifikation von Sturmlagen verglichen mit allen bisher durchgeführten Vergleichsstudien. Für die erfolgreiche Identifikation einer Sturmlagen sollten im besten Falle fünf verschiedene Kriterien erfüllt sein: (1) mittlere

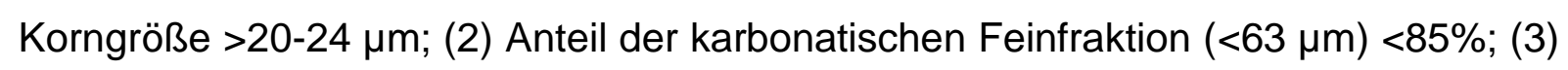


Mächtigkeit der Sturmlage $>2.5 \mathrm{~mm}$; (4) gelb-braune Farbe und (5) $\mathrm{Sr} / \mathrm{Ca}$ Verhältnis $>0.025$. Im Sedimentbohrkern „BH6 konnten auf dieser Grundlage insgesamt 157 grobkörnige Sturmlagen (Silt, Sand; mittlere Korngröße >20 $\pm 4 \mu \mathrm{m}$ ) identifiziert werden. Der Vergleich mit historischen Sturmaufzeichnung hat ergeben, dass das "Great Blue Hole" Archiv generell verwendet werden kann, um alle Sturmkategorien vom tropischen Sturm bis hin zum Hurrikan der Kategorie 4/5 zu rekonstruieren.

Der präsentierte Datensatz spiegelt die höchste Sturmhäufigkeit während der Modernen Globalen Erwärmung (>1900 n.Chr.), einen deutlichen Rückgang auf eine gemäßigte Aktivität während der Kleinen Eiszeit (1400-1800 n.Chr.) und erneut eine hohe Aktivität in der Mittelalterlichen Warmzeit (1100-1400 n.Chr.) wieder. Das Dunkle Zeitalter (500-900 n.Chr.) und die Römischen Warmzeit (0-500 n.Chr.) sind durch eine niedrige Sturmaktivität gekennzeichnet. Als ursprüngliche Forschungshypothese wurde erwartet, dass in Zeiten erhöhter und/oder steigender SST eine größere Häufigkeit von tropischen Zyklonen erwartet werden kann (Saunders und Lea 2008). Diese Hypothese konnte im Rahmen dieser Doktorarbeit bestätigt werden. Es wurde weiterhin berücksichtigt, dass großräumig wirkende Klimaphänomene einen stärkeren Einfluss auf das langfristige Auftreten (>multi-dekadisch) von tropischen Zyklonen zu haben scheinen als lokale Temperaturschwankungen, die die Sturmaktivität eher auf inter-annuellen Zeitskalen regulieren (Mann et al. 2009; Denommee et al. 2014). Die Ergebnisse dieser Dissertation stützen diese These. So konnte gezeigt werden, dass für die letzten 1,885 Jahre ein Zusammenhang zwischen langfristigen Häufigkeitsveränderungen im Auftreten tropischer Zyklone und großräumig wirkenden Klimaphänomen existiert. Deren Wirken und Zusammenspiel hat sich als Reaktion auf diverse spät Holozäne Klimavariationen immer wieder signifikant verändert. Damit bietet diese Arbeit gleichzeitig auch einen sehr umfangreichen konzeptionellen und vergleichenden Einblick in die globale Klimadynamik der Neuzeit, indem alle für die Bildung von tropischen Zyklonen relevanten atmosphärischen und ozeanographischen Kontrollmechanismen mit in die Diskussion eingeschlossen wurden. Zu diesen gehören die El-Niño-Südliche-Oszillation (ENSO), die Atlantischen Multi-dekadische Oszillation (AMO) und die Nordatlantischen Oszillation (NAO). Diese drei Klimaphänomene nehmen durch ihr gegenseitiges Wechselspiel Einfluss auf die thermodynamischen Voraussetzungen für eine verstärkte bzw. gehemmte Bildung 
von tropischen Zyklonen, indem sie, vor allem auf multi-dekadischen (sekundär) aber auch längeren Zeitskalen (primär), die ozeanographischen und atmosphärischen Rahmenbedingungen großer tropischer Gebiete regulieren (z.B. SST, Windscherung). AMO-Phasenänderungen wurden in dieser Dissertation erfolgreich mit Zeitintervallen korreliert in denen eine höhere (AMO+) und geringere (AMO-) Häufigkeit von tropischen Zyklonen vorlag. Das AMO-Klimaphänomen hat die Sturmaktivität während der letzten 1,700 Jahre im tropischen Westaltantik überwiegend auf multi-dekadischen Zeitschienen geprägt, indem es multi-dekadische SST Anomalien erzeugt hat. Die Mittelalterliche Warmzeit (MWP) ist ein überaus wichtiges Klimaintervalle der letzten zwei Jahrtausende. Die MWP wurde in dieser Dissertation als wichtiges Referenzintervall zur heutigen Klimasituation identifiziert. Während der MWP bestand eine auffällige Übereinstimmung zwischen einer stark erhöhten Häufigkeit tropischer Zyklone und beträchtlich positiven und den gesamten Atlantik umfassenden, wenn nicht sogar global auftretenden SST Anomalien. Eine südwärts gerichtete Verschiebung der intertropischen Konvergenzzone (ITCZ) verursachte wahrscheinlich, und in Kombination mit weitreichenden hydroklimatischen Veränderungen, eine Modifikation des tropisch-atlantischen Sturmregimes (van Hengstum et al. 2016). Für die süd-westliche Karibik wurde eine Häufigkeitsveränderung von tropischen Zyklonen rekonstruiert, die sich von einem stabilen und weniger aktiven Stadium (100-900 n.Chr.) zu einem sehr viel aktiveren und variableren Zustand (>1100 n.Chr.) wandelte.

In diesem Zusammenhang ist es interessant, dass sich fünf außergewöhnlich dicke Sturmablagerungen (bis zu $28 \mathrm{~cm}$ Mächtigkeit) mit Zeiten ( 1000 n.Chr.), in denen längere Dürrephasen im Maya-Tiefland auftraten, überschneiden (Hodell et al. 2001; Haug et al. 2003; Kennett et al. 2012). Es erscheint denkbar, dass starke tropische Zyklone, im Zuge dieser, während der MWP ablaufenden Klimaveränderung, häufiger im Maya-Tiefland auf Land trafen. Diese haben im Küstentiefland vermutlich immense Schäden hervorgerufen, Überflutungen verursacht und zu Ernteausfällen geführt. Ein vermehrtes Auftreten von Sturmereignissen kann somit ein weiterer klimatischer Faktor sein, der die negativen Auswirkungen der MWP (Dürrephasen) verstärkt haben könnte. Während dieses, der heutigen Klimaveränderung sehr ähnlichen Intervalls, scheint die Maya-Zivilisation also in Folge weitreichender klimatischer Veränderungen allmählich an ihre Grenzen gestoßen zu sein. Vergleicht 
und extrapoliert man das heutige Gefahrenpotential von relativ häufigen und intensiven tropischen Zyklonen für die Bevölkerung der Karibik, so wird deutlich, dass solch eine signifikante Veränderung im Sturmregime, wahrscheinlich großen Einfluss auf den Entwicklungstand und das gesellschaftliche Leben der einstigen Maya Hochkultur hatte.

SST und AMO Rekonstruktion.- Die aus den kurzen instrumentellen Aufzeichnungen wohl bekannten Manifestationen der globalen Klimadynamik und deren Einfluss auf Ozeantemperaturen konnten mit Hilfe der hier gezeigten SST und AMO Rekonstruktionen (Kapitel 3), zu einer fast zwei Jahrtausende umfassenden Perspektive erweitert werden. Durch diese Doktorarbeit wurde die Möglichkeit geschaffen die globale Klimadynamik in einer zeitlich sehr viel längeren Perspektive zu betrachten und über hochauflösende Einblicke zu verstehen, wie Muster von vergangenen Klimavariationen auf künftige Klimaschwankungen extrapoliert werden können. Die zu diesem Zweck generierten Klimadatensätze basieren auf jährlich aufgelösten stabilen Sauerstoff- und Kohlenstoffisotopen $\left(\delta^{18} \mathrm{O}, \delta^{13} \mathrm{C}\right)$ und einer erstmals an „Blue Hole“ Abfolgen durchgeführten molekularen Proxyanwendung mit multi-dekadischer Auflösung (TEX 86 ). Die $\delta^{18} \mathrm{O}$ und TEX ${ }_{86}$ Datensätze dieser Studie übertreffen alle verfügbaren SST Archive der Karibik mir einer sehr viel höheren Auflösung um mehr als 700 Jahre. Die Auswertung der $\delta^{18} \mathrm{O}$ und $\delta^{13} \mathrm{C}$ Daten ergab, dass das Sedimentarchiv des „Great Blue Holes“ ausgesprochen gut dazu geeignet ist, um die spät Holozäne Klimavariabilität während fünf unterschiedlicher Warm- und Kaltphasen der Neuzeit abzubilden (Römische Warmzeit, Dunkles Zeitalter, Mittelalterliche Warmzeit, Kleine Eiszeit, Modern Globale Erderwärmung). Der $\delta^{18} \mathrm{O}$ Datensatz wurde erfolgreich als Proxy verwendet, um relative SST Veränderung zu rekonstruieren. Die SST Rekonstruktion mit Hilfe von TEX 86 ist, eine von der Salinität unabhängig Methode (Schouten et al. 2002; O’Brian et al. 2014), um absolute Wassertemperaturen zu ermitteln. Für die süd-westliche Karibik konnten mit Hilfe der marinen Sedimentabfolgen aus dem „Great Blue Hole“ für die letzten 1,885 Jahre erstmals kontinuierlich absolute Ozeantemperaturen rekonstruiert werden. Die an den Warven gemessenen $\delta^{13} \mathrm{C}$ Signaturen können generell als Proxy für verschiedene Umweltveränderungen herangezogen werden. Zu diesen gehören der fluviatile Abfluss, der Eintrag von Nährstoffen oder die Primärprodiktion (Gischler et al. 2008). Diese Dissertation liefert erste Hinweise darauf, dass $\delta^{13} \mathrm{C}$ Signale aus den 
warvierten Abfolgen überfluteter Karsthöhlen verwendet werden können, um den fluviatilen Abfluss vom Mittelamerikanischen Festland bzw. die Raten der Bodenerosion abzuschätzen. Diese Hypothese stützt sich auf die rekonstruierte Häufigkeitsveränderung im Auftreten tropischer Zyklone und deren Einfluss auf den Niederschlag, den fluviatilen Abfluss und die Rate der Bodenerosion.

Betrachtet man die letzten zwei Jahrtausende der Neuzeit in diesem Rahmen, dann zeigen sowohl Sauerstoffisotopen- als auch TEX ${ }_{86}$-Daten einen generellen SST Anstieg von $0.5^{\circ} \mathrm{C}$ bis $1.3^{\circ} \mathrm{C}$, der im Karibischen Raum etwa ab 1000 n.Chr. einsetzte. Die Regulierung der SST lief über die letzten $\sim 2,000$ Jahre auf zwei unterschiedlichen Zeitniveaus ab. Sonnen- (Hodell et al. 2001) und Vulkanaktivität (Sigl et al. 2015) verursachten unterschiedlich ausgeprägte Klimaschwankungen, die wiederum Reaktionen der AMO (Black et al. 1999), der NAO (Trouet et al. 2009) und der ENSO (Frappier et al. 2002) nach sich zogen. Deren sich verändernde Wirkungsweisen zu- und untereinander konnten in dieser Dissertation als eine mögliche Ursache für primäre, oder besser langzeitliche SST Anomalien (Jahrhunderte) bestätigt werden. Die $\delta^{18} \mathrm{O}$ Daten haben außerdem eindrucksvolle Beweise geliefert, dass Klimaphänomene einen sekundären und auf multi-dekadischen Zeitskalen verwirklichten Einfluss auf die SST Variabilität nehmen. Die beobachtete Fluktuation der SST mit einer Periodizität von 32-64 Jahren konnte erfolgreich mit zyklischen AMO Phasenwechseln (50-70 Jahre) korreliert werden. Dieser positive Rückkopplungsmechanismus zwischen der AMO und SST konnte für die südwestliche Karibik über fast die gesamte Neuzeit ( 1,885 Jahre) nachverfolgt werden.

Der $\delta^{13} \mathrm{C}$ Datensatz zeigt neben einem generellen Abnahmetrend in Richtung Gegenwart nur zwei auffällig negative Anomalien. Solche negativen $\delta^{13} \mathrm{C}$ Exkursionen wurden vor dieser Studie ausschließlich mit intensiven Phasen der Entwaldung und großflächigen Landschaftsveränderung während der kulturellen Hochphase der Maya Zivilisation erklärt (Gischler et al. 2008). Berücksichtigt man diese Argumentation, dann sollten die $\delta^{13} \mathrm{C}$ Signaturen nach dem kulturellen Niedergang der Maya Kultur ab etwa 1000 n.Chr. auf einem konstanten Niveau schwanken (Anselmetti et al. 2007). Nach dem Ende der klassischen Maya Kultur müsste ein Vegetationswechsel hin zu ausgedehnten Wäldern und weniger Ackerflächen demnach, der während der Hochphase der landwirtschaftlichen Nutzung angestiegenen Bodenerosion entgegenwirken. Das Ende der negativen 
$\delta^{13} \mathrm{C}$ Anomalie beginnt jedoch erst um ca. $1400 \mathrm{n}$. Chr., also deutlich nach dem kulturellen Niedergang der Maya Kultur. Eine weiter kulturelle Hochphase um 400800 n.Chr., sowie eine Phase schnellen Bevölkerungswachstums (650-800 n. Chr.), die beide sicherlich ebenfalls zu einer starken Entwaldung und zur Schaffung von Ackerflächen geführt haben müssten, werden beide nicht durch die hier gezeigte $\delta^{13} \mathrm{C}$ Rekonstruktion abgebildet. Die $\delta^{13} \mathrm{C}$ Kurve zeigt für diese Zeiträume keine negativen Exkursionen. Diese Dissertation bietet eine andere Erklärung an, die die beiden negativen $\delta^{13} \mathrm{C}$ Exkursionen erklären könnte. Die Intervalle mit auffällig negativen $\delta^{13} \mathrm{C}$ Signalen überschneiden sich mit Zeitintervallen von signifikant erhöhter Sturmaktivität, wohingegen die drei stabil schwankenden Plateaus hingegen mit Zeiten geringer Aktivität überlappen. Wenn tropische Zyklone auf Land treffen, tritt sehr starker Niederschlag auf, der zu einer deutlich erhöhten Bodenerosion und zum Transport von überschüssigem ${ }^{12} \mathrm{C}$ in den angrenzenden Ozean führt. Die Auswirkungen, die dieser Prozess auf die Signatur der Kohlenstoffisotope hat (negative Exkursion), kann natürlich durch Vegetationsänderungen und intensive Landwirtschaft im Zuge der vorangegangen Maya Hochkultur verstärkt worden sein. Folgt man dieser neuen Interpretation der Daten, dann kann die erste Anomalie ( 1000-1400 n.Chr.) sicherlich auf das hoch aktive Sturmregime der Mittelalterlichen Warmzeit zurückgeführt werden. Die zweite Kohlenstoffanomalie (>1900 n.Chr.) tritt zwar auch während eines weiteren hoch aktiven Sturmintervalls auf, ist aber sehr viel wahrscheinlicher das Resultat des "Suess Effekts", also der Auswirkung der Industriellen Revolution auf die Zusammensetzung der Kohlenstoffisotope.

Faziesanalyse.- In der durchgeführten sedimentären Faziesanalyse (Kapitel 4) wurde die Zusammensetzung der spät Holozänen Sedimentabfolge des „Great Blue Holes" erfolgreich quantifiziert. Dieser Abschnitt der Dissertation beschreibt ausführlich die beiden vorliegenden Sedimentationsdynamiken (Schönwetter(Sturmsedimentation) und nimmt dabei explizit Bezug auf das spezielle Ablagerungsmilieu der Karsthöhle innerhalb des Lagunensystems von Lighthouse Reef. Sedimente, die unter beiden Bedingungen gebildet wurden, sind nach ihrer Textur kategorisiert worden, indem klassische Sedimentparameter, wie zum Beispiel die mittlere Korngröße oder Sortierung bestimmt wurden. Die kompositionelle Zusammensetzung der unterschiedlichen Sedimente wurde über 40 verschiedene Dünnschliffe quantifiziert. Der Vergleich mit Oberflächensedimenten aus der Lagune 
und dem Randriff von Lighthouse Reef ergab, dass eine enge Verbindung zwischen den jährlich geschichteten Warven, den zwischengeschalteten Sturmlagen und den beiden Sedimentationsbedingungen (Schönwetter-/Sturmsedimentation) und den Hauptablagerungsräumen (Lagune/Randriff) des Riffsystems besteht. Die Schönwettersedimente der "Great Blue Hole" Abfolge sind vergleichbar mit typischen Oberflächensedimenten des lagunären Ablagerungsraums von Lighthouse Reef. Sie bestehen im Durchschnitt aus 81\% karbonatischem Feinmaterials, 12\% Halimeda Plättchen, 3\% Korallen Fragmenten, 2\% organischem Material, 1\% Mollusken Schalen, 1\% Foraminiferen Gehäusen, und einigen wenigen Fragmenten von korallinen Rotalgen und Echinodermen $(<1 \%)$. Die mittlere Korngröße der Schönwettersedimente beträgt $19 \pm 4 \mu \mathrm{m}$. Trotz aller Gemeinsamkeit existiert ein deutlicher Unterschied zum typischen Lagunensediment von Lighthouse Reef. Der Anteil des karbonatischen Feinmaterials ist in der warvierten Abfolgen des "Great Blue Holes" deutlich höher. Die höheren Gehalte können am besten durch die besondere Geomorphologie der Karsthöhle erklärt werden, die zu einer Anreicherung von sehr feinkörnigem Material geführt hat. Tropische Zyklone unterbrechen die Schönwetter-Sedimentation und erzeugen aufgrund von Sturmfluten und Sturmwellen eine Veränderung in der Sedimentkomposition, die eher der des typischen Randriff Oberflächensediments gleicht. Diese Veränderung wird durch den Eintrag von groben, aus dem Randriff stammenden Riffbruchstücken gewährleistet. Die Sturmlagen unterscheiden sich dadurch maßgeblich von den Schönwettersedimenten und zwar einerseits durch generell niedrigere Gehalte an karbonatischem Feinmaterial (50\%), erhöhten Anteilen von eingeschwemmten Halimeda Plättchen (28\%) und/oder Korallen Skeletten (6\%) und andererseits durch eine deutlich höhere mittlere Korngröße $(97 \mu \mathrm{m})$. Durch die granulometrischen, kompositionellen und statistischen Analysen, die in Kapitel 4 gezeigt werden, konnten vier unterschiedliche sedimentäre Fazies nachgewiesen werden, die eindeutig zur Schönwetter- (mudstone) oder Sturmsedimentation (Halimeda wackestone, algae-rich packstone, coralgal rudstone) zugeordnet werden konnten. Außerdem konnte eine Übergangsfazies (wackestone) identifiziert werden. Die Übergangsfazies ist eine durch tropische Zyklone hervorgerufene Modifikation (z.B. erosive Basis, Materialdurchmischung) der warvierten Sedimentabfolge. Die wackestone Übergangsfazies tritt vor allem unter und zwischen mächtigen Sturmlagen der packstone und rudstone Fazies auf, die in der Regel durch eine 
erosive Basis charakterisiert sind. Solche Abschnitte, die überprägte SchönwetterSedimente darstellen, treten auch in Kernabschnitten mit zeitlich rasch aufeinander folgenden Sturmlage auf, die eine Vermischung der Sedimenteigenschaften zur Folge haben. Die texturelle und kompositionelle Identifikation der drei Sturmfazies (Halimeda wackestone, algae-rich packstone und coralgal rudstone) und deren Unterschiede zur Schönwetter-Fazies (mudstone) konnten als wichtiges semiquantitatives Hilfsmittel etabliert werden, um Sturmlagen von tropischen Zyklonen in nicht verfestigten „Blue Hole“ Sedimentabfolgen zu identifizieren, allerdings mit der Einschränkung, dass die Schönwettersedimente (mudstone Fazies) manchmal durch nachfolgende Stürme überprägt wurden.

\section{Follow-up project}

\subsection{Motivation}

During this Ph.D. project, an $8.5 \mathrm{~m}$ long core recovered from the bottom of the "Great Blue Hole", Belize, has been investigated at annual resolution. This exceptional storm and climate archive encompasses the past 1,885 years, i.e., almost the entire Common Era. Both tropical cyclone and climate archives reflect the late Holocene climate periods of the Roman Warm Period (RWP), Dark Ages Cold (DAC), Medieval Warm Period (MWP), Little Ice Age (LIA), and Modern Global Warming (MGW). Short-term and longer-term climate phenomena such as the El-Niño-Southern Oscillation (ENSO), the North Atlantic Oscillation (NAO), and the Atlantic Multidecadal Oscillation (AMO) have apparently influenced climate and storm patterns in the wider study area. The beginning of the Medieval Warm Period (900$1100 \mathrm{CE}$ ) represents a significant transition phase during which storm activity and sea surface temperature (SST) increased and became more variable. Interestingly, the final collapse of the Classical Maya high culture falls within this time window.

Based on the known sedimentation rate, a maximum of some $30 \mathrm{~m}$ of annually layered Holocene sediments likely accumulated at the bottom of the sinkhole since marine inundation ca. $6.8 \mathrm{kyr} \mathrm{BP}$, underlain by earlier Holocene, postglacial and glacial lacustrine sediments. Annually-layered marine sediments may even be expected further downcore; in case the sinkhole existed already during previous interglacials and glacials of marine isotope stages (MIS) 3-5. In the continuation of this Ph.D. project, the research team plans to return to the "Great Blue Hole" with a larger drill rig to core the entire late Quaternary deposits. The recovered core 
material would allow extending this unique (continuous and annually-resolved) storm and climate archive several thousand years back in the Holocene as well as to obtain the underlying lacustrine and marine deposits/archives of the late Pleistocene.

\subsection{Objectives}

The follow-up project has two major objectives including (1) the extension of the storm and climate record back in time, at least into the mid-Holocene and into the Holocene Climate Optimum (5-9 kyrs BP) as well as (2) the identification of the nature and age of the sediments underlying the Holocene archive, probably older lacustrine and marine early Holocene and Pleistocene sediment successions. Both objectives are scientifically relevant in order to create a completely new perspective on climate dynamics in the Holocene and Pleistocene, and climate phenomena maintenance of SST and cyclone activity modulation in the south-western Caribbean region. It will then be possible to compare at high temporal resolution climate variability and cyclone frequency to the entire time span, in which the classical Maya culture occurred, including the early phases of cultural development from 2-3 kyrs BP. Based on this, it will be feasible also to evaluate as to how Mesoamerican hydroclimate changes operated as a catalyst for the local cultural development and how they appeared as a potential factor for the collapse of a past high civilization (Fig. 24).
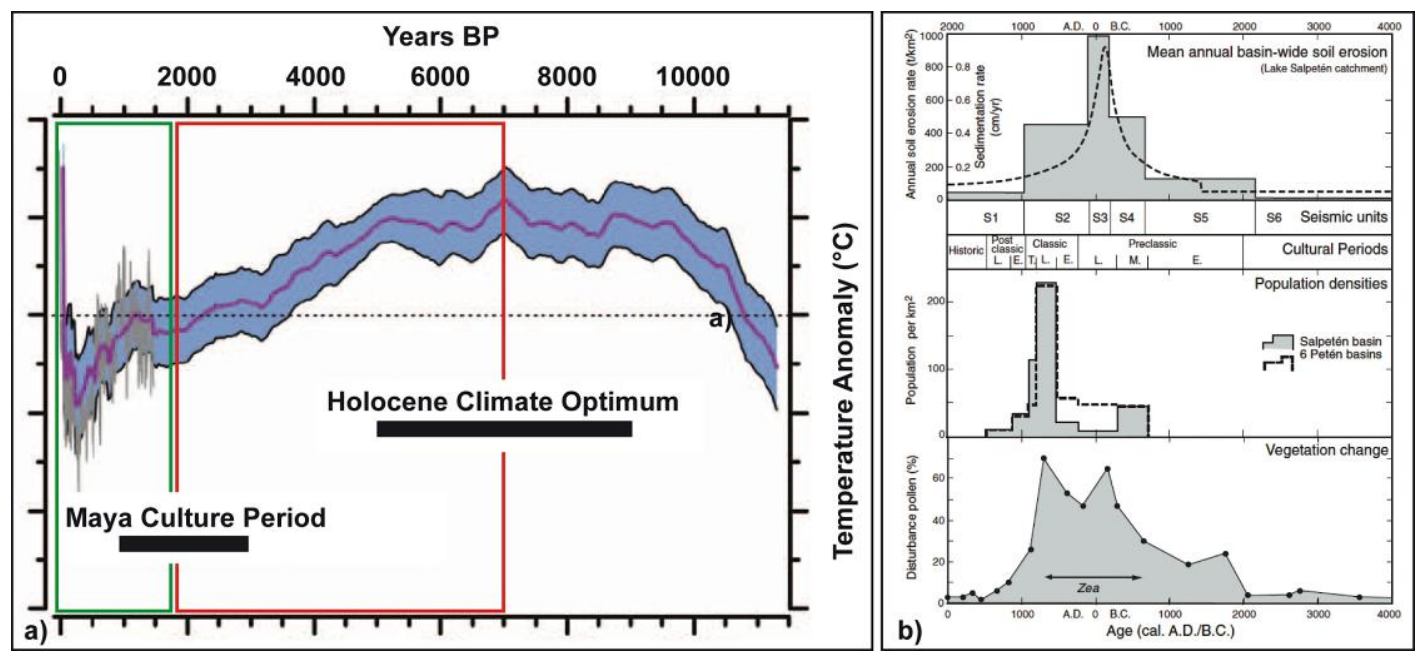

Figure 24. (a) Overview of Holocene climate variability-globally stacked SST anomaly (Marcott et al. 2013). Green box illustrates the duration of high-resolution climate records, including the newest ones of this Ph.D. thesis. The red box highlights the expected perspective of the follow-up project. Note that highly resolved archives reach back only some 2,000 yrs. (b) Maya culture population influence on soil erosion rates and pollen disturbance (Anselmetti et al. 2007). 


\subsection{Key questions and hypotheses}

Key question 1: What is the high-resolution climate variability and storm frequency in the Central American realm during the past 4.7 to 7.0 kyrs BP?

Hypothesis 1: "Great Blue Hole" sediment record will continuously track climate variability and storm frequency back into the Holocene Climate Optimum at annual resolution.

In the SW Caribbean, cyclone frequency changed from a stable and less active stage (100-900 CE) to a more active and variable state (>1100 CE). The follow-up project will answer the key question, whether the pattern of low cyclone activity coinciding with relatively low northern-hemisphere/global SSTs and atmospheric conditions inappropriate for storm formation continues back to the Holocene Climate Optimum, or, whether there are some comparable high-frequency modulations as noted during the Common Era. The cyclone activity in the south-western Caribbean could be expected to have significantly increased during the Holocene Climate Optimum because of global positive SST anomalies (Renssen et al. 2012). Some discontinuous and lower-resolution studies from Puerto Rico (Donnelly and Woodruff 2007; Woodruff et al. 2008) and the Belize coast (McCloskey and Liu 2012) provide first indications for a noteworthy rise of Caribbean storminess within the Holocene Climate Optimum (Fig. 25).

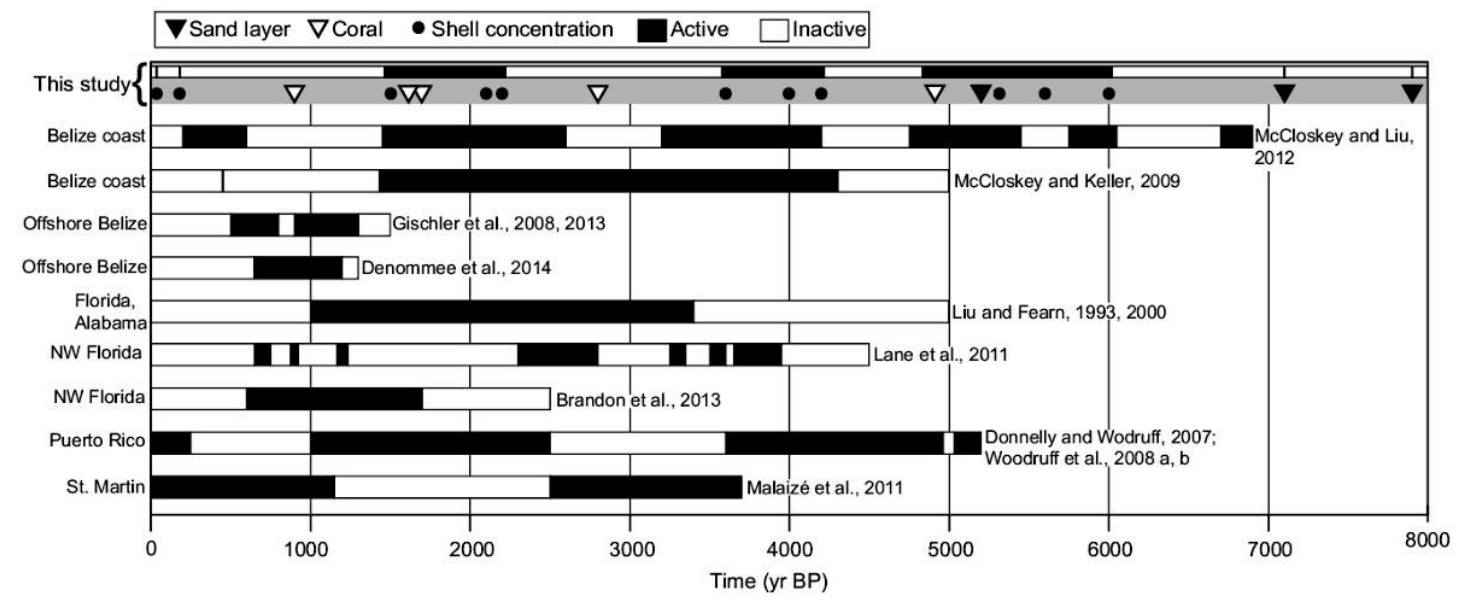

Figure 25. Cyclone records from Belize, the Gulf Coast, and the Antilles archipelago (from: Adomat and Gischler 2016).

Given the ongoing discussion on climate change, it would be interesting to know whether recurrence rates of cyclone landfalls will agree or significantly disagree with 
the rates reconstructed for the Common Era. Based on these aspects, it is also necessary to create a 5,000-7,000-year long record of continuous and annually resolved Atlantic SST data and AMO variability. As discussed in this Ph.D. thesis, practically all circum-Caribbean and Atlantic SST and AMO records are unfortunately too short and too fragmentary to provide the required information. Therefore, there is an urgent need to extend the isotopes-based, relative SST record and absolute TEX ${ }_{86}$ SST record, established in this Ph.D. thesis, further back in time.

Key question 2: What is the nature and age of the strata underlying the identified late Holocene sediments of the "Great Blue Hole"?

Hypothesis 2: Early Holocene and late Pleistocene sediments (including annually layered ones) make up the base of the "Great Blue Hole" sediment package.

Results from this Ph.D. thesis strongly suggest that Pleistocene sediments occur ca. 20-30 m below the modern seafloor in the "Great Blue Hole". Upon sea-level rise, the sinkhole was connected to the sea level-controlled hydraulic head, and a freshwater or brackish lake likely formed during the late glacial period and the early Holocene. Marine waters reached the cavern presumably via karst conduits in the surrounding Pleistocene reef limestone. Radiocarbon dates of aragonite cement on a stalactite in $30 \mathrm{~m}$ water depth range from 10.82-9.95 kyrs BP (Gischler et al. 2017) and fit the postglacial seal-level data of Bard et al. (1990). The top of the pedestal of the Lighthouse Reef platform was reached by rising sea during 7.80-6.85 kyrs BP (Gischler 2003) based on basal mangrove peat and coral radiocarbon age data. Lagoonal carbonate sedimentation on top of basal peat units started after a 2-kyrhiatus probably since $4.7 \mathrm{kyr} \mathrm{BP}$ according to radiocarbon age data from basal lagoonal carbonate deposits (Schultz et al. 2010, Gischler et al. 2013). A lag in sedimentation probably developed before the carbonate factory was in full operation, presumably due to inimical (nutrient-rich and turbid) lagoon waters that prevailed after marine inundation of soils and peaty sediments. Possibly, sedimentation of marine carbonate sediments started at the bottom of the "Great Blue Hole" even earlier, after $6.85 \mathrm{kyr} \mathrm{BP}$, when the first reefs developed at the platform margin (Gischler and Hudson 1998). Eventually, an estimated 20-30 m thick succession of Holocene muds and silts accumulated under marine conditions. This sediment 
package could potentially comprise, from top to bottom: annually layered marine carbonates, freshwater and/or brackish carbonates, and/or organic-rich sediments, the latter two being deposited during initial transgression when the "Great Blue Hole" was a karst hole (cenote) in a subaerially exposed carbonate island. Van Hengstum et al. (2011) summarized the succession to be expected in coastal caves and sinkholes during sea-level rise, ideally including deposits of the vadose (talus, soil), littoral (mud, peat), anchialine (diamictite), and marine (carbonate-rich sediments) phases. It is unknown whether or not sediments of late Pleistocene sea-level cycles have potentially been deposited beneath the Holocene succession. The additional coring will enable us to shed light on the sedimentary evolution of this unique cave system. Depending on the thickness and diagenetic alteration, possible late Pleistocene varved, marine sediments may be analysed in comparable ways as the overlying annually bedded Holocene deposits. 


\section{REFERENCES}

Adomat, F., Gischler, E. (2015): Sedimentary patterns and evolution of coastal environments during the Holocene in Central Belize, Central America. J. Coast. Res. 31, 802-826.

Adomat, F., Gischler, E (2017): Assessing the suitability of Holocene environments along the central Belize coast, Central America, for the reconstruction of hurricane records. Int. J. Earth Sci. 106, 283-309.

Anselmetti, F.S., Hodell, D.A., Ariztegui, D., Brenner, M., Rosenmeier, M.F. (2007): Quantification of soil erosion rates related to ancient Maya deforestation. Geology 35, 915-918.

Bard, E. (1998): Geochemical and geophysical implications of the radiocarbon calibration. Geochem. Cosmochim. Acta 62, 2025-2038.

Bard, E., Hamelin, B., Fairbanks, R.G., Zindler, A. (1990): Calibration of the ${ }^{14} \mathrm{C}$ timescale over the past 30,000 years using mass spectrometric $U$-Th ages from Barbados coral. Nature 345, 405-410.

Bard, E., Raisbeck, G.M., Yiou, F., Jouzel, J. (1997): Solar modulation of cosmogenic nuclide production over the last millennium: comparison between ${ }^{14} \mathrm{C}$ and ${ }^{10} \mathrm{Be}$ records. Earth Planet. Sci. Lett. 150, 453-462.

Bard, E., Raisbeck, G., Yiou, F., Jouzel, J. (2000): Solar irradiance during the last 1200 years based on cosmogenic nuclids. Tellus 52B, 985-992.

Baumann, L.M.F., Taubner, R.-S., Bauersachs, T., Steiner, M., Schleper, C., Peckmann, J., Rittmann, S.K.-M.R., Birgel, D. (2018): Intact polar and core lipid inventory of the hydrothermal vent methanogens Methanocaldococcus villosus and Methanothermococcus okinawensis. Org. Geochem. 126, 33-42.

Bender, M.A., Knutson, T.R., Tuleya, R.E., Siritius, J.J., Vicchi, G.A., Garner, S.T., Held, I.M. (2010): Modeled impact of anthropogenic warming on the frequency of intense Atlantic hurricanes. Science 327, 454-458. 
Biktash, L. (2017): Long-term global temperature variations under total solar irradiance, cosmic rays, and volcanic activity. J. Adv. Res. 8 (4), 329-332. https://doi.org/10.1016/j.jare.2017.03.002

Black, D.E., Peterson, L.C., Overpeck, J.T., Kaplan, A., Evans, M.N., Kashgarian, M. (1999): Eight centuries of North Atlantic Ocean atmosphere variability. Science 286, 1709-1713.

Black, D.E., Abahazi, M.A., Thunell, R.C., Kaplan, A., Tappa, E.K., Peterson, L.C. (2007): An 8-century tropical Atlantic SST record from the Cariaco Basin: baseline variability, twentieth century warming, and Atlantic hurricane frequency. Paleoceanography 22, PA4204.

Blott, S.J., Pye, K. (2001): Gradistat: a grain size distribution and statistics package for the analysis of unconsolidated sediments. Earth Surf. Process. Landforms 26, $1237-1248$.

Brandon, C.M., Woodruff, J.D., Lane, P., Donnelly, J.P. (2013): Tropical cyclone wind speed constraints from resultant storm surge deposition: A 2500-year reconstruction of hurricane activity from St. Marks. FL. Geochem. Geophys. Geosyst. 14, 2993-3008.

Brown, L.A., Reinhard, E.G., van Hengstum, P.J., Pilarczyk, J.E. (2014): A coastal Yucatan sinkhole records intense Hurricane events. J. Coast. Res. 30-2, 418428.

Brönnimann, S., Franke, J., Nussbaumer, U.S., Zumbühl, J.H., Steiner, D., Trachsel, M., Hegerl, C.G., Schurer, A.,Worni, M., Malik, A., Flückiger, J., Raible, C.C. (2019): Last phases of the Little Ice Age forced by volcanic eruptions. Nat. Geosci. 12, 650-656.

Burke, R.B. (1982): Reconnaissance study of the geomorphology and benthic communities of the outer barrier reef platform, Belize. in: Rützler, K., Macintyre, I.G. (eds.) The Atlantic Barrier Reef Ecosystem at Carrie Bow Cay, Belize, vol. 12. Smithson. Contrib. Mar. Sci., pp. 509-526. 
Burn, J.M., Palmer, E.S. (2015): Atlantic hurricane activity during the last millennium. Sci. Rep. 5, 12838. https://doi.org/10.1038/srep1238

Böning, P., Fröllje, H., Beck, M., Schnetger, B., Brumsack, H.-J. (2012): Underestimation of the authigenic fraction of $\mathrm{Cu}$ and $\mathrm{Ni}$ in organic-rich sediments. Mar. Geol. 323-325, 24-28.

Calhoun, R.S., Fletcher C.H., Harney, J.N. (2002): A budget of marine and terrigenous sediments, Hanalei Bay, Kauai, Hawaiian Islands. Sediment. Geol. 150, 61-87.

Chave, K.E., Smith, S.V., Roy, K.J. (1972): Carbonate production by coral reefs. Mar. Geol. 12, 123-140.

Cherubin, L.M., Kuchinke, P.C., Paris, B.C. (2008): Ocean circulation and terrestrial runoff dynamics in the Mesoamerican region from spectral optimization of Sea WiFS data and a high-resolution simulation. Coral Reefs 27, 503-519.

Choi, D.R., Ginsburg, R.N. (1982): Siliciclastic foundation of Quaternary reefs in the southernmost Belize lagoon, British Honduras. Geol. Soc. Am. Bull. 93, 116-126.

Chu, P.S. (2004): ENSO and tropical cyclone activity. in: Murnane, R., Liu, K.B. (eds.) Hurricanes and Typhoons: Past, Present and Future: New York, Columbia University Press.

Crowley, T.J. (2000): Causes of climate change over the past 1000 years. Science 289, 270-277.

Croudace, I.W., Rothwell, R.G. (2015): Micro-XRF studies of sediment cores applications of a non-destructive tool for the environmental sciences (Developments in Paleoenvironmental Research. Springer Heidelberg. https://doi.org/10.1007/978-94.017.9849-5

Curtis, J.H., Brenner, M., Hodell, D.A., Balser, R.A., Islebe, G.A., Hooghiemstra, H. (1998): A multi-proxy study of Holocene environmental change in the Maya lowlands of Petén, Guatemala. J. Paleolimnol. 19, 139-159. 
DeLong, K.L., Flannery, J.A., Poore, R.Z., Quinn, T.M., Maupin, C.R., Lin, K., Shen, C.-C. (2014): A reconstruction of sea surface temperature variability in the south-eastern Gulf of Mexico from 1734 to 2008 C.E. using cross-dated Sr/Ca records from the coral Siderastrea siderea. Paleoceanography 29, 403-422.

Delworth, T.L., Mann, E.M. (2000): Observed and simulated multidecadal variability in the Northern Hemisphere. Clim. Dynam. 16, 661-676. https://doi.org/10.1007/s003820000075

DeMaria, M., Kaplan, J. (1994): Sea surface temperature and the maximum intensity of Atlantic tropical cyclones. J. Clim. 7, 1324-1334. https://doi.org/10.1175/1520-0442(1994)007<1324:SSTATM>2.0.CO;2

Denommee, C.K., Bentley, J.S., Droxler, A.W. (2014): Climatic controls on hurricanes patterns: a 1200-y near-annual record from Lighthouse Reef, Belize. Sci. Rep. 4, 3876. http://DOI:10.1038/srep03876

Dijkstra, H.A., tee Raa, L., Schmeits, M., Gerrits, J. (2006): On the physics of the Atlantic multidecdal oscillation. Ocean Dynam. 56-1, 36-50.

Dill, R.F. (1977) The blue holes, geologically significant submerged sinkholes and caves off British Honduras and Andros, Bahamas Islands. in: Proceedings of the 3rd International Coral Reef Symposium, 2, 237-242.

Dill, R.F., Land, L.S., Mack, L.E., Schwarcz, H.P. (1998): A submerged stalactite from Belize: petrography, geochemistry, and geochronology of massive marine cementation. Carbonates Evaporites 13, 189-197.

Dillon, W.P., Vedder, J.G. (1973): Structure and development of the continental margin of British Honduras. Geol. Soc. Am. Bull. 84, 2713-2732.

Doherty, M., Riemer, N., Hameed, S. (2008): Saharan mineral dust transport into the Caribbean: observed atmospheric controls and trends. J. Geophys. Res. 113, D07211. https://doi.org/10.1029/2007JD009171 
Donnelly, J.P., Woodruff, J.D. (2007): Intense hurricane activity over the past 5,000 years controlled by El-Niño and west African monsoon. Nature 447, 465-468.

Donnelly, J.P., Hawkes, A.D., Lane, P., MacDonald, D., Shuman, B.N., Toomey, M.R., van Hengstum, P.I., Woodruff, J.D. (2015): Climate forcing of unprecedented intense-hurricane activity in the last 2000 years. Earth's Future 3-2, 49-65.

Dunham, R.J. (1962): Classification of carbonate rocks according to depositional texture: in: Ham, W.E. (eds.) Classification of carbonate rocks. Amer. Assoc. Petrol. Geol. Mem. 1, 108-121.

Elsner, J.B., Kara, A.B., Owens, M.A. (1999): Fluctuations in North Atlantic hurricane frequency. J. Clim. 12, 427-437.

Elsner, J.B., Jagger, T.H., Niu, X.-F. (2000): Changes in the rates of North Atlantic major hurricane activity during the 20th century. Geophys. Res. Lett. 27, 1743-1746.

Elsner, J.B., Murnane, R.J., Jagger, T.H. (2006): Forecasting US hurricanes 6 months in advance. Geophys. Res. Lett. 33, L10704. https://doi.org/10.1029/2006GL025693

Emile-Geay, J., McKay, N., Kaufman, D., et al. (2017): A global multiproxy database for temperature reconstructions of the Common Era. Sci. Data. 4, 170088. https://doi.org/10.1038/sdata.2017.88

Enfield, D.B., Mestas Nunez, A.M., Trimble, P.J. (2001): The Atlantic multidecadal oscillation and its relation to rainfall and river flows in the continental U.S. Geophys. Res. Lett. 28, 2077-2080.

Enos, P. (1974): Surface sediment facies map of the Florida Bahamas Plateau. Geol. Soc. Amer. S, Map MC-5.

Enos, P., Perkins, R.D. (1977): Quaternary Sedimentation in South Florida. Geol. Soc. Amer. Mem. 147,198. 
Esker, D., Eberli, G.P., McNeill, D.F. (1998): The structural and sedimentological controls on the reoccupation of Quaternary incised valleys, Belize southern lagoon. AAPG Bull. 82, 2075-2109.

Ferro, C.E., Droxler, A.W., Anderson, J.B., Mucciarone, D. (1999): Late Quaternary shift of mixed siliciclastic-carbonate environments induced by glacial eustatic sea-level fluctuations in Belize. Spec. Publ.- SEPM 63, 385-411.

Flügel, E. (2004): Microfacies of carbonate rocks: analysis, interpretation and application. 976 pp, Berlin, Springer.

Fodor, T. (2014): Quantitative Analyse von Karbonatproduzenten und deren Verteilungsmuster im Dünnschliff von modernen Sedimenten auf Moorea, Französisch-Polynesien. Unpubl. B.Sc.-thesis, J.W. Goethe-Univ., Frankfurt, Germany.

Folk, R.L, Ward, W.C. (1957): Brazos River bar: a study in the significance of grain size parameters. J. Sediment Petrol. 27, 3-26.

Frajka-Williams, E., Beaulieu, C., Duchez, A. (2017): Emerging negative Atlantic Multidecadal Oscillation index in spite of warm subtropics. Sci. Rep. 7-(1),11224. https://doi.org/10.1038/s41598-017-11046-x

Frappier, A., Sahagian, D., González, L.A., Carpenter, S.J. (2002): El-Niño-events recorded by stalagmite carbon. Science $\mathbf{2 9 8}, 565$.

Gabrié, C., Montaggioni, L. (1982): Sediments from fringing reefs of Réunion Island, Indian Ocean. Sediment. Geol. 31, 281-301.

Ginsburg, R.N. (1956): Environmental relationships of grain size and constituent particles in some south Florida carbonate sediments. Amer. Assoc. Petrol. Geol. Bull. 40, 2384-2427.

Gischler, E. (1994): Sedimentation on three Caribbean atolls: Glovers Reef, Lighthouse Reef and Turneffe Islands, Belize. Facies 31, 243-254.

Gischler, E., Hudson, J.H. (1998): Holocene development of three isolated carbonate platforms, Belize, Central America. Mar. Geol. 144, 333-347. 
Gischler, E., Lomando, A.J. (1999): Recent sedimentary facies of isolated carbonate platforms, Belize-Yucatan system, Central America. J. Sediment. Res. 69, 747-763.

Gischler, E., Zingeler, D. (2002): The origin of carbonate mud in isolated carbonate platforms of Belize, Central America. Int. J. Earth Sci. 91, 1054-1070 .

Gischler, E. (2003): Holocene lagoonal development in isolated carbonate platforms of Belize. Sediment. Geol. 159, 113-132.

Gischler, E., Hudson, J.H. (2004): Holocene development of the Belize Barrier Reef. Sediment. Geol. 164, 223-236.

Gischler, E., Oschmann, W. (2005): Historical climate variation in Belize (Central America) as recorded in Scleractinian coral skeletons. Palaios 20, 159-174.

Gischler, E., Shinn, A.E., Oschmann, W., Fiebig, J., Buster, A.N. (2008): A 1500-year Holocene Caribbean climate archive from the Blue Hole, Lighthouse reef, Belize. J. Coast. Res. 24, 1495-1505.

Gischler, E., Swart, P.K., Lomando, A.J. (2009): Stable isotopes of carbon and oxygen in modern sediments of carbonate platforms, barrier reefs, atolls, and ramps: patterns and implications. in: Swart, P.K., Eberli, G.P., McKenzie, J.A. (eds.) Perspectives in Sedimentary Geology: A Tribute to the Career of Robert N. Ginsburg, vol. 41. International Association of Sedimentologists-Special Publication, pp. 61-74.

Gischler, E. (2011): Sedimentary facies of Bora Bora, Darwin's type barrier reef (Society Islands, South Pacific): the unexpected occurrence of non-skeletal grains. J. Sediment. Res. 81, 1-17.

Gischler, E., Anselmetti, A.S., Shinn, E.A. (2013): Seismic stratigraphy of the Blue Hole (Lighthouse reef, Belize), a late Holocene climate and storm archive. Mar. Geol. 344, 155-162.

Gischler, E., Isaack, A., Hudson, J.H. (2017a) Sediments of the Dry Tortugas, south Florida, USA: facies distribution on a ramp-like isolated carbonate platform. Sediment. Geol. 351, 48-65. 
Gischler, E., Birgel, D., Brunner, B., Eisenhauer, A., Meyer, G., Buhre, S., Peckmann, J. (2017b): A giant underwater encrusted stalactite from the Blue Hole, Lighthouse Reef, Belize, revisited: a complex history of biologicallyinduced carbonate accretion under changing meteoric and marine conditions. J. Sediment. Res. 87, 1260-1284.

Goldenberg, S.B., Landsea, C.W., Mestas-Nunez, A.M., Gray, W.M. (2001): The recent increase in Atlantic hurricane activity: causes and implications. Science 293, 474-479.

Gray, W.M. (1984): Atlantic seasonal hurricane frequency: Part I: El-Niño and 30-mb quasi-bienniel oscillation influences. Mon. Weather Rev. 112, 1649-1668.

Gray, W.M. (1986): Global view of the origins of tropical disturbances and storms. Mon. Weather Rev. 96, 669-700.

Gray, S.T., Graumlich, L.J., Betancourt, J.L., Pederson, G.T. (2004): A tree ringbased reconstruction of the Atlantic Multidecadal Oscillation since 1567 A.D. Geophys. Res. Lett. 31. https://doi.org/10.1029/2004GL019932

Gregory, B.R.B., Peros, M., Reinhard, E.G., Donnelly, J.P. (2015): Middle-late Holocene Caribbean aridity inferred from foraminifera and elemental data in sediment cores from two Cuban lagoons. Palaeogeogr. Palaeoclimatol. Palaeoecol. 426, 229-241. https://doi.org/10.1016/j.paleo.2015.02.029

Gussmann, O.A., Smith, A.M. (2002): Mixed siliciclastic-skeletal carbonate lagoon sediments from a high volcanic island, Viti Levu, Fiji, Southwest Pacific. Pac. Sci. 56, 169-189.

Hammer, O., Harper, D.A.T., Ryan, P.D. (2001): Paleontological statistics software package for education and data analysis. Palaeontol. Electron. 4, 1-9.

Haase-Schramm, A., Böhm, F., Eisenhauer, A., Dullo, W.-C., Joachimski, M.M., Hansen, B., Reitner, J. (2003): $\mathrm{Sr} / \mathrm{Ca}$ ratios and oxygen isotopes from sclerosponges: temperature history of the Caribbean mixed layer and thermocline during the Little Ice Age. Paleoceanography 18, PA1073. 
Harney, J.N., Grossman, E.E., Richmond, B.M., Fletcher, C.H. (2000): Age and composition of carbonate shoreface sediments, Kailua Bay, Oahu, Hawaii. Coral Reefs 19, 141-154.

Haug, G.H., Hughen, K.A., Sigman, D.M., Peterson, L.C., Röhl, U. (2001): Southward migration of the intertropical convergence zone through the Holocene. Science 293, 1304-1308.

Haug, G.H., Günther, D., Peterson, L.C., Sigman, D.M., Hughen, K.A., Aeschlimann, B. (2003): Climate and the collapse of Mayan civilization. Science 299, 1731-1734.

Hauser, I., Oschmann, W., Gischler, E. (2007): Modern bivalve shell assemblages on three atolls offshore Belize (Central America, Caribbean Sea). Facies 53, 451-478.

Hetzinger, S., Pfeiffer, M., Dullo, W.-C., Keenlyside, N., Latif, M., Zinke, J. (2008): Caribbean coral tracks Atlantic Multidecadal Oscillation and past hurricane activity. Geology 36-1, 11-14. https://doi.org/10.1130/G24321A.1

Hillesheim, M.B., Hodell, D.A., Leyen, B., Brenner, M., Curtis, J.H., Anselmetti, F.S., Ariztegui, D., Buck, D.G., Guilderson, T.P., Rosenmeier, M.F., Schnurrenberger, D.W. (2005): Climate change in lowland Central America during the late deglacial and early Holocene. J. Quat. Sci. 20, 363-376.

Hodell, D.A., Anselmetti, F.S., Ariztegui, D., Brenner, M., Curtis, J.H., Escobar, J., Gilli, A., Grzesik, D.A., Guilderson, T.J., Kutterolf, S., Müller, A.D. (2008): An 85-ka record of climate change in lowland Central America. Quat. Sci. Rev. 27, 1152-1165.

Hodell, D.A., Curtis, J.A., Jones, G.A., Higuera-Gundy, A., Brenner, M., Binford, M.W., Dorsey, K.T. (1991): Reconstruction of Caribbean climate change over the past 10,500 years. Nature 352, 790-793.

Hodell, D.A., Curtis, J.H., Brenner, M. (1995): Possible role of climate in the collapse of classic Maya civilization. Nature 375, 391-394. 
Hodell, D.A., Brenner, M., Curtis, J.H., Guilderson, T. (2001): Solar forcing of drought frequency in the Maya lowlands. Science 292, 1367-1370.

Isaack, A., Gischler, E., Hudson, J.H., Anselmetti, F.S., Lohner, A., Vogel, H., Garbode, E., Camoin, G.F. (2016): A new model evaluation Holocene sediment dynamics: insights from a mixed carbonate-silicilcastic lagoon (Bora Bora, society Islands, French Polynesia, south Pacific. Sediment. Geol. 343, 99-118.

James, N.P. (1979): Facies models. 9. Introduction to carbonate facies models. in: Walker RG (eds.) Facies models. Geoscience Canada Reprint Series v. 1. Geol. Assoc. Canada, Waterloo, Ontario, pp. 105-107.

James, N.P., Ginsburg, R.N. (1979): The geological setting of Belize reefs. in: James, N.P., Ginsburg, R.N. (eds.) The Seaward Margin of Belize Barrier and Atoll Reefs. International Association of Sedimentologists-Special Publication v. 3. Blackwell Scientific, Oxford U.K., pp. 1-15.

Jones, A.T., Dill, R.F., Jackson, T.A. (2002): Great Blue Hole of Lighthouse Reef Atoll, Belize, Central America: deep technical diving to collect sea-level records. in: Caribbean Geology into the Third Millennium: 15th Caribbean Geology Conference, Transactions, pp. 181-193.

Keim, B.D., Muller, R.A. (2007): Spatiotemporal patterns and return periods of tropical storm and hurricane strikes from Texas to Maine. J. Clim. 20, 3498-3509.

Kennett, D.J., Breitenbach, S.F.M., Aquino, V.V., Asmerom, Y., Awe, J., Baldini, U.L., Bartlein, P., Culleton, B.J., Ebert, C., Jazwa, C., Macri, M.J., Marwan, N., Polyak, V., Prufer, K.M., Ridley, H.E., Sodemann, H., Winterhalder, B., Haug, G. (2012): Development and disintegration of Maya political systems in response to climate change. Science 338, 788-791.

Kerr, R.A. (2000): A North Atlantic climate pacemaker for the centuries. Science 288, 1984-1985. https://doi.org/10.1126/science.288.5473.1984 
Kilbourne, K.H., Quinn, T.M., Webb, R., Guilderson, T., Nyberg, J., Winter, A. (2008): Paleoclimate proxy perspectives on Caribbean climate since the year 1751: evidence of cooler temperatures and multidecadal variability. Paleoceanography 23, PA3220. https://doi.org/10.1029/2008PA001598

Kim, J.-H., van der Meer, J., Schouten, S., Helmke, P., Willmott, V., Sangiorgi, F., Koç, N., Hopmans, E.C., Sinninghe Damste, J.S. (2010): New indices and calibrations derived from the distribution of crenarchaeal isoprenoid tetraether lipids: implications for past sea surface temperature reconstructions. Geochem. Cosmochim. Acta 74, 4639-4654.

Klotzbach, P.J. (2011): The influence of El-Niño-southern oscillation and the Atlantic multidecadal oscillation on Caribbean tropical cyclone activity. J. Clim. 24, 721-731.

Knight, J.R., Allan, R.J., Folland, C.K., Vellinga, M., Mann, M.E. (2005): A signature of persistent natural thermohaline circulation cycles in observed climate. Geophys. Res. Lett. 33-20. https://doi.org/10.1029/2005GL024233

Knutson, T.R., McBride, J.L., Chan, J., Emanuel, K., Holland, G., Landsea, C., Held, I., Kossin, J.P., Srivastava, A.K., Sugi, M. (2010): Tropical cyclones and climate change. Nat. Geosci. 3, 157-163.

Kossin, J.P., Camargo, S.J., Sitkowski, M. (2010): Climate modulation of North Atlantic hurricane tracks. J. Clim. 23, 3057-3076.

Kuhnert, H., Pätzold, J., Schnetger, B., Wefer, G. (2002): Sea-surface temperature variability in the 16th century at Bermuda inferred from coral records. Palaeogeogr. Palaeoclimatol. Palaeoecol. 179, 159-171.

Lachniet, S.M., Bernal, P.J., Asmerom, Y., Polyak, V., Piperno, P.A. (2013): 2400year Mesoamerican rainfall reconstruction links climate and cultural change. Geology 40, 259-262.

Landsea, C.W., Pielke, R.A., Mestas-Nunez, A. Knaff, J.A. (1999): Atlantic basin hurricanes: Indices of climatic changes: Clim. Change 42, 89-129. 
Landsea, C.W., Franklin, J., Beven, J. (2019): Atlantic Hurricane Database HURDAT2.Web. https://www.aoml.noaa.gov/hrd/hurda t/Data_Storm .html. Accessed 17 July 2019.

Lane, P., Donnelly, J.P., Woodruff, J.D., Hawkes, A.D.A (2011): decadally-resolved paleohurricane record archived in the late Holocene sediments of a Florida sinkhole. Mar. Geol. 287, 14-30.

Latif, M., Roeckner, E., Botzet, M., Esch, M., Haak, H., Hagemann, S., Jungclaus, J., Legutke, S., Marsland, S., Mikolajewicz, U. (2004): Reconstructing, monitoring, and predicting multidecadal-scale changes in the North Atlantic thermohaline circulation with sea surface temperature. J. Clim. 17, 1605-1614. https://doi.org/10.1175/1520-0442(2004)017<1605:RMAPMC>2.0.CO;2

Lean, J., Beer, J., Bradley, R. (1995): Reconstruction of solar irradiance since 1610: implications for climate change. Geophys. Res. Lett. 22, 3195. https://doi.org/10.1029/95GL03093

Li, J., Xie, S.-H., Cook, E.R., Morales, M.S., Christie, D.A., Johnson, N.C., Chen, F., D’Arrigo, R., Fowler, A.M., Gou, X., Fang, K. (2013): El-Niño modulations over the past seven centuries. Nat. Clim. Change 3, 1-5. http://DOI:10.1038/NCLIMATE1936

Lund, D.C., Curry, W. (2006) Florida Current surface temperature and salinity variability during the last millennium. Paleoceanography 21, PA2009.

Madden, R.H.C., Wilson, M.E.J., O'Shea, M. (2013): Modern fringing reef carbonates from equatorial SE Asia: an integrated environmental sediment and satellite characterisation study. Mar. Geol. 344, 163-185.

Malaize, B., Bertran, P., Carbonel, P., Bonnissent, D., Charlier, K., Galop, D., Limbert, D., Serrand, N., Stouvenot, C., Puyol, C. (2013): Hurricanes in the Caribbean during the past 3700 years BP. Holocene 21, 911-924. 
Mann, M.E., Zhang, Z., Hughes, M.K., Bradley, R.S., Miller, S.K., Rutherford, S., Ni, F. (2008): Proxy-based reconstruction of hemispheric and global surface temperature variations over the past two millennia. Proc. Natl. Acad. Sci. U.S.A. 105, 13252-13255.

Mann, E.M., Zhang, Z., Rutherford, S., Bradley, S.R., Hughes, K.M., Shindell, D., Amman, C., Faluvegi, G., Ni, F. (2009): Global signatures and dynamical origins of the Little ice age and Medieval climate anomaly. Science 326, 1256-1259.

Marcott, A.S., Shakun, J.D., Clark, P.U., Mix, A.C. (2013): a reconstruction of regional and global temperature for the past 11,300 years. Science 339, 1198-1201. https://DOI:10.1126/science.1228026.

Masse, J.P., Thomassin, B.A, Acquaviva, M. (1989): Bioclastic sedimentary environments of coral reefs and lagoons around Mayotte Island (Comoro Archipelago, Mozambique Channel, SW Indian Ocean. J. Coast. Res. 5, 419-432.

Mayewski, A.P., Rohling, E.E., Stager, C.J., Karlen, W., Maasch, A.K., Meeker, D.L., Meyerson, A.E., Gasse, F., van Kreveld, S., Holmgren, K., Lee-Thorp, J., Rosqvist, G., Rack, F., Staubwasser, M., Schneider, R.R., Steig, J.E. (2004): Holocene climate variability. Quat. Res. 62, 243-255.

McCloskey, T.A., Keller, G. (2009): 5000-year sedimentary record of hurricane strikes in the central coast of Belize. Quat. Int. 195, 53-68.

McCloskey, T.A., Liu, K. A. (2012): 7000-year record of paleohurricane activity from a coastal wetland in Belize. Holocene, https://doi.org/10.1177/0959683612460782.

McTaggart-Cowan, R., Davies, E.L., Fairman Jr., J.G., Galarneau Jr., T.J., Schlutz, D.M. (2015): Revisiting the $26.5^{\circ} \mathrm{C}$ sea surface temperature threshold for tropical cyclone development. Bull. Am. Meteorol. Soc. 96, 185-192. 
Metcalfe, S.E., O'Hara, S.L., Caballero, M., Davies, S.J. (2000) Records of late Pleistocene-Holocene climate changes in Mexico - a review. Quat. Sci. Rev. 19, 699-721.

Milliman, J.D. (1967): Sedimentation on Hogsty Reef, a Bahamian atoll. J. Sediment. Petrol. 37, 658-676.

Milliman, J.D. (1969): Carbonate sedimentation on four southwestern Caribbean atolls and its relation to the "oolite problem". Gulf Coast Assoc. Geol. Soc., Trans. 19, 195-206.

Miller, G.H., Geirsdottir, A., Zhong, Y., Larsen, D.J., Otto-Bliesner, B.L., Holland, M.M., Bailey, D.A., Refsnider, K.A., Lehman, S.J., Southon, J.R., Anderson, C., Björnsson, H., Thordarson, T. (2012): Abrupt onset of the Little Ice Age triggered by volcanism and sustained by sea ice/ocean feedbacks. Geophys. Res. Lett. 39, L02708. https://doi.org/10.1029/2011GL050168

Moberg, A., Sonechkin, D.M., Holmgren, K., Datsenko, N.M., Karlen, W. (2005): Highly variable Northern Hemisphere temperatures reconstructed from lowand high-resolution proxy data. Nature 433, 613-617.

Murakami, H., Levin, E., Delworth, L.T., Gudgel, R., Hsu, P.-C. (2018): Dominant effect of relative tropical Atlantic warming on major hurricane occurrence. Science 362, 794-799.

Murnane, R.J., Liu, K.-B. (2004): Hurricanes and Typhoons: Past, Present, and Future. Columbia University Press, New York.

Nyberg, J., Malmgren, B.A., Kuijpers, A., Winter, A. (2002): A centennial-scale variability of tropical North Atlantic surface hydrography during the late Holocene. Palaeogeogr. Palaeoclimatol. Palaeoecol. 183, 25-41.

O'Brian, C.L., Foster, G.L., Martinez-Boti, M.A., Abell, R., Rae, J.W.B., Pancost, R.D. (2014): High sea surface temperatures in tropical warm pools during the Pliocene Nature Geosci. 7, 606-611. 
Oppo, D.W., Rosenthal, Y., Linsley, B.K. (2009): 2,000-year-long temperature and hydrology reconstructions from the western Pacific warm pool. Nature 460, 1113-1116.

Park, J., Li, T. (2019): Interdecadal modulation of El-Niño-tropical north Atlantic teleconnection by the Atlantic multi-decadal oscillation. Clim. Dynam. 52, 5345-5360. https://doi.org/10.1007/s00382-018-4452-4

Perry, C.T. (1996): The rapid response of reef sediments to changes in community composition: implications for time averaging and sediment accumulation. J. Sediment. Res. 66, 459-467.

Perry, C.T. (2000): Factors controlling sediment preservation on a north Jamaican fringing reef: a process-based approach to microfacies analysis. J. Sediment Res. 70, 633-648.

Purdy, E.G. (1963): Recent calcium carbonate facies of the Great Bahama Bank. 1. Petrography and reaction groups. 2. Sedimentary facies. J. Geol. 71, 334-355/472-497.

Purdy, E.G. (1974): Karst determined facies patterns in British Honduras: Holocene carbonate sedimentation model. AAPG Bull. 58, 825-855.

Purdy, E.G., Gischler, E. (2003a). The Belize margin revisited: 1 Holocene marine facies. Int. J. Earth Sci. 92, 532-551.

Purdy, E.G., Gischler, E., Lomando, A.J. (2003b): The Belize margin revisited: 2. Origin of Holocene antecedent topography. Int. J. Earth Sci. 92, 552-572.

Rankey, E.C., Reeder, S.L. (2010): Controls on platform-scale patterns of surface sediments at shallow Holocene platforms, Bahamas. Sedimentology 57, 1545-1565.

Reimer, P.J., et al. (2013): IntCal13 and Marine13 radiocarbon age calibration curves, 0- 50,000 Years cal BP. Radiocarbon 55, 1869-1887. 
Reijmer, J.J.G., Swart, P.K., Bauch, T., Otto, R., Roth, S., Zechel, S. (2009): A reevaluation of facies on Great Bahama Bank I: New Facies Maps of Western Great Bahama Bank. in: Swart, P.K., Eberli, G.P., McKenzie, J.A. (eds.) Perspectives in carbonate geology: a tribute to the career of Robert Nathan Ginsburg. Int. Assoc. Sediment. Spec. Publ. 41, Wiley, Chichester.

Richey, J.N., Poore, R.Z., Floweer, B.P., Quinn, T.M. (2007): 1400 yr multiproxy record of climate variability from the northern Gulf of Mexico. Geology 35, 423-426.

Renssen, H., Seppä, H., Crosta, X., Goosse, H., Roche, D.M. (2012): Global characterisation of the Holocene Thermal Maximum. Quat. Sci. Rev. 8, 7-19. https://DOI:10.1016/j.quascirev.2012.05.022.

Robock, A. (2000) Volcanic eruptions and climate. Rev. Geophys. 38, 191-219. https://doi.org/10.1029/1998RG000054.

Rosenmeier, M.F., Hodell, D.A., Brenner, M., Curtis, J.H. (2002) A 4000-year lacustrine record of environmental change in the southern Maya lowlands, Petén, Guatemala. Quat. Res. 57, 183-190.

Roth, S., Reijmer, J.J.G. (2005): Holocene millennial to centennial carbonate cyclicity recorded in slope sediments of the Great Bahama Bank and its climatic implications. Sedimentology 52, 161-181.

Rosenthal, Y., Kalansky, J., Morley, A., Linsley, B. (2017): A paleo-perspective on ocean heat content: lessons from the Holocene and Common Era. Quat. Sci. Rev. 155, 1-12.

Saenger, C., Cohen, A.L., Oppo, D.W., Halley, R.B., Carilli, E. (2014): Surfacetemperature trends and variability in the low-latitude North Atlantic since 1552. Nat. Geosci. 2, 492-495.

Saunders, M.A., Lea, A.S. (2008): Large contribution of sea surface warming to recent increase in Atlantic hurricane activity. Nature 451, 557-560. 
Schmitt, D., Gischler, E. (2017): Recent sedimentary facies of Roatan (Bay Islands, Honduras), a Caribbean oceanic barrier reef system. Facies 63:5, https://doi.org/10.1007/s10347-016-0485-5.

Schmitt, D., Gischler, E., Anselmetti, F.A., Vogel, H. (2020a): Caribbean cyclone activity-an annually-resolved Common Era record. Sci. Rep. 10:\#11780.

Schmitt, D., Gischler, E., Birgel, D., Peckamnn, J., Anselmetti, F.S., Vogel, H. (2020b): Great Blue Hole (Lighthouse Reef, Belize): a continuous, annuallyresolved record of Common Era sea surface temperature, Atlantic Multidecadal Oscillation and cyclone-controlled run-off. Quaternary Science Reviews 247:\#106570.

Schmitt, D., Gischler, E., Walkenfort, D. (2020c): Holocene sediments of an inundated sinkhole - facies analysis of the Great Blue Hole, Lighthouse Reef, Belize. Facies, accepted October 2020.

Schouten, S., Hopmans, E.C., Schefuss, E., Sinninghe Damsté, J.C. (2002): Distributional variations in marine crenarchaeotal membrane lipids: $n$ new tool for reconstructing ancient sea water temperatures? Earth Planet. Sci. Lett. 204, 265-274.

Schultz, S., Gischler, E., Oschmann, W. (2010): Holocene trends in distribution and diversity of benthic foraminifera assemblages in atoll lagoons, Belize, Central America. Facies 56, 323-336.

Scoffin, T.P. (1992): Taphonomy of coral reefs: a review. Coral Reefs 11, 57-77.

Shinn, E.A., Reich, C.D., Locker, S.D., Hine, A.C. (1996): A giant sediment trap in the Florida Keys. J. Coast. Res. 12, 953-959.

Sigl, M., Winstrup, M., McConnell, J.R., Welten, K.C., Plunkett, G., Ludlow, F., Büntgen, U., Caffee, M., Chellman, N., Dahl-Jensen, D., Fischer, H., Kipfstuhl, S., Kostick, C., Maseli, O.J., Mekhaldi, F., Mulvaney, R., Muscheler, R., Pasteris, D.R., Pilcher, J.R., Salzer, M., Schüpbach, S., Steffensen, J.P., Vinther, B.M., Woodruff, T.E. (2015): Timing and climate forcing of volcanic 
eruptions for the past 2,500 years. Nature 523, 543-549. https://doi.org/10.1038/nature14565(2015)

Spötl, C., Vennemann, T. (2003): Continous-flow isotope ratio mass spectrometric analysis of carbonate minerals. Rapid Commun. Mass Spectrom. 17, 1004-1006.

Stoddart, D.R. (1962): Three Caribbean atolls: Turneffe Islands, Lighthouse reef, and Glover's reef, British Honduras. Atoll Res. Bull. 87, 151.

Stoddart, D.R. (1963): Effects of hurricane Hattie on the British Honduras reefs and cays, October 30-31,1961. Atoll Res. Bull. 95, 142.

Stuiver, M., Braziunas, T.F. (1993): Modeling atmospheric ${ }^{14} \mathrm{C}$ influences and ${ }^{14} \mathrm{C}$ ages of marine samples to 10,000 BC. Radiocarbon 35, 137-189.

Sugi, M., Yoshida, K., Murakami, H. (2015): More tropical cyclones in a cooler climate?. Geophys. Res. Lett. 42, 6780-6784.

Tierney, J.E., Abram, N.J., Anchukaitis, K.J., Evans, M.N., Giry, C., Kilbourne, K.H., Saenger, C.P., Wu, H.C., Zinke, J. (2015): Tropical sea surface temperatures for the past four centuries reconstructed from coral archives. Paleoceanography 30, 226-252.

Toomey, M.R., Donnelly, J.P., Woodruff, J.D. (2013): Reconstructing mid-late Holocene cyclone variability in the Central Pacific using sedimentary records from Tahaa, French Polynesia. Quat. Sci. Rev. 77, 181-189.

Trouet, V., Esper, J., Graham, N.E., Baker, A., Scourse, J.D., Frank, D.C. (2009): Persistent positive north Atlantic oscillation mode dominated the Medieval climate anomaly. Science $324,78-80$.

Udden, J.A. (1914): Mechanical composition of clastic sediments. Geol. Soc. Amer. Bull. 25, 655-744.

Van der Plas, L., Tobi, A.C. (1965): A chart for judging the reliability of point counting results. Amer. J. Sci. 263, 87-90. 
van Hengstum, P.J., Scott, D.B., Gröcke, D.R., Charette, M.A. (2011): Sea level controls sedimentation and environments in coastal caves and sinkholes. Mar. Geol. 286, 35-50.

Van Hengstum, P.J., Donnelly, J.P., Toomey, M.R., Albury, N.A., Lane, P., Kakuk, B. (2013): Heightened hurricane activity on the Little Bahama Bank from 1350 to 1650 AD. Continent. Shelf Res. 86. https://doi.org/10.1016/j.csr.2013.04.032

Van Hengstum, J.P., Donnelly, P.J., Fall, L.P., Toomey, R.M., Albury, A.N., Kakuk, B. (2016): The intertropical convergence zone modulates intense hurricane strikes on the western North Atlantic margin. Sci. Rep. 6, 21728. http://DOI:10.1038/srep21728.

Velasco, V.M., Mendoza, B. (2008) Assessing the relationship between solar activity and some large-scale climatic phenomena. Adv. Space Res. 42-5, 866-878.

Wallace, E.J., Donnelly, J.P., van Hengstum, P.J., Wiman, C., Szullivan, R.M., Winkler, T.S., d'Entremont, N.E., Toomey, M., Albury, N. (2019): Intense hurricane activity over the past 1500 years at south Andros Island, the Bahamas. Paleoceanogr. Paleocl. 34-11,1761-1783.

Wang, C. (2007): Variability of the Caribbean low-level jet and its relation to climate. Clim. Dyn. 29, 411-422.

Wang, J., Yang, B., Ljungqvist, F., et al. (2017): Internal and external forcing of multidecadal Atlantic climate variability over the past 1,200 years. Nat. Geosci. 10, 512-517. https://doi.org/10.1038/ngeo2962

Wantland, K.F., Pusey, W.C. (1975) Belize shelf-carbonate sediments, clastic sediments and ecology. AAPG Stud. Geol. 2, 599.

Webster, P.J., Holland, G.J., Curry, J.A., Chang, H.R. (2005): Changes in tropical cyclone number, duration, and intensity in a warmer environment. Science 309, 1844-1846.

Wefer, G., Berger, W.H. (1991): Isotope paleontology: growth and composition of extant calcareous species. Mar. Geol. 100, 207-248. 
Wentworth, C.K. (1922): A scale of grade and class terms for clastic sediments. J. Geol. 30, 377-392.

Woodruff, S.D., Diaz, H.F., Elms, J.D., Worley, S.J. (1998): COADS release 2 data and metadata enhancements for improvements of marine surface flux fields. Phys. Chem. Earth 23, 517-527.

Woodruff, J.D., Donnelly, J.P., Mohring, D., Geyer, W.R. (2008): Reconstructing relative flooding intensities responsible for hurricane-induced deposits from Laguna Playa Grande, Vieques, Puerto Rico. Geology 36, 391-394.

Wooller, M.J., Behling, H., Guerrero, J.L., Jantz, N., Zweigert, M.E. (2009): Late Holocene hydrologic and vegetation changes at Turneffe atoll, Belize, compared with records from mainland central America and Mexico. Palaios 24, 650-656.

Wu, C.H. et al. (2017): Changes to Yucatan Peninsula precipitation associated with salinity and temperature extremes of the Caribbean Sea during the Maya civilization collapse. Sci. Rep. 7, 15825. https://doi.org/10.1038/S4159801715942-0.

Wuchter, C., Schouten, S., Coolen, M.J.L., Sinninghe Damste, J.S. (2004): Temperature dependent variation in the distribution of tetraether membrane lipids of marine Crenarchaeota: implications for TEX 86 paleothermometry. Paleocenanography 19. http://PA4028.doi10.1029/2004PA001041

Yao, P., Wang, X.C., Bianchi, T.S., Yang, Z.S., Fu, L., Zhang, X. H., et al. (2020): Carbon cycling in the world's deepest blue hole. J. Geophys. Res. Biogeosciences, 125, e2019JG005307. https://doi.org/10.1029/2019JG005307 
Ph.D. APPLICANT: Schmitt Dominik, M. Sc

\section{PERSONAL PROFIL:}

$\begin{array}{ll}\text { Name: } & \text { Schmitt Dominik, M.Sc } \\ \text { Date and place of birth: } & \text { 04.09.1989, Lohr am Main } \\ \text { Residential address: } & \text { Lärchenstraße, 31 } \\ & \text { 63856, Bessenbach/Oberbessenbach } \\ & \text { Germany } \\ \text { Business address: } & \text { Altenhöferallee, 1 } \\ & 60438, \text { Frankfurt am Main } \\ & \text { Germany } \\ \text { E-Mail: } & \text { d.schmitt@em.uni-frankfurt.de }\end{array}$

WORK EXPERIENCE:

05/2020 - 12/2020 Johann Wolfgang Goethe-Universität, Frankfurt am Main Teaching position at "Goethe-Orientierungsstudium Natur und Lebenswissenschaften" (Supervisor: Dr. Frederik Kirst, Frankfurt)

05/2017 - 12/2020 Johann Wolfgang Goethe-Universität, Frankfurt am Main Ph.D. student at Biosedimentology Group (Supervisor: Prof. Dr. Eberhard Gischler, Frankfurt) (Supervisor: Prof. Dr. Flavio Anselmetti, Bern)

01/2016 - 06/2016 Johann Wolfgang Goethe-Universität, Frankfurt am Main Scholarship at Biosedimentology Group (Supervisor: Prof. Dr. Eberhard Gischler Frankfurt)

10/2015 - 12/2015 Johann Wolfgang Goethe-Universität, Frankfurt am Main Student Research Assistant at Biosedimentology Group (Supervisor: Prof. Dr. Eberhard Gischler, Frankfurt) 
Loewe-Zentrum: „Helmholtz International Centre for FAIR” Student Research Assistant at HIC for FAIR

(Supervisor: Admin. Director Gabriela Meyer, Frankfurt)

02/2014-08/2015 Johann Wolfgang Goethe-Universität, Frankfurt am Main Student Research Assistant at Biosedimentology Group (Supervisor: Prof. Dr. Eberhard Gischler, Frankfurt)

\section{EDUCATION:}

$2017-2020$

Johann Wolfgang Goethe-Universität, Frankfurt am Main Ph.D. thesis at Biosedimentology Group

(Supervisor: Prof. Dr. Eberhard Gischler, Frankfurt)

(Supervisor: Prof. Dr. Flavio Anselmetti, Bern)

$2013-2015$

Johann Wolfgang Goethe-Universität, Frankfurt am Main Master of Science in Geoscience (Geology/Palaeontology) Final grade: 1,0

(Supervisor: Prof. Dr. Eberhard Gischler, Frankfurt)

(Supervisor: Prof. Dr. Wolfgang Oschmann, Frankfurt)

$2009-2013$

Johann Wolfgang Goethe-Universität, Frankfurt am Main

Bachelor of Science in Geoscience

Final grade: 1,9

(Supervisor: Prof. Dr. Eberhard Gischler, Frankfurt)

(Supervisor: Dr. David Storz, Frankfurt)

$2000-2009$

Franz-Ludwig-von-Erthal-Gymnasium, Lohr am Main

Abitur (Allgemeine Hochschulreife)

Final grade: 2.9 (equivalent to A-level)

\section{KNOWLEDGE AND SKILLS:}

Analytics

- XRD, XRF, GS-MS $\left(\delta^{18} \mathrm{O} / \delta^{13} \mathrm{C}\right)$, ICP-OES

- Polarisation microscope

- Laser Particle Analyser 
- ${ }^{14} \mathrm{C}$ AMS radiocarbon dating

- REM with EDS, EBSD, CL applications

- EPMA with EDS, WDS, CL and $\mu$-XRF

Software

- Microsoft Office (Word, Excel, PP)

- „PAST” (statistic software)

- „Panplot” (core logging software)

- "Gradistat” (grain size and sorting software)

- Adoble Illustrator, Photoshop

Fieldwork

- 4-week drilling campaign (Bora Bora, French Polynesia)

- 2-weeks drilling campaign at (Belize, Central America)

Conferences

- Ph.D. thesis: oral presentation at GeoMünster conference, Münster, 2019

- Ph.D. thesis: oral presentation at GeoBonn conference, Bonn, 2018

- M.Sc. thesis: poster presentation at PALGES conference, Dresden, 2016

Languages

- English, very good and fluent (writing and oral)

- German, native

November, 2020

Schmitt Dominik

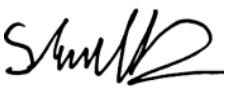

